\title{
Myth and reality of informed consent and the patient's choice to participate in clinical trials
}

Citation for published version (APA):

Verheggen, F. W. S. M. (1996). Myth and reality of informed consent and the patient's choice to participate in clinical trials. [Doctoral Thesis, Maastricht University]. Datawyse / Universitaire Pers Maastricht. https://doi.org/10.26481/dis.19960621fv

Document status and date:

Published: 01/01/1996

DOI:

10.26481/dis.19960621fv

Document Version:

Publisher's PDF, also known as Version of record

\section{Please check the document version of this publication:}

- A submitted manuscript is the version of the article upon submission and before peer-review. There can be important differences between the submitted version and the official published version of record.

People interested in the research are advised to contact the author for the final version of the publication, or visit the DOI to the publisher's website.

- The final author version and the galley proof are versions of the publication after peer review.

- The final published version features the final layout of the paper including the volume, issue and page numbers.

Link to publication

\footnotetext{
General rights rights.

- You may freely distribute the URL identifying the publication in the public portal. please follow below link for the End User Agreement:

www.umlib.nl/taverne-license

Take down policy

If you believe that this document breaches copyright please contact us at:

repository@maastrichtuniversity.nl

providing details and we will investigate your claim.
}

Copyright and moral rights for the publications made accessible in the public portal are retained by the authors and/or other copyright owners and it is a condition of accessing publications that users recognise and abide by the legal requirements associated with these

- Users may download and print one copy of any publication from the public portal for the purpose of private study or research.

- You may not further distribute the material or use it for any profit-making activity or commercial gain

If the publication is distributed under the terms of Article $25 \mathrm{fa}$ of the Dutch Copyright Act, indicated by the "Taverne" license above, 
MYTHAND REALITY OF INFORMED CONSENT AND THE PATIENT'S CHOICE TO PARTICIPATE IN CLINICALTRIALS 
ISBN 9052782164

Cover-design: Mireille Brouwer (Mixed Media, 1996), based upon a sell-portrait of James Ensor (Belgium, 1860-19.49), emphasizing respect for an individual"s autonomy, one of the basics of inflormed consent.

Lay-out: José Linders

Production: Datawyse Maastricht

This thesis has been mominated for 'The European Quality Award for Doctoral Theses on Total Quality Management 1995-1996" by the European Foundation for Quality Management (EFQM). Brussels. 


\title{
MYTH AND REALITY OF INFORMED CONSENT ANDTHE PATIENT'S CHOICE TO PARTICIPATE IN CLINICALTRIALS
}

\author{
PROEFSCHRIFT \\ ter verkrijging van de graad van doctor aan \\ de Rijksuniversiteit Limburg te Maastricht, \\ op gezag wan de Rector Magnificus, Prof. Mr. M.J. Cohen \\ volgens het besluit van het College van Dekanen, \\ in thet openbaar te verdedigen \\ op vrijdag 21 juni 1996 om 16.00 uur \\ door \\ Franciscus Wilhelmus Servatius Maria \\ Verheggen \\ geboren op 8 maart 1965 te Beek
}

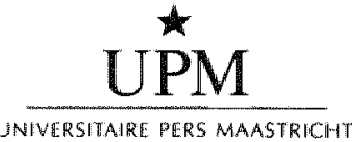




\section{Promotores}

Profmr. F.C.B. van Wijmen

Prof.dir. G. Kok

Prof.dr. E. Reerink

\section{Co-promotor}

Dr. F.H.M. Nieman

\section{Beoordelingscommissie}

Prof.dr. J.M.J.P. van der Linden (voorzitter)

Prof.dr.I. de Beaufort (Erasmusuniversiteit Rotterdam)

Prof.dr. H.W van den Borne

Dr.A.G. Mulley (Harvard Medical School Boston)

Prof.dr. H. Philipsen 
Ter nagedachtenis van Finy 



\section{Contents}

\section{Chapter}

I Introduction

2 Myth and reality of informed consent in clinical trials from a medico-legal perspective

3. Informed consent in clinical trials: a review of the research literature

4 Determinants of patient's participation in clinical trials in the context of informed consent: why patients enter a clinical trial or not

5 Patients' perceptions of informed consent and the quality of information disclosure in clinical trials

6 Patient satisfaction with clinical trial participation

1. Concluding remarks

8 Summary

Samenvatting

Dankwoord

Curriculum Vitae 


\section{Introduction}

\section{General introduction}

Informed consent can be defined as a process of decision-making, resulting in a deliberate and voluntary giving or refusing consent towards a medical treatment or participation in a clinical trial, based upon adequate information disclosure which is sufficiently well understood by a competent patient. Informed consent is an important aspect in biomedical research and one of the most obvious requirements of ethically acceptable clinical research. It is a tenet of clinical care and clinical research inwolwing disclosure, comprehension, voluntariness, competence and finally consent [1]. There is a growing public demand for information about results from diagnostic interventions, standard therapies and especially participating in trials. Respect for the autonomy of the patient, one of the foundations of informed consent, is also growing. Moreover, the issue of informed consent has been attracting increasing public and professional attention, especially in relation to clinical research [2]. Modern medicine has made room for the consent doctrine and has recognized the right of patients to consent and refuse consent to certain kinds of treatment. An increasing concern about ethics and law of experimentation on humans resulted in guidelines for the protection of human subjects in clinical research. Trialclinicians and other professional workers in health care are increasingly under an obligation to provide adequate information disclosure and to obtain informed consent from patients prior to involving them in clinical trials [3].

In this study, we will focus upon informed consent and the patient's choice to participate in clinical trials. The quality of information disclosure as perceived by patients and their satisfaction with trial participation is also analyzed. The aim of this study is to obtain more insight into how informed consent in clinical trials actually works in dailly practice and to focus upon practical problems in providing adequate information and obtaining consent when patients are asked to participate in a clinical trial. Informed consent in clinical trials is primarily being analyzed from the patient's point of view. Different scientific perspectives have been used in this analysis: the law to analyze legal aspects of informed consent, social psychology to analyze behavioral aspects of trial participation, patient education to evaluate the quality of information disclosure and quality assurance to assess patient's satisfaction with trial participation.

\section{Informed consent from a medico-legal point of wiew}

Chapter two presents a medico-legal perspective about what is known about myth and reality of informed consent in clinical trials. Patient rights, upon which informed consent is based, should be realized, to obtain a valid consent [4]. A WHO European Consultation on the Rights of Patients endorsed a common framework of the 'Principles of the Rights of Patients in Europe:, as a set of principles for the promotion and implementation of patient's rights in WHO's European Member States [5]. The Nuremberg Code (1949) laid down the basic principles for medical experimentation. It states that the voluntary consent of the human subject is absolutelly necessary. Informed consent is meant to guarantee the voluntary nature of participation in research studies. Only willing consent legitimizes the 
experiment and mere acquiescence is not enough. This consent also requires that the subject should have suficient knowledge and comprehension. In addition, the Declaration of Helsinki (1964) re-emphasized these fundamental obligations on medical researchers [6]. It demands that the potential subject must be adequately informed of the aims, anticipated benefits, and potential hazards of the study and the discomfort it may entail, while permitting proxy consent when the subject is legally incompetent. Clinical trials depend on thase who give their consent freely.

Informed consent may wary according to legal requirements in different countries. But it requires that the physician explains to the patient the risks of the intended procedure. potential alternatives to the procedure and a competent, voluntary and understanding consent secured from the patient in order to proceed. Inherent is the obligation that each patient be prowided with information about the treatments which can be understood. So one of the general prerequisites for a legally valid consent is that the consenting person must be aware of the circumstances relevant to her or his decision [7]. To be informed means to be someone who is instructed, who knows the facts. If a person is to be in a position to give informed consent to a course of action, he or she must possess all the relevant facts before giving permission. Otherwise the person would be ignorant and so not able to give informed consent. A patient only is truly be able to give adequate informed consent if all aspects relevant to knowing about the participation have been revealed. The basics of informed consent and patient rights derived from the principles of respect for autonomy and competence will be focused upon. We focus upon a distinction between medico-legal requirements of informed consent in medical treatment vs. clinical research, and the way this has been confirmed by the Dutch health care legislation. Reality reveals that a voluntary and deliberate consent for medical treatment or participation in a clinical trial is based upon judicial assumptions which are not always effective in daily practice. The premise of informed consent as a rational decision-making process, implying an informed consideration, assessment and patient choice therefore may be perceived as an ideal in the nature of a myth. We suggest a new standard of informed consent be based not only upon the views of physicians, judges, lawyers or philosophers, but also on those of patients.

\section{Empirical research on informed consent in clinical trials}

Chapter three reviews the empirical literature on informed consent in medical treatment and clinical trials. Empirical research on informed consent may be defined as: "the study of actual informed consent decisions by patients (or their proxies) with regard to consent, and the impact of consent on patients or the clinical trial outcome [8]. A distinction is made between studies on comprehension of information disclosure ("informed') and studies on decision-making procedures and patient motivation to participate in a clinical trial ("consent"). Study on information disclosure as a prerequisite of informed consent has been given much emphasis. Such empirical studies about informed consent focus upon patients' knowledge, comprehension and recall. Little research has been conducted to assess patient's perceptions on the informed consent process. Lack of knowledge is found in literature about motivational aspects of informed consent and social-psychological factors of entering a trial. Very little work has been done to determine why patients agree or decline to enroll in clinical trials. Informed consent still has proven difficult to define and, when defined, difficult to achieve in practice. That informed consent on several 
occasions tends to be an ineffective ritual has both anecdotal and empirical support. There is "however ${ }_{\text {" }}$, huch room to expand upon current findings. When trying to obtain more insight into how informed consent actually works in the daily practice of clinical trials, patient's evaluation of information disclosure should be examined. We also should get more insight into the reasons behind the choice: why patients decide to enter a clinical trial or not.

\section{Sample-survey}

Based on findings out of the medico-legal and empiricalliterature about what is known about myth and reality of informed consent to date, we have conducted a hospital-wide sample-survey at the university hospital Maastricht. We interviewed patients who were asked to participate in clinical trials. The study was designed to answer the following three questions:

1. On which grounds do patients choose to participate in clinical trials and what are the reasons for some of them not to participate in a clinical trial?

2. How do patients experience and evaluate the information disclosure on the clinical trial as provided by the trial-clinician and which factors influence the patient"s evaluation of information disclosure?

3. How do patients experience and evaluate their participation in a clinical trial and which factors influence the eventual patient satisfaction with clinical trial participation?

The results of the sample survey are presented in separate sections, one questioning patient motivation and reasons behind the choice (chapter 4), one focusing on patient's evaluation of information disclosure (chapter 5) and one assessing patient satisfaction with trial participation (chapter 6). An outline of the sample-survey will follow next.

\subsection{Material and methods}

Data in the sample-survey were obtained by means of two questionnaires. At the start of the clinical study or trial a one-hour personal interview was held within a month of the patient agreeing to participate. By interviewing patients who decided to participate and those who decided to decline trial participation, data have been collected on patient motivation towards trial participation and patient's perceptions of information disclosure. Respondents were recruited from patients who, between February and October 1993, were appiroached and asked to participate in prospective clinical trials at the university hospital Maastricht. The sampling procedure is described in chapters 4 and 6 . The 26 clinical trials for which respondents were asked for can be subdivided into "purely diagnostic" and "therapeutic" ones, studies involwing "invasive" and "non-invasive' diagnostic procedures and 'drug-related' and 'therapeutic' intervention situdies. Research protocols could be characterized by using following 6 categories: invasive diagnostic trials (ID); invasive diagnostic trials with medication (IDM); non-invasive diagnostic trials (NID); noninvasiwe diagnostic trials with medication (NIDM); therapeutic intervention trials (TI) and medication intervention trials (MI). An overview of clinicall trials used in the sample-survey and number of respondents per study is given in table $\|$. 
Table 1: Clinical trials involved in the sample-survey

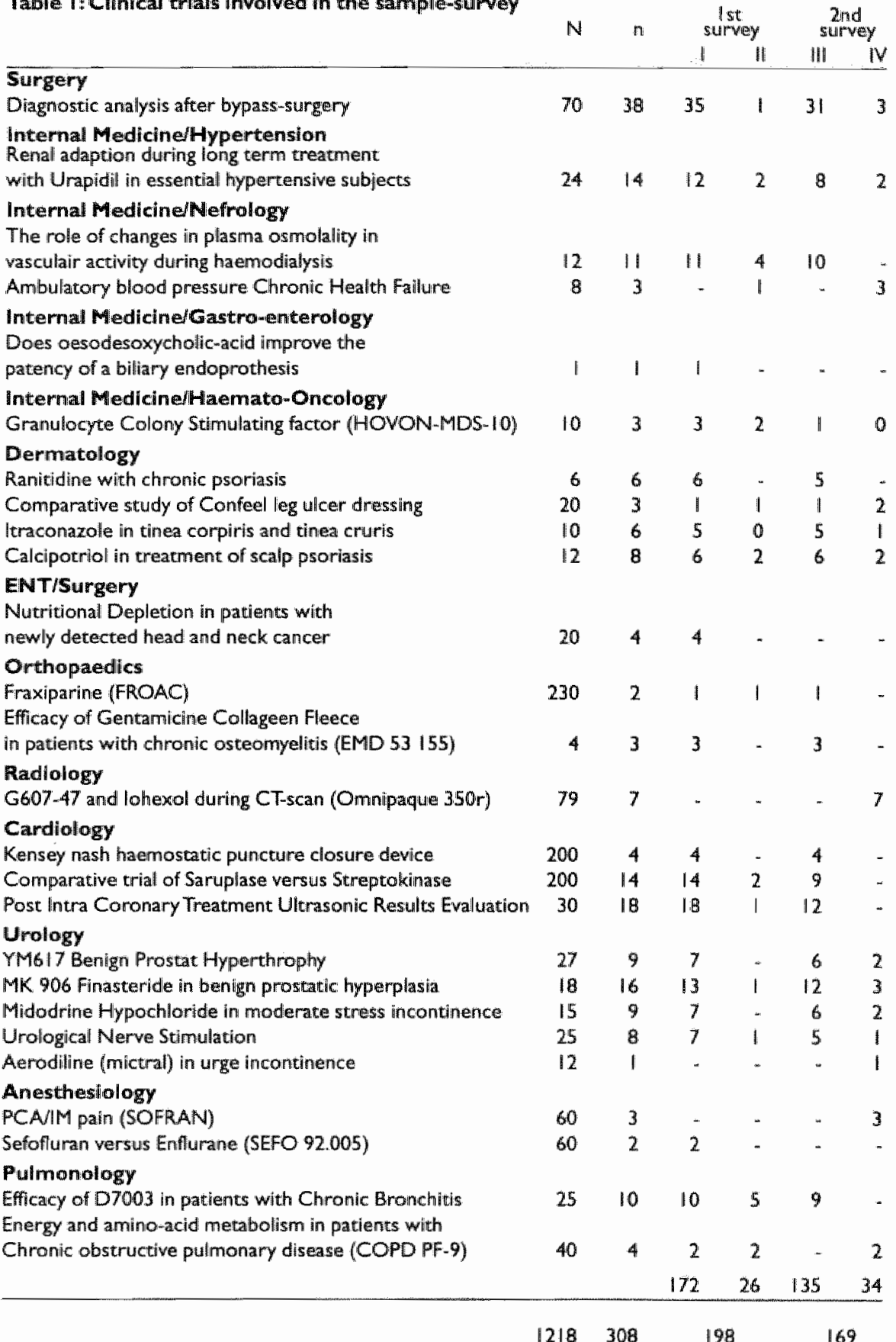

I. participants II: nom-participants III: interwewed twice IV: interviewed once (control) 
Data were collected over a nine-month time frame. During that time, 308 eligible patients were identifled, the names of 225 of whom were given to us during that period. Several patients could not be appiroached due to scheduling conflicts. In total 198 adult patients out of 26 clinical trials have had a one-hour personal interview, after they were asked to participate (88\% response). We also acknowledged those patients who choose to refuse to enter a trial; 1172 participants ( $93 \%$ response) and 26 non-parcicipants ( $86 \%$ response) were interviewed. Before our field work started, we based the size of the sample upon an average estimation of $13.6 \%$ of refusals of trial-participation, based on primary judgments by several experienced trial-clinicians in our hospital. In the final sample, $13.1 \%$ nonparticipants were included.

\subsection{Interview setting}

In total, four interviewers were involved in the field-work. All of them received - or had previously had - clinical training in counseling. The first interview took place in most cases before or after outpatient visits, at the outpatient department $(n=30)$ or at our researchunit $(n=128)$. Interviews sometimes also took place at nursing wards $(n=20)$ and in some cases at the patient's home $(n=20)$. None of the patients in the sample-survey was asked to come to the hospital only for the personal interview, without combining it with another outpatient visit. In nearly all trials there was an administrative interval of several days to one week between the decision to participate and the day the patients actually went to the first control visit. In one trial, we agreed with the trial-clinician that patients first saw him $(n=15)$, so he could ask their consent for the interwiew. Just after their consent patients were interviewed in an outpatient room. All patients were interviewed within three weeks after taking a final decision.

Next, a telephone interview was conducted at least three months after the first interview, to obtain data for analyzing patient satisfaction with trial participation. We interviewed 169 participants by telephone after a three-month period of enrollment about their satisfaction with trial participation. Of those who finally participated, 135 respondents were interviewed again about their satisfaction with the clinical trial (response rate 78.5\%). Additionally a control group of 34 patients, who had not been approached at our first interview, was also interviewed. We decided to include this control-group to analyze whether the evaluations and perceptions of patients on informed consent had been influenced by our first interview. Several statistical techniques have been used on available data, like descriptive statistics (correlations and crosstabs), factor analysis, (logistic) regression analysis, analysis of variance and path-analysis. Results of data-analyses of the first personal interview questionnaire are given in chapters 4 and 5 . The results of dataanalysis of available data from the second telephone questionnaire are presented in chapter 6.

\footnotetext{
In total, 1218 patients comprised the theorecical number of patients that needed to be recruited in the 26 prospective clinical trials. The size of the sample was expected to provide reliable results and conclusions for the total population (reliabilicy $=5 \%$; standard error $=2.5 \%$ with estimated refusals $p=136$ and estimated population parameter $k=3$ ). The sample size and estimated precision is based upon the following formula [9].
}

$1.96 \quad \frac{.136 * .864}{n} \frac{N-n}{N}=\frac{P}{k}$ 


\subsection{Additional information obtained from trial-clinicians}

To achieve better understanding of the informed consent procedure and relevant context variables of each research protocoll, interviews were also held with the trial-clinicians responsible, who obtained informed consent during the invitation procedure. In total 32 trial-clinicians involved in one of the 26 clinical trials in the sample-survey were interviewed after the field-work ended. Relevant findings can be found in chapter five, focusing on the quality of information disclosure.

\subsection{Informed consent procedure}

Like the clinical trials respondents were recruited from, the sample-survey has also been reviewed by the Institutional Review Board of the university hospital Maastricht (IRB; in Dutch, known as medical ethical committee). We thus advanced the proposal to solicit for the study of informed consent and the patient's choice to participate in clinical trials and followed the same medico-legal and ethical standards we expected from the trialclinicians. The response within the IRB toward the sample-survey was favorable. Trialclinicians were asked to inform eligible patients about the sample survey, both those who decide to enter the clinical trial and those who declined participation. The IRB has no information about eligible patients and which of these patients are actually being asked to participate. Patients therefore could only be contacted by actively involving the trialclinicians responsible for patient recruitment in the trial. We decided that it would be the most appropriate that trial-clinicians would ask their patients for their consent to be involved in the sample-survey, alongside the clinical trial. Usually this took place after their own informed consent procedure was finished. This procedure is in our opinion legally sound, and differs from a procedure in a specific scudy on informed consent, in which neither clinicians nor patients were aware in advance that the specific trial would become the subject of investigation so were not be able to give their consent, prior to sending them a questionnaire [10].

Most trial-clinicians responded to our requests. Only a few trial-clinicians were apprehensive about the sample survey. Informed consent for the sample-survey was obtained separately from the clinical trial solicitation and irrespective of their decision to enter the clinical trial or not. Only after a patient gave his or her consent to the trialclinician, were names and telephone numbers provided for the sample-survey. At that time patients could be approached for interview. At the end of the personal interview, patients were then asked if they also consented to be approached again via a tellephone conversation about how they experienced trial participation. An explanatory leaflet about the sample-survey was available for patients, if necessary or requested.Also it was specified that those responsible for sample-survey were not associated with the trialclinicians of medical departments. Questionnaires were identified only by code numbers, to assure confidentiality and anonymity. 


\section{The patients" choice to participate or not}

Concerning the first research question, we analyzed differences in attitudinal factors to compare those who comply with those who do not comply in term of trial participation. The purpose of gathering data on these socio-psychological and behavioral aspects of trial participation was to examine the congruence of motivations towards the consent decision. We wanted to analyze what kind of decision regarding participation in the clinical study or trial was solicited from which kind of patients. Therefore, we assessed the patient's subjective interpretation and evaluation of attitudes towards medical care and research, perceived benefits, risks and discomforts, using the Health Belief Model as a frame of reference. These findings are presented in chapter four, focusing upon the research question at hand, materials and methods, results, conclusions and a discussion. To enable trial-clinieians to obtain more insight into patient motivation for entering a clinical trial, a Patient Motivation Classification (PMC) is suggested. This is described in more detail in the next chapter.

\section{The quality of information disclosure}

With regard to the second research question we have analyzed the patient's perception of information disclosure from the perspective of patient education. We accepted and did not examine patient's decision-making capacities. Our sample-survey was not designed to evaluate whether the information disclosure was accurate or comprehensive. Instead, we analyzed patient perceptions on information disclosure and factors having an impact on it, in addition to patient's expectations toward the clinical trial. Satisfaction with information disclosure is thereby assumed as a measurement of the quality of the informed consent process. To improve the quality of informed consent, an Informed Decision-making Checklist (IDC) is suggested as a general outline for patient education. This part of the sample-survey, focusing on the quality of information disclosure, is found in chapter five.

\section{Patient satisfaction with trial participation}

When focusing on the third research question we have analyzed the patient's satisfaction with trial participation. Patient satisfaction is perceived as an indicator for assessing the quality of trial participation [11]. Patient satisfaction with trial participation is multifaced and multidimensional and has been analyzed in two distinct ways. A first assessment of patient satisfaction entails the patient's evaluation of aspects of trial participation which cannot be anticipated beforehand, i.e. at the beginning of the trial.As a second way to assess patient satisfaction with trial participation, parient's expectancies at the moment of taking a decision to enter the trial and evaluations in the course of the clinical trial have been compared with each other. An outline of this part of the sample-survey, analyzing patient satisfaction with trial participation is given in chapter six. Based upon the factors having a substantial impact on patient satisfaction with trial participation, more insight might also be obtained into the so-called "suspected non-compliance". When trial-clinicians use this term, they refer to their subjective prior estimation of refusals and dropouts who enrol in a clinical trial. 


\section{Concluding remarks}

In the concluding remarks in chapter seven, we will focus upon the insight we have abtained by the sample-survey into what is admittedly a subjective and qualitative interaction between patients and trial-clinicians. Appeals to patient's right of selfdetermination from the common law and legal vision of informed consent alone do not adequately enable patient involvement in medical decision-making. This also requires an exploration of interactions between patients and trial-clinicians in the informed consent process in daily practice. Although there is a growing interest in the role of patients in medical decision-making, few standards have been developed and relatively little is known about how this complex process occurs [12]. Empirical research into patients' motiwation to participate when being recruited for clinical trials and of what has been recounted during the informed consent process is scance. Understanding the distinction between what might be called myth and reality of informed consent is relevant for assessing how it could be improved in daily practice. The sample-surwey provides valuable insight into what aspects are most relevant for those who consent to participate, what the concerns are of those who decline participation, the role of information disclosure and to what extent patients are satisfied with trial participation. Whether myth can and should be reconciled more satisfactorily with reality remains to be seen [13]. Suggestions are given in order to improve informed consene in clinical trials and its functioning in daily practice. Relevant outlines of follow-up research are also provided.

\section{References}

1. Applebaum P.Assessing patients" capacities to consent to treatment. New England Journal of Medicine 319 (1988) 1635-1638.

2. Maslin A.A survey of the opinions on 'informed consent' of women currently involved in clinical trials within a breast cancer unit. European Journal of Cancer Care 3 (1994) $153-162$.

3. Brahams D. Randomized trials and informed consent. Laneer, ii, (1988) 1033-1034.

4. Hencheimer A. The rights of the patient in clinical research. Lancet ii, (1988) $1128-1130$.

5. Leenen H.A declaration of the promotion of patient's rights in Europe. Consultation of the Regiomal Office for Europe of the World Health Organization. Tijdschrift voor Gezondheids recht 5 (1994) 275-281.

6. World Medical Association. (1964) Declorotion of Heisinki: Recommendations guiding physicians in biomedical research involving human subjects. Adopted by the 18th World Medical Assembly, last. amendment in Hong Kong, (1989).

7. Rynning. E. Consent to medical core and research.A. legal study luscus Forlag. Uppsala (1994).

8. Simel D. Feussner J.A randomized controlled trial comparing quantitative informed consent formats. JClin Epidemiol 44 (1991) $771-777$.

9. Kahn H. Sempos C. 5tatistical methads in Epidemialogy. Oxford University Press. New York/Oxford (1989).

10. Lynöe, N, Sandlund, M. Dalqvist, G. Jacobson, L. Informed consent: study of quality of information given to participants in a clinical trial. British Medical fournal 303: (1991) $610-613$.

11. Cleary J. MeNeil B. Patient satisfaction as an indicator of quality care. In: L.Wyszewianskik (ed.). The challenge of quality. Inquiry (special issue) 25 (1988) 33-48.

12. Coulton C. Decision making in support: patient perceptions and preferences. / Clin Epidemial (Suppi.) 43 (1990) $515-545$

13. Kaq J. The silent world of doctor and potient. Collier Macmillan Publishers. New York/London, 1984. 


\title{
2 Myth and reality of informed consent in clinical trials from a medico-legal perspective
}

\author{
FWSM Werheggen, FCB van Wijmen
}

Submitted for publication in adapted version as: 'Myth and reality of informed consent in clinical trials'.

\begin{abstract}
Informed consent is a prerequisite for any medical intervention or for participation in scientific research. Legal requirements in health care towards informed consent provide qualifications of information disclosure and focus on procedures to obtain a valid consent. The premise of informed consent as a rational decision making process implies an informed consideration, assessment and patient choice and may be perceived as an ideal in the nature of a myth. These principles and assumptions will be discussed to obtain more insight into informed consent in clinical trials. A cogent model of informed consent is presented, which could be useful in clinical trials. We suggest a gradual distinction between informed consent in regular treatment vs. clinical trials, based on concepts like achievable benefits and risk disclosure.

Suggestions are made for further empirical research, to obtain more insight into the myth and reality of informed consent in clinical trials.
\end{abstract}

\section{Key words:}

informed consent; competence; medical experimentation; trial participation. 


\section{Myth and reality of informed consent: an outline of the question at hand}

This analysis of informed consent in clinical trials from a legal perspective is based upon a sample-survey in a university hospital in the Dutch health care system about patient motivation towards trial participation [1]. According to current law such a decision, based upon adequate information disclosure, should be taken well-considered and in freedom (informed consent).Adequate information disclosure is a necessary prerequisite to enable a patient to give a valid consent [2]. Information should be comprehensible for an average person, to enable a patient to make a deliberate decision. Legally valid informed consent also implies that the consent giver has adequate decision making capacities [3,4]. Informed consent of patients in medical treatment and research has been a subject of concern for several decades [5]. The goal of the informed consent doctrine is to enhance and encourage a responsible patient-physician relationship in treatment decisions [6]. Several developments have pushed medicine out of its traditional mysteriousness towards a paradigm of shared decision making and therefore the need of informed consent [7]. It is more and more seen as a fundamental precept of the doctor-patient relationship [8]. We will question what we call the myth and reality of a rational decision making and deliberate consent Informed consent as a rational decision-making process supposes an active role of a patient: an informed consideration, assessment and patient choice. Information should enable a patient to make a knowing, rationale choice [9]. Informed consent can only be obtained if a patient understands the provided information and is fully capable of making a decision. If the requirements in the law will be followed we speak from a legal point of view about a valid informed consent. We should realize that the "basics" of rational decision-making are not always met in daily practice of medical care and research. In this way, informed consent might be considered to be an ideal in the nature of a myth [10]. Factors which are relevant in trying to obtain insight into how principles and assumptions of informed consent work in daily practice are summarized in figure I. The presumption of patient comprehension and competence might be impeached by diminishing factors, having a potential effect on patient's decision-making abilities. These impediments towards informed consent are also found in figure 1.

Figure 1: $\quad$ Relevant exogenous and endogenous factors of informed comsent

$\begin{array}{lll}\text { Information dilsclosure } & \text { Consent } & \text { Impediments } \\ \text { Risks } & \text { Seffodetermination/Autonomy } & \text { Health status } \\ \text { Achievable Benefits under study } & \text { Comprehension } & \text { Ariziety } \\ \text { Benefits achieved known to date } & \text { Competence } & \text { Illness } \\ \text { Constraints/efforts } & \text { Motivation to participate } & \text { Uncertainty } \\ \text { Discomforts } & \text { Decision-making } & \text { Dependence }\end{array}$

The (intended) legal requirements towards informed consent and its basic backgrounds will be described. Next, some general legal theories about informed consent will be explored. More specific insight will be provided about the principles underlying the concept of informed consent, like voluntariness, patient autonomy and competence. We finally will discuss a cogent model of informed consent, which could be more realistic and effective in daily practice of clinical trials. 


\section{Informed consent from a legal perspective}

The informed-consent doctrine primarily has been elaborated for medical treatment. In the context of clinical trials it obtains additional sharpness. Informed consent for research is mandatorily, while informed consent for therapy may be scanty or comprehensive, depending on the individual physician [11].According to current law in many Western countries information disclosure and consent in a clinical trial should meet additional requirements. Informed consent has been specified in more detail in the Dutch health care legislation in recent years. It has been exemplified in (draft) legal rules, both for the medical treatment and for participating in clinical trials. Requirements of informed consent are provided in two distinctive laws: the Medical Contract Act [12] and the Medical Research with Human Beings Bill [ 13$]$ to protect human test subjects. When analyzing informed consent more closely, a distinction can be made between information disclosure and the eventual consent [14]. Several legal requirements refer to qualifications of information disclosure, whereas others refer to the procedure to obtain a valid consent. This is summarized in tables $\mid$ and 2.

Table 1: Qualifications of information disclosure

\section{Medical Research BIII}

Nature, duration and aim of trial

(Achievable Benefits)

Disclosure of reasonable and

foreseeable risks involved

in the trial treatment

Therapeutic exception not valid

Information disclosure provided both oral as in writing (explanatory leaflets)

Risks and consequences of withdrawing for the subject's state of health

Drawbacks for the experimental subject brought along with the clinical trial

\section{Medical ContractAct}

Nature and purpose of examination or treatment (Benefits Achieved known to date)

Likely attendant risks and consequences for health or well-being of the patient, expected risks and consequences if examination or treatment would not take place

Other possible methods of examination or treatment

The state of health and prognosis of the patients, in so far as these relate to the examination or treatment

Information should not be provided if a patients has expressed a wish not to be informed, except when withholding information could be harmiful

Therapeutic exception applicabie, if information could cause significant harm to a patient

Oral infiormation disclosure, if necessary or requested in writing 
Table 2: Requirements towards the procedure of obtaining informed consent

\section{Medical Research Bill}

Informed consent is always required before involving a patient in a clinical trial

Consent may not be assumed

Consent should be based upon adequate and relevant information

Consent should be provided voluntary

Consent should be given by

any comperent patient

Incompetent patients only can be inwolved in therapeutic research

No consent required in emergency situations; but only in therapeutic types of research

Patient should be provided time to reconsider

Experimental subjects must grant consent in writing

Experimental subject may withdraw consent or stop cooperation at any time without giving

any reasons

Trial-climician should verify if patient

understands disclosed information

\section{Medical Contract Act}

Informed consent of the patient is required for performing examination of treatment

Consent may be assumed if medical interventions are not far-reaching or minor

Consent should be based on adequate and relevant information

Consent should be provided voluntary

Consent should be given by

any competent patient

Incompetent patients should be guided by proxy consent

No consent required in emargency situations

\section{I The Medical Contract Act}

Concerning the qualification of information disclosure in medical care and treatment. several requirements are mentioned in the Medical Contract Act (article 7:448).

Information should be provided upon: the nature and purpose of the examination or treatment procedures; the likely attendant risks to and consequences for the health of the patient; other alternative methods of examination or treatment and the state of health and prognosis of the patient, related to the examination or treatment [15]. Procedures carried out for the purpose of implementing a treatment contract require the consent of the patient (art 450 section 1). Consent can thus be said to be a necessalry prerequisite for a valid contractual agreement. People under the age of sixteen are not allowed to make a decision themselves (art. 450 sections 2 and 3). At the request of the patient, the care provider in any event sets out in writing the procedures for which the latter has given his consent and informs if necessary in writing about the proposed examination or treatment (art. 451 and arc. 448 section 1 ). 
Exceptions to the rule of informed conisent are also included in the act. Patients firstly might voluntarily give up the right to be informed - known as the waiver exception - and prefer to consent in advance to what a physician considers the appropriate form of action. trusting in the physician's or surrogate's judgement (art. 449). Disclosure nevertheless should always take place where the interest of the patient is outwheighted by the harm to himself or others which may ensue from withholding information. The patient's right to make the final participation decision indeed includes the right to determine the degree of participation in the decision-making process, even to the point of deferring to the decision of the physician. The second is the emergency exception, when there is insufficient time to pursue informed consent because recovery could be jeopardized by the loss of time.A third exception exists of withholding informed consent from a competent patient, based on therapeutic privilege, in case the information could cause substantial harm to a patient (art. 448 section 3). This privilege actually applies very rarely. The information nevertheless should be provided later when there is no longer any danger of causing harm. Another kind of exception for not providing full information exerts when the risks of the proposed treatment or procedure are minor and well known to the average person, such as risks involved when drawing blood. A patient consent then may be assumed implicitly [16].

\subsection{The Medicall Research with Human Beings Bill}

To protect human test subjects, the Medical Research with Human Beings. Bill requires that all the pros and cons of a trial have to be assessed and disclosed, to be reviewed by an Institutional Review Board (IRB). Informed consent is also a concern in the conduct of a study-design and will be scrutinized carefully by this review board. Subjects should know why they have been selected to participate in terms of inclusion criteria for the study. If the subjects are patients, they should undersitand the distinction between procedures that are experimental and procedures, if any, that are proposed to serve their personal needs [14]. Key elements in information disclosure are: aim, type and duration of medical research and details of the research study; reasonable and foreseeable risiks of the trial for the subject's state of health; risks of withdrawal during the trial for the subject's state of health drawbacks of the trial for the human test subject and a note indicating the voluntary nature of any participation. Information disclosure to subjects is required both oral and written. Additional informed consent qualifications concern information disclosure in a manner that the subject involved might be expected to comprehend its content. Time to reconsider is required explicitly, to enable a patient to take a careful considered decision about the consent being asked. Experimental subjects also must grant consent in writing. In most other western countries, patients also need to sign a written document. This procedure separates trial participation from everyday medical practice. Explicitly is mentioned that a person may withdraw his or her consent or cooperation at any time without giving any reasons. Subjects must also be informed that they can abstain from participation in the research-study and are free to withdraw their participation at any time without any risk with regard to the quality of the ordinary medical treatment [17]. Exceptions towards informed consent as mentioned earlier - the waiver, emergency and therapeutic exception - are not as such applicable in clinical trials. Only the emergency exception towards informed consent incidently might become relevant in the course of a specific trial, like circumstances beyond one's control and unexpected adverse events,
which require immediate intervention. 


\section{Therapeutic vs. non-therapeutic trials}

A distinction between 'therapeutic' and 'non-therapeutic' types of research refers to whether or not the research may be of direct benefit to the individual concerned under study [18]. This depends on whether such research is intended or expected to provide a benefit to the subject. Examples are the early stages of medicine testing and intervention studies with a control group not undergoing treatment. While in randomized controlled trials [RCTs] a direct benefit to the individual concerned might be possible, we generally perceive double-blind and placebo-controlled trials as non-therapeutic experiments. In the US a higher standard of consent may be required by the courts for non-therapeutic biomedical research. This distinction between therapeutic and non-therapeutic interventions is not recognized in the law in the UK [19]. In Dutch health care a further distinction is being made between medical experiments (incl. therapeutic and nontherapeutic types of research) and experimental treatments, summarized in table 3 [20]. Experimental treatments of individual patients do not have to be reviewed by an Institutional Review Board. Legal requirements towards informed consent in experimental treatments seem less strict, as they are evaluated as a type of medical treatment. This seems to be based on a practical point of view from the legislator, as the difference between a trial treatment and an experimental treatment is not always very clear in daily practice. It even could be argued that the distinction between research and therapy grows more blurred everyday.

Table 3: Medical experiment vs. experimental treatment

Medical Research Bill

Medical experiment

In trial setting and conditions

Measurements take place

for research aims

In the rule focus upon

larger number of research subjects

Airm only (or also) improvement of scientific knowledge

Acceptability is determined by the extent of risk for the research subject

\section{Medical Contract Act}

Experimental treatment

In regular treatment setting

No more measurements than necessary for prosperity of the treatment

Focus only on individual patient

\author{
Aim is onlly focused on the patient's \\ interest \\ Is concerned with individual \\ calculation of probability, in which \\ the dispoisition of 'ultimum refugitum' prevalls
}

\section{The issue of competence}

\section{I Diminishing factors of competence and autonomy}

Informed consent has been proposed, aiming to come forward to patient's self-determination and to encourage patient participation in decision making. Another requirement of a valid consent is competence, that is, the adequacy of a person's 
dectsion-making capacities. One of the reasons of the presumption of competence lies in the high priority given to freedom and self-determination from a legal perspective. A basic assumption underlying informed consent is that most patients are sufficiently capable of understanding, evaluating and making decisions about their medical situation and prospects. Given the importance of respecting autonomy, the law presumes that the adult patient is competent to participate in decision making and give informed consent. Patient's interests are generally protected in those cases where the individual's decision making capacity for decision making is non-existent or permanently reduced, like children, people who are unconscious and those who are mentally disturbed or handicapped. Competence to consent is presumed in most other cases, unless evidence to the contrary has been proven. Many factors, summarized in figure 1 , tend to diminish patient's abilities to understand, evaluate and decide, undermining patient's competency to consent. The process of informed consent takes place at a time when anxiety probably threatens to compromise the whole experience. Illness also can impair patient's usual ability to think and decide responsibly. Illness is often accompanied by factors such as fear, stress, pain, the effects of the treatment, e.g. drugs, or the effects of the disease, e.g. lessened oxygenation of the brain due to pulmonary deficits. And such factors tend to diminish a patient's ability to understand and make decisions. A patient's diminished competence may be occasioned by the effects of illness. Anecdotes exist of patients with such deficits who, while satisfying minimal competency requirements, refused treatment, but later did not remember they had said anything. Some of them might indeed be seen as competent, while others might well fail to perform up to a minimally acceptable standard of decision-making. In some cases, informied decision making is not an outcome that one should assume is easily gained and the presumption of competence even is impeached. Physical and emotional efforts of sickness may alter patient's perception on information disclosure [21]. In this respect, clinicians may be justified by thinking that it is foolish to approach any patient as a capable co-participant in decision making.

\subsection{Assessment of competence}

Competence in the functional sense of the ability to understand information and capacity to make a decision must be seen as a spectrum, ranging from the impressively knowledgeable and decisive patient to the patient who gives no sign of coherent response. Admittedly, competence may be found in degrees. One's decision making abilities even can vary over times and circumstances [19]. If a patient does not seem to understand the disclosed information this might indicate that the patient's competence leaves to be desired. It is however equally possible that the disclosure of information was not as clear as it should have been.

If diminishing factors of competence are given too much significance, competence would be questioned too often. This has led to a quite low-threshold view of competence in dayto-day assessments. The law generally expects a modest standard of competence with only a modicum of ability to comprehend information about one's options and to make a choice. The legal precept is that the patient does not need to actually understand in order to be entitled to manage his own affairs. He only needs to be capable of understanding. No assessment is required from a physician towards patient's understanding and capability on making decisions. The law has given low attention to the process by which the patient evaluates the information disclosed, deliberates about its significance and then reaches a 
decision. The legal doctrine of informed consent supplies a generic presumption rather than specific criteria for assessing competence. Coping with it as a "black box' suggests that excessive assessment of the competence of individual patients would tend to undermine freedom. This presumption also advances the concern of efficiency it rejects the need to perform a detailed assessment of the patient's decision-making capacities. Instead of simply assuming the presence of competence, we might be triggered to assess it further. An operational notion of competence then is required, so that one can determine who shall or should not be offered informed consent. No formula is available as to how such a process should be conducted. Competence or capacity to consent should be assessed individually in terms of the situation, circumstances or decision at hand. This might well be conducted on a generic level, assessing patient's cogmitiwe and decision-making capacities or on a more specific "to the task" level towards the actual decision [2I].

\subsection{Competence as accountability}

Others have suggested that the determination of competence should be guided by the question of whether a person can be judged accountable or responsible for his or her decision retrospectively $[21,22]$. The patient then should understand fully the nature and consequences of his or her actions and choices. This implies that patients should be enabled to make decisions for which they can be held responsible. Defining competence as merely an ability would then be incomplete. The question is when a person may not be held accountable for his decisions. We could say that a person is not accountable for an action if he or she has acted in ignorance or under compulsion. Under these circumstances, we would not regard that decision as a competent one. The specifics of the physician's task in helping the patient to make decisions for which they can be held responsible will then depend on what factors impede decision making. Problems with the patient's capacities to understand and reason are just one sort of impediment [22]. This would incline that is not very easy to devise a simple, quick, and definitive test of competence.A determination of competence will include a wide range of factors, which makes a test a complicated affair [24].

\section{Discussion: a model of informed consent}

Patients who are asked to participate in clinical trials should be informed adequately. However, the art of seeking consent is astonishingly difficult. Physicians must strike a delicate balance between submerging their patients in information, thereby diminishing patient's ability to make rational choices and restricting the information, to simplify decision making [26]. If the concern for self-determination is emphasized in the legal doctrine, this merely tends to motivate clinicians to (hyper)inform patients "just to be safe". This attitude seems to come apparent when informed consent is obtained, protecting for malpractice suits, like in the US. Information overload impedes uinderstanding and should be avoided. The physicians' goal is not to minimize liability, but to help the patient to make the best decision.

A cogent model for informed consent has been suggested as a useful tool for medical management [23]. This model, to be used by practicing physicians, copes with the problem of informed consent and aims to fashion to a compromise between proponents of the legal doctrine of informed consent and those who are more skeptic about it. It focuses upon the highilighting of basic, discrete choices, the gaining of permission for the patient, 
and the articulation of what seems minimally necessary in all cases. This discrete model consisting of three stages could prove to be useful with regard to informed consent procedures in clinical trials. Its features would provide the necessary foundation for any further process of education and counseling. The model also implies a psycholegal construct of competence to consent [28]. It depends on a patient's ability to understand the relevant information necessary to reach a decision; deliberate about the disclosed information and to formulate and express the final decision at hand. An outline of the model is presented in table 4.

Table 4: Informed consent model

\section{Stages of Informed}

conitent (Wear 1993)

\author{
Psycholegal consittituct of \\ competence of comsent \\ (Tepper, 1984)
}

\footnotetext{
Stagel Comprethensive disclosure

- context of medical history

- diagnosis and recommendation of treatment

- benefits and risks of treatment

- specification of alternative treatments

Stage II Core disclosure

- essentials of the cholce

Stage 111 Assessment, clarification and patient choice

- interactive elements

- feedback elements
}

\begin{abstract}
Ability to analyze, integrace and process disclosed information so that consent giwen is

knowledgeable
\end{abstract}

Deliberation about disclosed information
necessary to reach a decision

Express final decision to accept or reject tral treatment; based upon understanding and deliberation of disclosed information

The comprehensive disciosure stage emphasizes the integrated, detailed provision of information. The goals of this stage are to give a patient the opportunity to gain a full understanding of the situation as well as to rule himself in or out regarding hesitancy. ambivalence, misconceptions or a desire for more information or discussion. Patients should be informed about the problem or diagnosis, the recommended intervention as well as alternate modalities, with their significant benefits and risks and the prognosis if no intervention is attempted.

The core disclosure stage attempts to counter the information overload tendency of the first stage, during which information has already been provided in detail. The basic goal of the core disclosure stage is to present the essentials of the choice at hand to the patient in an approachable and palatable fashion. The core disclosure should center around whacever choice that patient is being asked to make, either authorizing the interwention that a physician feels is clearly indicated, or asking a patient to engage in a personal assessment of alternative modalities. A core disclosure of the choice at hand should enable the patient more readily to recognize the essential character of his authorization.

Assessment, clorification and moking a choice will be the next, more interactive part of the informed consent process, eventually aiming to enable a patient to make an informed choice. Getting the relevant information across is only the first step. The physician must 
not only provide the patient with sufficient information but should also reassure that the patient understands the situation well enough to decide whether or not to provide a consent. Consideration must be given whether the disclosure of information is sufficient in quantity, if it is fully comprehended; if the consent is truly woluntary and if the patients are competent [6]. This interactive part of the informed consent even could assist in identifying the subtly but functionally incompetent patient, respond to any significant misconceptions, false hopes or fears that the patient may have and stimulate the patient to be more forthcoming with information, leading a patient to a realistic appreciation of his situation and prospect.

We should hope that the patient will not only grasp the bits and pieces of information, but reflectively assess such information disclosure in terms of own values, beliefs and lifeexperiences, to the extend he desires and needs to [23]. To the extent there is a choice between different courses of action, it is the basic lineaments of this choice that patients are expected they will perceive, evaluate and pass on in a reflective fashion. There is more in it than formal soliciting the patient's consent to therapeutic recommendation. Simply to speak of consent once the information has been provided is to ignore the underlying. process of evaluation, which we might hope a patient will accomplish. The extent to which patients can participate in medical decision making will wary depending on how complex the treatment options are [26]. If treatment options approach the ideal of 'clearly indicated" case that no such decision making on the parient's part is needed, the informed consent procedure could have a function as a rule-out procedure whereby the hesitant, fearful, risk-aversive patient can identify himself and trigger further discussion. In a dyadic process-oriented informed consent, the patient's erroneous interpretations, misperceptions, and distortions may eventually be corrected; late-arising questions, doubts. concerns and fears may be answered and allayed [27]. Reliance by physicians on patient's estimates of their need for information may also prowide some of the answers to problems faced in the informed consent procedure [28], next to the evaluation of patient's readiness to assimilate information adequately by eliciting discussion during the informed consent process [29].

\section{Conclusion}

The competent patient's choice towards trial participation, to be fully valid, should be informed and voluntary [30]. This demands several steps in the processing of disclosed information. A patient should be able to comprehend its meaning anid balance pros and cons against each other, to draw inferences from the information with reasonable rationality, to assess the situation at hand, sufficient to guide this choice and finally to make a deliberate decision on the basis of the available information. We wonder whether assumptions like this will work in daily practice. We may conclude that the legal doctrine of informed consent to date must be seen as insufficient to fashion a model of informed consent which is realistic and effective in daily practice. Its procedure should be adopted and presented in a clear fashion. The model of informed consent which has been suggested by Wear [23] might be useful in this respect.

As clinical trials stand at the interface between original biomedical scientific research and the application of results to patient care, we suggest to take into consideration a gradual distinction between informed consent in medical care and clinical trials. Legal informed 
consent requirements become more strictly if a clinical trial is non-therapeutic and more experimental. Additional efforts and discomforts might be indined, in particular in a clinical trial. Information disclosure on these aspects will much depend upon the invasiveness of clinical procedures, type of regimen and duration of control visits. The quality of information disclosure on these and scientific aspects of the trial like randomization will at least in part be implied from the quality of the decision at hand. For the distinction in informed consent requirements from a legal perspective between medical care and research they are less relevant. Instead, concepts like risk vs. benefits disclosure might be useful in this respect as a frame of reference.

The concept of 'achievable benefits not achieved' (ABNA), recognizes that the ultimate purpose of health care is improved outcomes [3/ ]. In clinical trials, factual 'benefits achieved' until so far are less known than in regular medical treatment. In the latter case, we therefore even agree about a commitment and obligation of treatment results. 'Achievable benefits' might become more known by means of clinical research, depending. from the type of study. 'Achievable benefits" are expected to be rather high in new treatments being investigated in clinical research. But potential or expected benefits for the patients under study are yet unknown, in particular in non-therapeutic types of research. Information disclosure about 'achievable benefits' might become most relevant on the crossroads of experimental treatment and therapeutic research, as the probability that they will come forward will increase.

Another relevant factor in the informed consent procedure might be the situation in which the information is given. It should be avoided that a patient is informed under circumstances that are conceived as humiliating or insulting or do not meet reasonable requirements of a valid informed consent. In accordance with Wear [23], we expect that several problems could be prevented by an ongoing attempt to anticipate, educate and counsel - where possible - a patient on beforehand, instead of trying to get a patient to decide in a crisis-like or acute situation. Patients often need help and encouragement towards accomplishing further reflection and insight. Sometimes they are essentially incapable of doing so.

Assessing patients' comperence and judgement about the content of a clinical trial is one of the problems of informed consent [25]. Although a variety of approaches have been used to insure appropriate patient knowledge, the best method is unknown. Adequate methods for studying these aspects of informed consent also do not exist [32]. While the development of instruments to assess competence is an active research area [33], the lack of such instruments limits research in actual clinicall situations. The informed consent doctrine does not require that patients be tormented with numerous complexities, uncertaintles and possibilities, however remote. Rather it is the essential information that should be provided. The question is at what point an extended enclosure becomes so detailed and complex, that the essential of the choice and decision at hand is obscured and the patient is overwhelmed rather than edified by the information provided [23]. Information disclosure should be adjusted to the individual needs and the patient's capacity to understand and consider the information he or she receives [2]. 
We should accept the ldea that a detailed actual understanding might not be necessary for an adequate informed consent, allowing the patient to determine the level of detail and insight wanted. A patient does not have to comprehend more of the disclosed information than is necessary for nature and range of the decision at hand. Detailed actual understanding might or might not be important, depending from the decision, the patient's interest in appreciating the details and the physician's perception of the need for such detailed insight. If key issues about a clinical trial are being presented appropriately, with sufficilent time and care given to explanation, also lay people may comprehend them. $A$ physician may held responsible to recognize when such actual understanding is important, as when important personal decisions are at hand, compliance and cooperation needs: showing up or when counseling and values clarification is indicated. When trying to get more insight into how informed consent actually works, patient's comprehension is only part of the puzzle. The essentials of the choice are relevant. We then should also get more insight into reasons behind the choice: why patients decide to enter a clinical trial or not.

Informed consent still has proven difficult to define and, when defined, difficult to achieve in practice. The preponderance of evidence from empirical research indicates that the ideals of informed consent are not yet fully achieved [34]. Empirical findings on these issues of informed consent have been discussed more extensively elsewhere [35]. There is however much room to expand upon current findings and still much to be gained by actually talking to patients and asking them why they did or did not elect trial participation. We therefore have conducted a hospital-wide sample survey at the university hospital Maastricht, in which we acknowledged patients who participated in clinical trials and also those who chose to refuse [1]. We wanted to know on which grounds patients choose to participate in a clinical trial they are asked for and the reasons some of them do not wish to participate in a clinical trial. We also wanted to obtain more insight into how patients evaluate the information disclosure about the clinical trial [36] and to what extent they are satisfied with participating in it [37]. By means of this sample-surwey we aim to obtain more insight into myth and reality of informed consent in clinical trials. 


\section{References:}

1. Verhegiun F Nieman F, Jonkues R. Determinarits of patent participacion in clinical trials in whe context of informed corstenc why patients enter a dinical trial or not university hospital Maastrichc Submitted (1995).

2. Rymning E Consent to medical care and research. A legal study lustus Förlag Uppsalla (1994).

3. Faden R. Beauchamps T. A History ond Theory of informed Consent Oxford university press. New York: Oxford University Press (1986).

4. Meisel Aoth L. What do and do we not know about intomed consent fownol of the Americon Medical Associotion, 246 (19Bi) $2437-2477$

5. Kauman C.Informed consemt and patient research. Social Science and Medicine 21 (1983) 1657-1664.

6. Marsh B. editorial] informed consent - help or hindrance Joumd of the Royol Saciety of Medicine 83 (1990): 603-605.

7. Lantos J. Informed consent:The whole truth for the patients? Cancer 9 (1993) 28/1-2815.

8. Melsel A. Editorial Informed consent. Arthritis ond Rheumatsm 35 (1992) 1264 1266.

9. McLean S.A Potient's Rugtht to Know. Infarmation disclosure, The doctor and the Low Hants: Darthmouth (1989).

10. Kirby M. Iritormed consent. what does it mean? Journal of Medical Ethics 9 (1983) 69-75.

11. Levine R. Unformed consent in research and practice. Smilarities and differences. Arch Intern Med 143 $(1983): 1229-1231$.

12. Medical Contract Act amending the Civil Code and other legislation concerming the contract to provide medical treatment Dulletin of Acts and Decrees $1993-1994,21561$ (1994).

13. Medical Research with Humam Beings Bill, Bulletin of acts and Decrees, nr, 9, 22588 (1996).

14. Portney L. \& Watkins M. Faundotions of clinicol research. Applications to practice, Appleton 2 Lange, Connecticut 1993).

15. Roscam Abbing H. 'Het recht op informatie en het toestemmingsvereiste' (The right of information and consent). PP.22-32, in; J. Legemaate (ed.), DeWGBO, wan tekst nator toepossing. Houten: Bohn, Stafleu, van Loghum (1995).

16. Wijmen F van. "Verantwoorde zorg en de geneeskundige behandelingsovereenkonst" (Sound care and the Medical Contract Act). Kwaliteit \& Zorg 2 (1994) $94-97$.

17. Wijmern F van, "Het nederlands wetswoorstel inzake medische experimenten" (The Dutch bill concerming Medical Experiments). Mooms Tjjochrift voor Gezondheidsrecht 13 (1992) 86-95.

18. Beaufort 1. de. 'Ethiek en medische experimenten met mensen' (Ethics and medical experiments with human beings). Van Goncum, Assen/Mastricht (1985).

19. Horton $R$. The context of consent The Lancet 344 (1994) $211-212$.

20. National Council for Health Policy ("Nationale Raad voor de Volksgezondheid") 'Advies betreffende het voorontwerp von de wet regelen inzake medische experimenten" (Advice on the Bill concerning Medica) Experiments). Zoetermeer (1988) 18-20.

21. Sulmasy D. "Lehmann L. Lewine D. Faden R. Patienes" perception of the quality of informed consent for common medical procedures. Special section: Informed consent in clinical practice. The Journol of Chical Ethics 5 (1994) 189.194:243.250

22. Haavi Momrain E. Impairments and mpediments in pratient s decision making reframing the competence question. The foumol of Clinicol Ethics 4 (1993) 294-307.

23. Wear S. informed consent potient outonomy and physicion beneficence within clinicol medicine. Dordrecht:
Kluwer $(1993)$.

24. Elliot C. Compretence as accouncability. The Journal of Clinical Ethics 2(1991) 167.171. 25. Tepper A Elwork A Competence ta consent to treatrment as a psycholegal construct. Low and Humom
Behovior $8(1984) 205-223$.

26. Mark J. Spira H. Informed corsent for colonscopy Archives of Internal Medicine 150 (1990) 777.760.

27. Cautheil). (editorial) Commentary to "impaiments and impediments in patient decision making". Journal of
Clinicol Ethics 4 (1993) $340-34$. 28. Wallace L Informed consent to elecrive surgery: the "therapeutic' value? Sociol Science and Medicine 22
$(1996) 29-33$.

29. Lasko L. Dermatis H. Penman D. Holland J. Patients", parents' and oncologists" penceptions of informed

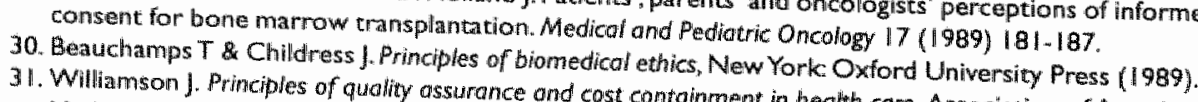
Medical Colleges, jossey -Bass Publishers, 5 an Fost contomment in heath care. Association af Americam 
32 Simel D. Feussner I.A randomized controlled trial comparing quantitative informed consent formats. Joumal of Clinical Epidemialogy 44 (1991) $771-777$.

33. Applebaum P.Assessing patients" capacities to consent to treatinentw New England joumal of Medicine 319 (1988) 1635 m 1638

34. Gotay C.Accrual to cancer clinical trials: directions from the reseanch literature Sociol Science ond Medicine $33(1991) 569-57 \%$.

35. Verheggen F. vam Wijmen F. lnformed consent in clinical trials: a rewiew of the research literature university hospital Maastricht. Forthcoming (1996).

36. Verheggen F. Jonkers R. Kok G. Patient's perception on informed consent and the quality of information disclosure in clinical trials, university hospical Maastricht. Forthcoming (1996).

37. Verheggen F. Nieman F. Reerink E. Kok G. Patient satisfaction with clinical trial participation. universicy hospital Maastricht Submitted (1995). 


\title{
3 Informed consent in clinical trials: a review of the research literature.
}

FWSM Verheggen. FCB van Wijmen

Accepted for publication in Healch Policy 36:3 (1996) as:

"Review: Informed consent in clinical trials"

\begin{abstract}
A review is provided in this paper on empirical literature about informed consent from 1979 until 1995 referring to information disclosure and trial participation in clinical trials. Articles being reviewed focus upon information disclosure, reactions to disclosure and recall, features of consent and perceptions of informed consent, both in hypothetical as in real life situations. It is concluded that further research is needed to study the process of informed consent in clinical trials, to obtain more insight into myth and reality of informed consent in daily practice. Future studies should address the limitations of previous empirical research on informed consent. Additional research should focus on the perspectives of patients who accept or decline trial participation.
\end{abstract}

Key words:

informed consent; patient accrual; trial participation; patient decision making. 


\section{I.INTRODUCTION}

As a part of a study on the decision making process of persons who are invited to participate in clinical trials we made a review of empirical literature of informed consent. Although the ethical and legal articles on the topic of informed consent in are even more numerous, this review focused on empirical studies on informed consent in medical research between 1979-1995. We also included some earlier studies which provided documentation for some of the current developments. Empirical research on informed consent may be defined as: "the study of actual informed consent decisions by patients (or their proxies) with regard to consent, and the impact of consent on patients or the clinical trial outcome [1]. We made a distinction between studies of information disclosure and comprehension ("informed") and studies of decision-making procedures and patient motivation to participate in a clinical trial ("consent"). The latter ones may be distinguished in studies of patients who actually were or had been enrolled in a clinical trial and those who are asked in a study to give hypothetical answers but were not, nor ever had been enrolled in a clinical trial.A visual overview of this distinction is provided in figure 1 . Then we will focus on factors which have been associated in empiricalliterature with accrual in clinical trials. Next, we discuss the potential bias in trial results which may be caused by non-compliance when patients decide not to enter a clinical trial. Behavioral concepts influencing patient satisfaction, derived from models of social psychology will be focused upon, which might be used as a frame of reference in empirical studies of informed consent and trial participation in clinical trials.

Figulre I"

empirical studies of informed consent

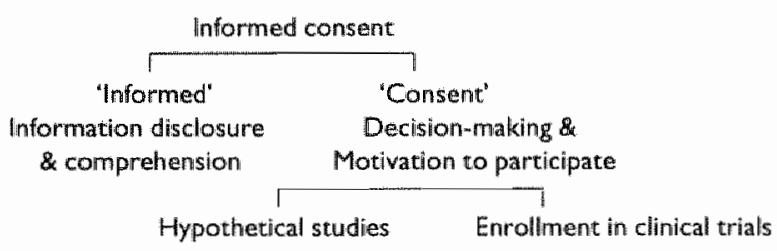

\section{METHODS AND PROCEDURE}

Based on earlier reviews of empirical literature of informed consent [2-10] we conducted a literature search of articles appearing in medical, legal and social science journals from 1979 to 1995. In these earlier reviews, the implications of obtaining informed consent have been analyzed from ethical, legal and medical viewpoints, and from both individual and societal perspectives. The purpose of our search was to analyze the research literature on behavioral aspects of clinical studies requiring informed consent. We focused upon studies towards information disclosure in clinical trials and variables associated with participation in clinical trials. Studies of informed consent in psychiatric research have not been taken into consideration. The list of key words which have been used in the analysis of empirical literature were: informed consent; human experimentation; decision making clinical trial: RCT; compliance; accrual; participation; patient education and decision making. Articles were also identified by title in MEDLINE under the subject headings "informed consent", 
'clinical trial' and 'experimentation'. Abstracts of the articles were reviewed for content before including any article in the count. Foreign non-english articles, letters and one-page news items were excluded. In total about 150 articles have been found focusing upon empirical research on the issue of informed consent. Finally 96 articles were accepted from the review, using the following selection criteria: quantitative empirical research techniques were used in the analysis; the research should focus upon informed consent in reference to clinical trials; results and conclusions had to focus upon either motivation for patient participation, evaluation of information disclosure or patient compliance and satisfaction. A detailed description of the empirical studies on informed consent, reviewed in this manuscript can be obtained in printed form from the authors.

\section{RESULTS}

\section{I Empirical studies toward information disclosure and patient comprehension}

Study on information disclosure as a prerequisite of informed consent has been given much emphasis. Studies have been focused on the influence of information disclosure upon the decision-making process [11-13]. Other studies have been published that focused upon comprehension of information in clinical trials, attermpting to define the reasons for the failure of currently used methods to ensure that patients that gave their consent are indeed informed [14-15]. Comprehension is one of the factors involved in the total informed consent process, though an important one, and one that presumably has been studied most directly and often [10]. Studies focusing on comprehension of disclosed information relate to aspects such as: type and desire of information disclosure [16], the amount and clarity of disclosed information $[14,17-19]$, signed informed consent $[15,20]$, methods of presentation, such as type of personnel [14], length and time of information disclosure [15. 21-25] and techniques for improving the informed consent procedure [26-30].

Empirical studies of comprehension show that research subjects often do not understand major proportions of that to which they have consented [31-33]. Studies focus upon patients recall of information and/or on readability of consent forms have reported that patients can, at best only recall half of the information supplied $[2,34-37]$. The value of written information is sometimes doubted because the information provided may be scanty, misunderstood, or forgotten [38]. If patients are asked to enter a clinical trial they might be anxious and frightened. The informed consent process, though imperfect, should convey enough information about the study and alternative management strategies to allow patients to make a rational choice in what is invariably an emotionally turbulent setting. Several empirical research activities have been conducted to identify strategies to enhance comprehension of information on informed consent. Possible factors that influence comprehension of information in informed consent procedures include a) the type and nature of information and the use of strategies to involve the subject actively in processing information (amount, clarity and complexity); b) methods of presentation of information, such as health care personnel presenting the information, the length of time between presentation of the information and signing the informed consent form, the format in which the information is presented [35] c) demographic factors such as education, race, age, gender and marital status [28] and d) personal factors that affect 
comprehension of information disclosure, such as subject's health e.g. illness or other disruptive life situations $[2,25]$, patterns of recall, depending upon time of which a comprehension-test is carried out and the nature of disclosed information [16, 39-40].

Several studies focus upon patients' knowledge and recall of information disclosure. Sometimes terms such as comprehension, know, understand and recall are used as interchangeable even though all do not have the same meaning. A point of discussion is whether recall of information is an adequate indicator for comprehension. It is conceivable that one can have adequate recall with inadequate comprehension. Memory or recall does not necessarily imply poor comprehension. Also, even a single measure such as recall is not necessarily a homogeneous measure [35]. Even though comprehension is assumed to be necessary for a rational decision about research participation, most evaluation studies have actually measured memory (e.g. immediate or delayed recall) and not comprehension [37]. When comprehension even is the variable under study, memory could be a confounding factor. Two aspects could be distinguished concerning comprehension: patient knowledge of informed consent as a mechanism to protect individual's self-determination and the information necessary for informed consent to be given. Several authors stated that they were studying the former, when in fact they studied the latter $[15,32,41]$ : the information needed by research subjects to decide whether or not to participate in a given study e.g. purpose, risks, barriers and benefits. In general, subjects have poorer recall as the length of time between information disclosure and test-taking increases and as the amount of information increases [42]. Attitudes towards the informed consent process, showing, that patients with strong opinions about the need of informed consent forms had higher scores. on a recall test than did patients who did not have these opinions [16].

There is no consistent pattern concerning what patients remember about informed consent. Several investigators have confirmed that patients tend to forget threatening. information [5]. The literature further repeatedly indicates that research subjects and patients undergoing therapeutic procedures do not adequately understand the programs involved [28]. Patient information tools are a useful tool for informing patients to consent but if they are to perform this desired function they must be designed careful and evaluated thoroughly [43]. One accepted approach is the use of patient information leaflets to providing additional information next to the explanation by the trialleclinician. It seems likely that the success of the use of information leaflets depends upon patient motivation as influences by atcitudes towards decision-making autonomy and physician dependence. Patients who are eager to participate in medical treatment decisions would be expected to seek out information more avidly than those who feel more physiciandependent.

The existence of a signed consent form does not assure that patients have been informed and does not record what they comprehend what is explained to them [41]. It appears that written informed consent forms and a careful verbal explanation of the situation can not reassure that the patient really knows what is going on [20]. If informed consent forms become increasingly lengthy and complicated, the existence of such consent forms may even obstruct rather than improve the process of obtaining informed consent $[44,25]$. In general, information overload impedes understanding and should be avoided. A discussion is whether the amount and content of information provided affect entry 
decisions from patients [43]. According to Fetting [45], patients wanting specific information, simply informing them may be inadequate, because this does not guarantee patient understanding. Additional effort is required to ensure that patients comprehend what they have been told. Strategies such as asking patients to repeat in their own words what they have been told can be useful. Another discussion is whether and how often patients may decline specific information about being treated in a clinical trial, and how these wishes should be respected. Several studies have examined the desire for information and participation in decision making from the patients' point of view $[13,43]$. Patients often appear to say they wamt to know everything. There is no evidence, however, that people who are told "everything" are more satisfied or do better medically than pieople who are given less complete information [46]. Some question whether the desire for information ultimately leads to involvement in the decision making process [47]. Others however demonstrate a strong association between preference for information and participation in a specific cancer trial [16].

\subsection{Empirical research on decision procedures and patient motivation towards participation in clinical trials: hypothetical and real life siltuations}

Cassileth and her coauthors [2] made an important distinction between individuals who actually were or had been enrolled in a clinical trial and those who gave hypothetic answers but were not, nor ever had been enrolled in a clinical trial. In our review, hypothetical data come from surveys of people who are not facing a participial medical choice in a clinical triall, but are asked what they would do if they were. 'Actual' consent decisions occur when patients believe they are making a real decision about treatment or participation in a clinical trial. Some studies have been undertaken to elicit attitudes towards participating in clinical trials by actual participants while others have surveyed patients not enrolled in studies [48]. Whether hypothetical decisions are comparable to real life decision making is an open question. There is often a very real and marked difference between the reactions of individuals who actually have been involved in trial research and of those whose responses are based only on conjecture and supposition [49]. In hypothetical situations substantial numbers of people are prepared to participate, even in the most demanding situations [50]. An obvious criticism made by us is that people may react very differently when they are ill and then should make an actual decision about. trial participation. Opinions of respondents in hypothetical situations may not be representative of patients who actually refuse trial entry. One study showed no significant differences in the attitudes towards participation in clinical trials between a group of patients, one comprising cancer patients and a control group from the general public [51]. In our view, a distinction between individuals who actually were or had been enrolled in a climical trial and those who gave hypothetic answers but were not nor ever had been enrolled in a clinical trial seems also relevant for other reasons. A higher rate of refusal is attributable to the hypothetical nature of study designs, where the subjects are not actually suffering from the illiness and may be more inclined to refuse a procedure because of its risks than persons actually suffering from an illness. In one study for example, LlewellynThomas and coworkers [53] were interested in determining if there were differences in risk/benefit atcitudes and the trial entry decision in a trial of adjuvant radiation therapy in early breast cancer. The agree/refuse frequency distributions were significantly different $(p<.001)$, indicating that surrogates were much more likely to refuse trial entry ( 58 
refusals/2 agreed) compared with patients (44 refused/16 agreed). Compared with patient refusers, surrogate-refusers tended to demand more benefit in terms of recurrence prevention before undertaking the time commitment and risks of side effects associated with this radiation therapy protocol.

A high refusal rate also can be the result of investigators' bias in setting up a hypothetical trial or the patient's unfamiliarity with the clinical investigator.

The empirical studies that were identified which addressed attitudes towards participation in clinical trials are summarized in table $\mathbb{I}$. These focus on issues such as public and patients attitudes to clinical trials and informed consent [50-52] and accrual and decision procedures [53-56]. An overview is given in table I about: author; cases; population; type of patients; study question; study design and used statistics. Data are mostly gathered from respondents by means of questionnaires (survey, interview). Five studies were found, using randomized assignment of informed consent formats (see table 1). No empirical study however was found, focusing upon motivational determinants for participation behavior in clinical trials.

Most studies on accrual and decision procedures provide descriptive statistics (frequencies, crosstabs, correlations); only few of them used Chi-square statistics $[55,57]$, Student t-tests [1 2], McNemars" tests [58-59] and multiple regression analysis [28, 45]. However, these latter studies - which appeared most interesting - refer to small populations in a specific type of clinical trial, which has implications for the generalizations to be drawn. Some stuidies analyzed the impact of disclosure of information on perceived medical outcome [45,60-61]. In one study the results provide no evidence for the hypothesized negative effects - anxiety, treatment refusal, reduced compliance and increased side effects - of providing patients with extensive disclosures [60]. This was also confirmed in a study on providing detailed information about risks of surgery in an atternpt to obtain fully informed consent [62]. 


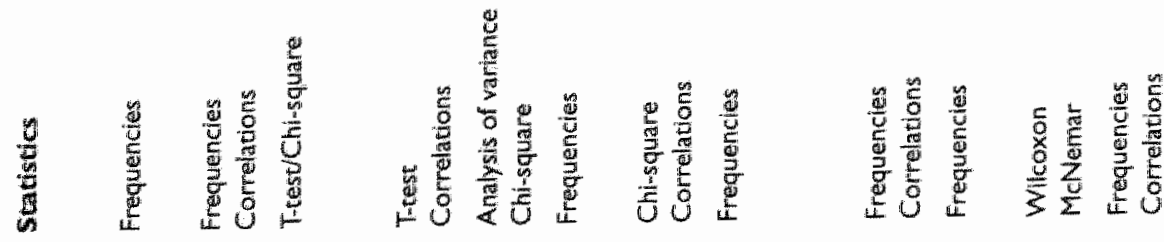
要

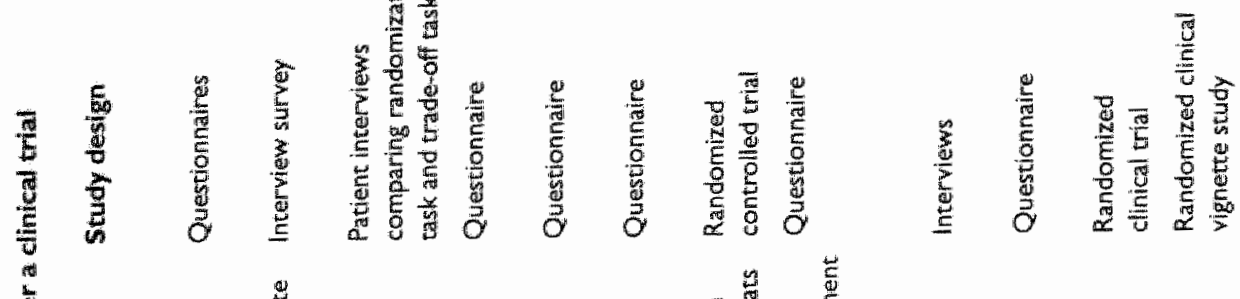

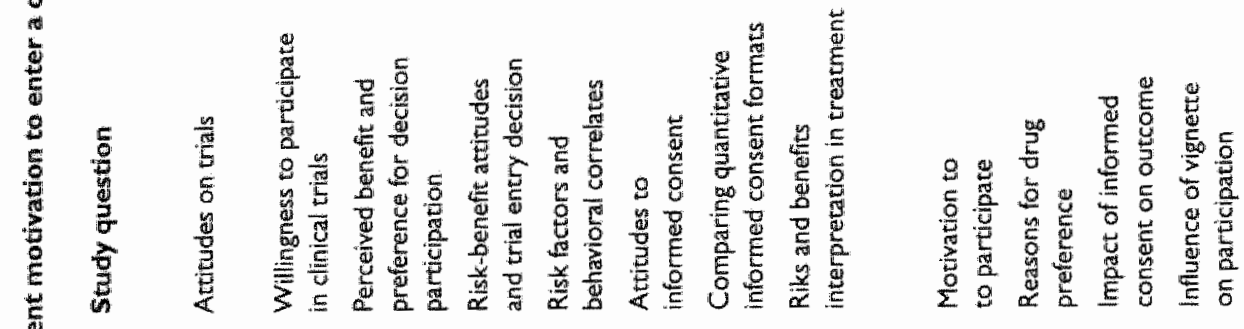

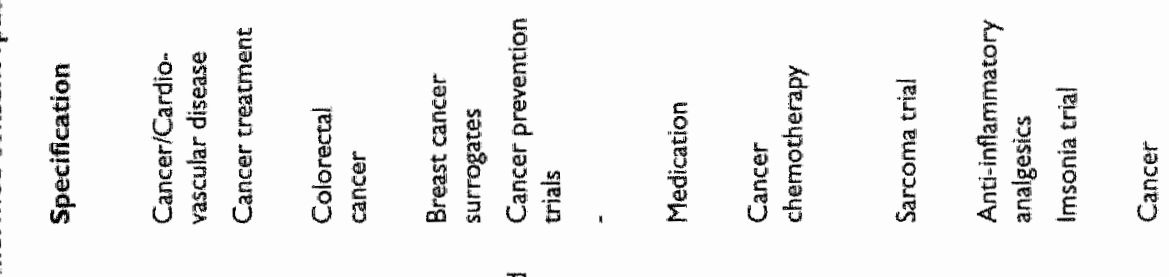

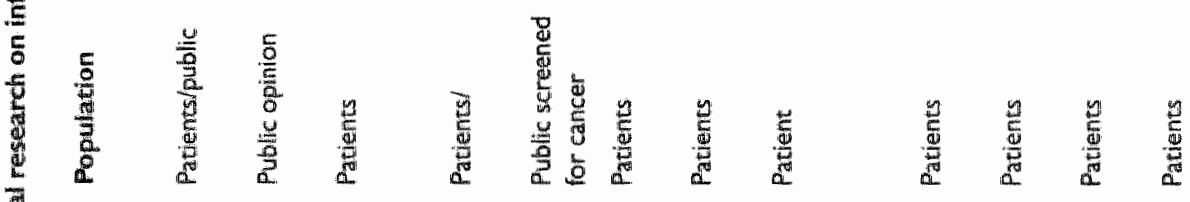

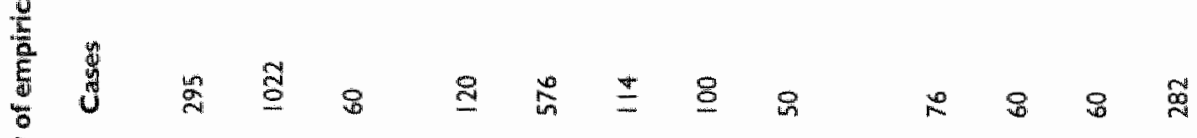

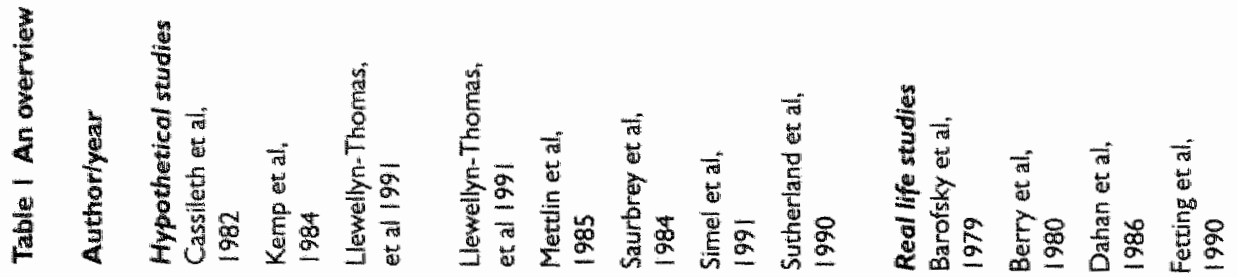




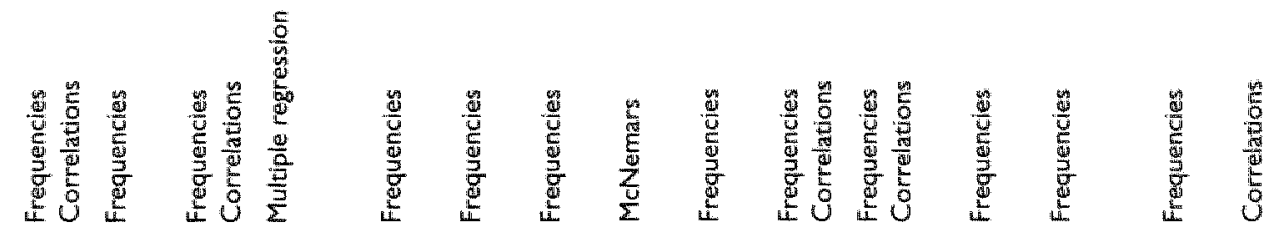

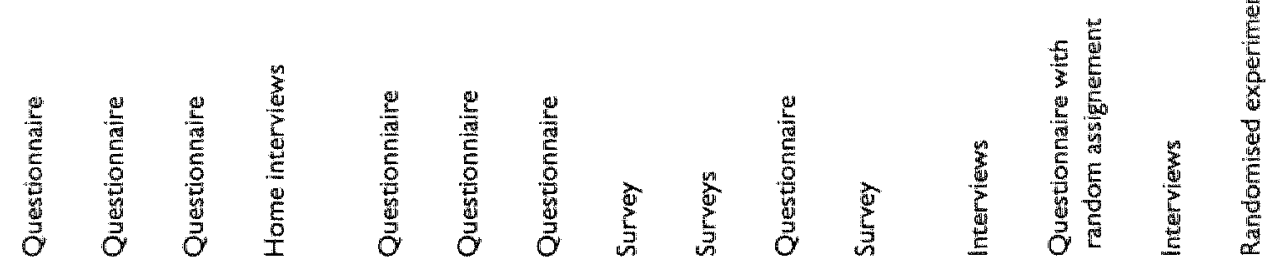

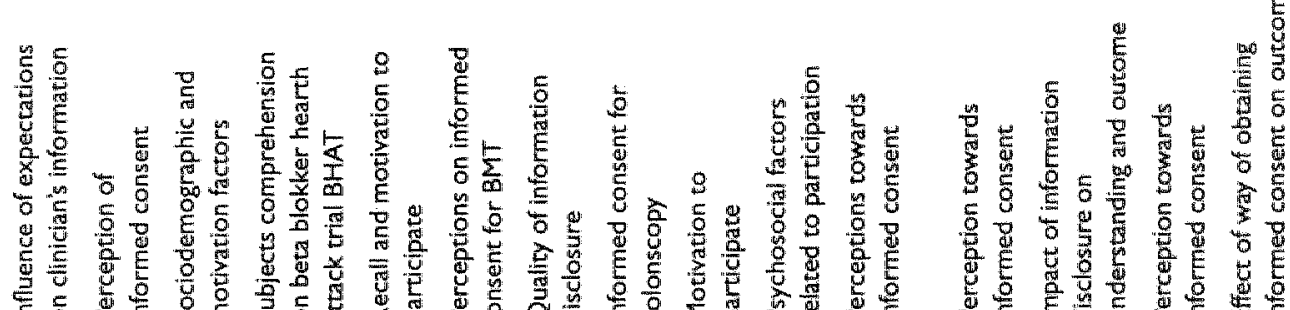

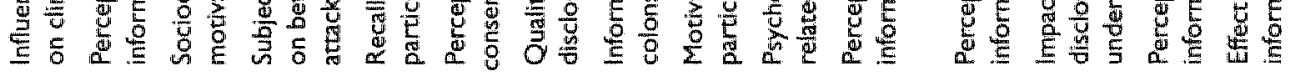

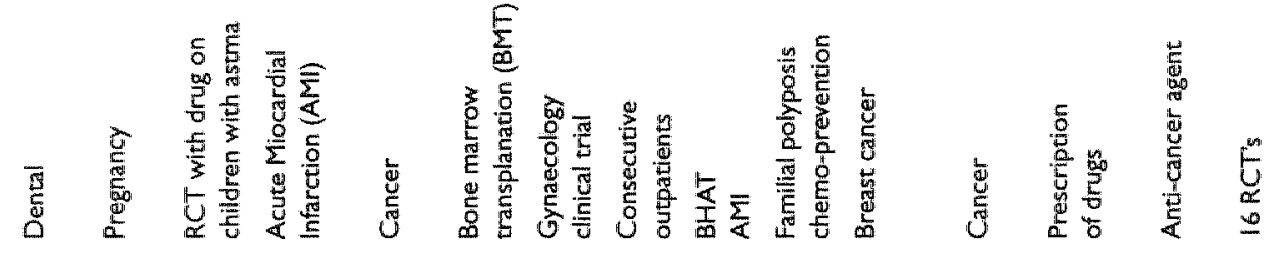

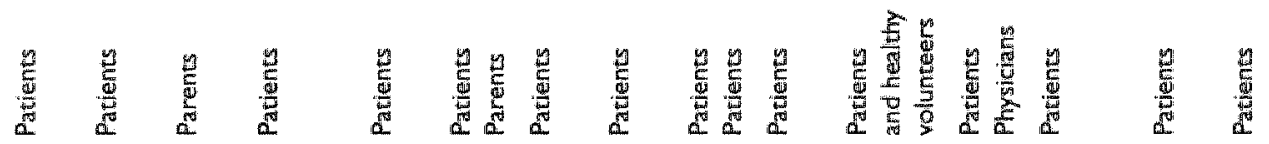

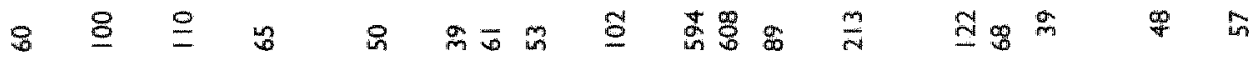

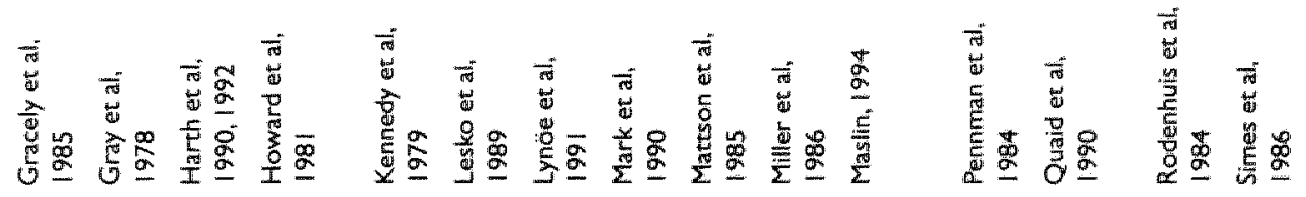


An interesting methodological point is to determine if patients who differ in the clinical trial entry decision also differ in their strength of preference for the possible benefit offered by trial participation as determined by a trade-off task in clinical trial entry using probability statements, as analyzed by Lliewellyn-Thomas and coauthors [12]. These researchers were reluctant to include their inventory in the design of an actual trial because of the potential risk of affecting the trial's accrual rate in unknown rates. Their experience indicated that the relevant diagnosis renders this decision problem highly salient to these type of patients [53]. Others indicate however that the opinions of patients surveyed in hypothetical situations may not be representative of patients who refuse trial entry in actual situations [6]. An important issue then related to efforts in this direction is the possibility that the explicit and wisual presentation of clinical trial information in the manner required by the probability trade-off technique may systematically affect the entry decision itself [12].A point of concern when comparing studies in hypothetical versus real life situation is that results of hypothetical studies imply that trial accrual is not likely to be adversely affected by incorporating explicit and interactive probilem representations [12], like those used in the probability trade-off technique, into real trial entry decision situations [6/]. On the other hand, follow-up research could also indicate the probability of trade-off technique, compared with usual methods of providing information, foster more fully informed consent to either accept or refuse trial entry $[5,7,29]$. Further experimental studies should guide the development of ways to seek informed consent that will promote information understanding [2], while avoiding the danger of systematically influencing patient's trial entry decision making [61].

\subsection{Attitudes of physicians vs. patients towards informed consent}

The accrual of patients into clinical trials has also been studied from the viewpoint of clinician-scientist [44,63-72]. From the clinician's point of view the approach and attitude towards informed consent also depends upon the type of treatment under investigation. Practical considerations can interfere with the actual act of including patients in clinical trials and preliminary studies have been conducted to try co understand the underlying dynamics [69-70]. Several studies compared patient's and physicians' perceptions of informed consent $[7,45,67,73-76]$. These showed significant differences between patients' and doctors' expectations towards the trial treatment, while patients usually prefer more detailed disclosures. Patients usually prefer more medical information than they receive [64].

\subsection{Variables associated with accrual in clinical trials}

A research-overview of accrual in cancer clinical trials suggests that non-participation might be associated with physician and patient variables, as well as by protocol characteristics [4]. These are presented in table 2. Patients generally perceive both societal and personal benefits from participating in clinical trials [6]. Although a number of such variables has been identified as influences on acerual, and some have been studied in more detaill, we may conclude that the direct impact of such factors on trial-participation itself has not been assessed. Non-changeable patients demographic characteristics, such as age, gender and sociodemographic status, along, with characteristics that remain relatively stable during treatment, such as disease stage, overall health status and performance status also have been related to accrual to elinical trials $[28,45,50,57,67,77-82]$. 
Table 2 Variables associated with accrual to clinical trials (Gotay 1991)

Physicians charocteristics

Demographic correlates of referral to trials

Atritudes towands clinical trials

Motivations for referral

Patient charocteristics

Demographic correlates of trial participation

Artitudes towards clinical trials

Motwations for pratients who choose to enrall

Choracteristics of specific protocols

Availlability of the trial

Patient eligibility

Trial design (e.g. differences in treatment arms)

Informed consent procedures

Modes of presentation of information

Physicians and patient knowlegde

\subsection{Introducing bias in trial results, influenced by non-compliance}

From a scientific perspective, studying what happens if patients decide whether or not to enter a clinical trial may improve the analysis of results of that trial [12]. Close attention to recruitment, enrollment, adherence and compliance of participants could aid in the cooperation of participants essential for the success of trials [83]. Patients who agree and those who refuse clinical trials may differ in attitudes towards decision control and expected benefits. To the extent that these reasons for refusal to enter are unknown, the inferences drawn from the trial results are threatened with bias, if only observing those who agree to participate. Particularly in trials with health-related quality of life as an important consideration, such bias may render invalid the use of trial's results to select the apparent 'best' treatment alternative.

If sufficient numbers of subjects decline to take part in a study a bias may be introduced, especially if the reasons for refusal are confounded with the dependent measures. When physicians are concerned that the relationship with their patients could be compromised by enrollment procedures, they selectively may approach only the patients they anticipate will not have difficulty with the ensuing relation, thereby introducing bias into the experiment as a result of suspected non-compliance [70]. In extreme circumstances such bias may yield seriously misleading results. If behavioral factors interact differently with treatment and control conditions in actual clinical trials, they can introduce serious confounding into treatment comparisons by adding to, subtracting from, or multiplying the effects in the experimental or control conditions [84]. Whether a biased population as a result from an informed consent procedure may alter the outcome of a clinical trial has been the topic of several studies [58,85-87]. These studies have several limitations in study design (e.g. small amount of respondents) and focused only on issues as insomnia and pain relief and also only placebo aspects have been taken into account. Within these limitations they point out that knowledge from patients as trial participants on aspects as placebo cant influence the clinical outcome of the treatment under study. Psychosocial factors which could be identified to account for confounding of the outcome of a trial include 
participant"s reasons for entering the trial "patient's belief about the treatment arm to which they are randomized, patient perceptions of the treatment impact and its side effects and patient's adherence that might affect the scudy outcome [49].

An increased refusal rate would be of particular concern to investigators who are primarily interested in enrolling a full complement of trial participants. An ethical dilemma is whether explicit representations of information foster more fully informed consent to either accept or refuse trial entry than usual methods of providing information. Some evidence exists that these dilemmas will not emerge [12]. The problems of informed consent in randomized controlled trials and the effect upon outcome have led to suggestions and arguments, as there should not be a need always to have obtained informed consent [88]. Nevertheless this does not give enough evidence and can not deny that patients should be given informed consent before taking part in a clinical trial, although it could provide extra bias. No empirical studies have been found by us in our review which have focused on this issue further.

\subsection{Behavioral concepts infuencing patient participation}

Lack of knowledge is found in literature about motivational aspects of informed consent and social-psychological factors of entering a trial. Few studies are known focusing on patient motivation and socio-psychological factors therein for entering a clinical trial or not [78, 89]. What motivates patients to participate in research? For some, participation may be an altruistic gesture. Other reasons include direct possible inducements, a desire to please or oblige the doctor, or hope of obtaining the latest or best possible treatment [8I].The motivation to participate in a clinical trial might be expected to be linked closely to personal benefit, such as therapeutic and other perceived advantage. On the other hand, distance between home and clinic of public communications as well as social and altruistic factors may act as distinctives to participation [90]. Conflict between clinical trial entry and other life events also may interfere with patient participation. A patient may provide a justification for not entering a clinical trial, if this trial is not perceived as important enough or if he or she simply wants to provide a situational acceptable excuse for not participating (too busy at the moment, job conflict, etc.). From a patient's perspective, risk communication plays a critical role in determining compliance behavior in terms of trial participation. We may conclude that risk disclosure will induce a patient to refuse a clinical trial treatment. Next to the perceived severity of risks of the treatment, this also could concern the probability these risks will occur. Furthermore the patient's perspectives about perceived risk of treatment might be evaluated in comparison with the risks of the disease. The physician's willingness to disclose the risks and uncertainty the patients faces when entering a clinical trial is a major factor influencing accrual compliance. So physician's knowledge and perception of risks of trial treatment and the manner and extent to which risks are communicated and understood by patients plays a substantial role in a patient's decision to enter a trial or not. Although the active resistance to treatment may be a function of risk-avoidance, passive resistance may be a function of the lack of perceived benefits of trial participation. Passive accrual noncompliance may be attribu. ted to the unwillingness of patients to refuse directly the request of health professionals. Patients who agree and those who refuse clinical trial entry may differ in attitudes towards decision control and the benefics associated with the trial arms, which may have implications for the process of obtaining informed consent [12]. When conducting these 
types of empirical studies, we suggest to refer to current theories for explaining behavioral aspects of trial participation and the role of information disclosure therein. Within social psychology, models are being developed to explain and predict indiwidual health and illness related behavior:These models, which briefly can be summarized as follows, might be useful when studying patient motivation towards trial participation.

The theory of reasoned action (TRA) hypothesizes that behavior is determined by an individual's intention to perform the behavior, which in turm is determined by the person's attitude towards the behavior and the perceived expectations of others important to the individual [91]. Underlying these two components are determinants known as behavioral and normative beliefs. The Health Belief Model (HBM) postulates that, in the presence of internal or external cues to action, the probability that a person will perform a particular health-related behavior depends on his or her perception of the susceptibility to the health threat, the severity of the threat, the benefits of the action in decreasing the risk or severity of the threat and the costs or barriers to action [92]. The variables central to this. modell include perceived susceptibility and severity of a disease or condition, barriers and benefits to action, a cue to action and general health motivation. in tirying to find an integrated framework to study behavioral aspects of clinicall trials from behavior theory, four general behavioral concepts are suggested to be central to health behavior: probability of an expected outcome or health condition, perceived severity, effectiveness in terms of probable success and the perceived costs of adopting a particular course of action [9]. These four concepts are common in theories and conceptual models to explain and predict the health behavior of individuals, like the TRA and the HBM.

\section{Table 3: Behavioral concepts infuencing patient participation}

\section{Factors}

\section{Probability}

\section{Risk factors}

Perceived health state (like illiness, family history and susceptibility to health consequences)

\section{Severity}

Perceived health state flike severity, worrying and urgency)

\section{Effectiveness}

Knowlegde and prerceptions of treatment and aliterratives

Expected benefits

\section{Costs}

Expected barriers

Discamforts

Logistic costs (travel, inconvenience)
Might be ilnfluenced by (Mlarrow et all, 1994)

Framing or presentation of the trial Knowledge and perception of disease and impact of intervention

Framing or presentation of trial Willingmess and ability to make trade-off decisions

Framing or presentation of the trial Desire to get best possible care Fear that illuess will worsen Assessment of difficulty of follow-up Preference fior specific treatment Trust in medical care, doctor or hospital Altruistic motives Subjective norm

Willingness and ability to make trade-off decisions Preference for participating in medical deciston making 
Factors which are hypothesized to influence patient accrual in clinical trials from a patient"s point of view can be organized within the four behavioral concepts defined above. The probability-, severity-, effectiveness- and cost-factors are summarized in table 3. These factors might on their way be influenced by personal beliefs held by patients, such as general atritudes towards medical care and research and issues related to the informed consent procedure. Based on the previous conceptual models these factors could be used as an organizing framework for further empirical research. Although most of the factors were identified from descriptive studies to date, some reports have used more structured methodology and provided scatistical tests of significance [12]. Lawrence [93] put forth different areas that constitute patient barriers and obstacles to clinical trial participation. They are possible conflicts between the interest of the individual patient and research in

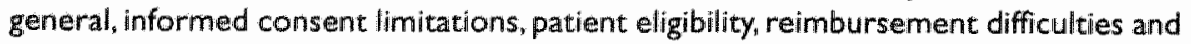
negative attitudes about the research process. These areas of concern are referred to repeatedly [69-70,94]. Additional categories that have not been explored very much are those patient wariables that may constitute barriers to participation, related to practical considerations and convenience issues [49].

\section{CONCLUSION AND DISCUSSIION}

Informed consent still has proven difficult to define and, when defined, difficult to achieve in practice. Debates concerning informed consent will probably continue, hopefully with more concrete, empirical ewidence. We may conclude that the concept of clinical research is complex and may not be readily understood by patients. This particularly comes to the fore in earlier studies of the informed consent process [31-33,95-97]. An earlier evaluation of these empirical studies concluded that 'whether informed consent is or is not feasible is still an open question' [25]. Nowadays, we can still entertain the same conclusion, although more is know about the complex process of informed consent. The informed patient as a decision maker however has just not materialized. Informed consent as a maxim of clinical care and research has been accepted by many without actual proof that the process works [I]. Communication about clinical trials towards patients has been found to be ineffective in many cases [75]. Questions have been raised about the "efficacy" of informed consent and about whether it is ever possible to determine if trial participants have been fully informed, and if they have given true consent. Empirical studies have already been useful here and have demonstrated that patients who have given their "informed consent' may remain ignorant of the most basic information $[2,23,98]$. This is true, irrespective of the procedure or treatment involved. The information fails to get across $[24,41,99]$ and patient sometimes consent to trials simply because they trust their doctors [7]. Trial-clinicians should provide adequate information on benefits, risks and barriers in a clinical trial, and should strive at an appropriate balance between them when asking patients to enter a clinical trial and obtaining informed consent. It helps patients to make informed choices, which seems a laudable goal, and information disclosure does not lead to negative effects in terms of a lower patient compliance. Physicians projections during the informed consent procedure on benefits, risks and barriers may be particularly important, as several studies also suggest that from one fourth to one third of the patients who enroll in a clinical trial lack a basic understanding of the trial, do not comprehend that the randomization procedure rather than the physician selects their treatment. 
Several studies show that a substantial amount of patients prefers to defer the decision to undergo treatment to the dinician $[13,29,54,74]$. Sometimes patients may feel compelled to enter a clinical trial to please their physician or out of fear of being deserted by their physician if they refuse [7]. A patient's expectations about how the physician's behavior is likely to be affected by participation in a clinical trial are likely to motivate trial enrollment and adherence [49]. The impact that a physician makes overtly or covertly to the enrollment cannot be minimized [ 100$]$. That informed consent in several occasions tends to be an ineffective ritual has both anecdotal and empirical support. It has been shown that "informed consent' does not work [ 101 ]. The preponderance of evidence from empirical research therefore indicates that the ideals of informed consent are not yet fully achieved [4]. This problem also clearly extends well beyond the range of clinical experimentation into everyday practice where common law always has required the patients consent to medical treatment in all but exceptional circumstances [102].

Deficits in the informed consent process have been noted as a problem [2, 103]. Trial designs, especially pre-existing treatment preferences, pose significant problems for physicians and patients. There are very few circumstances in which patients should be exposed to dangerous procedures, and the rights of subjects are recognized to be adequately informed about the experimental methods and to decline to participate [104. 106]. Analysis of reasons for patient accession problems tends to center on physician and institutional characteristics, with patient data emphasizing sociodemographic and diseaserelated factors [94]. Intervention strategies have focused on alternative trial designs [107], improving the informed consent process and increasing the patient's knowledge about trials. What can be done to determine with any certainty whether or not participants understand the full implications of what they have been told in information disclosure [108] ? Question is also how it can be known whether or not any given information would have had a potential effect on the patient's decision [109]. Interpretation to what amounts to a real consent depends on the assessment of quality, nature and extent of information disclosure. What should, or can be done to determine with any certainty whether or not participants understand the implications of what they are told in a disclosure procedure of informed consent [1 10]? Does informed consent succeed in providing protection for enrolled patients and result in respect for patients' autonomy? [108]. Would improved information leaflets or consent forms result in a higher likelihood of trial participation? Or is it possible that the opposite would occur: well-informed patients being more likely to form a treatmenc preference and less likely to participate in clinical research? [12]. The current literature prowided the basis for hypotheses like this, as well as for interventions that require testing in future studies.

The present literature on accrual to clinical trials and informed consent illustrates an interesting mix of multi-disciplinary research [4]. There is however much room to expand upon current findings. Individual studies may be limited in scope and perspective. Specific studies may be criticized on methodological grounds, such as studies based on small sample sized and survey studies with low response rates, bringing the generalizability of findings into question. Many of the studies do not include information about the reliability or validity of the instruments involwed. Results of studies investigating correlates of patient entry into clinical trials are not completely consistent, given the varying research 
protocols, correlates and populations. A deficiency in a large number of the empirical studies is their lack of compiarability and generalizability. They are studies in reiatively small, diverse populations with varying degrees of illness.

Limitations of previous empirical research on informed consent include [38]: the use of non-patient subjects or hypothetical situations, failure to consider what physicians actually told the patient, focusing only on patient recall as the key to understanding, a lack of generalizability of results, allowing investigator bias where the investigator is also the subject's physician. Another major aspect of social science research dealing with informed consent is the lack of a direct and explicit link between the empirical research in physicianpatient communication and the implications of these research findings for the formation of policies dealing with informed consent [5]. A new empirical approach in studying informed consent has to deal with these methodological problems and limitations that characterize previous research on informed consent. This scientific approach to understanding the informed consent process will allow to realize more fully the intended goals of informed consent [111]. It also can allow to find out whether and which solutions actually work in practice [1 2]. Empirical studies of informed consent may also lead to a better understanding of the consent process by describing patient characteristics and factors that affect consent rates.

The question of efficacy of informed consent shoull be examined to determine how to make it work better [1]. Additional research should focus on the perspectives of patients who accept and decline trial participation and on interventions designed to affect accrual [4]. To understand how the informed consent process works, the information disclosure by trial-clinicians and risks, discomforts and benefits as perceived by patients being asked to enroll should me examined.A truly patient-centered view of decision-making in the context of clinical trials require a different sort of research than which has been done so far - one that evaluated the responses of actual patients to different approaches to communication about treatment options, risks and benefits [46]. One finding is that there is no evidence that an 'excessive pursuit' of informed consent will result in any significant. increase in patient's understanding of information disclosure [98]. And there is still no general agreement as to what information must be effectively imparted to the patient if he or she is to reach a rational decision [7]. Although results of some studies suggest that what patients assimilate from the informed consent process affects the decision to participate and plays a powerful part in preference $[12,60,55,61,73]$, we do not expect additional insight from new empirical studies, analyzing the impact of information disclosure on patient accrual in clinical trials. Studies show already that patients being asked in clinical trials use information provided during the informed consent process to make their decision, implying the relevancy of an appropriate balance between potential risks and benefits [11].

The literature dealing with recruitment of patients for clinical trials offers little information on motivations and attitudes of those who volunteer [6]. There is much to be gained by actually talking to patients and asking them why they did or did not elect trial participation. Despite the requirements of informed consent during clinical care and research, there only have been few empirical trials of the actual decision-making process during consent [1]. Only a few studies have asked patients why they did or did not choose to participate in 
clinical trials $[77,79-80,113]$, while some interviewed only patients on trials $[41,76,114$ [116]. The reasons why some subjects refuse to participate in clinical research are however more than passing interest [117-119]. This matter has not been studied much, which might have to do with the fact that it's difficult to persuade individuals to answer further questions once the have declined participation. We may conclude that this field of research would be enriched by more such efforts [4].

Results from empirical studies stay ambiguous, unless one states very clearly what to achieve, when conducting a study on informed consent. Some questions might lkeep unanswered, as our scientific methods to investigate them do not provide valid answers. Adequate investigation on patient autonomy and competence when being asked to enter a clinical trial might be relevant in this respect, but also seems difficult to realize [120]. While the development of instruments to assess competence is an active research area, the lack of such instruments limits research in actual clinical situations. Little research has been conducted to assess patient's perception of the informed consent process. While many observations of informed consent procedures have focused on information aspects, fewer systematic investigations have focused on patient perceptions of the encounter [76]. In our apinion, very little work has been done to determine why patients agree or decline to enroll in clinical trials. Also, no studies were found in our review, focusing upon the patient's satisfaction with trial participation. Prospective studies with baseline and periodic determination of motivations, expectations and levels of satisfaction as the trial progresses could examine predictive relationships with adherence behavior [6].

We used the findings out of the literature review to conduct a hospital-wide sample surwey at the university hospital Maastricht, in which we acknowledged patients who participated in clinical trials and also those who chose to refuse. Aim of this study has been to obtain more insight into how informed consent in clinical trials actually works in daily practice and to focus upon practical problems in providing adequate information and obtaining consent when patients are asked to participate in a clinical trial.. lin this survey, informed consent in clinical trials has been analyzed from different disciplines and domains. Judicial, social psychological, health educational as well as quality assurance aspects of informed consent have been studied. Research questions have been focused upon patient motivation, information disclosure and patient satisfaction. We wanted to know on which grounds patients choose to participate in a clinical trial they are asked for and the reasons some of them do not wish to participate in a clinical trial [121]. The model of explanation in our sample-survey has been based on the social psychology models and behavional factors, found in literature. We also wanted to obtain more insight into how patients evaluate the information disclosure about the clinical trial [122] and to what extent patients are satisfied with participating in it by means of follow-up measurements [1/23].

\section{References}

1. Simel D. Feussner J. Suspended judgement. Clinical trials of informed consent, Controlled Clinical Trials 13 (1992) $321-324$

2. Cassileth B. Zupkis. R. Sutton-Smith K. March V. Informed Consent - why are its goals imperfectly realized? New England journal of medicine 302 (1980) 896-900.

3. Cipriano Silva M. Merkle Sorrel J. Enhancing comprehension of information for informed consent a review of clinical research. IRB a human review of human subjects research wol 10\%1. Hostings Center Report $₫(1988) 1-5$. 
4. Gotay C.Accrual to cancer clinical trials directions from the nesearch liturature. Sociol Seience and Medicine $33(1994) 569-577$.

5. Kauman C. Informed consent and patient research. Socid Sciemce and Mtedicine $21(1983) 1657-1664$.

6. Matson M. Participation in a Clinial Trial. The patient's point of view. Controlled Chiniol Triols 6 (1985) 156-167.

7. Mackillop W. Johnson A. Ethical problems in clinical ressearch the reed for empirical studies of the clinical trial proces Jounal of Chromic Diseose 3 (1986) $177-188$.

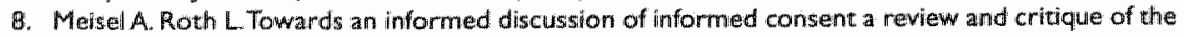
empirical studies. Arizona Low Review 25 (1983) 265 -346.

9. Morrow G. Hickok J. Burish T. Behawional aspects of clinical trials. An integrated framework for behavional theory. Concer 74 (1994) (suppl 9) $2676-2682$.

10. Taub H. Comprehension of informed consent for research issues and directions for future sudy IRB a review of thuman subiects research. Hostüng Center Report $\| 2$ (1986) 7-10.

11. Ende J. Kazis in. Asth A. Moskowitz M. Measuring patients' desire for autonomy Decision making and irformation seeking preferences among medical patients. Jownol of Generol hternal Mediche 4 (1989) $23-30$.

12. Llewellyn-Thomas $H$. et al. Patients willinghess to enter clinical trials measuring the association with perceived benefit and preference for decision prarkicipation. Social Science ond Medicine 32 (1991) 35 42.

13. Sutherland H. Cancer patients their desire for information and participation in treatment decisions. Joumal of the Royal Society of Medicine 82 (1989) 260-263.

14. Muss H. White D. Michielutce R. at all, Written informed consent in patients with breast cancer, Cancer 43 (1979) $1549-1556$.

15. Morrow G. Gootnick J. Schmale A.A simple technique for incireasing patients' knowledge of informed consent to treatment. Concer 42 (1978) $793-799$.

16. Cassilleth B. Zupkis R Sutton-Smith K. March V. Information and participation preferences among cancer patienes. Annols of internal Medicine 92 (1980) 832-836.

17. Jensen A. Madsen B. Andersen P Rose C. Information for cancer patients entering a clinical trial - ath evaluation of an information strategy. European fournal of Concer 16 (1993) 2235-2238.

18. Lavelle jones C. Byrne D. Rice p. Cuschieri A. Factors affecting quality of informed consent British Medicol jownal $306(1993) 885-890$.

19. Christens en I. Boyce W. Harrel H. Gardener M. Circumcision and informed consent is more information always better? Medical Care 25 (1987) 856.

20. Byrne D. Napier A. Cushieri A. How informed is informed consent? British Medicol Journol 296 (1988) 839-B40.

21. Freeman W, at. Effect of informed consent and educational background on patient knowledge an $x$ iety and subjective responses to candiac catheterisation. Catherisation and Cordiovascular Diagnosis $7(1981) 119-134$.

22. Katz J. Daltroy L. Brennen T. Liang M. Informed consent and the prescription of nonstenoidal anthinflammatory drugs. Arthritis and Rheumotism 35 (1992) $1257-1263$.

23. Oddens B.Algra A. van Gijn j. Hoe goed zujn deelnemers aan een kliniseh onderzoek geinformeerd? Nederlonds Tijdschrift voar Geneeskunde 46 (1992) $2272-2276$.

24. Rimer B. Jomes W. Keintz M et al. Informed comsent a crucial step in cancer patient education. Heofuth Evedution Qwarienly $10(1984) 3042$.

25. Roth L. Lidx C. Meisel AS et al. Competency to decide about treatment or research. Ar overview of some empirical data thternoutonol foumd of Law and Psychiotry $5(1982) 29.50$.

26. Aarovison N. Zittoun R. linformed consent and cancer clinical trials. In: Holland J Zittoun R. (eds) Psychological aspects of oncology. Springer, Bertitin (1990)

27. Dodd M. Mood D Chemotherapy: helping patients to know the drugs they are receiving and their possible side effects. Concer Nursing 4 (1981) $311-8$.

28. Howard J. DeMets D. BHAT research group. How informed is informed consent? The BHAT experience. Cantrolled Clinical Trols 2(1981) $287-303$.

29. President's commission for the study of ethical problems in medicine and biomedical and behavional research. Moking heath core decisions the ethical and legol implications of informed consent in the potientpractitioner relotionship. US Government. Printing Office, Washiniton DC (1982).

30. Uden M. vam Dam F. Informed consent bü klinisch karkeronderzoek. psychologische aspecten. Nederlonds Tijdschrift woor Geneeskunde 46 (1986) $2087-2092$.

31. Priluck I. Robertson D. Buettrer H. What patients recall of preoperative discussion after retinal detatchment surgery. Am J Opthalmology 87 (1979) $620-623$

32. Robinson $\mathrm{G}$. Meraw A. Informed consent. Recall by patients tested postoperatively. Ann Thoroc Surg 22 
(1976) $209-212$

33. Schulat A. Pardee G. Ensinck J.Are research subjects really informed. West J Med 123 (1975) 76-80.

34. Askew G. Pearson K. Cryer D. Informed consent: can we educate patients? fournd of the Royol College of Surgeons Edinburg 35 (1990) 308-310.

35. Cipriano Silva M. Merklle Sorrel j, Factors influencing comprehension of information for intormed consent. international Journal of Nursing Studies 4 (1984) 233-240.

36. Rivera R. Reed J. Menius. Evalluating the readability of informed consent forms used in contraceptive clinical trials. Internotional journal of Gynaecology Obstetry 38 (1992) 227-230.

37. Taub H. Baker M. Sturr J. Informed consent for research. Effects of readability, patient age and educacion. journal of the American Geriotric Saciety 34 (1986) 601-608.

38. Meisel A. Rath L. What do and do we not know about informed consent. fournal of the American Medical Association 246 (1981) 2437-2477.

39. Morrow $G$. Bennet J. Carpenter P. Informed consent to treatment in clinical trials. Biomedicine \& Pormacotherapy 37 (1983) 10-13.

40: Taub H. Informed consent, memory and age. Gerontologist 20 (1980) 686-690.

41. Kennedy. B. Lillerihaugen A. Patient recall of informed consenc. Medical ond Paedizutric Oncology 7 (1979) 173- 178.

42. Bergler J. Pennington A. Metcalf M Freis E. Informed consent how much does the patient understand? Clinical Pharmacology The ropy 27 (1980) 435.

43. White D. Muss H. Miechielutte R. et al. Informed consent: patient information forms in chemotherapy trials. American Journol of Chinical Oncology 7 (1984) 183-190.

44. Epstein L. Lasagna L. Obtaining informed consent: form or substancel Archives of Internal Medicine 123 (1969) 682-688.

45. Fetting J. Siminoff L. Piantadadosi S. Abeloff M. Damron D. Sarsfield A. Effect on patients" expectations of benefit with standard breast cancer adjuwant chemotherapy on participation in a randomized clinical trial a clinical vignette study. Journal of Clinical Oncology 8 (1990) 1467-1482.

46. Lantos J. Informed consent. The whole truth for the patients? Cancer 9 (1993) 2811 -2815.

47. Krantz D. Baum A. Wideman M.Assessment of preferences for self-treatment and information in health care Journol of Personal Social Psychology 39 (1980) 977-990.

48. Sutherland H.A study of diet and breascancer prevention in Canada why healthy women participate in controlled trials. Cancer Causes Control 4 (1993) $521-528$.

49. Schain W. Barriers to clinical trials. Part ll: knowlegde and attitudes of potential participants. Cancer 74 (1994 (9 suppl) 2666-2671.

50. Kemp N. Skinner E. Toms ]. Randomized clinical trials of cancer treatment a public opinion survey. Journol of Clínical Oncology 10 (1984) 155.161.

51. Cassileth R. Lusk E. Miller D. Hurwtiz S. Attitudes towards clinical trials among patients and the public. Journal of the American Medical Association 248 (1982) 968-970.

52. Maslin A. A survey of the opinions of 'informed consent' of women currently involved in clinical trials within a breast cancer unit. Europear Journal of Cancer Care 3(199.4) 153-162.

53. Llewellyn-Thomas H. Thiel. E.Clark R. Patients wersus surrogates whose opinion counts on ethic review panels? Clinical Research (1991) $501-105$.

54. Saurbrey N. Jensen J. Rasmussen P. Danish patients' atcitudes to sclentific-ethical questions. Acto Medica Seandinavia 215 (1984) 99-104.

55. Simel D. Feussner J.A randomized controlled trial comparing quantitative informed consent formats. Journal of Clinicol Epidemiology 44 (1991) $771-777$.

56. Sutherland H.Are we getting informed consent from patients with cancer" Journal of the Royal saciety of Medicine $83(1990) 439-443$.

57. Mettlin C, Cummings M, Walsh D. Risk factors and behawioral correlates of willingness to participate in cancer preventive trials. Nutrition and Concer 7 (1985) 189-198.

58. Dahan R. Caulin C. et at. Doe informed consent influence therapeutic outcome! A clinical trial of the hypnotic activity of placebo in patients admitted in a hospitall. British Medical Journal 293 (1986) 363-364.

59. Mark J. Spiro H. Informed consent for colonscopy. Archives of Internal Medicine 150 (1990)777-780.

60. Quaid K. Faden R. Vining E. Freeman J. Informed consent for a prescription drug impact of disclosed information on patient understanding and medical ourcomes. Patiert Educotion and Counseling 15 (1990) 249-259.

61. Simes R. Randomized comparison of procedures for obtaining informed consent in clinical trials of treatment for cancer. British Medical fournol 239 (1986) 1065 1068. 
62. Kerrigan D.Thevasagayam R. Woods T et al. Who's afraid of informed consent? British Medical foumal 306 (1993) 298-300.

63. Ende J. Kazis L. Moskowitz M. Prefference for autonomy when patients are physicians. Journd of Cenerol Internal Medicine 5 (1990) 506-509.

64. Faden R. Becker C. Lewis C. Freeman J. Faden A. Disclosure of information to patienis in medical care. Medical Care $19(1981) 718-733$.

65. Feinleib M. The epidemiologist's responsibilities to study participants. Journol of Clinicol Epiderniology suppl II. 44 (1991) $735-79 s$.

66. Langley G. Why are (or are not) patients given the option to enter clinial trials! Controlled Clinial Tricis 8 (1987) 49-59.

67. MoCusker J.Wax H. Bennet ل. Cancer patient accessions into clinical trials A pilot investigation into some patient and phycisian determintants of entry. American fournol of Clinical Oncology (CCT) 5 (1982) 227-236.

68. Strull W. Lo B. Charles G. Do patients want to participate in medical decision making? Journof of the American Medical Associotion 252 (1984) 2990-2994.

69. Taylor K. Informed consent: the physicians' perspective. Social Science and Medicine 24 (1987) 135-143.

70. Taylor K. Margolese R. Soskolne C. Physicians" reasons for not entering eligible patients in a randomised clinical trial of surgery for breast cancer. New England Journal of Medicine 310 (1984) 1363-1367.

71. Williams C. Zwitter M. Informed consent in european multicenter clinical trials. Are patients really informed? European journal of Cancer 7 (1994) 907-910.

72. Moore M. O'Sullivan B. Tannock I. How expert physicians whould wish to be treated if the had genitourinary cancer. Journal of Chinical Oncology if (19:8B) 1736-1745.

73. Faden R. Beauchamp T. Decision-making and informed consent: a study of the impact of disclosed information. Sacial indicators. Research (1980) 313-336.

74. Lesko L. Dermatis H. Penman D. Holland Ju Patients' parents' and oncologists" perceptions of informed consent for bome marrow transplantation. Medical and Pediatric Oncology 17 (1989) $181-187$.

75. Siminoff L. Fetting J.Abeloff M. Doctor-patient communication about breast cancer adjuvant therapy journal of Clinical Oncology 7 (1989) $\| 192-1200$.

76. Penman D. Holland ]. Bahna G. Morrow G. Schmale A. Deragatis L. Carnrike C. Cherry R. Informed consent for investigational therapy. patients' and physicians' perceptions. Journal of Clinical Oncology 10 (1984) 849-855.

77. Barofsky I. Sugarbaker P. Determinants of patient nonparticipation in randomized clinicakl trials for the treatment of sarcomas. Cancer Clinicol Triols 2 (1979) 237-246.

78. Harth S.Thong Y. Sociademographic and motivation characteristics of parents who volunteered their children for clinical research a controlled study. British Medical journal 300 (1990) 1372-1375.

79. Harth S. Thong.Y.The psychological profile of parents who wolunteer their children for clinical research a contralled study. Journal of Medical Ethics IB (1992) 86-93.

80. Miller H. Bauman L. DeCosse J. Psychosocial adjustment of familial polyposis patients and particpation in a chemoprevention trial. Int J Pych Med 3 (1986) $2 \| 1$ - 230.

B1. Stanley B. Guido J. Stanley M. Shortell D. The elderly patient and informed consent. Empirical findings. Jeurnel of the Arnericon Medical Associotion 252 (1984) 1302-1306.

82. Thornquist M. Patrick D. Omen G. Participation and adherence among older men and women recruited to the beta-carotene and retinol efficacy trial (CARET). Gerontologist 31 (1991) 593-597.

83. Rimer B. Participant enrollment, participation, and compliance in chemoprevention trials. The Biology and prevention of Aerodigestive Tract Cancers (1992) $\| 11-117$.

84. Leventhal H. Nerenz D. Leventhal E. Lover R. Benda L. The behavioral dynamics of clinical trials. Preventive Medicine 10 (1991) 132.146. 85. Berry H. Bloom B. Mace B. Hamiltan A. ec all. Expectations and patient preference - does it matter? Journal
of the Royal Society of Medicine 73 (1980) 34.38.

86. Gracely R. Clinicians expectations influence placebo analgesia. The Lancet (1985) 43.

87. Skovlund E. Should we tell trial patients that they might receive a placebo? The Loncet 337 (1991) 1041 .

B8. Baum M. Do we need informed consent? The Lancet $1 / 1$ (1986) $911-912$.

89. Editorial. Informed consent: How informed? The Lancet 338: (1991) 665-666.

90. Koch H. The concept of balanced auconomy in therapeutic and nom-therapeutic trials. Controlled Clinical
Trials 16 (1995) 182-183.

11. Fishbein MAizen 1. Beir

Addison-Wesley, (1975). 
92. Janz N. Becker M. The Health Belief Model. A decade later. Health Educotion Quarterly II (1984) 1.47.

93. Lawrence W. Barriers to recrutment of patients to clinical trials. Oncology Times (1993), aug: 23. Cired in: Schain (1994) ref [49].

94. MCCusker J.Wax A. Bennex J. Cancer patient accessions into clinical trials American journal of Clinical Oncology (CCT) $5(1982) 227-236$

95. Alfidi R. lnformed conisent: a study of patient meaction. Journal of the Ameriton Medical Association 216 (1971) 1325 .

96. Beecher H. Ethics and clinical research. New Englond Joumal of Medicine $274(1966) 1354$.

97. Gray B. Cooke R. Tamnenbaum A. Research involving human subjects. Science $2101(1978) 1094-1111$.

98. Lidz $C_{n}$ Barriers to informed consent. Annals of Mnternal Medicine 99 (1983) $539-543$.

99. White W. Informed consent ambiguity in theory and practice. Journol of teoth Polloy ond we Law 8 (1983) 99- 119

100. Ingelfinger F. Arrogance (special arcicle). New England Journot of Medicine 303 (1980) $\| 507-1508$.

101. Wear S. Informed consent: patient outonomy and physician beneficence within clinical medicine. Dordrecht: Kluwer (1993).

102. Fried C. Medical experimentotion:persanal integrity and sociol policy. Amstordam (1974). Cited in: J. Mackllop (1986) ref [7].

103. Leader A. Side effects of obtaining informed consent Camadian Medical Association 7 (1986) $\| 01$.

104. Baum M. Zilka K. Houghton J. Ethics of clinical reseanch: lessons for the future. British Medical journo! 299 (1989) $251-253$.

105. Peckham M. Informed consent. Ethicall, legal and medical implications for doctors and patients who participate in randomized clinical trials. British Medical Journol 286 (1983) 1117.1121 .

106. Portney L. Watkins M. Foundatians of clinicol research. Applications to practice. Appleton \& Lange, Connecticut (1993).

107. Zelen M. Randomised consent desigm for clinical trials: an update. Stotistics in Medicine 9 (1990) 645-656.

108. Silwerman W. The myth of informed consent in daily practice and in clinical trials. Journol of Medical Eunics 15 (1989) 6- 11.

109. Davis S. Seay J. Stone J. et al. Does knowing about clinical trialls increase participation! Proc Am Soc Clim Oncol 9 (1990) A232.

1 10. Merz J.An empirical analysis of the medical informed consent doctrine: search for a "standard" of disclosure. Risk 27 (1991) $27-76$.

111. Mazur D.Why the goals of informed consent are not realized. Journal of Gienerol Internol Medicine 3 (1988) $370-380$.

1 | 2. Brody D The patients" role in clinical decision-making. Annols of internal Medicine 93 (1980) $7 \| 6-722$.

1 | 3. Wilhelmsen L. Ljungberg S. Wedel H.Werko L.A comparision between participants and non-participants in a primary preventive trial. Journol of Chronic Disease 29 (1976) $331-339$.

114. Gray B. Cooke R. Tannenbaum A. Research involving human subjects. Science 2101 (1978) $1094-1111$.

1 15. Lynöe N. Sandlund M. Dalqvist G. Jacobson L. Informed consent study of qualicy of information given to participants in a clinical trial. British Medical fourral $303(1991) 610-613$.

116. Rodenhuis S. van den Heuvel W. Annyas A et al. Patient motivation and informed consent in a phase I study of an anti-cancer agent. European Journol of Cancer Clinical Oncology 20 (19:4) 457.462 .

117. Dudley H. Informed consent - issues for the 19905 Britsh Journal of Urology 68 (1991) $561-564$.

1 18. Fisher B. Ory clinical trial participation (editorial). Joumol of Clinicol Oncology \# I (1991) 1927-1930.

119. Marsh B. (editorial) Informed consent - help or hindrance Joumol of the Royal Society of Medicine 83 (1990) $603-605$.

120. Applebaum P.Assessing patients' capacities to consent to treatment. New Englond journol of Medicine 319 (1988) $1635-1638$

121. Verheggen F. Nieman F. Jonkers R. Determinants of patient participation in clinical trials in the context of informed consent: why patients enter a clinical trial or not university hospital Maastrichut. Submitted (1995).

122. Verheggen F. Jonkers R. Kok G. Patient's perception on informed consent and the quality of information disclosure in clinical trials at the university hospital Maastricht university hospital Mastricht. Forthcoming $(1996)$

123. Verheggen F. Nieman F. Reerink E. Kolk G. Patient satisfaction with clinical trial participation. university hospital Mastricht. Submitted (1996). 


\title{
4 Determinants of patient's participation in clinical trials in the context of informed consent: why patients enter a clinical trial or not.
}

\author{
FWSM Verheggen, FHM Nieman, $R$ Jonkers
}

Revised to be accepted for publication in Health Serwices Research in adapted version.

\begin{abstract}
In a hospital-wide sample surwey we have studied the reasons why some patients choose to participate in clinical trials while others decline. Interviews were held with 198 adult patients, just after they had been asked by the trial-clinician to participate. We interviewed patients who were asked to participate in a clinical trial, including those who decided not to participate. The theoretical guidelines to explain participation were based on an extended form of the Health Belief Model.

Patients being asked for a clinical trial decide by drawing up a personal balance account. This comprises the physical and emotional added value patients hope to gain from the trial treatment compared to the non-trial treatment, minus the risks they expect in the trial and minus the extra time they expect the trial will take. The extent they feel physically threatened by their illness will also influence their decision. Furthermore, this personal balance account was found to depend on patient opinions about medical care and caregivers in general and on how patients regard their illness. Relatively long-term patients show a slightly different motivation to participate in a clinical trial than short-term patients.

In line with the Health Belief Model, both motivational beliefs on the relevance to reducing the threat to the patient's health condition ("values'), and the evaluations of the clinical trial the patient is approached for ("expectancy"), are relevant in explaining patient behawior. Moreover, specific evaluative frames of reference are relevant in patients faced with the choice to participate or not. Suggestions are made to improve insight into patient motivation during the informed consent procedure of clinical trials.
\end{abstract}

\section{Key words}

patient compliance; clinical trials; Health Belief Model; patient beliefs; informed consent procedure.. 


\section{NTRODUCTION}

When patients are approached about participating in a clinical trial "they are subjected to a specific informed consent procedure. In many countries the clinician is llegally bound to provide fair and adequate information about the trial to enable a patient to make a decision whether to participate or not. Beside medico-legal requirements regarding informed consent, there are social and socio-psychological aspects to trial participation and compliance. Only recently has attention been drawn to this interesting area of research. There has been much debate about the amount and kind of information prowided, the circumstances under which disclosure is required and the criteria for determining the adequacy of the information provided [1]. While there is a need for empirical research to understand the informed consent process and realize its goals little has been done [2]. Such empirical research could be defined as 'the study of actual informed consent decisions by patients (or their proxies) with regard to consent, and the impact of consent on patients or the clinical trial outcome" [3]. Study of informed consent must concentrate upon some of the limitations characterizing empirical research. These limitations are [4]: use of non-patient subjects or hypothetical situations - whether hypothetical decisions are comparable to actual patient and/or physician decision in daily practice is debatablle; failure to consider what physicians actually told the patient; focus only on patient recall as the key to understanding; lack of generalizability of results and investigator bias because the investigator is also the subject's physician.

A new empirical approach to studying informed consent has to resolve these methodological problems. Empirical studies of informed consent may also yield a better wnderstanding of the informed consent process by describing patient characteristics and factors that affect consent rates. Despite the requirements of informed consent during. clinical care and research, only a few empirical studies of the actual decision-making process have been performed to determine why patients agree or decline to enrol [3]. There is much to be gained by actually asking patients why they did or did not choose trial participation. In an analysis of the literature on accrual to clinical trials, Gotay [5] concludes that this field of research would be enriched by more such efforts. This paper addresses the following question: ${ }^{\circ}$ n which grounds do patients choose to participate in the clinical trial they are asked for and what are the reasons some of them decline?' In a sample survey we chose to interview patients who were actually being asked to participate in a clinical trial. Differences in motivational factors were analyzed to compare those who consent to participate with those who do not.

\section{MATERIAL AND METHODS}

\section{Inclusion and exclusion criteria}

The target population for the survey consists of all patients who between February and October 1993 were approached and asked to participate in prospective clinical trials being held at the university hospital Maastricht. Thus, patients in purely retrospective clinical crials were excluded. Patients in the target population could either be recruited from experimental (cohort) studies, non-experimental, diagnostic studies or a combination of both, provided the study was prospectively designed. Information on clinical trials taking place during 1993 was obtained from the Institutional Review Board (IRB). Only after the 
approval of the trial protocol by the IRB is a clinician allowed to recruit patients for a trial. Patients were excluded if they belonged to clinical trials not reported to nor approved by the IRB. In this way, at the end of 1992 we had registered about 80 clinical trials. This number comprised prospective and non-prospective trials. Some of them were in their concluding stages, some were in mid-term or dormant and some had yet to start from scratch. The initial target population included about 4300 patients. Patients had to be competent to give consent for the clinical trial: thus all patients in trials with proxy and deferred consent were exelluded (trials with children, psychiatric or neurological patient trials). Since we wished to measure patients" expectations about the trial, a limit was set a priori on the duration between the first approach for each clinical trial and the interviewing: a maximum of four weeks. The median of days we have interviewed patients measured from the day they underwent the informed consent procedure was 10 . The last decile of patients was interviewed within the fourth week. A longer period of time would mean that the expectations participating patients had risked being overshadowed by their experiences in control visits of the trial. It also was important that non-participants remembered the approach by the trial-clinician and the reasons why they had refused to participate. In successive steps the number of eligible prospective trials was narrowed down to about 40 (approximately 2100 patients). Next, the trial-clinicians were asked to cooperate with our study and to provide names of the patients they had approached for their trial. Some trials, however, were not to be started during the nine month period of field work After removal of the "empty" ${ }^{\prime}$ delayed and aborted trials, 28 clinical trials remained, comprising a theoretical number of about 1280 patients. Finally two trialclinicians were reluctant to provide patient names for the sample survey, and refused cooperation.

\subsection{Selection of empirical cases and field work deseription}

Of the theoretical 1200 patients in the 26 clinical trials we estimated that during the period of fieldwork only about 300 patients would actually be eligible for survey sampling. We were unable to control the process of selection of these potential respondents. because this was done by the triall-clinicians. Some selection bias could have occurred at this stage. One phenomenon is what clinicians call: "suspected non-compliance'. Before a clinician actually approaches patients for a trial, he or she will judge a patient's whilingness to cooperate beforehand. Each trial-clinician probably will use his or her own criteria. Second, trial-clinicians might not report to us all patients they were approaching, because they might easity overlook the non-participants in the trial, or could forget to inform patients about the sample survey despite all our efforts. Third, some trial-clinicians were understandably anxious to reserve their right to determine which patients could not be interviewed (too Ill, emotionally unbalanced or momentarily too disturbed). Regrettably, all these patients had to be excluded from interviewing.

Finally, of the 300 eligible patients, the names of 225 patients were reported to us. Patients were registered in an address-file, containing names and telephone-numbers, day and location at which the patients could be interviewed and the name of the trial. We had to exclude patients who could not be interviewed (e.g. not traceable within four weeks of the first approach by the trial-cinician) and patients who did not give consent to being interviewed. This brought the number of patients actually interviewed to 198. Respondents in the sample survey were derived from nine clinical departments: Surgery (I trial, 38 
patients); Dermatology (4 trials; 23 patients); ENT (I trial; 4 patients); Internal Medicine (5 trials, 32 patients); Urology ( 5 trials; 43 patients); Cardiology ( 3 trials; 36 patients); Pulmonology ( 2 trials; 14 patients); Orthopedics ( 2 trials; 4 patients); Radiolog) (1 trial; 7 patients) and Anesthesiology ( 2 trials: 5 patients). Clinical trials in the sample-survey concerned: 5 invasive diagnostic studies (ID) 2 invasive diagnostic studies with medication (IDM); 2 non-invasive diagnostic studies (NID); 2 non-invasive diagnostic studies with medication (NIDM); 7 medication intervention studies (MI) and 8 therapeutic intervertion studies (TI). Of the 26 clinical studies 20 were multicenter-based; 21 were randomized controlled trials (RCTs); I of the RCTs were double-blinded. In 8 of the RCTs a placebogroup was used. In I3 RCTs new trial treatment and regular treatment were compared.

\subsection{Response rate}

The empirical sample consists 198 respondents of which $172(86.9 \%)$ were participating in a clinical trial and $26(13.1 \%)$ were not. The overall response rate in the survey was 88 percent (198/225). Non-response in the group of non-participants (14/40) was significantly thigher in comparison with the group of participants $(13 / 185)$ (chi-square $=21.8 ; d f=\|$; $p<.0001)$. We define trial participation as the patient's agreement or refusal to comply with the clinical trial as proposed by the clinician. The behavior resulting from this compliance was operationalized by registering which patient was reported by the triall-clinician as a participant and which as a non-participant.According to estimations of all clinicians involved, an average of $13.6 \%$ of patients refuse to participate in their trials. This corresponds very well with the trial non-participation rate found in our study $(13.1 \%$; $\mathrm{p}=.93$ in two-tailed binomial test).

Mean age of respondents was $57.8(s . d=13.8)$. Of the respondents 122 were men $(61.6 \%)$ and 76 were women $(38.4 \%)$. In total 118 outpatients $(59.6 \%$ ) and 80 clinical patients (40.4\%) were involved in the sample. Of the respondents $40(20.2 \%)$ had been involved in a previous clinical trial, of which $25(69.7 \%)$ evaluated their involvement positively. In total, 31 respondents $(15.7 \%$ knew someone in their direct environment who had participated in or been asked for a clinical trial.

\subsection{Conceptual model: an extended Health Belief Model (HBM)}

From social psychollogical models to explain and predict individual health and illness related behavior, we have selected an extended form of the Health Belief Model (HBM) to explain participation behavior in clinical trials. The HBM is used as a guide in operationalizing patient motivation towards participating or not in clinical trials. The model assumes that subjective health considerations determine whether people perform a specific health related action [6,7]. The original HBM hypothesizes that behavior depends mainly upon (1) the value placed by an individual on a particular goal (value) and (2) the individual's estimate of the likelihood that a given action will achieve that goal (expectancy). The correspondences in explaining health actions for patients are (I) the desire to get well, if ill (or to avoid sickness, if well) and (2) the belief that a specific health action will restore health, prevent or ameliorate illness. Furthemore the HBM suggests the working of some stimulus, mecessary to trigger the decision-making process, which is called the 'cue to action'. This cue to action can be evoked by an individual's personal perception and motivation or by information about health matters provided by others, e.g 
physicians. In clinical trials the decision whether or not to participate may be explained by the extent to which a patient perceives a threat to his or her health and the degree to which a patient believes that trial participation will be effective in reducing that threat, given the perteived effectiveness of "regular" ways of treatment. Then, the more benefits and the fewer disadvantages or barriers a patient perceives, the greater the possibility that he or she will parcicipate into a clinical trial.

An alternative behavional model to explain behavior developed by Fishbein \& Ajzen is the theory of reasoned action (TRA) [8]. Briefly, the theory suggests that intention to behave determines behavior. An individual's intention is, accordingly, the function of two important factors personal attitude towards a behavior and social influence, called 'subjective norms". Underlying these two components are determinants known as behavioral and normative beliefs. Howewer we chose the HBM as a guide to measure health beliefs about participation, because we do not consider the intention to comply - a relevant factor in the TRA - a useful instrument in explaining trial participation. We could only interview patients who had made their decision to participate or not, so intentional (compliance) behavior did not apply to our problem. Nonetheless, we decided to add 'subjective norm', stressing social influences on behavior, to the HBM. Respondents wene asked whether they had talked about joining the clinical trial with other people apart from the trial-clinician. These could include partner, children, other family, friends, other physicians, nurses and general practitioners. Respondents had to judge the importance of these people's opinion with respect to entering the trial or not. Finally, patients could indicate whether they felt encouraged to enter the trial by these people or discouraged. Besides this extension to the original Health Belief Model, we also incorporated a number of general health values and orientations of patients and an instrument of "locus of control" in our model [9]. We have decided to include the first number to ascertain in which way patient motivation to participate or not was related to general health views patients had before being approached by the trial-clinician. Locus of control was added to the madel because we were interested in the relationship between patient motivation and patient orientation towards physicians ta control health problems [10].

\subsection{Definition of concepts and operationalization}

Figure I presents a diagram of the model of explanation for trial participation, based on the extended Health Belief Model (HBM). Several blocks of concepts can be distinguished in this model. The patient's expectations towards the clinical trial in terms of advantages and disadvantages of participation and nonparticipation include subjectively defined risks, the degree of comfort and discomfort to be expected and perceived barriers to trial participation. The patient's attitude to the trial-clinician and the patient's evaluation of how he or she is informed by the trial-clinician includes the manner of information disclosure, such as the clarity and adequacy of oral and written information. The evaluation of the content of information disclosure is classified under the patient's expectations towards the trial. The patient's attitude towards the trial-clinician includes the evaluation of the clinician's friendliness, clinical competence and ability to communicate. The patient's own health and illness perceptions include subjectively defined health status, severity of illness, susceptibility to symptoms of a disease and the degree in which the patient feels threatened by his or her health problems. 
Figure 1: Model of explanation for trial participation.

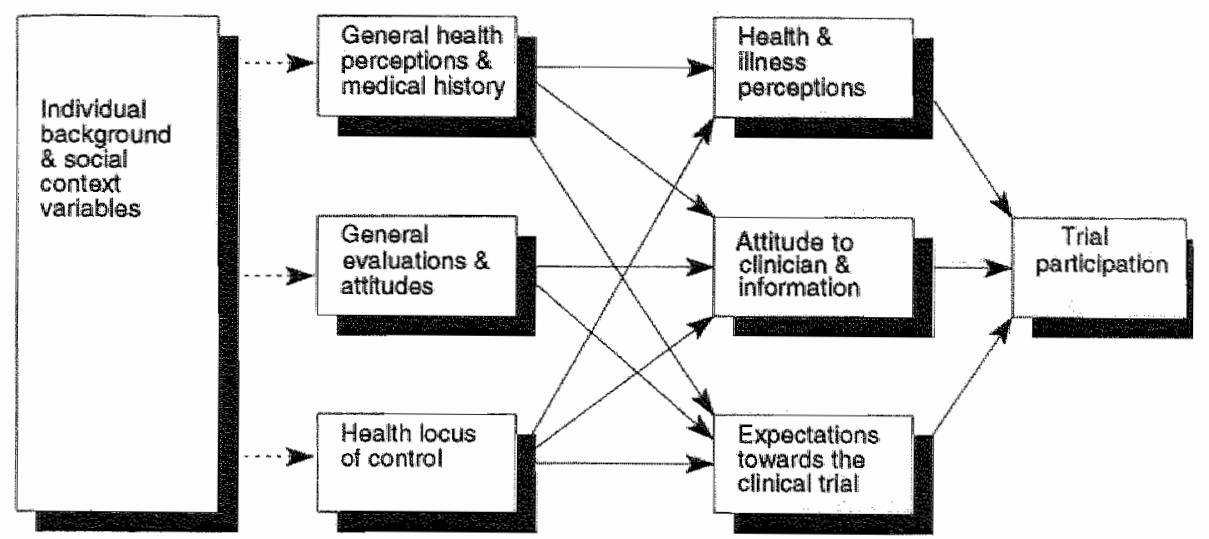

The patient's general health perceptions and subjectively defined 'medical history" during the months prior to the approach include vulnerability to disease in general and interest in medical affairs in general. Subjectively defined medical history comprises a posteriori evaluations about the state of health and illmess during the three months prior to the approach.

The patient's general evaluations and attitudes include evaluations of clinical care and research and attitudes towards physicians in general and health care institutions.

Evaluations also comprise the patient's altruistic idea that one should contribute to the clinician's effort in reducing the plight of disease by volunteering for trials.

The Health Locus of Control includes the patient's general orientation towards the controllability of the problems regarding his or her health. The instrument of health locus of control consists of a scale measuring the internal control and one measuring external control (physicians in general). The third scale measures a feeling of powerlessness in health matters.

The patient's individual background and social context include socio-economic, sociodemographic, socio-geographic and socio-cultural characteristics. These cover socioeconomic class measured by (family) occupation status, gender, region of residence and years/ type of schooling. Also included are the name of the triall a patient is approached for and other hospital-contextual variables. Finally, we have placed here the self-reported influence important others may have on participation or non-participation ('subjective norm ).

\subsection{Measurement procedures}

Patient background-variables have generally been measured by direct questioning or by using information from hospital data-sources. The second type includes predominantly information about trial-protocols presented to the IRB and information on trials given directly by the trial-clinicians. We interviewed the 198 respondents by means of 
questionnaires just after they had been asked to participate in a clinical trial. The questionnaire was used in a personal interwiew with the patient by four interviewers especially trained for this purpose. On average, an interview lasted about 45 minutes. In almost all cases interviews were held at the Uniwersity Hospital. Motivational factors which could be important to trial participation were generally expressed as specific statements with which patients could agree or disagree. Concepts like patient expectations, attitudes, orientations and perceptions were operationalized using multiple 5-point Likert-scale items. Items contained subjectively phrased evaluative statements with which patients could agree or disagree. Prowisions were made to allow for response categories like "no opinion at all" and "not applicable'. To test validity and reliability of the operationalization of concepts, item analysis, principal component analysis (PCA), reliability tests and scale-construction techniques were applied to the data. Principal Axis Factoring. (PAF) and Factor Analysis by Maximum Likelihood estimation (FAML) were used to cluster items into scales. The empirical factors found had to correspond in a unidimensional way to the concepts as defined in the hypothetical model. Factor-analysis was performed on 40 intended factors, which yielded 34 scales. These scales were then tested for internal consistency using Cronbach"s alpha. This proved to be satisfactory for almost all scales. Alphas varied between 60 and 90 . (mean alpha was .80). All scales were additively constructed without transformation of original scores. Methodology in scale-construction comprises a list of rules:

- SPSSPC+ has been used (version 5.0).

- Pairwise deletion of missing walues was applied:

- For inclusion in a factor, an item had to meet the following criteria:

- correlations $>.30$ with at least one other item of the factor:

- communality within PCA and FA must be $>.40 ;$

- factor loadings must be $>.50$ (PCA) and $>.40$ (FA):

- the item must belong to the intendied factor (unidimensionality) and not have high factor-loadings on other factors ("simple structure' rule).

- The eigenvalue of a factor has to be $>1.0$ in PCA and FA.

- Rotation: the factor loadings matrix was always obliquely rotated (Oblimin), if two or more factors correlated $>.30$; In one case the correlation of factors was $<.30$, so an orthogonal solution has been used (Varimax).

- For refiabillity tests of the scalles, Cronbach's alpha was computed. Intended scales with an alpha below .60 were eliminated as unreliable.

Results of factoranalysis and scale constructions are given in annexes on p 73-75. Scale-constructions have been made by averaging the Likert scores for each scale. Table I lists definitions of a selection of the concepts.

Table 1: Definitions of concepts used within the blocks presented in the model of explanation

\section{Expected benefits}

ADVCONT patient's eraluation of the emotional comfort gained from being repeatedly checked upon one's health within the trial (comfort-no comfort)

ADVFEEL patient's evaluation of getting more personal comfort in the trial, compared to that of the pre-trial or non-trial (regular) treatment (no comfort-high comfort)

ADVINSI patient's evaluation of the speciall knowledge of his/her own case gained from participating in the trial (not-more insight)

ADVRETR the patient's evaluation of the comfort conmected to the idea that one always and at least has the right to withdraw from the trial at any time (no comfort-comfort) 
ADVPLEA patient's evaluation of being regarded as a special kind of patient, if you participate in the trial (no comfort-comfort)

ADVTREA patient's evaluation of obtaining a better medical treatment within the trial, compared to that of the pre-trial or non-trial (regular) treatment (low benefit-high benefit)

\section{Expected discomforts, risks and barriers}

DISRAND the patient's evaluation of the consequences of running the risk of getting no or onlly standard treatment, caused by the randomization procedure (negative-positive)

DISRETA the patient's evaluation of the negative implications refusing to participate will have on the follow up treatment or subsequent non-trial treatment (yes-no)

DISRISK patient's evaluation of the risks by undergoing new, untested diagnostic procedures or treatment in the trial (high-low)

DISTIME patient's evaluation of the burden imposed upon daily life by parcicipating, in terrns of the amounts of time trial participation requires, or "time-consumingmess" of the trial (high-low) General evaluations and attitudes

MEDEXP the patient's attitude towards medical experiments on patients in general (positive-negative) INTGPHY the patient's trust in the integrity of clinicians in general, dealing with clinical trials (low-high) ALTRUIS the patient's altruistic idea that future patients having the same afflictions may benefit from the results of the trial (not having-having)

EARLTR the patient's evaluation of his/her medical treatment preceding the approach for the clinical triall (positive-negative)

ACAHOSP the patient's trust in university hospitals (low-high)

\section{Attitude towards the trial-clinician:}

COMPETEN the patient's trust in the medical competence of the trial-clinician (high-low)

RISKAVOI the patient's trust in the capacities ascribed to the trial-clinician in controlling and reducing risks and side- effects of the triall treatment (high-low)

\section{Health locus of control}

LCINTERN the patient's feeling to have own control over health (high-low)

LCCLINIC the patient's evaluation of the way physicians in general have to have comtrol over his/her health problems (low-high)

LCCHANCE the patient's feelings of the uncontrollability of own health problems (having-not having)

\section{Health and IIIness pierceptilons}

PERHEALTH the perceived health condition at the moment of interviewing (good-bad)

URGENCY the perceived threat to one's health condition culminating into to the notion one should be treated immediately or as soon as possible (having-not having)

WORRYING the perceived threat to one's health condition expressed into a feeling of worrying over problems with your health (not having-lyaving)

SEVERITY the perceived severity of illness (high-low)

SUSCEPT the perceived susceptibility of abtaining the same afflictions with regard to one"s health (low-high)

\section{INTEREST}

ILLNESS

PAIN

INFODISC

INFOTEXT

\section{General health perceptions and percelved medical thistory}

the patient's interest in medical affairs in general (much-none)

feefling ill during the three months preceding the approachment for the clinical trial (very ill-not ill)

suffering from pain during the three month's preceding the approachment for the clinical trial (much-not)

\section{Evaluation information disclosure}

the patient's evaluation of the way information was given on the clinical trial during the first approach by the trial-clinician (positive-negative)

the patient's evaluation of the written information disclosure on the trial, given by explanatory leaflets (negative.positive) 
UNDETEXT the patent's evaluation of the diffeulty of understanding the writien information disclosilre on the trial (difficult-easy)

RECONSIO the patient's ewaluation of the adequacy of time to reconsider participation in the trial (positivenegative)

\subsection{Preliminaries to data-analysis: specification of causal order and hypotheses} Hypotheses to explain trial participation are always multicausal.According to the diagram in figure I we hypothesize that a patient's expectations in terms of advantages and disadvantages, his specific attitudes towards the trial-clinician and his evaluation of the way information disclosure was provided, combined with his health and illness perceptions are the three principal factors to explain trial participation. To give an example of the many hypotheses one can distill from causal diagram I, if patients think no risiks are involved in being treated within the trial, if they have a high regard for the clinician who approached them, and if they have the subjective notion that their health condition is severe, they are bound to participate within the trial. On the other hand, patients who judge the treatment within the trial as risky, have a relatively lower regard for the capacities of the clinician and do not regard their health state as severe, will tend to refrain from participating. In accordance to the causal diagram, it is also assumed that these principal factors themselves will be dependent on other blocks. The causal model shows that to explain expected benefits, discomforts and barriers to trial participation, potential determinants are restricted to three blocks: 1) general attitudes, evaluations and values about medical care, research and institutions already present before the informed consent procedure, 2) general health perceptions and the self-reported medical history and 3) the health locus of control. It assumes further that attitudes and evaluations, originated during the informed consent procedure will also be influenced by these three blocks. As a thind step, indirect causal orders can also be deduced from the diagram: general evaluations and attitudes about medical care, research and institutions will have an indirect influence upon trial participation by influencing specific attitudes and expectations during informed consent. By estimating the indirect effects of evaluations and attitudes one is able to gauge the effects pre-informed consent patient views have on participation behavior. Finally, all variables may be assumed to vary according to individual background and social context-variables. In accordance with the Health Belief Model, patients faced with the choice to participate or not will evaluate the pros and cons of the trial given their subjectively defined health and illness condition. The set of a priori rules to order health and illness perceptions in the causal model is partly deduced from logical assumptions (actual "time order" between everts) and partly based upon the Health Bellief Model itself. This results in the causal order as depicted in figure 2.

\section{8 Descriptive statistics}

Participants versus non-participants. Comparison of background characteristics of participants and non-participants showed no significant differences for inpatient or outpatient at the time of interview: age, gender, highest education followed, family socio. economic status and previous involvement in a clinical trial. Social-economic status of the family was constructed by using rank occupation class of both respondent and partner [11]. Differences between both groups have been analyzed by means of Student t-test, Pearson Chi-square test or use of Kendall's tau-b. 
Long-term versus short-term patients. Data analysis rewealed an important distinction between patients. Some patients indicate that they had problems with their" health that date from more than three months ago. We have termed such patients old cases" ( $N=130)$. Other patients had no prior problems with their health, but developed their symptoms in the three-month period before being approached for the trial; we have termed these patients "new cases" $(\mathrm{N}=68)$. Motivation to participation in the trial differed between 'old', long term patients and 'new', short-term patients (see results). No significant differences between "new' and "old" cases could be found regarding: age, gender, highest education followed, marital and social-economic status of the family, and previous involvement in a clinical trial. They differ significantly however with regard to being an inpatient or outpatient at the moment of interview. Long-term patients were somewhat younger (mean $=56 ; s . d .=14.1)$ in comparison with short-term patients (mean $=61 ; s . d .=$ 21.1).

Figure 2: Model of explanation in the block of health perceptions.

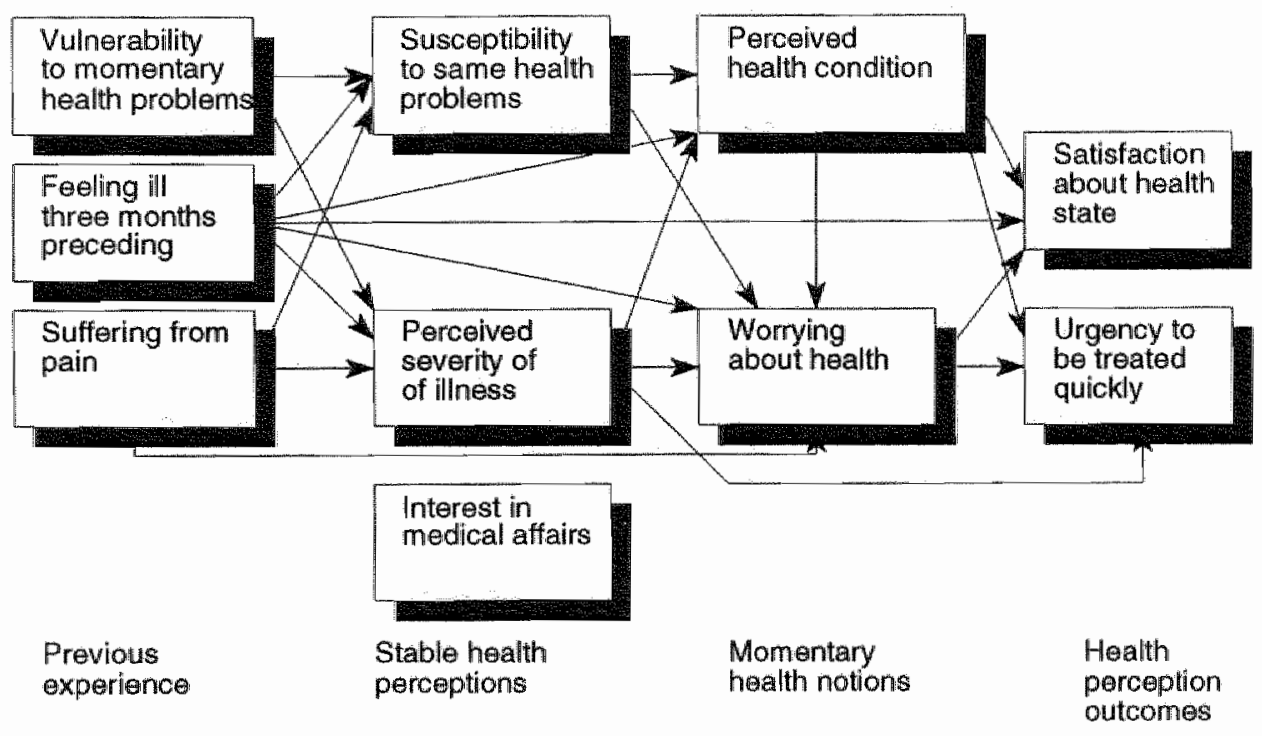

\subsection{Methods of data-analysis: causal analysis}

Two techniques of causal data analysis have been used to explain trial participation: path analysis and logistic regression analysis. Path analysis is a linear-additive technique which enables many (blocks of) variables in the extended HBM to be handled in a situation where many potential causal factor's come together to explain trial participation. Successively we entered scales into the equation concerning blocks of patient's expectations, attitudes towards the trial clinician and evaluation of the way information was given and finally health and illness perceptions. All variables from each block having. path coefficients with p-values of less than 05 were kept within the analysis. 
Eventually a group of wariables remained with significant parameters: the equation using these variables was called the basic model. As a check for the causal model of diagram I many variables from the blocks remaining in the model of explanation were entered into this basic equation. Results of pach analysis for 'old' and 'new' cases are presented separately. Only "independent" variables showing significant results within path analysis have been taken into consideration these variables are called determinants. An interpretation of the correlation of each determinant with trial participation ( $r$ and $p$-value) and the standardized partial regression coefficient of this determinant in the eventual path analysis (beta coefficient and its $p$-value) are given.

We also tested for potential interactions between "independent' variables. None of the interactions turned out to have significant effects when we tested for interactions between "value" and expectancy" predictors. Furthermore, the overall variance explained in the eventual path analysis models is provided. Indirect effects of variables on trial participation may be estimated as well, which is an advantage of linear, additive path modeling [12]. In path analysis the assumption is that trial- participation is a normally distributed variable. In fact, trial participation is dichotomous and this may result in predicted values which lie outside the dependent variable range of trial participation. We also have to cope with problems of heteroskedasticity of variance in the explanation of trial participation. This concerns the heterogeneity of variance in the error terms between participants and non-participants. Therefore, as a second step logistic regression analysis was done, in which the dependent variable trial participation was transformed into a threshold curve. The basic model resulting from path analysis was again tested within this step.

We firstly used linear causal path-analysis as a preliminary model of explanation. After this exploratory analysis, we used again only those predictors which showed some promise of significance, tested by non-linear logistic regression analysis. Results of linear and nonlinear models will be presented consecutively.Another reason for using linear causal pathmodeling was that we also were interested in analyzing determinants of trial-participation, which were assumed to be normally distributed variables. Indirect effects, deduced from the causal model, were estimated in path-analysis by muitiplying beta-coefficients. We used linear models" because indirect effects can not be quantified in non-linear models. These results will be presented next. Conclusions about explaining trial-participation are based upon results from logistic regression analysis. Conclusions abour explaining indirect effects are based upon results from path-analysis and could only be interpreted from old cases.

\section{RESULTS}

\section{I Results of data-analysis for "old cases"}

In "old cases" $(n=130)$ six determinants of participation turn out to have significant betacoefficients in path analysis. These six determinants together explain .58 of the variance of trial participation. Table 2 shows the results of the eventual path model. Other variables pertaining to the model of explanation turned out to have no direct effect on trial participation. interaction terms constructed by multiplying scores of patient perceptions. on health and illness by those of expectations towards the trial turned out to be nonsignificant. These results are contrary to what is hypothesized in the HBM. 
The evaluation of risks by undergoing new untested diagnostic procedures or treatment in the trial (DISRISK) is significantly correlated with trial participation $(r=.587 ; p<.001)$. In the eventual path model the effect is highiy significant (beta $=-.33 ; p<.0001)$. So if patients expect high risks in the new, untested, diagnostic procedures or treatment in the clinical trial they are asked for, they are likely to refrain from participating.

The expected time-involvement of the trial (DISTIME) is also highly correlated with trial participation $(r=-.563 ; p<.001)$. In the eventual model the effect on trial participation is statistically significant (beta $=-.26 ; p<.00$ I). If patients think that the trial will take much more of their time than the regular treatment, they are bound to refuse participation. However, if they expect that the trial will not take much of their time, or if they think a high time-involvement is not a problem at all "they tend to participate.

Furthermore, expecting better personal comfort in the trial, compared to that of the pre. trial or non trial (regular) treatment (ADVFEEL) is also positively correlated with trial participation $(r=-.497 ; p<.001)$. In the eventual analysis the effect also is significant (beta $=-25 ; p<.001$ ). Patients do tend to participate, if they anticipate better personal comfort than experienced during their earlier treatment, or if they think they will feel better under the trial treatment than under regular treatment,

Trust in the risk-avoiding or risk-reducing capacities of the trial clinician (RISKAVOI) is significantly correlated with trial participation $(r=394 ; p<.001)$. Patients who have a positive opinion about these specific capacities of the trial clinician tend to participate. Although the effect appears to be rather weak (beta $=14 ; p=.06)$, we have chosen to keep this factor within the eventual path model and test it again in logistic regression. Feeling that it is imperative to be treated immediately or as quickly as possible (URGENCY) is significantly correlated to trial participation $(r=.256 ; p<01$ ). The variable has a substantial impact on trial participation (beta $=-.22 ; p<.01$ ). If patients feel it is highly imperative to be treated immediately or as quickly as possible, they tend to participate in the trial, but if they do not, they will not participate.

The subjectively defined illness condition during the three months preceding the approach for participation (ILLNESS) is not correlated with trial participation $(r=.001 ; p>.50)$. Yet, in the eventual path model, the more patients have felt ill during these three months, the less they tend to participate in the trial (beta $=-.18 ; p<.01$ ). Subsequently, a dummy regression analysis was done to gauge the effect of the categories of this variable. The effect of subjectively defined illness is significant only for those patients who have fielt "constanilly" or" "repeatedly' ill, when all other variables in the basic model of explanation are held constant $(b e t a=.20 ; p<.01)$. A curvilinear or exponential relationship between subjectively defined illness and trial participation holds, when the Z-scores of error-terms of the equation are plotted. This means that beyond a specific, "high" threshold in subjectively defined illness, pacients tend to refuse trial participation. 
Table 2: Path analysis results for the group of "old cases'. Dependent variable is trial participation (painwise deletion of missing cases $117<n<130$; trial participation: $1=$ yes $2=$ no)

\begin{tabular}{|c|c|c|c|c|}
\hline & B & SE B & Beta. & $\operatorname{sig} T$ \\
\hline ILLNESS (very ill - not ill) & .521 & .195 & $\therefore 18$ & .0088 \\
\hline URGENCY (not having - having) & .064 & .020 &. .22 & .0020 \\
\hline RISKAVOI (high trust - low trust) & .065 & .034 & .14 & .0595 \\
\hline ADVFEEL (no comfort - high comfort) & .081 & .023 & -.25 & .0005 \\
\hline DISRISK (high risk - low risk) &. .145 & .033 & -.33 & .0000 \\
\hline DISTIME (much -Jow) & .085 & .024 & -.26 & .0007 \\
\hline (Constant) & 2.557 & .203 & & .0000 \\
\hline $\begin{array}{l}\text { Variance explained. } .58 \\
F=25.3\end{array}$ & & & & \\
\hline
\end{tabular}

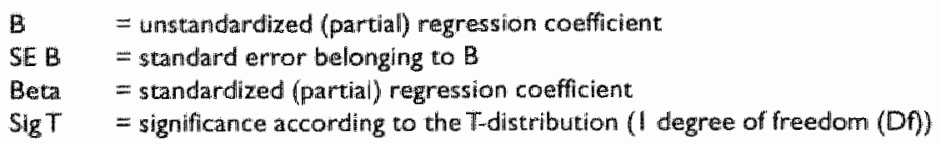

\subsection{Results of data-analysis for 'new cases'}

For 'new' cases $(n=68)$, four determinants to participation turn out to be significant in path-analysis. These determinants together explain. 48 of the variance of trial participation in the eventual pach model. Table 3 shows the results of the eventual path model. Interaction terms constructed out of patient perceptions and expectations again turned out to be non-significant.

The patient's evaluation of risks by undergoing new, untested diagnostic procedures or treatment in the trial (DISRISK) is negatively correlated with trial participation $(r=-533 ; p<.001)$. In the eventual model the expected effect is statistically significant (beta $=-.48 ; \mathrm{p}<.0$ I). If patients expect high risks from new, untested diagnostic procedures or treatment in the clinical trial, they are likely to refrain from participating.

The expected time-involvement of the trial (DISTIME) is also negatively correlated with trial participation $(r=-448 ; p<, 001)$. If patients regard the extra time they will spend in the triall as a problem, they are bound to refuse participation. Although this effect appears to be not significant (beta $=-.23 ; p=.07$ ), we have chosen to keep this factor within the eventual path model and test it again in logistic regression.

Expecting a better or more advanced treatment while participating in the trial as compared to the earlier or the expected non-trial/regular treatment (ADVTREA) is significantly correlated with trial participation $(r=-.415 ; p<.01)$. In the eventual model the effect also appears to be significant (beta $=-.33 ; \mathrm{p}<, 01$ ). If patients expect to get a better medical treatment in the trial as compared to the pre-trial or the regular non-trial treatment, they tend to participate.

Worrying about your health (WORRYING) appears to have no significant correlation with trial participation $(r=.054 ; p>.50)$. Yet, in the eventual model "worrying about your health" has a substantial impact on participation (beta $=-26 ; p<.05$ ). So if patients do tend to worry a lot about their health, they will participate. The fact that the factor worrying about your 
health" becomes statiscically significant is caused by its correlation with the patient's. evaluation of risks $(r=-.48 ; p<.01)$. Patients who worry a lot about their health expect relatively high risks in undergoing the new, untested treatment in the triali expecting high risks causes patients not to participate. However, we find that patients who worry a lot about their health do tend to participate. The "real" effect of worrying only becomes apparent, if we introduce the 'expected risks of trial treatment' in the path equation. So this factor tends to act as a suppressor variable by masking the real effect from the factor worrying on trial participation.

Table 3: Path analysis results for the group of "new cases".

Dependent variable is trial participation (pairwise deletion of missing cases $50<n<69$ )

\begin{tabular}{lllll} 
& B & SE B & Beta & SigT \\
\hline WORRYING (low - high) & -.06559 & .03202 & -.26 & .0463 \\
ADNTREA (low-high) & -.08564 & .02943 & -.33 & .0056 \\
DISRISK (high risk - low risks) & -.16704 & .04870 & -.48 & .0013 \\
DISTIME (much - low) & -.07335 & .03920 & -.23 & .0679 \\
(Constant) & 2.52671 & .25058 & & .0000
\end{tabular}

Variance explained: 48

$F=10.28$

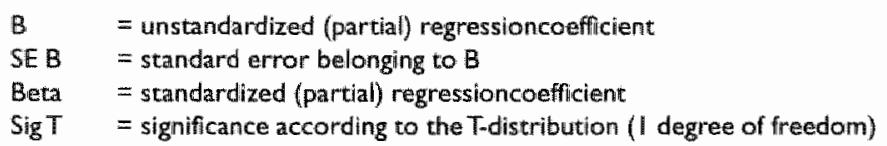

\subsection{Logistic regression results}

Because of missing data on some predictors numbers of 'old cases' declined from 130 to 113 and those of "new cases" from 68 to 50 . Logistic regression analysis shows that $97 \%$ of the 'old cases' ( $n=113$ ) can be correctly predicted regarding entering a clinical trial or not. Only four of the six determinants found in the linear path model are sufficient for this result. These are: the subjectively defined risks by undergoing new, untested diagnostic procedures or treatment in the trial; the patient's evaluation of the expected timeinvolvement of the trial; the patient's evaluation of better personal comfort in participating in the trial, compared to that of the pre-trial treatment or the expected regular treatinent; the perceived urgency to be treated immediately or as quickly as possible.

Logistic regression also shows that $96 \%$ of the 'new cases' $(n=50)$ can be correctly predicted regarding entering a clinical trial or not. Only two out of the four determinants found in the linear path model are sufficient for this result. These are: patient's evaluation of the expected time-involvement of the trial and expecting a better treatment in the trial, compared to the pre-trial or regular non-trial treatment. In old and new cases interaction terms between patient perceptions and expectations of the trial turned out to be nonsignificant. Results of the logistic regression models are presented in table 4. Interpretation of these results is the same as mentioned under path analysis results, only the number of determinants has been reduced in the model. 
Table 4: Logitanalysis results with dependent varlable participation ("old-cases", Hstwise deletion of missing cases $n=\| 13$ and new cases listwise deletion of missing cases $m=50$ )

\begin{tabular}{|c|c|c|c|c|c|c|}
\hline & $B$ & $5 E$ & Wald & Df & Sigt & $\operatorname{Exp}(B)$ \\
\hline \multicolumn{7}{|l|}{ Old cases } \\
\hline DISTIME (much-low) & -1.44 & .74 & 3.81 & 1 & .0509 & .236 \\
\hline DISRISK (high-low) & $-2,65$ & 1.01 & 6.85 & 1 & .0090 & .070 \\
\hline ADVFEEL (low high) & -5.61 & 2.28 & 6.03 & 1 & $.0 \% 40$ & .004 \\
\hline UR GENCY (not having-hawing) & -1.46 & .75 & 3.77 & 1 & .0521 & .232 \\
\hline (Consitant) & 27.63 & 9.49 & 8.47 & 1 & .0036 & \\
\hline
\end{tabular}

Log likelihood ratio is 19.9. Chi-square $=72.23,4$ Df:p<.001.

New cases

ADVTREA (low-high)

DISTIME (much-low)

(Constant)
$-2.80$

$-2.94$

13.48
1.30

1.50

5.90

Log likelihood ratio is 10.8; Chi-square $=21.71 .2 \mathrm{DF}: \mathrm{p}<.001$.

Classification table (old cases)

$$
\text { Predicted }
$$

\section{Observed}

yes no

yes

96

2
Percentage

correct

$98.97 \%$

$14 \quad 87.5 \%$

Overall: $97.35 \%$

\section{Classification table (new cases)}

Predicted

Observed yes no $\begin{aligned} & \text { Percentage } \\ & \text { correct }\end{aligned}$

Yes

44

$97.78 \%$

No

$\|$

$80 \%$

\footnotetext{
$\mathrm{B} \quad=$ unstandardized (partial) regressioncoufficient

$S E=$ standard error

Wald = Wald-statistics

Df = degrees of freedom

SigT = significance according to the T-distribution (I degree of freedom)
}

\subsection{Indirect effects of general patient beliefs on trial participation}

According to the explanatory model presented in figure 1, determinants of trial participation may be found in the blocks directly adjacent to the dependent variable. We have analyzed the dependencies of all determinants to these variables for 'old" and new' cases by path-analytical methods. Only results where beta-coefficients were statistically significant are presented in figure 3. Patient general beliefs and evaluations of recent medical history have no direct influence on trial participation, but they have direct effect on determinants of trial participation, and thus indirectly on trial participation. 
These indirect effects on trial-participation are rather interesting and take the form of chain relations. General ideas patients have before being informed by trial clinicians will influence their motivation to participate and this motivation will influence their eventual behavior. We will interpret and comment upon some of these chain relations on trial participation for 'old cases'. Lack of statistical power in the analysis of 'new cases' forces us to omit any definite conclusions for these patients, as far as indirect effects are concerned.

Figure 3: Path analytical diagram for "old cases" (long term patients)

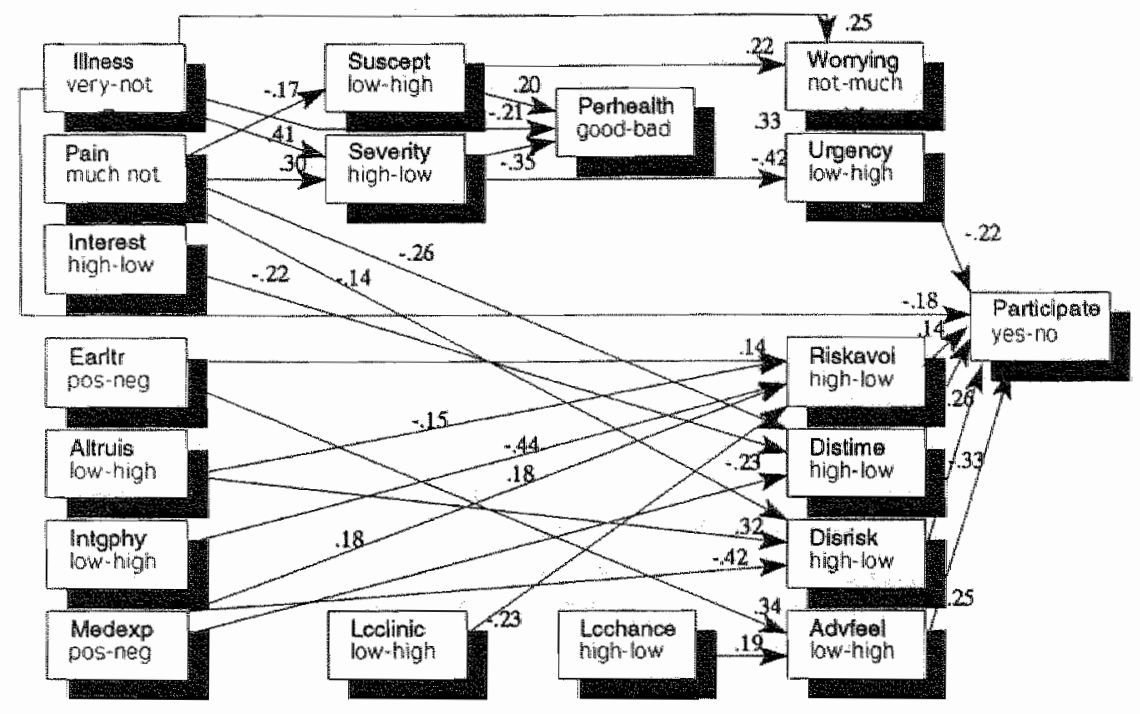

As can be seen from path-diagram 3, the opinion a patient has of clinical experiments in general (MEDEXP) is a very interesting factor. If patients have a prior positive attitude towards medical experiments in general, they tend to think that the risks of new, untested clinical procedures of the trial are relatively low, which in its turn will make them participate. Conversely, a critical attitude beforehand leads them to expect risks to be relatively high, which will increase the probability of non-participation. The pach-diagram also shows that patients with a prior positive opinion on medical experiments in general will regard the extra time-involvement of the trial as a minor problem, and this -again- will make them participate. So patients who are approached for a trial tend to evaluate the burden of extra time involved in trial participation within the context of their approval or disapprovall of medical experiments in general. A patient's altruistic outlook on clinical trials in general (ALTRUIS) also has an indirect effect on trial participation, because it tends to mitigate his or her wiew of the expected risks of the new untested clinical procedures in the triall, thus increasing the chances of entering the trial. $A$ high alltruistic attitude also leads to regarding the time-involvement of the clinical trial as less troublesome, which in its turn leads to higher participation. The patient's attitude to his or her pre-trial treatment 
(EARLTR) has an indirect effect on trial participation in that a critical attitude towards pretrial treatment will tend to raise expectations of feeling higher personal comfort in the trial, as compared to non-trial/regular treatment, which in turn will make participation mone ikely.

The patient's preference for university hospitals over general hospitals (ACAHOSP) also has a substantial indirect effect on trial participation. Patients with high trust in university hospitals will expect a higher personal comfort in the trial, as compared to earlier treatment or non-trial/regular treatment. This again will make patients parcicipate.A high value on the 'chance' locus of control (LCCHANCE), indicating feelings of powerlessness on matters concerning health and illness, will lower chances of expecting to feel better personal comfort in the trial compared to the standard treatment, which in turn leads to lower chances of participation. In contrast, patients with a high score on the external locus of control (LCCLINIC), showing the patient's high reliance on physicians to solve his or her problems in health matters, engenders a high trust in the risk-avoiding capacities of the trial clinician, which in turn has a favorable effect on trial participation.

Some general health and illness perceptions have indirect effects on trial participation. either by having an effect via the more specific perceptions, or by influencing benefits, discomforts and barriers of trial participation. The more a patient professes to suffer from pain during the three months preceding the approach for the trial (PAIN), the more the extra time involved in the trial is seen as a minor obstacle, thus increasing chances of participation. The more a patient suffers from pain during the three months preceding the approach, the lower the risks of new, untested clinical procedures of the trial are expected to be, rendering participation more likely. 'Feeling pain' (PAIN) also has another indirect effect on trial participation, as it leads to a higher perceived severity of illness, which in turn affects the feeling of urgency, which subsequently increases the probability that a patient will participate. The patient's interest in medical affairs in general (INTEREST) also has an indirect effect, as it will lead to a more lenient view on the problem of timeinvolvement, hence raising the chances to participate. Worrying about health (WORRYING) also appears to have a substantial indirect effect on trial participation, by influencing the perceived urgency of having to be treated immediately or as quickly as possible, which again leads to participation. Worrying is also influenced by the perceived health condition (PERHEALTH) and thus via the same chain participation probability is increased. The indirect effect of the patient's severity of illness (SEVERITY) on trial participation is quite large. It affects the perceived urgency of treatment, raising chances to participate. So the more serious a patient thinks the illness is, the more likely participation in a trial will be, because it will affect the patient's need of threat reduction. The perceived susceptibility and resusucepibility (SUSCEPT) has a small indirect effect on trial participation, as it influences 'worrying about health' directly. Via perceived health condition it will result in a higher feeling of urgency of treatment, which in turn will lead to participation.

\subsection{Non-relevancy of certain patient beliefs to explain trial participation}

When introducing some potential determinants concerning 'general evaluations and attitudes towards medical care, research and institutions', 'health locus of control', and 'general health perceptions and medical history' into the eventual path model, none of them turns out to be relevant in the explanation of trial participation (see table 5). A quite 
notable point is in this respect is that patient beliefs on the benefit of obtaining more insight into the state of health' or 'the comfort of being checked on your health more often than in regular treatment' turn out to be only secondary reasons to participate in a trial. Primary positive reasons are rather to be found in more direct gratifications of trial participation, like a better, more advanced treatment or the feeling of comfort attached to this in comparison to experiences with an earlier treatment or to the expectancy that the standard treatment will offer less relief.

Patients evaluations of legal requirements when obtaining informed consent in clinical trials (indicated with an ${ }^{\circ}$ in table 5), turn out to have no direct impact upon the decision to partake in a clinical trial. Patients do not consider these as reasons to participate or not in a clinical trial. When approached by the trial-clinician patients must act in a situation of uncertainties, in which their beliefs will guide them to their behavior. When speaking of patient rights, however, uncertainties have disappeared and certainties have taken over. Our model of explanation for trial participation based upon social-psychological determinants then will take a step aside, because only knowledge notions on the existence of the patient right should be sufficient to explain behavior. At the same time we know that behavior entails a certain amount of irrationality and is based on more affective beliefs, sometimes called motivation. It is this part of the behavior of patients towards trial participation which we wish to explain. Examples of 'comfort felt by patient rights' in our study are the notion that a patient always has 'the right to withdraw from a trial at any time' and 'negative feelings attached to the idea that refusing to participate will have negative implications for one's follow up treatment'.

Table 5. Nom-relevancy of potential factors in explaining trial-participation, when including them in the eventual path model for old and new cases, painwise deletion of cases (correlations and standardized partial regression coefficients shown).

Old cases

\section{Advantages}

ADVFEEL feeling better comfort in the trial as compared to the regular/non-trail treatment

ADVTREA expecting better medical treatment in trial, as compared to the non-trialiregular treatment

ADVCONT expecting security by extra check-ups on health during the trial

ADVPLEA expecting to be treated as a special kind of pacient within the trial

ADVI obtaining more insight into one's health and illiness condition

ADVTIME having a more sensible way of spending one's time while being ill

ADVRETR ${ }^{\circ}$ expecting to feel comforted in knowing one can at least withdraw from the trial at any time

\section{Disadvantages}

DISPHYS expecting to experience nausea, dizziness

DISRAND ${ }^{\circ}$ expecting drawbacks caused by trial randomisation procedure: risk of getting no or only standard treatment

NUMBER
R

B

R

$-.43 \quad-.02$

.32 样* .01

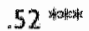

$-.41 \% \quad .08 \quad-.39 *-.03$

$-.38 \% \quad .02 \quad-.50 \%-.05$

$\begin{array}{llll}-.38 \text { *ate } & -.05 & -.29 * & -.09\end{array}$

$-.05$

.05

.07

.05

$-.49 * \quad .002$

$.04 \quad .36 *$

$-.35$

.001

. .19 


$\begin{array}{rrrr}-35 * 07 & -.26 * & .17 \\ -28 * 0 & .25 * & .16 \\ -.21 & -.006 & -.03 & -.01\end{array}$

Speciffe attitudes towards trial chinician and informed consent

COMPETEN trust in medical competence of trial clinician

RISKAVOI trust in the risk-avolding capacities of the trial-clinician

INFODISC the evaluation of the way oral information was given during the first approach

INFOTEXT the evaluation of the written information on the trial by explanatory leaflets

UNDTEXT the difficulty of understanding the written information

\section{Generall attitudes}

EARLTR patient's evaluation of the pre-trial treatment benefit of future patients hawing the same affliction

RESPHYS trust in physicians in general

PHARMA evaluation on the role of pharmaceutical industry in clinicial triats

ACAHOSP atcitude towands university hospitals as compared to general hospitals

MEDEXP attitude towards medical experiments

IMPORES relevance of doing cilinical trials for patient care

UNTGPHY belief in integrity of physicians doing clinical research with patients

\section{Multiditmensilonal Locus of controll}

LCCLINIC externally oriented locus of control

LCCHAMCE'Chance' oriented locus of control

Health and illness perceptions

WORRYING worrying about your health state

URGENCY urgency to be treated as quickly as possible

INTEREST interest in medical subjects in general

MULNERAB vulnerabilicy towards diseases in general

SUSCEPT perceived susceptibility to identical health problems in naxt future

PERHEALTH perception on health and illness condition now SEVERITY perceived severity of Hilness

PAIN suffering from pain during the past three months

SATHEALTH satisfaction with health and Illness condition

\section{Subjective norm}

SUBNORM subjective norm (encouragement) subjective norm (disencotragemunt)

Tilme to reconsider ${ }^{\circ}$

CONOPP' opportunity to have time to reconsider CONIMP' Importance to have time to reconsider

CONSAT ${ }^{\circ}$ satisfaction about amount of time to reconsider
ALTRUIS altruistic attitude concerning trifl treatment for the

LCINTERN internally oriented locus of control

ILLNESS feeling ill during the past three months

CONTIME duration of time to reconsider"$$
31 \text { or }
$$$$
.30-01
$$

$-.24 *-.02$

$\begin{array}{llll}.002 & -.71 & .38 * & .06 \\ .26 * & -.05 & -.45 * & -.12 \\ .09 & -.22 * & .29 * & .10 \\ .18 * & .04 & .001 & .09 \\ .15 & -.02 & .10 & -.17 \\ .30 * * 1 \% & -.06 & .12 & .02 \\ .17 * & -.005 & .24 * & -.04 \\ .18 * & .07 & -.28 * & .08\end{array}$

\section{.07}

$$
.03
$$

$\begin{array}{llll}.03 & -.06 & -.04 & -.05 \\ .23 & -.12 & -.04 & -.002\end{array}$

* $p<05$ * $p<01$ * * $p<001$, all other values ns

a wrables pertaining to legal requirements of informed consent. 


\section{CONCLUSIONS AND DISCUSSION}

This study was set up as a hospital-wide survey to provide more insight into sociopsychological determinants of patient participation in the average clinical trial. Our conclusions are that patient motivation to participate in a clinical trial mainly consists of a weighing up of beliefs for and against the trial, a sort of personal balance account of beliefs. Concurrently the patient's belief that he or she is threatened by health problems in such a way that the patient should be urgently treated (or as soon as possible) influences strongly the decision to participate in the trial in question.

When health motivational beliefs are defined in terms of the Health Belief Model and trial participation is regarded as illness coping behavior, patients are quite predictable. Both motivational beliefs on the relevance in reducing the threat to the patient's health condition ("values') as well as the evaluations of the clinical trial the patient is approached for ("expectancy") are relevant in explaining patient behavior. Furthermore, evaluative "frames of reference' are relevant in patients faced with the choice to participate or not. First, a set of beliefs consisting of general evaluations on medical affairs appears to have an impact on the patient's view on the characteristics of the trial as presented by the trialclinician. For instance, patients who have a prior low regard for medical experiments in general tend to view as rather high the risks of undergoing new, untested diagnostic procedures or treatment in the trial they are asked for. If these same patients also show little interest in altruistic motives to participate (for the benefit of future patients), they tend to regard these risks even higher, lowering the probability of participation in the trial considerably. Another example is the way patients evaluate their pre-trial treatment. It seems to be plausible that patients who are highly satisfied with their recent medical treatment will tend to regard the gain of extra comfort from the trial treatment as negligible. If patients are satisfied, they are likely to wish to continue their previous treatment. If they are dissatisfied with their treatment, they will have high hopes of deriving higher feelings of comfort by following the trial regimen.

Second, patient expectations are also influenced by another evaluative 'frame of reference': the patient's locus of control. If patients feel that even the clinicians themselves are losing control over their health and illiness condition, they evidently expect no extra advantages in joining "something new".

Third, if specific thresholds in health and illness perceptions are crossed, patients may want to stabilize feelings of threat by embracing the opportunity given by a trial. This far more intricately interrelated 'frame of reference" is the self-assessed health condition, in which an unfavorable perceived Illness condition may act as a motor in arousing feelings of threat. Fourth, this self-assessed health condition in turn is influenced by another evaluative "frame of reference: the patient's view of his or her recent medical history. Patients who have suffered much pain and who have felt rather poorly before the approach by the trialclinician are likely to be more severe in regard to their health condition. These same patients also tend to regard barriers like the extra time involved in a trial as no problem at all and will go so far as to underplay the risks of new, untested diagnostic procedures or treatment in a trial.

'Old cases' apparently have a slightly different motivation towards participating in a clinical trial, compared to 'new cases'. These differences in motivation are only relative, because short-term patients will eventually become long term patients. The distinction, however, 
proved to be useful in data-analysis. "New cases" tend to participate in a clinical trial, if they expect to run low risks in the trial, if they think the extra time the trial demands is no big problem, if they expect to get better treatment compared to the pre-trial or regular treatment and if they worry about their health. In 'old cases' the variable "urgency to be treated as immediately or quickly as possible' seems to play the role 'worrying about your health state' has in 'new cases." Worrying over one's health and illness condition' might be interpreted as a pre-cursor to the phase of "urgency". "New cases' appear moreover to have highly optimistic expectations of 'better' medical treatment when entering a clinical trial. In "old cases" this expectation does not determine their behawior whether to enter the trial or not, and seems to be replaced by the hope for higher personal comfort in the trial, as compared to their previous or non-trial/regular treatment.Arguments to distinguish patients into "old" and "new cases" can be theoretically grounded in the variants of the Health Belief Model.According to the HBM, patient behavior can be distinguished into "illness behavior" and "sick role behavior" [13]. The general "theory" of the HBM is not very specific about this distinction. The basic problem in explaining illness behavior is: "In the presence of symptoms, what will the individual do and why will he or she do it?". It is an activity undertaken by a person who becomes ill, to define the state of his or her health and to discover a suitable remedy. Sick role behavior focuses upon the 'activity undertaken by patients who consider themselves ill, for the purpose of getting well" [14]. We suppose that "old cases" will be more likely to perform 'sick role behavior", because they have been feeling ill for some time, the same symptoms recur regularly and they have already been treated for some time. On the other hand we expect 'new cases' are be more likely to perform "illness behavior". They have only recently become ill, their symptoms are recent and they have just managed to obtain professional help for their illness.

Patient consent to trial participation can be explained by only a couple of variables, but the motivations for patient refusal are evidently quite diverse and patient-bound. The few reasons for participation are easier to categorize. We presume that patients who finally enter a clinical trial only have to comply with a trial-clinician's request, while those who decide not to participate will have to oppose it explicitly.

The stuidy shows the failure of certain comforting or discomforting notions to be relevant in the decision to participate or not. Results suggest that evaluations on the rights one has as a patient (so-called medico-legal aspects of informed consent) are not decisive factors at all in the choice to participate in a trial. For instance, the comforting thought that one has the right to withdraw from the trial at any time has no effect on the decision making process. The expectancy of negative implications that refusing to participate would have on the follow-up or subsequent non-trial treatment is also not relewant in this respect. The same holds for the time to reconsider before taking a decision to enter the trial or not. Trial-clinicians stress these rights for patients explicitly in their information disclosure of the trial. One could argue that all patients regard these medico-legal requirements towards informed consent as unquestionable rights, so therefore they become irrelevant in decision-making.

In this study, most of the patients were quite satisfied about the oral and written information disciosure, whether they decided to participate or not.Also, the evaluation of the role the clinician plays in the information disclosure was very positive. We found that 
very few patients had any doubts about the medical competence and risk-avoiding capacities of the trial-clinicians they encountered. Due to this lack of discriminating power, these factors are not relevant in the decision to participate or not. Patient beliefs about the benefit of obtaining more information on the state of their health, the comfort of having their health checked more often than in regular treatment and drawbacks of the randomization procedure prove out to be only secondary reasons to participate in a trial. Subjective norm also appeared to be not relevant in explaining trial participation. It seems that the decision to enter entering a clinical trial is taken on personal grounds. Entering a clinical trial or not is the patient's own, individual choice.

Finally, we would like to make some remarks about the limitations of our study. The impact of possible selection bias as a result of the trial-clinicians" role in sellecting patients could not be traced by us, because of the demands of the IRB in our survey. Names of potential respondents could only be given to us, if the trial-clinicians agreed to cooperate with the survey and then only after they had obtained consent from their patients to participate in the interview. We also were not able to obtain information from the $\mathbf{2 7}$ individuals who could not be interviewed by us. We have interviewed patients within a median of ten days after their decision to participate or not in the trial. We have tried to keep the interval between decision and the approach of the patient for the interview as short as possible to avoid contamination of expectations by real trial experiences. It was however not feasible to interview patients before they took a final decision and even if we had been allowed to do so, one could always expect criticism that we had disturbed the natural process of decision making. Luckily, in almost all trials there was an administrative interval of several days to one week between the decision to participate and the day the patient actually went to the first control visit. Controlling for trial and physician characteristics was not feasible in this setup. This requires a type of stratified design and this will generally mean that higher numbers of respondents are needed.Also, the relatively small number of nonparticipants in the sample-survey also did not enable us to analyze determinants per trial or per type of clinical trial. In follow-up research it would be interesting to explore the association between trial characteristics and patient participation. We would also suggest to incorporate stratification of respondents in old and new cases within the survey design to find replications of our results.

To clarify the procedure of informed consent we suggest developing a check-list to classify patient motivation towards trial participation. Relevant factors found in our data analysis to explain patient participation could be used as criteria for such a classification. A Patient Motivation Classification would enable trial-cliniclans to obtain more insight into the personal motivation of patients they have approached for a clinical trial. Another check-list could be developed for the benefit of patient education. It should give a clear account of the pros and cons of a particular clinical trial in language the average patient could understand. The list could be provided to patients during the informed consent procedure. This could enable the flow of information in the informed consent procedure in clinical trials to be managed in a clear and succinct way. 
Trial-clinicians, patients and their representative organizations and IRB's may be interested in the implications of increased participation in and completion of clinical trials. If trialcliricians would focus upon patients" reasons to participate or not by means of a Patient Motivation Classification, this not necessarily would have to lead to higher participation rates. An early detection of non-compliars later on in a trial will also be relevant for clinicians and would lower dissatisfaction in both patients and clinicians in the course of the trial.

\section{References}

1. Quaid K. Faden R.Vining E. Freeman J. Informed consent for a prescription drug: impact of disclosed information on patient understanding and medical outcomes. Patient Education and Counseling 15 (1990) 249-259.

2. Maxur D.Why the goals of informed consent are not realized. Joumal of General internal Medicine 3 (19.98) 370.380.

3. Simel D. Feussner J.A randomized controlled trial comparing quantitative informed consent formats. Journal of Clinicol Epidemiology 44 (1991) $771-777$.

4. Meisel.A. Roth L. What do and do we not know about informed consent'. Journol of the American Medical Association 246 (1 981 ) 2437-2477.

5. Gotay C.Accrual to cancer clinical trials: directions from the research literature. Social science and Medicine 33 (1991) $569-577$.

6. Lauwer D.A theory of care seeking behavion. Journal of Nursing Scholorship 24 (1992) 281-287,

7. Gillam S. Understindting the uptake of cervical cancer screening the contribution of the health berleid modell. British journal of Generol Practice 41 (1991) 510.513.

8. Morrow G. Hickok J. Burish T. Behavioral aspects of elinical trials. An integrated framework from behavioral theory. Cancer (supplement) 74: (1994) 2676-2682.

9. Wallston K.Wallston B. Health Locus of Control scales. In: Research with the locus of control canstruct vol I: Assessment methads, edited by H. Lefcourt. Academic Press . New York (1981) 189-243.

10. Marshall G. Collins G. Crooks V.A comparison of the multidimensional health locus of control. Journol of Personodity Assessment 54 (1990) 181.190.

11. Westerlaak J. Kropman J. Collaris J. Beroepenklapper (Outch instrument for social economic cllass). Instituut voor Toegepaste Sociologie. Nijimegen (1975).

12. Asher, H. Cousol Modeling, Sage Publications. Beverly Hills, London, New Delhi (1983).

13. Janz N. Becker M. The Health Belief Model: a decade later. Health Educotion Quarterfly 11 (1984) 1-47.

14. KasI S. Cobb S. Health behawior, illness behavior and sick role behavior: Archives Environmental Heaich $\| 2$ (1966) 246-266 


\section{Amnex: Measurement procedures and operationalisation.}

We give an example of two separate runs of factor analysis on 55 ittems, comprising 15 out of the intended factors, one run on 7 intended factors and one run on 8 intended factors. We thus measured the following concepts, operationalised in items of which definitions of 24 of the 34 scale-constructions are presented. derived from all relevant blocks in the model of explanation.

Finally scale-constructions have been made by aweraging the Likert scores for each seale. A procedure has been used to compute scales corresponding with each factor, in which each individual score on each item of the factor results in a combined score upon a scale, using siemi- continue/semi-discrete scale frequencies between $\|$ and 5 (score on scale $=$ score item $1+$ score item $2+\ldots+$ score item 5$)$.

\section{Results on factor-anallysis by Maximum Likelihood} (factor loadings, communality $\left(\mathrm{h}^{2}\right)$, cronbach's alpha)

\begin{tabular}{|c|c|c|c|c|c|c|c|c|}
\hline Scole items & $\begin{array}{l}\text { factor ! } \\
\text { Disrisk }\end{array}$ & $\begin{array}{l}\text { foctor } 2 \\
\text { Adverea }\end{array}$ & $\begin{array}{l}\text { Poctor } 3 \\
\text { Distime }\end{array}$ & $\begin{array}{l}\text { foctor } 4 \\
\text { intgphy }\end{array}$ & $\begin{array}{l}\text { foctor } 5 \\
\text { Earltor }\end{array}$ & $\begin{array}{l}\text { factor } 6 \\
\text { Altruis }\end{array}$ & $\begin{array}{l}\text { foctor } 7 \\
\text { Medexp }\end{array}$ & $\begin{array}{l}\text { Commundity } \\
h^{2}\end{array}$ \\
\hline $\begin{array}{l}\text { varl } 63 \\
\text { varl } 6 \\
\text { varl } 2 \\
\text { varl } 27\end{array}$ & $\begin{array}{l}.85 \\
.78 \\
.74 \\
.71\end{array}$ & $\begin{array}{r}.05 \\
. .04 \\
-.05 \\
.02\end{array}$ & $\begin{array}{r}.01 \\
.01 \\
.07 \\
.04\end{array}$ & $\begin{array}{r}.01 \\
.06 \\
-.04 \\
.06\end{array}$ & $\begin{array}{r}.03 \\
.02 \\
-.03 \\
-.08\end{array}$ & $\begin{array}{r}-.02 \\
.01 \\
-.06 \\
.02\end{array}$ & $\begin{array}{r}.04 \\
.03 \\
.02 \\
.08\end{array}$ & $\begin{array}{l}.71 \\
.64 \\
.72 \\
.61\end{array}$ \\
\hline $\begin{array}{l}\text { warl } 13 \\
\text { warl } 26 \\
\text { warl | } \\
\text { warl } 31\end{array}$ & $\begin{array}{r}.04 \\
.01 \\
.02 \\
-.09\end{array}$ & $\begin{array}{l}.83 \\
.78 \\
.72 \\
.70\end{array}$ & $\begin{array}{r}-.01 \\
-.10 \\
.08 \\
-.05\end{array}$ & $\begin{array}{l}-.05 \\
.01 \\
.03 \\
.01\end{array}$ & $\begin{array}{r}.07 \\
.02 \\
.09 \\
. .14\end{array}$ & $\begin{array}{r}-.03 \\
.08 \\
-.04 \\
.01\end{array}$ & $\begin{array}{r}.05 \\
.02 \\
.09 \\
. .14\end{array}$ & $\begin{array}{l}.68 \\
.69 \\
.48 \\
.59\end{array}$ \\
\hline $\begin{array}{l}\text { var| } 53 \\
\text { var| } 51 \\
\text { var } 47 \\
\text { var } 119 \\
\text { var } 14\end{array}$ & $\begin{array}{r}.07 \\
. .11 \\
.06 \\
.08 \\
.16\end{array}$ & $\begin{array}{l}.06 \\
.07 \\
.06 \\
-.15 \\
-.11\end{array}$ & $\begin{array}{l}.89 \\
.77 \\
.67 \\
.63 \\
.59\end{array}$ & $\begin{array}{l}-.01 \\
.03 \\
.04 \\
.06 \\
. .09\end{array}$ & $\begin{array}{r}.02 \\
.08 \\
.07 \\
. .13 \\
.01\end{array}$ & $\begin{array}{l}.08 \\
-.04 \\
.07 \\
-.01 \\
-.02\end{array}$ & $\begin{array}{r}.09 \\
.04 \\
.08 \\
.06 \\
.07\end{array}$ & $\begin{array}{l}.86 \\
.54 \\
.55 \\
.58 \\
.53\end{array}$ \\
\hline $\begin{array}{l}\operatorname{var} 212 \\
\operatorname{var} 23 \\
\operatorname{var} 220\end{array}$ & $\begin{array}{r}.07 \\
.11 \\
-.05\end{array}$ & $\begin{array}{r}.05 \\
-.06 \\
.01\end{array}$ & $\begin{array}{r}-.01 \\
.09 \\
-.02\end{array}$ & $\begin{array}{r}.90 \\
.53 \\
.50\end{array}$ & $\begin{array}{r}.07 \\
-.15 \\
.07\end{array}$ & $\begin{array}{l}-.02 \\
-.05 \\
-.02\end{array}$ & $\begin{array}{r}.01 \\
.05 \\
.05\end{array}$ & $\begin{array}{l}.79 \\
.28 \\
.50\end{array}$ \\
\hline $\begin{array}{l}\operatorname{var} 243 \\
\operatorname{var} 233 \\
\operatorname{var} 27 \\
\operatorname{var} 214\end{array}$ & $\begin{array}{l}.02 \\
.05 \\
.04 \\
.01\end{array}$ & $\begin{array}{l}.03 \\
.09 \\
.08 \\
.07\end{array}$ & $\begin{array}{l}-.08 \\
-.04 \\
-.04 \\
-.04\end{array}$ & $\begin{array}{r}.01 \\
-.03 \\
.08 \\
.07\end{array}$ & $\begin{array}{r}.75 \\
.74 \\
.71 \\
.68\end{array}$ & $\begin{array}{r}-.02 \\
.08 \\
.03 \\
. .11\end{array}$ & $\begin{array}{r}.02 \\
.00 \\
.00 \\
.02\end{array}$ & $\begin{array}{l}.61 \\
.56 \\
.55 \\
.52\end{array}$ \\
\hline $\begin{array}{l}\operatorname{var} 239 \\
\operatorname{var} 232 \\
\operatorname{var} 226\end{array}$ & $\begin{array}{r}.11 \\
.03 \\
.02\end{array}$ & $\begin{array}{r}.02 \\
.06 \\
.01\end{array}$ & $\begin{array}{r}-.09 \\
-.04 \\
.07\end{array}$ & $\begin{array}{r}.02 \\
.07 \\
-.01\end{array}$ & $\begin{array}{r}.01 \\
.01 \\
-.02\end{array}$ & $\begin{array}{r}-.83 \\
-.70 \\
.55\end{array}$ & $\begin{array}{l}.08 \\
.02 \\
.01\end{array}$ & $\begin{array}{l}.75 \\
.57 \\
.51\end{array}$ \\
\hline $\begin{array}{l}\operatorname{var} 215 \\
\operatorname{var2} 42 \\
\operatorname{var} 235\end{array}$ & $\begin{array}{r}11 \\
.03 \\
.02\end{array}$ & $\begin{array}{l}.02 \\
.06 \\
.01\end{array}$ & $\begin{array}{r}.09 \\
.04 \\
.07\end{array}$ & $\begin{array}{l}.02 \\
.07 \\
. .01\end{array}$ & $\begin{array}{l}.01 \\
.01 \\
-.02\end{array}$ & $\begin{array}{r}.01 \\
.02 \\
.09\end{array}$ & $\begin{array}{r}-.78 \\
.68 \\
-.67\end{array}$ & $\begin{array}{l}.64 \\
.50 \\
.52\end{array}$ \\
\hline Cronbach's alpha & .89 & .85 & .88 & .69 & .82 & .77 & $\pi 7$ & \\
\hline
\end{tabular}

Principal Axis Factoring using 7 intended faxtors $(160<\mathrm{m}<\| 96)$ results in am explained variance of $59.6 \%, 18$ residuals $>.05(5.0 \%)$ and Maximum Likellihood in an explained variance of $59.6 \%, 24$ resioluals $>.05(7.0 \%)$, Chi-square $=19229 ; d=164 ; \mathrm{p}=065$.

Disrisk Risks of new, untested clinicall procedures in the tria

Advtrea Better/more advanced medical treatment in trial ${ }_{\sharp}$ as compared to the non-trial/regulat" treatment

Distime Fearing a time-consuming committrment

Untgphy Belief in integrity of physicians doing dinical resiearch with patients

Earlitr Patienc's evaluation of pre-trial treatment.

Altruis Altruisticlegoistic attitude concerning trial treatment for the benefit of future patients

Medexp Attitude towards medical experiments

Mart General attitudes and walues towands clinical trials

War2 Benefits, risks, and barriers towards trial participation 


\begin{tabular}{|c|c|c|c|c|c|c|c|c|c|}
\hline Scolle titems & $\begin{array}{l}\text { fortar } 1 \\
\text { Adufeel }\end{array}$ & $\begin{array}{l}\text { foutar } 7 \\
\text { Interest }\end{array}$ & $\begin{array}{l}\text { foctor } 3 \\
\text { Worrying }\end{array}$ & $\begin{array}{l}\text { foctor } 4 \\
\text { Leclinic }\end{array}$ & $\begin{array}{l}\text { foctor } 5 \\
\text { Suscetpt }\end{array}$ & $\begin{array}{l}\text { foctar } 6 \\
\text { Lochance }\end{array}$ & $\begin{array}{l}\text { Joctor } 7 \\
\text { Urgency }\end{array}$ & $\begin{array}{l}\text { foctor } 8 \\
\text { Riskovioi }\end{array}$ & $\begin{array}{l}\text { Communalty } \\
h^{2}\end{array}$ \\
\hline $\begin{array}{l}\operatorname{var} 254 \\
\operatorname{var} 235\end{array}$ & $\begin{array}{r}1.00 \\
.72\end{array}$ & $\begin{array}{r}.01 \\
-.02\end{array}$ & $\begin{array}{r}.06 \\
. .05\end{array}$ & $\begin{array}{r}.09 \\
-.06\end{array}$ & $\begin{array}{r}-.03 \\
.03\end{array}$ & .02 & $\begin{array}{r}-111 \\
.14\end{array}$ & $\begin{array}{r}.08 \\
. .03\end{array}$ & .99 \\
\hline $\begin{array}{l}\text { var4 } 10 \\
\operatorname{var} 44 \\
\operatorname{war} 46 \\
\text { war } 415\end{array}$ & $\begin{array}{l}.02 \\
.07 \\
.04 \\
.06\end{array}$ & $\begin{array}{r}.92 \\
.85 \\
73 \\
.70\end{array}$ & $\begin{array}{r}.03 \\
.08 \\
.01 \\
.07\end{array}$ & $\begin{array}{r}.18 \\
-.02 \\
.08 \\
.07\end{array}$ & $\begin{array}{r}-.09 \\
.04 \\
.01 \\
-.07\end{array}$ & $\begin{array}{r}.01 \\
.01 \\
-.03 \\
.09\end{array}$ & $\begin{array}{l}.01 \\
.03 \\
.02 \\
.03\end{array}$ & $\begin{array}{r}.05 \\
.04 \\
.01 \\
.04\end{array}$ & $\begin{array}{l}.87 \\
.76 \\
.55 \\
.52\end{array}$ \\
\hline $\begin{array}{l}\text { var4 } 17 \\
\text { var4 } 5 \\
\text { var } 49 \\
\text { war } 1.4\end{array}$ & $\begin{array}{l}.01 \\
.02 \\
.00 \\
.00\end{array}$ & $\begin{array}{l}-.01 \\
.01 \\
.04 \\
.00\end{array}$ & $\begin{array}{r}.70 \\
.67 \\
.64 \\
-.58\end{array}$ & $\begin{array}{l}.09 \\
.02 \\
.02 \\
.00\end{array}$ & $\begin{array}{r}.05 \\
.02 \\
.08 \\
-.13\end{array}$ & $\begin{array}{l}.07 \\
.07 \\
.03 \\
.04\end{array}$ & $\begin{array}{r}.07 \\
-.05 \\
.22 \\
.06\end{array}$ & $\begin{array}{l}.09 \\
.03 \\
-.05 \\
-.06\end{array}$ & $\begin{array}{l}.57 \\
.47 \\
.60 \\
.38\end{array}$ \\
\hline $\begin{array}{ll}\text { war3 } & 15 \\
\text { var3 } 13 \\
\text { var3 } 5 \\
\text { var3 } 7 \\
\text { var3 } 5 \\
\text { war3 } 4\end{array}$ & $\begin{array}{l}.06 \\
.06 \\
.02 \\
.06 \\
.12 \\
.01\end{array}$ & $\begin{array}{r}.12 \\
-.10 \\
-.04 \\
.03 \\
.16 \\
-.07\end{array}$ & $\begin{array}{r}.09 \\
.03 \\
.04 \\
. .16 \\
.13 \\
.05\end{array}$ & $\begin{array}{l}.68 \\
.66 \\
.65 \\
.49 \\
.48 \\
.35\end{array}$ & $\begin{array}{r}.01 \\
-.05 \\
-.01 \\
.20 \\
-.02 \\
-.04\end{array}$ & $\begin{array}{r}-.07 \\
.12 \\
-.04 \\
.07 \\
.03 \\
.06\end{array}$ & $\begin{array}{r}-.02 \\
.01 \\
.01 \\
.11 \\
-.04 \\
.10\end{array}$ & $\begin{array}{r}. .04 \\
-.04 \\
.00 \\
-.12 \\
-.17 \\
-.28\end{array}$ & $\begin{array}{l}.52 \\
.49 \\
4 ! \\
.42 \\
.42 \\
.33\end{array}$ \\
\hline $\begin{array}{c}\operatorname{var} 418 \\
\operatorname{var} 413 \\
\operatorname{van} 43\end{array}$ & $\begin{array}{r}.00 \\
-.02 \\
.05\end{array}$ & $\begin{array}{r}-.01 \\
-.08 \\
.10\end{array}$ & $\begin{array}{r}.03 \\
.14 \\
-.01\end{array}$ & $\begin{array}{l}.01 \\
.08 \\
.111\end{array}$ & $\begin{array}{l}.90 \\
.76 \\
.74\end{array}$ & $\begin{array}{r}-.00 \\
.02 \\
.00\end{array}$ & $\begin{array}{r}-.05 \\
.06 \\
.06\end{array}$ & $\begin{array}{r}.03 \\
.08 \\
.09\end{array}$ & $\begin{array}{l}.80 \\
.69 \\
.61\end{array}$ \\
\hline $\begin{array}{ll}\text { var3 } & 16 \\
\text { war3 } & 12 \\
\text { war3 } & 10 \\
\text { var3 } & 3\end{array}$ & $\begin{array}{r}.01 \\
.05 \\
.01 \\
.04\end{array}$ & $\begin{array}{l}-.04 \\
-.05 \\
.02 \\
.09\end{array}$ & $\begin{array}{r}-.07 \\
.07 \\
-.00 \\
-.00\end{array}$ & $\begin{array}{r}.14 \\
.16 \\
.13 \\
.06\end{array}$ & $\begin{array}{r}.04 \\
.11 \\
-.04 \\
-.06\end{array}$ & $\begin{array}{l}.78 \\
.63 \\
.63 \\
.55\end{array}$ & $\begin{array}{r}.07 \\
-.04 \\
.05 \\
-.02\end{array}$ & $\begin{array}{r}.11 \\
-.14 \\
-.01 \\
.04\end{array}$ & $\begin{array}{l}.67 \\
.46 \\
.45 \\
.31\end{array}$ \\
\hline $\begin{array}{ll}\text { vard } 12 \\
\text { warn } \\
\text { var } 42\end{array}$ & $\begin{array}{l}.02 \\
.02 \\
.03\end{array}$ & $\begin{array}{r}.04 \\
.07 \\
-.02\end{array}$ & $\begin{array}{r}.03 \\
.03 \\
.19\end{array}$ & $\begin{array}{r}.04 \\
.10 \\
. .06\end{array}$ & $\begin{array}{r}.02 \\
. .02 \\
.06\end{array}$ & $\begin{array}{r}-.00 \\
.03 \\
-.10\end{array}$ & $\begin{array}{l}.86 \\
.81 \\
.60\end{array}$ & $\begin{array}{r}.02 \\
.08 \\
-.04\end{array}$ & $\begin{array}{l}.75 \\
.76 \\
.50\end{array}$ \\
\hline $\begin{array}{l}\text { Wars } 30 \\
\text { war5 } 11 \\
\text { vars } 25\end{array}$ & $\begin{array}{l}.01 \\
.08 \\
.06\end{array}$ & $\begin{array}{r}.08 \\
-.04 \\
-.00\end{array}$ & $\begin{array}{l}-.16 \\
-.02 \\
.04\end{array}$ & $\begin{array}{r}.00 \\
.16 \\
. .03\end{array}$ & $\begin{array}{l}.09 \\
.05 \\
.14\end{array}$ & $\begin{array}{r}.05 \\
.03 \\
.02\end{array}$ & $\begin{array}{r}.03 \\
-.04 \\
.05\end{array}$ & $\begin{array}{r}-72 \\
-.65 \\
.65\end{array}$ & $\begin{array}{l}.60 \\
.55 \\
.44\end{array}$ \\
\hline $\begin{array}{l}\text { cronbach's } \\
\text { alphat }\end{array}$ & 85 & .88 & .78 & .70 & .86 & .76 & .83 & .75 & \\
\hline
\end{tabular}

Principal Axis Factoring usirg 8 intended factors $(161<n<196)$ results in an explained variance of $56.6 \%, 26$ ressiduats $>.05(6.9 \%)$ and Maximum Likelhood in an explained wariance of $56.8 \%, 39$ residuals $>05(9.0 \%)$, Chiscuare $=200.32$ df $=202 ; p=50$.

Adweel Feeling more comfort in the trial treatment as compared to the regular or non-trail treatment Interest Interestin medical subjects in general

Worrying Worying about health state

Leclinic Externall locus of control: evaluation of the way physicians in general have to have control over health problems

Suscept Perceived susceptibility to momentary problems of health state in next fuiture

Lcchance Chance locus of control: feelings of uncomtrollability of health problems by any means at all

Urgency Perceived urgency to be treatment as quickly as possible

Riskavof Trust in the trial-chinician, concerning abillties to avoild and diminish risks

Varl Genoral attiudes and values towards cllinical trials

Var2 Benefits, risks, and barriers towards trial participation

Var3 Heath locus of control

Vart Health and illness perceptions

Var5 Specific arcitudes towands the trial-clinician 
Scale-constructions and variables used te explain trial participation (descriptive statistics).

\begin{tabular}{|c|c|c|c|c|c|c|c|c|}
\hline Variable & Mean & 5td Der & Skewness & SESkew & * Ronge & $N$ & Items & Alph \\
\hline $\begin{array}{l}\text { ADNCONT } \\
\text { ADNFEEL } \\
\text { ADVINS } \\
\text { ADVRETR } \\
\text { ADVPLEA } \\
\text { ADNTREA } \\
\text { ADNTIME }\end{array}$ & $\begin{array}{l}\text { Expect } \\
1.56 \\
2.85 \\
4.11 \\
4.49 \\
3.99 \\
3.17 \\
2.72\end{array}$ & $\begin{array}{c}\text { yefts } \\
.71 \\
1.19 \\
.92 \\
.62 \\
1.04 \\
1.10 \\
1.27\end{array}$ & $\begin{array}{r}1.80 \\
.23 \\
-1.36 \\
-1.86 \\
-1.07 \\
-.1 .5 \\
.05\end{array}$ & $\begin{array}{l}17 \\
.18 \\
.17 \\
.18 \\
.17 \\
.19 \\
.19\end{array}$ & $\begin{array}{l}3.75 \\
4.00 \\
4.00 \\
3.00 \\
4.00 \\
4.00 \\
4.00\end{array}$ & $\begin{array}{l}194 \\
179 \\
194 \\
192 \\
196 \\
168 \\
163\end{array}$ & $\begin{array}{l}4 \\
2 \\
3 \\
4 \\
3 \\
4 \\
2\end{array}$ & $\begin{array}{l}.87 \\
.85 \\
.80 \\
.88 \\
.92 \\
.85 \\
.86\end{array}$ \\
\hline $\begin{array}{l}\text { DISRAND } \\
\text { DISRETA } \\
\text { DISRISK } \\
\text { DISTIME }\end{array}$ & $\begin{array}{l}\text { Expect } \\
3.17 \\
4.16 \\
4.23 \\
3.71\end{array}$ & $\begin{array}{l}\text { discomfort } \\
1.40 \\
.74 \\
.82 \\
1.05\end{array}$ & $\begin{array}{l}5, \text { risks and } \\
-19 \\
-1.11 \\
-1.77 \\
-.85\end{array}$ & $\begin{array}{l}\text { arriers } \\
.19 \\
.17 \\
.18 \\
.17\end{array}$ & $\begin{array}{l}4.00 \\
4.00 \\
4.00 \\
4.00\end{array}$ & $\begin{array}{l}159 \\
193 \\
187 \\
194\end{array}$ & $\begin{array}{l}5 \\
3 \\
4 \\
5\end{array}$ & $\begin{array}{l}.96 \\
.61 \\
.89 \\
.82\end{array}$ \\
\hline $\begin{array}{l}\text { MEDEXP } \\
\text { WWGPHY } \\
\text { ALTRUIS } \\
\text { EARLTR } \\
\text { ACAHOSP }\end{array}$ & $\begin{array}{l}\text { Genero } \\
2.55 \\
3.79 \\
4.12 \\
1.79 \\
2.15\end{array}$ & $\begin{array}{l}\text { aluations o } \\
.98 \\
.84 \\
.83 \\
.77 \\
.81\end{array}$ & $\begin{array}{l}\text { and attitude } \\
.35 \\
-.72 \\
.1 .10 \\
1.62 \\
.89\end{array}$ & $\begin{array}{l}.17 \\
.19 \\
.17 \\
.17 \\
.19\end{array}$ & $\begin{array}{l}3.67 \\
3.67 \\
3.67 \\
3.75 \\
3.75\end{array}$ & $\begin{array}{l}195 \\
192 \\
196 \\
195 \\
169\end{array}$ & $\begin{array}{l}3 \\
3 \\
3 \\
4 \\
4\end{array}$ & $\begin{array}{l}.77 \\
.69 \\
.77 \\
.82 \\
.75\end{array}$ \\
\hline $\begin{array}{l}\text { COMPETEN } \\
\text { RISKAVOI }\end{array}$ & $\begin{array}{l}\text { Attitud } \\
1.55 \\
2.12\end{array}$ & $\begin{array}{l}\text { wards the } \\
.47 \\
.77\end{array}$ & $\begin{array}{l}\text { triatadinicio } \\
1.00 \\
64\end{array}$ & $\begin{array}{l}.17 \\
.18\end{array}$ & $\begin{array}{l}2.75 \\
3.67\end{array}$ & $\begin{array}{l}196 \\
190\end{array}$ & $\begin{array}{l}4 \\
3\end{array}$ & $\begin{array}{l}.71 \\
.75\end{array}$ \\
\hline $\begin{array}{l}\text { LCINTERN } \\
\text { LCCHANAE } \\
\text { LCCLINIC }\end{array}$ & $\begin{array}{l}\text { Health } \\
2.70 \\
3.12 \\
3.31\end{array}$ & $\begin{array}{l}\text { is of contr } \\
.67 \\
.89 \\
.84\end{array}$ & $\begin{array}{r}01 \\
.23 \\
-.24 \\
-.17\end{array}$ & $\begin{array}{l}.17 \\
.17 \\
.17\end{array}$ & $\begin{array}{l}3.03 \\
4.00 \\
3.50\end{array}$ & $\begin{array}{l}196 \\
195 \\
196\end{array}$ & $\begin{array}{l}6 \\
6 \\
4\end{array}$ & $\begin{array}{l}.78 \\
.70 \\
.76\end{array}$ \\
\hline $\begin{array}{l}\text { PERHEALTH } \\
\text { URGENCY } \\
\text { WORRYING } \\
\text { SEVERITY } \\
\text { SUSCEPT }\end{array}$ & $\begin{array}{l}\text { Healt } \\
2.77 \\
3.10 \\
2.72 \\
3.33 \\
3.75\end{array}$ & $\begin{array}{l}\text { 1. Iness pe } \\
1.01 \\
1.17 \\
1.08 \\
1.31 \\
.90\end{array}$ & $\begin{array}{c}\text { rceptions } \\
.77 \\
.01 \\
.50 \\
-.24 \\
-.60\end{array}$ & $\begin{array}{l}.17 \\
.17 \\
.17 \\
.17 \\
.18\end{array}$ & $\begin{array}{l}5.00 \\
4.00 \\
4.00 \\
4.00 \\
4.00\end{array}$ & $\begin{array}{l}196 \\
193 \\
197 \\
197 \\
187\end{array}$ & $\begin{array}{l}1 \\
3 \\
4 \\
1 \\
1\end{array}$ & $\begin{array}{l}\mathrm{na} \\
.83 \\
78 \\
\mathrm{na} \\
\mathrm{na}\end{array}$ \\
\hline $\begin{array}{l}\text { INTEREST } \\
\text { ILLNESS } \\
\text { PAHN }\end{array}$ & $\begin{array}{l}\text { Gener } \\
2.43 \\
3.83 \\
4.41\end{array}$ & $\begin{array}{l}\text { ahth perce } \\
1.18 \\
1.25 \\
1.69\end{array}$ & $\begin{array}{l}\text { ptions and } \\
.64 \\
. .60 \\
.46\end{array}$ & $\begin{array}{l}\text { erceived in } \\
.17 \\
.17 \\
.17\end{array}$ & $\begin{array}{l}4.00 \\
4.00 \\
5.00\end{array}$ & $\begin{array}{l}197 \\
197 \\
197\end{array}$ & $\begin{array}{l}4 \\
1 \\
4\end{array}$ & $\begin{array}{l}.88 \\
\mathrm{na} \\
90\end{array}$ \\
\hline $\begin{array}{l}\text { INFODISC } \\
\text { INFOTEXT } \\
\text { UNOETEXT }\end{array}$ & $\begin{array}{l}\text { Ewoltue } \\
1.85 \\
4.05 \\
4.03\end{array}$ & $\begin{array}{l}\text { of inform } \\
.70 \\
.54 \\
.85\end{array}$ & $\begin{array}{l}1.25 \\
-93 \\
-1.38\end{array}$ & $\begin{array}{l}.17 \\
.24 \\
.24\end{array}$ & $\begin{array}{l}3.38 \\
3.17 \\
4.00\end{array}$ & $\begin{array}{r}196 \\
103 \\
97\end{array}$ & $\begin{array}{l}6 \\
6 \\
2\end{array}$ & $\begin{array}{l}.87 \\
.77 \\
.62\end{array}$ \\
\hline
\end{tabular}

na not applicable 


\title{
5 Patients' perceptions of informed consent and the quality of information disclosure in clinical trials.
}

\author{
FWSM Verheggen, R Jonkers, G Kok \\ Accepted for publication in Patient Education and Counseling.
}

\begin{abstract}
In a survey on 26 dinical trials we studied how patients experience and evaluate the information disclosure on the clinical trial they are enrolled in and which factors influence patients' perceptions of information disclosure. Our abjective was to obtain more insight thereby in how informed consent is applied in the daily practice of clinical trials. Interviews were held with 198 adult patients and 32 trial-cliniclans. Instead of focusing on patient comprehension of the information disclosed we analyzed patient perceptions of informed consent. Patients proved to be quite satisfied with the oral and written information disclosure. Patients's perceptions of the manner and content of information disclosure are influenced by more general attitudes towards medical care, research and institutions. Patients" trust in medical experiments, belief in the integrity of physicians and interest in medical affairs have an impact on the way patients perceive information disclosure. To improve the quality of the informed consent procedure, we propose a patient motivation classification (PMC) to enable trial-clinicians to gain more insight into patient motivation. Rellevant factors found in our data have been used as criteria for classification. An informed decision making checklist (IDC) is suggested for patients as a general outline for patient education, covering relevant socio-psychological factors of enrollment.
\end{abstract}

\section{Key words:}

patient education, informed consent, information disclosure, patient satisfaction. 


\section{INTRODUCTION}

Informed consent is a essential part of the daily practice of clinical trials and the physicianpatient relationship. The patient's decision whether to participate in a clinical trial must be based on adequate information that permits an assessment of benefits and disadvantages of treatment. Informed consent is designed to ensure that the patient's right to be fully informed about a clinical trial is not infringed [1]. Several critical elements have been suggested in the process of obtaining informed consent [2]. When patients are asked to enter a clinical trial, the trial-clinician should provide relevant information on risks, barriers and benefits the clinical trial is concerned with, before patients decide to enter the trial or not. Patients should be explicitly informed that they are being invited to participate in a clinical trial in which an experimental diagnostic or treatment procedure is being studied. However, disclosure is not sufficient for adequate informed consent. A patient should also have adequate decision-making capacities and be able to understand the information disclosed. Furthermore, time for reconsideration should be given, before a patient is asked for a final decision. Patients must freely and voluntarily authorize their participation and it should be emphasized they can always withdraw from the trial whenever they wish to do so. Little empirical research has been done into how this 'theory of informed consent' is applied in the daily practice of clinical trials [3] and how patients perceive the quality of informed consent [4]. We therefore performed a study to analyze how patients invited for a clinical trial perceive the information disclosure, rather than what the trial-clinician communicates. Thus we assumed the notion of patient satisfaction as a measure of the quality of the informed consent process [5]. We did not however examine patient"s decision making capacities. Nor was our sample-survey designed to evaluate whether the information disclosure was accurate or comprehensible. We did not expect to add to current findings on patient comprehension [6-10]. Instead of focusing upon patient comprehension, we chose to focus on the patient's expectations towards the clinical trial to which he or she is invited for. Our interest lay in how patients experience and evaluate the quality of information disclosure. We thus wanted to obtain more insight into relevant aspects of the informed consent procedure which takes place in clinical trials. The study was designed to answer the following two questions: How do patients experience and evaluate the information disclosure on the clinical trial as provided by the trial-clinician at the time they are first approached and later on during the trial? Which factors influence patients' evaluation of the information disclosure on the clinical trial during the informed consent procedure?

\section{PRELIMINARIES TO DATA-ANALYSIS}

\section{I Model of explanation}

We assumed that beside the information disclosure by the trial-clinician as such, several "frames of references' might influence patients" expectations of a clinical trial. Variables concerning general attitudes, evaluations and values about medical care, research and institutions as measured in the sample survey were expected to explain patients" perception on risks, discomforts and benefits .Also general health permceptions, the patient's self-defined medical history and the health locus of control would be relevant to explaining the patient's perception of information disclosure. The empirical model of explanation can be represented by the path-model as given in figure 1. 
Figure 1. Path-diagram for the anahysis of the patient's evaluation of the information disclosure

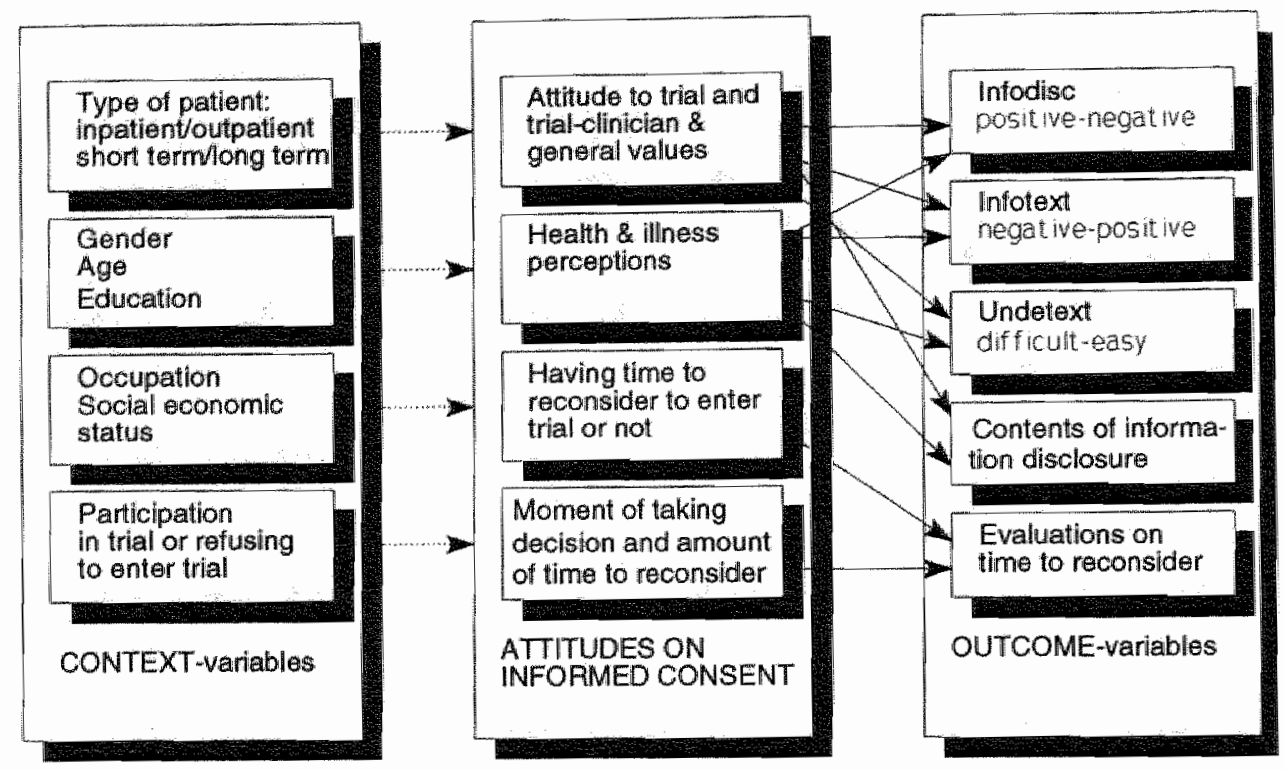

\subsection{Patient's view of a clinical trial}

Patients differ in their decision-making process towards trial participation ${ }_{*}$ depending on their expectations towards the clinical trial. They ask themselves what trial participation will mean. Patients' subjective interpretations of the information disclosure on the clinical trial, as provided by the trial-clinician, will be one of the relevant factors, like expected advantages, discomforts and barriers to entering the trial.

A distinction can be made between the way information about the clinical trial is provided and the content of information disclosure, concerning risks, discomforts and benefits. With regard to the method of information disclosure, written explanatory leaflets are provided in addition to the oral information by the trial-clinician. It is a legal requirement that patients invited for a clinical trial must also receive written information about it. An interpretation of the content of the information disclosed can be discerned from attitudinal variables, which yield an impression of the patient's perception of the risks, barriers, discomforts and benefits of entering a clinical trial.

Table I provides an overview of benefits, risks, barriers and discomforts which could be involved in a clinical trial from a patients point of view. Patient's expectations on all these variables have been measured in the sample-survey per clinical trial.A distinction was made berween aspects of information disclosure relevant to deciding to enter a trial and aspects which might be relevant to consideration of withdrawal from participation. 
Table 1: Patients" wiew on a specific clinical trial: evalluation of expected benefits and disadvantages

\section{Benefits}

Obtaining a better medical treatment within the trial, compared to that of the pre-trial or non-trial (regular) treatment

\section{Personal comforts}

Being repeatedly checked upon one's health in the triall

Getting more personal comfort in the trial, compared to that of the prewtrial or non-trial (regular) treatment

More insight in own health, gained from participating in the trial

Feeling comfort one alwrys and at least has the right to withdraw from the trial at any time

Being regarded as a special kind of patient, being asked to participate in the trial

Having a useful time-passing by participating

\section{Risks}

The risks by undergoing new, untested diagnostic procedures or treatment in the trial

The consequences of running the risk of getting no or only standard treatment, caused by the randomisation procedure

Expect that refusing to participate will have negative implications on the follow up

treatment or subsequent non-trial treatment

Discomforts

Expecting to experience nausea or dizziness when participating

Being treated as a number in the course of the clinical trial

Feeling as a guinea-pig in an experiment

Find it unpleasant to let blood regularly

Find it unpleasant to remember to take medicine or regimen regullarly

Getting a disturbed realtionship with the trial-clinician if not participating

\section{Barriers}

The 'time-consumingness' of the trial

Find it unpleasant to get up early in the morning

Being occupied too much in daily life, to be able to participate

Having trouble to have to follow a diet

Having to be treated longer in comparison with the regullar treatment

* These benefits, risks and barriers are indicated as items, making a comparison betweem the regular, non-trial theatment and the experimentai trial-treatment.

When evaluating these benefits, risks and barriers no such comparison is being made

\section{MATERIALS \& METHODS}

\section{I Patient recruitment}

Patients were interviewed by means of questionnaire after being asked for their consent. to participate in a clinical trial.Approval for the sample-survey was obtained from the medical ethical committee of the hospital (MEC). Patients were randomly selected from 26 clinical trials taking place during February and Octaber 1993. Patients were recruited from experimental (cohort) studies, from non-experimental diagnostic studies or from a. 
combination of both, provided that the study was prospectively designed.

The survey comprises a sample of 198 adult patients approached for clinical trials at the university hospital in Maastricht. In the sample surwey 172 participants in clinical trials (response rate $93 \%$ ) and 26 non-participants were included (response rate $86 \%$ ), being a representative sample of patients approached for clinical trials in a university hospital setting. The overall response rate was $88 \%$ (198/225). The sampling procedure is described in figure 2.

Figure 2: Sequence of recruirntent: samplinig procedure

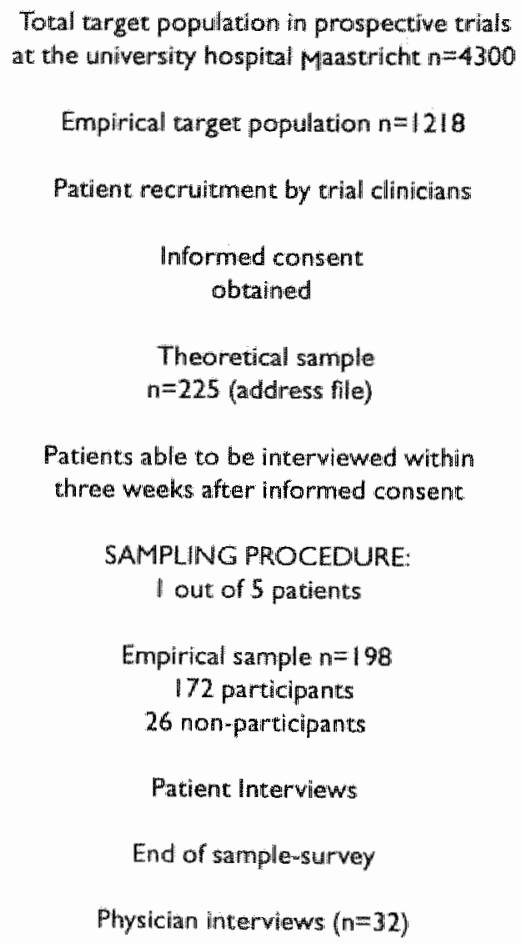

Interviews took place within four weeks after patients had been asked to participate in a clinical triall. Inclusion and exclusion-criteria, selection of empirical cases and fieldwork description have been described extensively [5]. We also compiled characteristics of the 198 patients. Mean age of respondents was 57.8 years $(s . d=13.8) ; 61.6 \%$ were male.

Of the respondents, $86.9 \%$ decided to participate in a clinical trial. Most of the patients were interwiewed as outpatients $(59.6 \%)$, the others as clinical patients; $65.7 \%$ were long term patients, coping with their health problems for longer than three months and the others short term patients. 


\subsection{Measurement procedures}

Patients were questioned about the following items concerning the informed consent procedure: approach by which clinician; attitude towards trial-clinician; information disclosure (oral and written); time to reconsider (between approach and final consent); methods of consent given (oral or written); discussion about the trial-participation with important others and their influence on participation ("subjective norm'). Besides these questions on the informed consent procedure, the questionnaire comprised items about general attitudes toward medical care, research and institutions; specific attitudes towards the trial-clinician; perceived benefits and risks of and barriers to participation; locus of control; health and illness perceptions and socio-demographic backgroundvariables. Concepts were operationalized using multiple 5-point Likert-scale items. To test validity and reliability of the operationalization of concepts into items, factor-analysis, reliability tests and scale-construction techniques were applied on the data. Principal Axis Factoring (PAF) and Factor Analysis by Maximum Likelihood estimation (FAML) were applied as methods of clustering. This resulted in considerable data-reduction. Intended scales were next tested for reliability using Cronbach's alpha. For almost all scales this proved to be satisfactory: alphas varied between .60 and .90 . (See: statistical and data-analytical assumptions p.56 and results of factor analysis p.73-75).

\subsection{Interviewing the trial-clinicians responsible}

To achieve better understanding of the informed consent procedure, personal interviews were conducted with all 32 trial-clinicians who obtained informed consent during enrollment procedure (100\% response). We held a one-hour structured interview after the fieldwork of on patients' questionnaires ended. Variables measured were: information disclosure, obtaining consent; attitude towards patients' comprehension of information; attitude towards medico-legal aspects of informed consent and assessment of patients' comprehension of these aspects. Physicians' opinion on informed consent was measured by items using a 5-point Likert-scale. Finally we recoded this to dichotomized categories (see table 2). We also took account of when the trial-clinicians gave a score of not relevant' regarding emphasis given to aspects of information disclosure and patient's comprehension of it during the informed consent procedure. Results from these interviews with trial-clinicians have been taken into consideration, when they provide additional insight in the informed consent process.

\subsection{Methods of data-analysis}

To explain aspects of information disclosure as perceived by patients, data were analyzed by means of: correlations, $t$-tests/chi-square statistics and path-analysis. Multivariate analysis was used to analyze the following dependent (outcome) variables: ways and content of information disclosure, time to reconsider, satisfaction and comprehension of explanatory leaflets. The presentation of the path-analysis results gives an interpretation of the correlation of each determinant ( $r$ and $p$-value) and the standardized partiall regression coefficient in the eventual path analysis (beta and $p$-value). All effects described were controlled for each other (ceteris paribus clause). All variables having path coefficients with p-values of less than .05 are presented as the basic modiel. Ve also tested for potential interactions between 'independent' variables. 


\section{RESULTS}

\subsection{Attitudes of trial-clinicians towards informed consent}

Of the 32 trial-clinicians, 30 perceive it as important that patients fully understand what trial-participation implies; 27 think their explanation about the clinical trials is comprehensible for patients, while 4 are not exactly sure about this; 25 think they can assess the extent to which patients actually understand information disclosure and 6 of them doubt their ability to do this; 27 also check whether patients understand what is going to happen before they give informed consenc, e.g. by asking if patients have any other questions or by asking them to tell in their own words what the trial will involve for them. According to 18 trial-clinicians nearly all patients ask questions of their own accord, 9 say some patients do while others do not, and 3 assert that most patients do not ask questions uninvited.

We asked trial-clinicians about their opinion on issues of informed consent which seem to be relevant from a medico-legal point of view. Adequate information disclosure is a necessary prerequisite to enable a patient to give a valid consent. Some twenty medicolegal aspects have been analyzed. Table 2 presents the trial-clinicians' interpretations of whether these issues are emphasized during the informed consent procedure and whether they expect patients to comprehend them adequately. In total 12 of the 20 medico-legal aspects are perceived as not applicable to some of the trials and therefore are not emphasized during informed consent: notably these are the frequency of control visits, measures to prevent or restrict possible harm, circumstances under which a trial will be stopped and possible risks of declining to participate. Some trial-clinicians perceived 10 aspects as not being relevant for the patients to comprehend in their clinical trial: the most salient are the same aspects just noted.

Trial-clinicians appear to be quite skeptical of patient's ability to comprehend nearly $\| 5$ aspects, such as type of study and study objective; treatment alternatives; collection of data; privacy and confidentiality of data; and the study design of the trial, including randomization and selection procedure.

On the other hand they expect to comprehend more easily aspects such as the involvement in a clinical trial, not having the regular treatment, trial-duration, name and reachability of those responsible, voluntary participation and no influence on treatment resulting from declining to participate and the possibility to withdraw from the trial at any time. 
Table 2: Attitudes of trial-clinicians towards informed consent and patient's comprehension of the aspects of information disclosure ${ }_{n}$ according to the trial-cinicians.

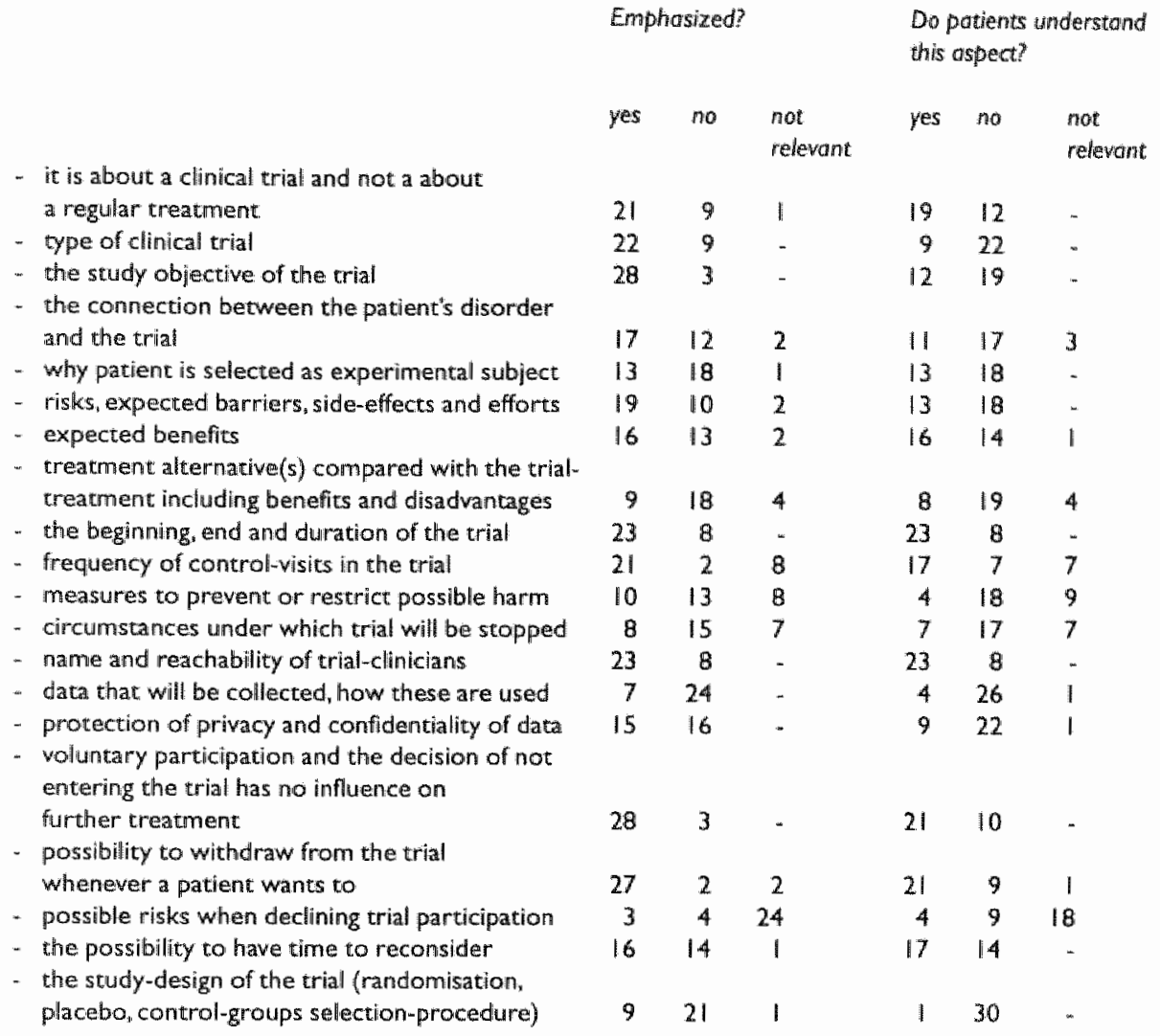

\subsection{Comparing emphasis on and comprehension of aspects of informed consent}

Some aspects which trial-clinicians expect to be understood easily by patients appear at the same time to be emphasized in the information disclosure. If a trial-clinician expects patients to comprehend each of the foilowing issues, they will also be emphasized during the informed consent procedure: the connection between patient's disorder and the trial (Chi-square $=4.99 \mathrm{df}=1 \mathrm{p}=.03$ ); why the patient is selected as experimental subject (Chi-square $=5.05 \mathrm{df}=\| \mathrm{p}=.03$ ); data being collected (Chi-square $=10.6 \mathrm{df}=1 \mathrm{p}=.001$ ); treatment alternatives (Chi-square $=6.41 \mathrm{df}=1 \mathrm{p}=.01$ ); protection of privacy and confidentiality of data (Chi-square $=6.20 \mathrm{df}=\mid \mathrm{p}=.01$ ); and the voluntary participation, in that declining has no influence on subsequent treatment (Chi-square $=3.97 \mathrm{df}=\| \mathrm{p}=.04$ ). If trial-clinicians expect patients to have more difficulty to understand one of these issues, they will not therefore emphasize the issue in the information disclosure. This seems to be the case with the data collection and the privacy and confidentiality of data, as most 
trial-clinicians do not expect patients to comprehend these issues easily.

Clinicians expect other issues, which they nearly always emphasize during informed consent, to be understood easily by patients, like voluntary participation and the possibility to withdraw at any time.

Some aspects reveal no association between the physician's perception of patient's understanding and physician's emphasis during the informed consent procedure.

We conclude therefore that trial-clinicians seem to emphasize the following aspects during informed consent or not, irrespective of their perceptions of whether patients can comprehend: the study objective; the experimental character of treatment; the type of study; risks, expected barriers, side effects and efforts expected benefits; circumstances under which a triall will be stopped and risks when declining to participate.

\subsection{Explanatory leaflets}

Twenty-eight of the 32 trial-clinicians emphasize they always provide an explanatory leaflet for the patient to read and consider, while 4 indicate that they did not always provide written information, in addition to the oral information disclosure. Reasons for not providing extra information leaflets are: the belief that their personal communication is comprehensive enowgh; forgetfulness; the experience that written information sometimes results in more questions or even uncertainty rather than in better comprehension; the feeling that the patients sometimes do not seem to want it; the belief that oral information disclosure is most important.

\subsection{Time to reconsider}

Twenty-two trial-clinicians mention giving every patient the opportunity to consider entering the trial or not, while 8 of them give time for consideration to some patients and do not mention this explicitly to those patients who apparently do not need time for consideration, but take a decision at once. The average time for consideration differs from a few minutes to half an hour, according to 5 , to a week according to 12 trial-clinicians.

\subsection{Obtaining informed consent}

None of the trial-clinicians appeared to have practical difficulties with the informed consent procedure. All trial-clinicians claim to have obtained informed consent, and assert that they never assume they have obtained consent of a patient without asking it explicitly: 25 always ask for written consent, while 6 do not do $\mathrm{SO}_{\mathrm{n}}$ after having obtained oral consent. Reasons for not asking for written informed consent are: forgetfulness of the trial-clinician; not having the consent form at hand at the moment of obtaining informed consent; the fact that it is not always possible to do so; the experience that it sometimes frightens patients; the fact that oral consent is also perceived as legally valid. Trial-clinicians also mention several reasons for obtaining signed consent (see table 3): at least in part it was obviously obtained for legal reasons. 
- it is a legal requirement $(7 x)$ :

- because it is a requirement in the protocol $(6 x)$ :

- the requirement of obtaining written informed consent by the $\mathbb{R B}(4 x)$;

- because it is a requirement from the pharmaceutical industry $(4 x)$;

- relationship based on mutual trust and matter of confidence (3x):

- is makes patients realise again what the triall will involve ( $3 \mathrm{xx}$ );

- it is an acknowledgement that you have informed the patient $(2 \times)$;

- because of insurance aspects of the trial;

- it emphasizes the patient's own decision to consent;

- it confirms that patients are willing to enter a trial;

- it makes patients aware they participate in a clinical study:

- the agreement is assigned fiormally:

- it is inherent of Good Clinial Practice (GCP).

- patients will understand what is going to happen (otherwise they should't sign):

- to inform patients lege artis.

Asked whether they perceive the signed informed consent as an adequate indicator for patient's understanding of the disciosed information and of what is going to happen in the course of the trial, 6 of the trial-clinicians respond affirmatively, while 22 do not think it is a good indicator, and 4 of them point out they hope so, but they are uncertain. So signing a consent form is not perceived as an adequate indicator of patient's comprehension of what they are signing for. Descriptive statistics on variables covering the informed consent procedure are presented in table 4.

Table 4: Physiclarns' perceptions on informed consent $(n=32)$

Query

Only recruiting patients on their own

Is patient recruitment difficulit (in-exclusion criteria)

Being patient's plyysicilan during trial

Separate infoumation session? two or mone?

Providing explanatory leaflets periceve this as relevant to do so?

Patient's understandirig of trial perceived as relewant? information disclosure expected to be understandable?

linformation disclosure dependent from patient's interest?

Do patients need time to reconsider?

Obtaining signed consent?

Adequate indicator for patient's comprehension?

\section{Yes}

12

10

12

28

9

29

17

30

27

28

24

25

6 


\subsection{Responses from patients}

Inforrnation provided by the trial-clinician. Descriptive statistics on patient perceptions on informed consent are shown in table 5 . The overall satisfaction with the oral information disclosure by the trial-clinician during the first encounter is very high: $90.8 \%(180)$ of the patients say they are satisfied about this. Participants are somewhat more satisfied about the information disclosure by the trial-clinician, in comparison with those who did not enter a clinical trial ( $t$-value $=-3.66 ; p<.001$ ). The way information has been provided is evaluated somewhat more positively by those who participated ( $t$-value $=-2.07 ; p<.05$ )

Table 5: Patlents' perceptions on informed consent $(n=198)$

$\begin{array}{lc}\text { Query } & \text { Yes } \\ \text { Being recruited by own physiclan? } & 53 \% \\ \text { Geing treated in the trial by own physiciar? } & 15.7 \% \\ \text { Knowing trial-clinician? } & 18.2 \% \\ \text { Satisfied with information disclosure? } & 90.8 \% \\ \text { Receiwed explanatory leaflets } & 58 \% \\ \quad \text { having read them? } & 81.7 \% \\ \quad \text { satisfied with contents? } & 86.7 \% \\ \text { Taking a decision at once about entering trial or not? } & 79.8 \% \\ \text { Hawing received time to reconsider? } & 62.6 \% \\ \quad \text { perceived it as important? } & 46.5 \% \\ \text { Signed consent form } & 86.3 \% \\ \text { Have comfont with right to withdraw from the trial at any time: } & 60.5 \% \\ \text { Expecting negacive implications when refusing to participate } & 94.3 \% \\ \text { Expecting physician not like it when participation is refused } & 9.3 \% \\ \text { Altrustic predlisposition } & 62.5 \%\end{array}$

The patients' evaluation of the way information disclosure was given during first approach can be explained as follows, yielding an explained variance of 39 percent. The longer the information session took, the more satisfied patients were with the way information was given during first approach $(r=-.53 ; p<.001 ;$ beta $=-.43 ; p<.001)$. Patients having a positive attitude towards medical experiments in general tended to evaluate the way the oral information was given on the clinical trial as positive $(r=30 ; p<.001 ;$ beta $=-.14 ; p<.05)$. It also appears that the higher the patient's belief in integrity of physicians doing clinical research, the more positive the perception of the way oral information disclosure took place $(r=-25 ; p<.001$; beta $=-.15 ; p<.05)$. The more interest patients had in medical subjects in general, the more satisfied they were about the way the oral information disclosure was provided $(r=27 ; p<, 001 ;$ beta $=14 ; p<.05)$. If a patient had no problems with the fact that the physician was involved in the clinical trial the attitude towards the oral information provided by the trial-clinician was more positive $(r=-26 ; p<.0001 ;$ beta $=.16 ; p<.05)$. The patient's worrying about health appears to be associated with the patient's evaluation of the way information has been provided by the trial-clinician $(r=.29 ; p<.0001)$. The more worried patients are about their health condition, the more critical they seem to be about 
the way information has been provided by the trial-clinician. If the way oral information disclosure took place is evaluated positively, the patient seems to be less worried about his or her health condition.

If a patient has talked about the clinical trial with important others, the information provided by the trial-clinician is evaluated more positively $(r=\ldots .14 ; p<.05)$. Of all patients $12.8 \%(n=25)$ talked about the clinical trial with the trial-clinician exclusively. However, $87.2 \%(n=171)$ talked it over with other people beside the trial-clinician: then they judged the importance of these people's opinion. Patients were also asked whether they felt encouraged or discouraged to enter the trial by important others. No striking differences have been found in this respect between participants and non-participants.

Written information disclosure. Of the 198 patients $58 \%$ indicated they had received written information from the trial-clinician, in addition to the oral explanation. Of these patients, $82 \%$ reported having read the written information thoroughly $11.7 \%$ indicated they had read it only globally and $6.3 \%$ said they had not read it at all. No differences were found between participants and non-participants with regard to written information disclosure (Chi-square $=.06 ; \mathrm{d} f=1 ; \mathrm{p}>0.05$ ). The extent to which explanatory leaflets were also read is also identical for both groups (Chi-square $=-28 ; d f=1 ; p>05$ ). Satisfaction with the written information disclosure is very high: $86.7 \%$ of the patients said they were satisfied with it; $11.4 \%$ gave a neutral answer (nelther satisfied, nor dissatisfied), and $1.9 \%$ reported dissatisfaction. Participants were hardly more satisfied with the written information in comparison to those who decided not to participate ( $t$-value $=-.35 p>.05$ ).

Concerning the patient's evaluation of written information disclosure, being provided by explanatory leaflets, multivariate regression analysis yields an explained variance of 17 percent. The more time to reconsider, the more satisfied a patient seems to be with the explanatory leaflets $(r=.23 ; p<.05 ;$ beta $=.24 ; p<.05)$. lit also appears that the more positive opinion a patient has towards medical experiments, the more satisfied he or she is with the contents of written information $(r=-.33 ; p<.0001 ;$ beta $=-.34 ; p<.01)$. Being interviewed as outpatient instead of inpatient $(r=21 ; p<.05)$ and perceiving time to reconsider as important $(r=25 ; p<.01)$ appear to be associated positively with the patient's evaluation of explanatory leaflets. The patient's interest in medical subjects in general appears not to correlate with the patient's evaluation of written information disclosure $(r=-15 ; p>05)$. No differences were found between participants and non-participants in their evaluation of explanatory leaflets ( $t$-value $=1.15 ; p>05$ ).

We asked patients if they could understand several aspects of information disclosure. Almost half of the patients $(44.9 \%)$, could not indicate how mary control visits would talke place during their involvement in the clinical trial they were asked for. Nearly the same percentage (42.4\%) did not know how long they would be inwolved in the elinical trial. These proportions are nearly identical for participants and non-participants alike (two tailed binomial test). No differences were found between participants and non-participants with regard to the level of understanding of written information disclosure (t-test $p>.5$ ) Analysis of the difficulty of understanding the message of the written information showed that the patient's level of education is the onlly independent variable having significant results in pathmanalysis, yielding an explained variance of 8 percent. 
The higher the level of education, the better a patient appears to understand the written information disclosure $(r=30, p<.01$ :beta $=30 ; p<.01)$. The correlation between patient's interest in medical subjects in general and the difficulty of understanding the message in the written information disclosure is not significant $(r=-.04 ; p>.05)$. Patient's understanding of the written information was identical for participants and non-participants $(t-v a l u e=-25 ; p>05)$.

Time to reconsider. Almost two-third of the patients $(62.6 \%, 124)$ reported that they had some time to reconsider participation before deciding whether to enter the clinical trial or not, while $30.3 \%$ (60) indicated they had not, and $2.5 \%$ (4) did not remember. The average time to reconsider ranged from a few minutes to more than a week. No significant differences were found between participants and non-participants regarding time to reconsider (Chi-square $=.08 ; \mathrm{df}=1 ; p>.05$ ). Non-participants had somewhat more time to reconsider in comparison with participants ( $t$-value $=-4.00 p<.001$ ). Most patients $(54.1 \%$. 107$)$ rated having time to reconsider as not important, while $29.5 \%$ (58) and $16.4 \%$ (33) evaluated it as important or very important respectively. Participants obwiously found it more important to have time to reconsider compared with non-participants (Chi-square $=11.89 ; \mathrm{df}=2 ; p<01$ ). Of the 124 patients who had time to reconsider, $77.4 \%$ thought they had had enough time to reconsider, whille $5.6 \%$ thought they had not, with $17 \%$ expressing no opinion. No significant differences were found between participants and non-participants regarding having enough time to reconsider (Chi-square $=.20 ; \mathrm{df}=1$; p $>$.05). Of the 172 patients who participated, $87.2 \%$ decided to do so during the first approach by the trial-clinician, whereas $26.9 \%$ of the 26 non-participants also made their decision during the first approach. Some of the refusals were irnmediate, but most of them occurred after reconsideration. Of all patients $17.2 \%$ indicated their intention to participate during the first approach, but din fact decided later on. No association was found between patient's "knowing the trial-clinician before the first approach for the clinical trial" and the moment of taking a decision $(r=014 ; p>.05)$. Similarly, the correlation between "being treated by own physician" and the moment of taking a decision is not significant $(r=-.04 ; p>.05)$.

Analysis of the importance of having time to reconsider yielded an explained variance of 20 percent. Patients who had more time to reconsider evaluated the time to reconsider as less important, while patients with less time to reconsider perceived it as more important $(r=-32 ; p<.001 ;$ beta $=-.21 ; p<, 05)$. Patients who take a decision at once about trial participation immediately during the first encounter with the trial-clinician perceive the time to reconsider as less important $(r=-.40 ; p<.001 ;$ beta $=-33 ; p<.001)$. Furthermore, analysis of the patient's perception of having enough time to reconsider produced an explained variance of 4 percent. The more patients get time to reconsider, the more likely patients will indicate that they have had enough time to reconsider $(r=-.20 ; p<.001 ;$ beta $=-.20 ; p<.05)$.

Oral versus written consent for trial participation. Of all 172 participants, $60.5 \%$ indicated they had signed a consent-form provided by the trial-clinician prior to the start of the trial; $33.1 \%$ did not sign such a document, so only giving oral consent, and $6.4 \%$ of the participants could not remember whether they had given written and oral consent to entering the trial. Reasons given by physicians for obtaining written informed consent are presented in table 4. 


\subsection{Explaining patient's perception of content of information disclosure}

We used correlational and multivariate analyses to determine how patients perceive risks, discomforts and benefits and which factors may influence patient perception of the content of information disclosure. Only those risks, barriers and benefits (from table 1), showing a substantial effect on the patient's choice to enter a clinical trial in the samplesurvey [5], are discussed. Numerical summaries of these findings are presented in table 6 .

Table 6: Results of correlational and path analysis on expected risks, discomforts and benefits (pairwise deletion of cases)

$\mathbf{R}$

\section{DISRISK}

INTGPHY

ALTRUIS

MEDEXP

Variance explained: 35

$F=31.69$

\section{DISTIME}

ALTRUIS

PAIN

PHARMA

MEDEXP

Variance explained: 21

$F=10.91$

\section{ADVFEEL}

EARLTR

LCCHANCE

RESPHYS

IMPORES

Variance explained: 15

$F=7.91$

\section{ADVTREA}

INTGHPY

$\mathbf{P}$

Beta

Sigt T

Variance explained: 03 .

$F=5.15$

\section{DISRAND}

MEDEXP

ALTRUIS

EARLTR

.001

.199

.0074

.193

.363

. .261

.0026

.0000

.0001

Wariance explained: 23

$F=1.4 .83$

$\mathrm{R}=$ = correlation coefficient

$P \quad=$ significance or correlation

Beta = standardized (partial) regressioncoefficient

$\operatorname{sig} T=$ significance according to the T-distribution (1 degree of freedlom (DN))
.140

.229

$-.26$

. .234

.011

$-.211$

.236

. .152

.001

.00311

.0019

.0532

$\begin{array}{lll}.05 & .210 & .0045 \\ .001 & .182 & .0112 \\ .01 & -.182 & .0259 \\ .001 & -.178 & .0260\end{array}$

$\begin{array}{rrrr}-.278 & .0001 & -.134 & .0002 \\ .406 & .0001 & .319 & .0000\end{array}$

$\begin{array}{llll}.302 & .0001 & .197 & .0088\end{array}$




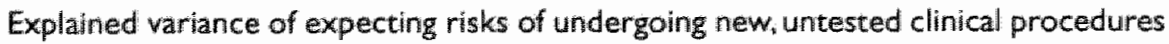
(DISRISK) amounted to 35 percent. Patients with a positive attitude towards medical experiments in general expect low risks from the new, untested (treatment) procedures during the clinical trial (MEDEXP $r=-.42 ; p<.001 ;$ beta $=-26 ; p<.001$ ). Also, patients who highly value the benefit that other patients might gain from the results of the clinical trial tend to anticipate low risks from such procedures (ALTRUIS $r=.48 ; p<.001$; beta $=.36$; $p<.001)$. It appears that the more trust a patient has in the physicians doing clinical research, the less the risks expected in the clinical trial (INTGPHY $r=-.56 ; p<.001$; beta $=19 ; p<.01)$.

Twenty percent of the variance of the expected time-involvement of the trial (DISTIME) can be explained. If parients tiust the role of the pharmaceutical industry in clinical trials, they think that the time they are inwolved in the clinical trial will be no problem (PHARMA $r=28 ; p<.01 ;$ beta $=24 ; p<.01$ ). Patients having a high confidence in medical experiments in general tend to regard their time-involvement in the trial as no problem at all (MEDEXP $r=.29 ; p<.001 ;$ beta $=-.15 ; p<.05)$. The same opinion is held by patients who highly value the possible benefits for other patients from the results of the clinical trial (ALTRUIS $r=.29$; $p<.001$; beta $=.20 ; p<.01)$. Unexpected, patients who had experienced quite a lot of pain during the previous three months consider their time-involvement in the trial as a minor problem (PAIN $r=-.19 ; p<.01 ;$ beta $=-.21 ; p<.01$ ).

Analysis of expecting better personal comfort in the trial, as compared to the nontrialiregular treatment (ADVFEEL) yielded explained variance of 16 percent. Patients having a negative attitude about their previous or alternative treatment expect more personal comfort in the clinical trial (EARLTR $r=.14 ; p<.05 ;$ beta $=.21 ; p<.01$ ). Patients who find it relevant that clinical research is being done for patient care tend to expect relatively better comfort in the trial treatment (IMPORES $r=-.23 ; p<.001$; beta $=-.18 ; p<.05$ ).

Furthermore, if patients feel relatively powerless regarding their own health condition they tend to expect low personal comfort from participating in the trial (LCCHANCE $r=.23$; $p<.00 \|_{\text {¿ }}$ beta $\left.=18 ; p<.05\right)$. Patients also having high trust in physicians in general tend to expect relatively better personal comfort in the trial as compared to the non-trial/regular treatment (IMPORES $r=-.26 ; p<.01$; beta $=-18 ; p<.05$ ).

Perceiving better personal comfort in the trial is highly correlated with the expectation of better medical treatment (ADVTREA) when participating as compared to the nontrial/regular treatment $(r=.74 ; p<.0001)$. Only three percent of this expectation can be accounted for. The more trust patients have in the integrity of trial-clinicians, the more they expect better treatment (INTGPHY $r=.16 ; p<.05 ;$ beta $=.17 ; p<.05$ ). None of the other independent variables appears to have a significant effect in the eventual model. We will comment on this later on.

Other risks, discomforts and barriers involved in a clinical trial as presented in table 1 might allso be analyzed by means of path-analysis. We give one example of this, by analyzing expecting risks of getting no treatment or only standard treatment, as a result of the randomization procedure (DISRAND), of which 23 percent of the variance can be explained. Patients who highly value the benefit for other patients from the results of the clinical trial tend to anticipate low risks of receiving no treatment or only standard treatment as a consequence of the randomization procedure (DISRISK $r=.40 ; p<.0001$; beta $=31 ; p<.001$ ). If patients have a negative attitude about their previous or alternative treatment, they appear to expect more risks in the randomization procedure in the trial 
(EARLTR $r=-30 ; p<.0001$; beta $=-20 ; p<.01$ ). Patients with a positive actitude towards medical experiments expect low risks of randomization (MEDEX: $r=28 ; p<0001$; beta $=-13 ; \mathrm{p}<.05$ ).

\subsection{Determinants of trial participation: using a patient motivation cllassification (PMC)}

Deciding to enter a clinical trial or not requires a patient to consider a variety of issues. Given the diversity of situational factors and values underlying patient's ability and willingmess to participate in a trial, a certain percentage of patients would be expected to refuse to participate. In our study we also acknowledged those patients who chose to refuse. We obtained more insight into the grounds on which some patients chose to

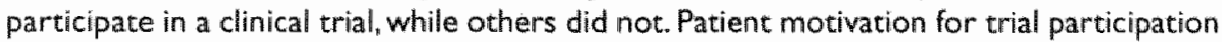
consists of an evaluation of beliefs for and against the trial, a sort of personal balance account of beliefs. Assessment of the perceived risks and barriers, compared with the perceived benefits, appears to describe the general process underlying the decision to participate in a clinical trial. Personal heaith and illiness perceptions also play a role in the choice to enter a trial or not. Motivational beliefs on the relevance in reducing the threat to one's health condition ('values") as well as the evaluations of the clinical trial the patient is approached for ("expectancy") are involved in explaining trial participation. Furthermore, this personal balance account is found to be dependent on patient opinions about medical care and caregivers in general and on the way patients regard their illness. Relatively longterm patients reveal a slightly different motivation to participate in a clinical trial than short-term patients [4].

The results of this study led us to develop for trial-clinicians a classification to explain patient motivation towards trial participation. It consists of a limited number of mutually exclusive categories on an ordinal scale, based on techniques of non-parametric scale construction (crosstabulations) to find empirical score patterns of the 198 patients. Scores have been recoded into a dichotomous rank order ( 2 classes). Only relevant factors to explain patient participation in clinical trials have been used as criteria for classification. It could be used as follows. When a patient expects low risks, motivation to enter a trial will be positive. If more risks are expected, a patient will be more likely to decline participation. Other patient expectations and perceptions on health relevant to a decision to enter a trial can also be assessed. We finally classified all respondents in three categories: patients being motivated to enter a clinical trial $(n=158)$, those not motivated to do so $(n=16)$ and an in-between group of patients who hesitate $(n=21)$. Onlly three patients were unclassifiable. When using this classification, $92.3 \%$ of our respondents could be correctly predicted in logistic regression analysis with regard to their motivation to enter a specific clinical trial or not ( $r$-squared $=.55$ ). Relevant score patterns are presented in figure 3.

In addition, an informed decision making checklist (IDC) is suggested for patients, covering relevant socilo-psychological aspects of enrollment (see table 7 below). The checklist refers to only those risks, barriers and benefits and patient's health and illnesis perceptions which appiear to have a substantial impact on patient's choice to enter a trial or not. It gives a clear account of the pros and cons of a particular trial in a language the average patient could understand. At the same time it provides the patient with an honest insight into his 
or her health and ilness state. We expected that this informed decision making checklist would enable patients to make an informed choice, when asked for a particular clinical trial.

Figure 3: Patient motivation classiffcation (PMC), to enable trial-clinicians to analyze patient's motivations of trial participation.

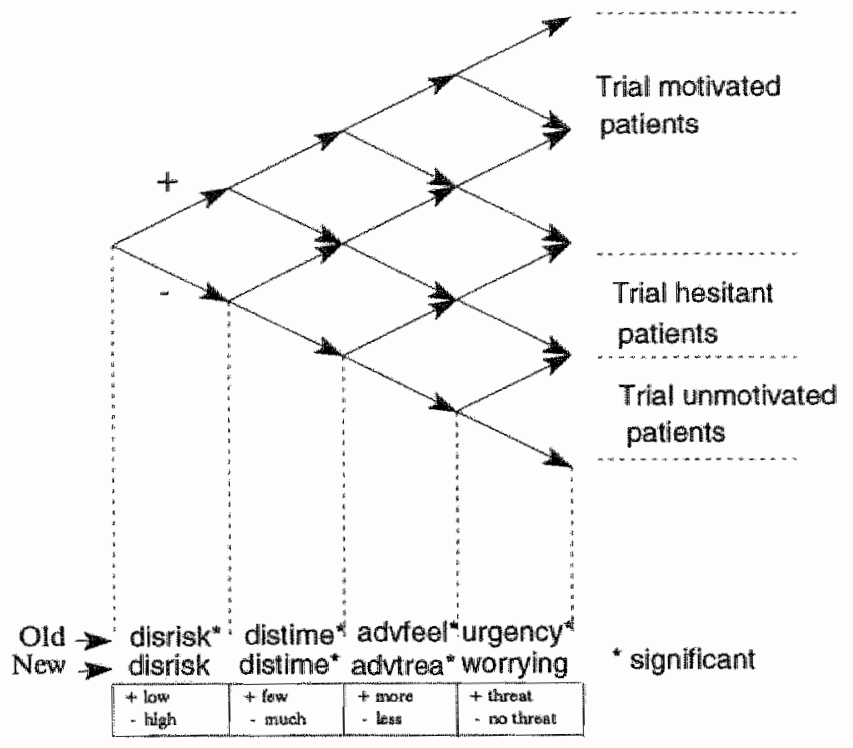

Table 7: Informed decision making checklist (IDC), to be pirowided to patients when they are being asked to enter a clinical trial.

\section{Introduction:}

explaining one is being asked for a clinical trial; information disclosure has been prowided to enable decision malking; it is important to give a voluntary consent; one is given some time to reconsider; not entering the trial has no consequence whatsoever on further treatment; one is free to withdraw at any time: confidentiality of data is guaranteed (medico-legal aspects).

Patient's statement after information disclosure

- I know my specific potient rights with tegord to entering the trial

\section{Benefits one could have}

Do you expect a better medical treatment in the clinical trial or better personal corntort in comparison with the regular, non-trial treatment?

- What was told by the trial-clinician or mentioned in explanatory leaflets about the benefits of the new clinical treatment under study? What is the purpose of the trial? Cain you expect more insight into or wetra contirol of your health? 
- What do you think about your medical treatment for your health problems up till mow? Are you satisfied with this previlous treatment?

- Do you expect a better treatment in comparison with the experiences you have had so far with regard to being treated for your health problems?

- What alternative treatment options are offered, next to the trial treatment?

Potient's statements after information disclosure

- I know the nature of procedure which is recommended

- I know whether or not there are any ather woys of treating my heolth problem

- I know what the advontages and benefits of the trial are

- I know what the prababifity of succes is

\section{Fisks in the trial}

Do you expect there will be risks involved in the treatment under study?

- What was told by the trial-clinician, or mentioned in explanatory leaflets about risks of the trial treatment under study?

- What do you know about risks of undergoing new untested diagnostic procedures or treatment in the trial?

- Do you expect the trial-clinician to be able to avoid and diminish these possible risks?

- Do you expect a risk of getting not the best treatment by undergoing a nandomisation procedure?

Patient's statement after information disclosure

- I know what the risks, disadvantages and side-effects of the trial-treatment are

\section{Barriers and other practical issues}

Do you expect the involvement in the clinical trial will take much of your time?

- What was cold by the trial-elinician, or mentioned in explanatory leaflets about extra control visits; duration of the triall; (i,e time-involvement in the trial and other limitations)

- Do you have to come regularly to the hospital, when being involwed in de clinical trial? How much time is involved in these follow up visits? What is your expected compliance with these follow up visits?

- Do you expect problems with time-inwolvement e.g because of daily-life occupations?

- Do you expect to be treated longer in the experimental treatment in comparison with the regular treatment?

Patient's statement after information disclosure

- Iknow whot the discomfarts and borriers of the trial treatment are

\section{Health and illness matters (threat)}

Do you worry abous your momentary state of health? Or do you perceive any urgency to be treated as quickly as possible with negard to your health problems?

- Do you suffer from pain?

- Do you feel ill momentarily?

- How do you perceive your severity of illness?

- Since when do you have thase problems with your health?

- How do you perceive your vulnerability in heaith condition?

Do you expect to be susceptible for the sarne health problems in next future?

- Do you feel powerless over your health and illness condition?

Other relevant issues.

- Do you have trust in medical experiments in general?

- Do you have truist in the intergrity of physicians doing clinical research?

- Do you expect that also other patients will benefit from the new treatrone being studied in the clinical triall?

Piatien's statement of ter information disclosure

- J understand all that I have been told, and I can explain it in my own words

- All my questions have been answered and I have had the the possibitity to discuss any additional cancerns 


\section{CONCLUSION AND DISCUSSION}

We have analyzed patients. perceptions of information disclosure on the clinical trial by the trial-clinician and obtained more insight into what is admittedly a subjective and qualitative interaction between patients and trial-dinicians [10]. Patients appear to be quite satisfied with the information disclosure on the clinical trial in which they are inwited to participate by the trial-clinician. With regard to the written information disclosure, only some of the patients who obtained explanatory leaflets actually read their consent forms carefully. It is possible that patients merely scan the forms because the material has already been communicated personally by the trial-clinician. As in other studies, the signed consent is not perceived as a guarantee that patients have actually understood what they have signed. A completed consent form implies only that a trial-clinician has made some effort to communicate with the patient, but its existence does not necessarily guarantee fulfilment of ethicall and legal responsibilities.

With regard to the contents of information disclosure, patients" perceptions of risks, barriers and benefits of the trial may be weighted against previous experiences and general actitudes. Patient characteristics, prior experiences with a physician or facilities and the environment in which medical care is provided may contribute importantly to patients" perceptions of the information disclosure of risks, barriers and benefits. We have seen that several factors concerning a patient's general attitude towards medical care and research may influence patient perceptions on information disclosure. Much of what a patient hear's is based on his or her past experience and beliefs about the disease being discussed.

The patient motivation classification (PMC) could provide valuable insight for trialclinicians in socio-psychological factars of enroliment, which seem relevant for patients if they ask them to consider participation in a clinical trial. The informed decision-making checklist (IDC) could be handed out to patients by their trial-clinician when providing information on a clinical trial. We suggest trial-clinicians present the list during the first appraach to patients to enter a trial. It could be filled out individually by patients during the usual time of consideration. Its use could be specified at the more specific session in which a patient gives final consent. This general outline for patient education can easily be individualized to meet specific patient needs per clinical trial. One might add, for example, questions concerning the patient's expectation of having trouble with randomization, the expectations towards undergoing extra control visits or obtaining more insight into his or her health problems. The IDC might be added to an existing hospital brochure for patients called: "When you are asked for a clinical trial' [1 I]. This brochure has been developed in the course of the sample-survey and is used at the university hospical Maastricht as a supplement to the usual oral explanation and informed consent documents when patients are asked for a clinical trial. The brochure is provided to patients by trial-clinicians during the informed consent procedure.

Follow up investigations should also determine how the informed consent procedure could be improved, taking into account socio-psychologicall factors of participation. These should be taken into consideration, when one aims to improve the quality of informed consent in clinical trials. In this respect, an important finding from the literature is that there is no evidence that an 'excessive pursuit' of informed consent will result in any 
significant increase in patient"s understanding of information disclosure [7]. Only focusing on information disclosure as an event in itself seems not to be very fruitful. In another study. Llewellyn-Thomas and coworkers indicate that patients who agree and those who refuse clinical trial entry may differ in attitudes towards decision control and the benefits associated with the trial arms, which indeed may have implications for the process of obtaining informed consent [12]. Follow-up studies should guide the dewelopment of ways to seek informed consent that will promote information understanding while avoiding the danger of systematically influencing patient's trial entry decision making [ 13]. Some implications for the practice of informed consent derived from our study are summarized in table 8.

Evaluating the patient's retention and comprehension of information during the informed consent procedure may highlight for a trial-clinician areas that may need reinforcement or further explanation. Although there is a tendency to focus om the immediate issues and options at hand in pursuing informed consent, our results strongly suggest locating this discussion within the broader context of the patient's medical history and his or her overall situation and prospects. The informed decision making checklist might be useful for this purpose during the informed consent procedure in clinical trials. In getting more insight into the health perceptions of a patient, discussion might take place regarding the personal preferences that a patient may or may not have towards coping with his or her health problems.

Additional research should evaluate the practical use of the PMC and IDC during the informed consent procedure in clinical trials. An intervention study could be set up to analyze whether the patient motivation classification is relewant for trial-clinicians. The usefulness of the informed decision making checklist as a general outline for patient education for patients should also be further analyzed. It is expected that these instruments will result in a clear and succinct informed consent procedure and enable patients to make an informed choice, when they are asked for a particular clinical trial. 
Table 6: Practice implications

Patients" perceptions on informed consent in clinical crials appears to be quite satisfactory. When efforts are made to improve the quality of iniomed consent, socio-psycholcgical factors influencing trial participation should be taken mone into account.

Suggestions have been given to improve insight in patient motivation during the informed consent procedure of clinical trials. Trial clincians might use a patient motivation classification (PMC) during the informed consient procedure, enabling them to abcain more insight into patient motivation of trial participation.

Whet risks, discomforts and benefits on a clinical trial are being enclosed to patients during the informed consent procedure, it appears that patient perceptions on information disclosure are being influenced by general attitudes on medical care, research and institutions, health and illness perceptions, the patient's self determined medical history and locus of control. Trial-clinicians should be aware of this impact on patient's personal balance account determining the decision to participate or not, when informing patients about a clinical trial.

Trial-clinicians should provide a clear and succinct information disclosure to patients, enabling them to make an informed decision to enter a clinical trial or not. For this aim, an informed desicion making checklist (DDC) has been developed, as a general outline for patient education, which easily can be individualized to meet specific patient needs per clinical trial. 


\section{Refienences}

1. Morris L. Barofsky l. Impact of risk communication on accrual, negimen, and follow up compliance $p .57-69$. In: Cramer A. Spilker B. Patient compliance in medical proctice and dinical trials. New Yorlk, Raven press Led (1991).

2. Appelbaum P. Lidz C. Meisel A. Informed consent legral theory and clinical proctice. New York, Oxford University Press (1987).

3. Lesko L. Dermatis H. Penman D. Holland I. Patients', parents' and oncologists' perception of informed consent for bone marrow transplantation. Med Podediatr Oncol 17 (1989) $181-187$.

4. Verheggen, F. Nieman, F.jonkers, R. Determinants of patient participation in clinical trials in the context of informed consent: why patients enter a clinical trial or not. Submitted paper. Maastricht, University Hospital (1995).

5. Ware J. Dawies A. Rubin H. Patient assessments of their care. In: The quolity of medical care information for customers. US Congress. Office of technology Assessment (OTA-H-386). Washington DC: US Government Printing Office (1988).

6. Cassileth B. Zupkis R. Sutton-Smith K. March V. Informed Consent - why are its goals imperfectly realized? New England journal of Medicine 302 (1980) 896-900.

7. Wear, S. Informed consent. Patient outonomy and physician beneficence within clinicol medicine. Dordrecht/Boston/New York, Kluwer (1993).

8. Mark J. Spiro H. Informed consent for colonoscopy.A prospective study. Arch Int Med 150 (1990) 777-780.

9. Meisel A. Roth L. What we do and do not know about informed consent. JAMA 21: 246 (1981) 2473-2477.

110. Sulmasy D. Lehmann L. Levine D. Faden R. Patients" perception of the quality of informed consent for common medical procedures. Special section: Informed consent in clinical practice. The journol of Clinical Ethics 5(1994) 189-194:243m250.

11. Wittebrood L.'Gevraggd voor medisch-wetenschappelijk onderzoek'(When you are asked for a clinical trial. Information brochure on clinical trials. university hospital Maastricht (1993).

12. Llewellyn-Thomas H. McGreal M.Thiel E. Fine S. Patients willingness to enter clinical trials measuring the association with perceived benefit and preference for decision participation. 50 ciol $5 \mathrm{cience}$ and Medicine 32 (1991) 35-42.

13. Simes R. Tattersall M. Coates A. Raghavan D. Solomon H. Smartt H. Randomised comparison of informed consent in clinical trials of treatment for cancer. British Medical Journal 293 (1986) $1065-1069$. 


\title{
6 Patient satisfaction with clinical trial participation.
}

\author{
FWSM Vertieggen, FHM Nieman, E Reerink, G Kok
}

Submitted for publication in adapted version.

\begin{abstract}
To assess satisfaction of patients who participate in clinical trials requiring informed consent and to analyze factors determining patient satisfaction, a sample survey was conducted with two repeated measurements (panel study). Data were obtained by means of a questionnaire. A personal interview and telephone questionnaire were used consecutively $(n=135)$, to measure patient's expectancies during the informed consent procedure and evaluation of aspects of trial participation. An additional control group of 34 patients was interviewed only by telephone.

Methodologically, satisfaction has been assessed in two distinct ways. First, satisfaction was measured as the patient's subjective evaluation of the aspects of trial participation.

Secondly, we assessed patient satisfaction by means of repeated measurements. We then compared prior expectations and subsequent evaluations. Besides this methodological distinction, we have distinguished patient satisfaction with medical-technical, interpersonal and organizational aspects of trial participation. Changes in patient's heaith and illness perceptions were regarded as confounding factors in the relation between satisfaction and its possible causes, but did not have a linear relation with patient satisfaction. Although patient satisfaction was quite high, dissatisfaction with aspects of trial participation become apparent, when both prior expectations and subsequent evaluations are compared with each other. Prior expectations and general attitudes towards medical care and research before entering the trial prove to have a substantial effect on satisfaction with aspects of trial participation. So satisfaction with aspects of trial participation can be predicted from patient characteristics before the trial thas started.
\end{abstract}

\section{Key words}

patient satisfaction; trial participation; patient compliance; clinical trial. 


\section{I.INTRODUCTION}

Little is known about whether and in which way patients are satisfied when they participate in a clinical study or trial. Although anecdotical information about the experiences of participants has undoubtedly been acquired by medical investigators "few systematic studies have been carried out on this subject. The literature on patient evaluation of medicall care and patient satisfaction in general is, nevertheless, broad in scope.A major theme has been the relationship between patient satisfaction and quality of care, and the attempts to improve medical care by taking patient evaluations into account. However, literature on research subjects in clinical studies or trials has not focused on patient satisfaction [ $1-5]$. By means of a sample survey we expected to obtain more insight into patient satisfaction with trial participation. We interviewed patients invoived in the average clinical study or trial taking place at the university hospital Maastricht. The study was designed to answer the following questions: how do patients experience and evaluate their participation in the average clinical study or trial and which factors influence patient satisfaction with a clinical study or trial?

\section{MATERIAL AND METHODS}

\section{I Study design}

Patient data in our survey were obtained by means of two questionnaires. At the start of the study or trial a one-hour personal interview focused -among other issues- on patients" perceptions of the informed consent procedure, patients' expectations of the clinical study, some general attitudes patients had towards medical care and research and their subjective notions on their health and illness condition. This interview was held within a. month after the patient had agreed to participate. Next, a telephone interview was conducted at least three months after this first interview. From a sample of 172 patients who participated in 26 clinical trials at the university hospital Maastricht, 37 patients (21.5\%) could not be interviewed by telephone. So, $\| 35$ respondents formed the database for our satisfaction survey. Apart from this, a group of 34 patients were interviewed only by telephone. These respondents had not been approached at the time of our first interview. We decided to include this control-group to test whether the evaluations and perceptions of patients during the clinical study or trial had been influenced by the first personal interwiew.

\subsection{Selection of patients and typology of trials}

Respondents were sampled from patients who between February and October 1993, had agreed to participate in prospective clinical studies or trials at the university hospital Maastricht. Patients could either be recruited from experimental (cohort) studies, from non-experimental, diagnostic studies or from a combination, provided the study was designed prospectively. The 26 clinical studies or trials in which the patients agreed to participate can be subdivided into 'purely diagnostic' and 'therapeutic' ones, studies involving "invasive" and "non-invasive' diagnostic procedures and 'drug-related" and "therapeutic" interwention studies. Hereafter we refer to all the clinical studies or trials as "clinical trial", and "purely diagnostic trials" as "diagnostic trials'. Clinical trials that patients agreed to participate in can be classiffed as follows: 5 invasive diagnostic studies (ID); 2 invasive diagnostic studies with medication (IDM); 2 non-invasive diagnostic studies (NID); 2 non-invasive diagnostic studies with medication (NIDM); 7 medication intervention 
studies (MI) and 8 therapeutic interwention studies (TI).

Of the 26 clinical trials 20 were multicenter-based; 21 were randomized controlled trials (RCTs); II of the RCTs were double-blinded. In 8 of the RCTs, a placebo-group was used. In 13 RCTs new trial treatment and regular treatment were compared.A medico-legal distinction can be made between trials with "therapeutic" and "non-therapeutic experiments", depending on the extent to which direct benefit for patients was involved [6]. Whereas the definition of a 'therapeutic experiment' entails a direct benefit for patients, a trial with no direct benefit for patients is defined as 'non-therapeutic experiments'. The latter offer benefic for future patients with the same affliction. In our survey 17 of these so-called non-therapeutic experiments and 9 therapeutic experiments were included.

\subsection{Explaining satisfaction with trial participation}

We wished to examine how patients evaluated their involvement in a clinical trial and which factors influence their satisfaction or dissatisfaction with it. This assessment is mainly related to the patient's satisfaction with trial participation: the clinical process as experienced and evaluated by patients. To assess the determinants of patient satisfaction with trial participation we used expectancies of the trial's benefits and disadvantages measured prior to entering it, general attitudes on medical care and research, and health and illness perceptions at the first interview. The second interview provided us with evaluations of aspects during the clinical trial, in addition to health and illness perceptions during participation. In figure I a model of explanation is presented. We will now describe the hypotheticall relations between dependent and independent variables in this model.

Figure I : Model of explanation for satisfaction with trial participation

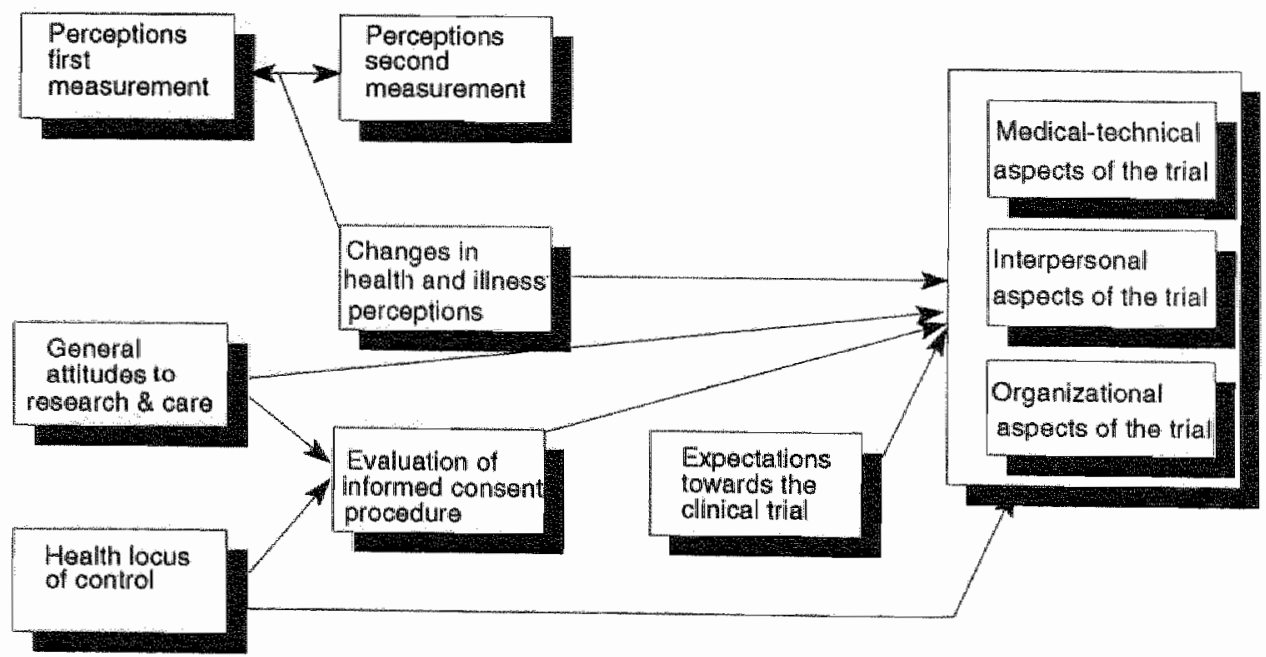


Operationally we defined satisfaction with participating in a clinical trial in two distinct ways.A first assessment of patient satisfaction entails the patient's evaluation of aspects of the trial given in the second interview. Satisfaction in this sense includes specific evaluations which cannot be anticipated beforehand, i.e. at the beginning of the trial. For instance, evaluation of waiting time, pain or unpleasant experiences during the trial can only be made, if patients have participated in the trial. Questions which refer to the patient's expectations on these matters cannot be legitimately answered. There are, however, more general aspects of the trial which can be anticipated by the patienc, such as the expectation that one will get a better treatment in the trial than standard care would provide. These types of questions formed part of the first personal interview. Patients gave their prior opinion on advantages and disadvantages of trial participation compared to the standard care they had experienced earlier, or the care they could expect if they did not participate. This second, operational type of satisfaction can be seen as the difference between a relatively high evaluation of an aspect of the trial and a relatively llow expectation, given previously, towards this aspect. Dissatisfaction then can be defined as the difference between a relatively low evaluation and an earlier expressed, relatively high expectation. So for this definition we need patient evaluations from both the first and the second interview. Satisfied patients have higher evaluations of the trial than they had expected, while dissatisfied participants have lower ones [7].

Besides the methodological distinction to assess patient satisfaction with aspects of trial participation, we have classified the dependent variable in a more substantial way, to facilitate the constructions of hypotheses. We have distinguished patient satisfaction with 1. medical-technical, 2. interpersonal and 3. organizational aspects of trial participation [B]. Given this tripartite distinction, we were interested in the following questions:

1. Are patients satisfied with the medical treatment they have received in the clinical trial? 'Medical treatment' from the viewpoint of patients may also contain all procedures necessary to make a clinical diagnosis.

2.Are patients satisfied with the way they have been treated as a patient (the so-called interpersonal aspects of trial participation)? That is, are they satisfied with the way the trial-clinician has informed them during the trial and with the behavior of the trialclinician as a person?

3.Are patients satisfied with the way organizational aspects of the trial have been handled? Have their expectations about discomforts (like efforts, or control wisits) turned out as they had expected?

4. How can we explain each type of patient satisfaction with trial participation, using patient characteristics at the first measurement (i.e before the trial has even started)? What conditions are likely to make patients satisfied or dissatisfied?

We also wanted to know whether patients actually feel better compared to the state they said they were in just before participating. We measured changes in health and illness using perceptions before and during trial participation. Did they feel or experience health 
progress by participating in the trial and by following the trial regimen? We wanted to be sure to exclude the case that patients are satisfied about trial participation for the sole reason that they see progress in their health condition, or, the contrary, that they are dissatisfied with trial participation primarily because they felt their health state has deteriorated.

\subsection{Operationalization and test-theoretical analysis}

Concepts which have been measured in the first and second questionnaires are presented in table 1. Operationalization of these concepts has been described in more detail elsewhere [9]. Alinost all concepts were operationalized using multiple 5-point Likert-scale items. To test face validity and internal consistency of the operationalization of concepts into items, factor-analysis, reliability tests and additive scale-construction techniques were applied on the data. Principal Axis Factoring (PAF) and Factor Analysis by Maximum Likelihood estimation (FAML) were applied as methods of clustering. Each intended scale was then tested for internal consistency using Cronbach's alpha. This proved to be satisfactory for almost all scales: alphas varied between .60 and .90 . Some 34 scales have been constructed from the personal questionnaire and 10 additional scales from the telephone questionnaire. Methodology in scale-construction comprises a list of rules:

- SPSSPC+ has been used (wersion 5,0).

- Painwise deletion of imissing values was applied;

- For inclusion in a factor, an item had to meet the following criteria:

- correlations $>30$ with at least one other item of the factor;

- communality within PCA and FA must be $>40 ;$

- factor loadings must be $>.50$ (PCA) and $>40$ (FA);

- the item must belong to the intended factor (unidimensionality) and mot hawe high factor-loadings on other fiactors ("simple structure: rule).

- The eigenvalue of al factor has to be $>11.0$ in PCA and FA.

- Rotation: the factor loadings matrix was always obliquely rotated (Oblimin), if two or more factors correlated $>.30$; In one case the correlation of faccors was $<30$, so an orthogonal solution has been used (varimaxil.

- For reliability tests of the scales, Cronbach's alpha was computed. Intended scales with an alpha below .60 were eliminated as unreliable. 
Table 1: Concepts measured within the model of explanation

\section{Personal interwiew}

(Ist questionnaire/before entering the trial)

\section{Informed consent procedure}

Atticude cowards the trial-clinician

Evaluation of information disclosure

Opinions on patient rights

General attitudes toward medical care, research and hospical

Trust in mredical experiments in general

Expecting benefit for future patients

\section{Expected benefits}

Obtaining insight into one' health

Obtaining extra health checkups

Better medical treatment

\section{Expected discomforts, risks and barriers}

Time-involvement

Risks of new trial treatment

Negative implications of withdrawal

\section{Health locus of control}

The subjectively defined controlability

of health problems

\section{Health and Illness perceptions}

Interest in medical affairs

Feeling ill

Perceived severity of illness

Perceived health condition now

Worrying about health

Perceived medical history

Patient socio-demographic

background characteristics

\section{Telephone interview}

(2nd questionaire/during of after the trial)

\section{Evaluation of control visits}

acritude towards the trial-clinician evaluation of information disclosure opinion on patient rights to withdraw

\section{Evaluation of benefits of the trial \\ Having obtained insight \\ Feeling secure by extra checkups \\ Evaluation of medical trial treatment \\ Perceived personal benefit}

Evaluation of discomforts, risks and barriers Unpleasant incidents:

Waiting times

\author{
Heallth and illness penceptions \\ Feeling itl \\ Perceived severity of illness \\ Perceived health condition \\ Worrying about health \\ Perceived improvement in heaith condition
}




\subsection{Methods of data analysis}

Response differences between patients interviewed twice and the control group who were interwiewed by telephone were analyzed by means of Chi-square statistics. MannWhitney tests and also by independent Student T-tests. Unless noted otherwise, numbers cited in tables of the results section are the Likert scale means of the items used. To explain both operational types of satisfaction we use separate explanatory models and different stacistical methods. To analyze "satisfaction" in the first sense ("evaluation at one moment") we used (linear) regression modelling or causal panel analysis. Regression analysis was performed to identify factors influencing this type of satisfaction. Confounding factors were the health and illness perceptions from first measurements. To analyze 'satisfaction" defined in the second manner, first differences between prior expectations and later evaluations were analyzed by means of paired T-tests. Repeated measurements analysis of covariance (ANCOVA) is the natural sequence to this. This ANCOVA can be seen as a mixed model, because it combines paired (repeated) data from both measurements with unpaired comparisons in data from the first measurement. These unpaired comparisons take place over values of the "independent" variables (the covariates) from the first measurement. In this way we can analyze the effects of more general and stable attitudes towards medical care and research before participation on satisfaction during trial participation. Changes in health perceptions between the first and second measurement, like feeling ill, severity of illness and perceived health condition were first analyzed using paired T-tests. As mentioned above, a perceived improvement in health might influence the patient's satisfaction with aspects of trial participation. This means that we have to test for the possibility that patients might becorne satisfied or dissatisfied, because they feel progress or decline in their subjectively defined health state. The way to deal with this confounding influence in analysis is a double-paired T-test using a two within factor-design in MANOVA. For descriptive analysis, satisfaction of patients in types of clinical trials was assessed using independent Student-T and chi-square tests. Trial characteristics have also been included as separate factors in regression analysis and analysis of covariance, to identify (partial) correlations with measures of patient satisfaction. All trial-clinicians involved in our survey were also interviewed $(n=32)$. Questions were asked about their views on achievable benefits of the trial treatment for patients. Results from this interview provided some additional insights into the informed consent procedure, which have been described elsewhere [10].

\subsection{Characteristics of the empirical sample}

By means of the first questionnaire 172 patients were personally interwewed. The first. interview response was 93 percent. Of these 172 respondents $135(78.5 \%)$ were interviewed again with the follow-up questionnaire. Loss of 37 patients $(21.5 \%)$ was due to three factors: 13 could not be traced, 14 dropped out soon after the baseline measurements of the trial, 6 respondents in one particular trial could not yet be interviewed and 4 respondents taking part in another trial could not answer questions due to a laryngectoimy. Of the 135 respondents interviewed twice, $37 \%$ (50) had finished the clinical trial when they answered the telephone questionnaire; $35.5 \%$ (48) had to attend trial control visits at least one more time and $27.5 \%$ (37) did not know how often they would have to attend. Of the 135 respondents, $1 /$ had to leave the trial on grounds of its rulles of exclusion and 4 patients had decided to withdraw themselves (dropouts). 


\section{RESULTS OF DATA ANALYSIS}

Patient background characteristics were compared with those of a sample from the total clinical hospital population in a recent survey on clinical patient satisfaction at the university hospital Maastricht [1 I]. Comparing both satisfaction studies, we have to bear in mind that our sample consists of clinical patients as well as outpatients. In our sample relatively more men than women could be found (2-tailed binomial test; $p<0001$ ). Respondents in our survey generally were older (Studert $T ; t=4.7 ; p<.001$ ). The mean age of respondents in our survey was $57.8(\mathrm{~s} . \mathrm{d}=13.8)$, whereas in the hospital population sample it was 51.5 (s.d=18.2). Patients from our survey also appeared to belong to the 'higher' socio-economic classes (Chi-square $=16.03 ; \mathrm{df}=5 ; p<.01$ ) compared to that of clinical patients.

\section{I Analyzing differences with the 'control group'}

Patients in the control group $(n=34)$ were somewhat more satisfied with their health condition in comparison with patients interviewed twice $(n=135)$. They were slightly less satisfied with their medical treatment and also seemed to be somewhat less satisfied with their personal contact with the trial-clinician. We have found no significant differences between both groups on all other health and illness perceptions and warious outcome measures during the trial. Results of these t-tests between both groups are presented in table 2.

Table 2: Differences between patients interviewed twice $(n=135)$ and the control group $(n=34)$, interviewed once

$\begin{array}{lll}\text { Means } & \text { Means } & \text { T-test } \\ \text { owice } & \begin{array}{l}\text { once } \\ (n=135)\end{array} & \text { t-value }\end{array}$

\begin{tabular}{|c|c|c|c|c|}
\hline \multicolumn{5}{|l|}{ Health and illness perceptions } \\
\hline Feeling ill & 4.16 & 4.21 & 23 & .821 \\
\hline Severity of illness & 3.80 & 3.84 & .21 & .830 \\
\hline Perceived health condition & 2.63 & 2.26 & -.20 & $.048^{*}$ \\
\hline Satisfaction with health & 2.48 & 2.29 & -91 & .338 \\
\hline Worrying on health & 2.81 & 2.64 & -.93 & .357 \\
\hline Perceiwed improwement in health & 3.19 & 3.41 & 1.21 & .246 \\
\hline \multicolumn{5}{|l|}{ Patlent evaluations and opinions } \\
\hline Satisfaction medical treatment & 1.60 & 1.85 & 2.09 & $.042^{20}$ \\
\hline Learnimg about health & 3.67 & 3.44 & .1 .38 & .175 \\
\hline Efforts during trial & 3.99 & 4.07 & .62 & .541 \\
\hline Felt secured by extra checkups & 4.15 & 3.94 & -1.13 & .262 \\
\hline Contact with trial-clinician & 1.58 & 1.85 & 2.44 & $.028^{*}$ \\
\hline Perceived personal benefit & 11.67 & 1.79 & .35 & .728 \\
\hline Benefit for future patients & 3.19 & 3.21 & .02 & .980 \\
\hline
\end{tabular}

* Significant difference at the 05 llevel 


\subsection{Clinical trial aspects}

Descriptive statistics on patient satisfaction with control-visits and opinions about trial participation are presented in table 3. Factors that could explain satisfaction with trial aspects according to the first definition (evaluations at one moment) will also be presented (correlations, explained variance and regression beta-coefficients). Factors which could explain patient satisfaction with aspects of trial participation following the second definition (expectancies minus evaluations) will be presented by their beta-coefficients in ANCOVA. Patient satisfaction will be measured for the following aspects of a trial:

\section{Medical-technical aspects}

- satisfaction with personal benefic

- satisfaction with the idea that future patients might benefit from the trial results

- satisfaction with medical treatment and unpleasant aspects of trial-treatment

- satisfaction with learning about one's health condition

- satisfaction with extra checkups on health

\section{Interpersonal aspects}

- satisfaction with the way information was disclosed

- satisfaction with the trial-clinician as a person

\section{Organizational aspects}

- satisfaction concerning the idea that trial participation was well worth the discomforts which had to be experienced

- satisfaction concerning the idea that participating in the trial was well worth the personal efforts made to follow it through

- satisfaction in relation to compliance to trial participation

Table 3: Patient"s evaluations on trial participation (likert scales range $\|-5)(n=135)$

\section{Control wisits}

Long duration of control wisits

Quick follow-up of contral wisits

Perceive control visits as boring

Unpleasant medical treatment

Perceive control visits as time-consuming

Experience control visits as pleasant

Annoying to get up early

Unpleasant feeling to come fasting

Control visits usually lasted longer

Contral wisits were useful time-passing

\section{Evaluations}

Obtaining more insight imto one's health

Feeling comfort by extra check-ups on health

Additional check-ups which cost much effor:

Satisfied with way of information disclosure

Positive attitude towards trial-clinician

Satisfied with personal approach of clinician

Perceived personal benefix

Perceived improvement in health condition

Satisfed with medical treatment

Anticipate benefit for future patients

\begin{tabular}{rrrrrr} 
yes & mean & st.dev & \multicolumn{4}{c}{ kurtosis skewness $\mathbf{N}$} \\
$14.8 \%$ & 3.80 & 1.01 & .50 & -.99 & 135 \\
$9.7 \%$ & 3.90 & .91 & 1.94 & -1.27 & 113 \\
$9.1 \%$ & 3.94 & .88 & .72 & -.90 & 132 \\
$3.7 \%$ & 4.23 & .80 & 3.27 & -1.41 & 135 \\
$32.8 \%$ & 3.27 & 1.31 & -1.05 & -.49 & 131 \\
$87.9 \%$ & 1.85 & .78 & 2.33 & 1.17 & 132 \\
$6.4 \%$ & 4.1 .8 & 1.07 & 1.91 & -1.56 & 78 \\
$3.0 \%$ & 4.26 & .86 & 1.85 & -1.44 & 42 \\
$17.0 \%$ & 3.80 & 1.13 & .18 & -.98 & 135 \\
$78.2 \%$ & 2.06 & .99 & 11.06 & 1.11 & 133 \\
& & & & & \\
& & & & & \\
$59.2 \%$ & 3.64 & .82 & -.63 & -.34 & 134 \\
$68.9 \%$ & 4.15 & .87 & 1.03 & -1.16 & 133 \\
$11.9 \%$ & 3.99 & .77 & 2.14 & -1.38 & 134 \\
$93.3 \%$ & 1.63 & .61 & 5.44 & 1.97 & 135 \\
$94.1 \%$ & 1.62 & .51 & 8.68 & 2.01 & 135 \\
$96.3 \%$ & 1.58 & .65 & 5.28 & 1.51 & 134 \\
$58.5 \%$ & 1.39 & .49 & -1.81 & .47 & 129 \\
$22.7 \%$ & 3.19 & 1.30 & -.86 & -.75 & 121 \\
$98.5 \%$ & 1.60 & .52 & -1.27 & -.11 & 134 \\
$60.9 \%$ & 1.87 & .68 & 1.25 & .70 & 110
\end{tabular}


Satisfaction with own personal benefit and that of future patients. We asked patients whether they experienced any personal benefit by participating in the clinical trial. Of all 135 patients, $58.5 \%$ indicated they had felt some personal benefit, and $37 \%$ said they did not and $4.4 \%$ could not answer this question. Of the respondents $22.7 \%$ experienced an improvement in their health state as a result of the dinical trial. $14.1 \%$ did not know for sure, $48.9 \%$ indicated no improvement, while $10.4 \%$ did not answer. About $61 \%$ of all participants were satisfied with the idea that the trial might be of benefit to future patients, $7.4 \%$ did not know for sure, $2.2 \%$ indicated they do not feel satisfied about this and $18.5 \%$ did not answer.

Analysis of patient satisfaction with getting personal benefit by participating in the clinical trial yielded explained variance in regression analysis of 13 percent. If patients expect the risks of the trial treatment to be relatively high, they will be less satisfied with the personal benefit they claim to have from it $(r=-32 ; p<.001$; beta $=-.26 ; p<.01)$. Furthermore, if they expect to be treated as a special kind of patient during the trial, they prove to be highly satisfied with the personal benefit they claim to have from the trial treatment $(r=-.26 ; p<.01 ;$ beta $=-.18 ; p<.05)$.

Satisfaction with medical treatment. Of the participants $98.5 \%$ indicated they were satisfied or very satisfied with the medical treatment as provided during the clinical trial, and none indicated they were dissatisfied. Satisfaction with the medical treatment correlates positively with having experienced personal benefit $(r=36 ; p<.001)$, a perceived improvement in health $(r=.24 \% p<.01)$, obtaining insight into one's health $(r=.27 ; p<.01)$ and feeling secure by extra health checkups $(r=33 ; p<.001)$. Because of the skewedness of the distribution of this variable, no further analysis could be done.

Satisfaction with the unpleasant aspects of the trial-treatment can be explained, yielded explained variance of 13 percent. If a patient feels an high urgency to be treated before the start of the trial, the medical trial treatment is evaluated as less unpleasant $(r=-.14 ; p<.05$; beta $=-17 ; p=.06$ ). Also, the more risks a patient expects from the new trial treatment, the more unpleasant the medical treatment is judged to be $\left(r=30 ; p<.001 ;\right.$ beta $\left.={ }_{n} 25 ; p<.01\right)$. And the more patients perceive their illness as severe, the less the medical treatment is evaluated as cumbersome $(r=-.17 ; p<.05 ;$ beta $=-.21 ; p<.05)$.

Satisfaction with obtaining insight into one's health condition. One of the many reasons patients may have for participating in a clinical trial is the comforting idea that it will lead to more insight into their own health and illness condition. The patient's expectation of 'obtaining more insight into his/her health and illness condition' before the trial was compared with the patient's evaluation of "learning more about his/her health and illness condition' during the clinical trial. Both items were measured in a 5-point Likert scale. This comparison leads to satisfaction with aspects of the trial according to our second definition. The difference in means turned out to deviate significantly from zero (means 4.28 vs. 3.66; paired t-test; $t$-value $=6.91: p<.0001$ ). So patient satisfaction with getting insight was rather low. Of all patients, $69.2 \%$ claimed to be relatively more disappointed about obtaining insight into their health condition than they had expected to be at the beginning of the trial, while $30.8 \%$ had higher evaluations on this than they had expected before. 
In trying to find an explanation of patient dissatisfaction with obtaining insight into ones health condition, we found that it is significantly related with the patient's 'interest in medical issues in general', the patient's "trust in medical experiments" and the "relevance of clinical research', all measured at the first interview. Patients with a low interest in medical affairs are more easily dissatisfied about getting insight into their health (beta $=-.16$; $\mathrm{p}=.053)$. If patients have a low trust in medical experiments in general, they will also be relatively dissatistied with obtaining insight (beta $=-.19 ; p=018$ ). Finally, if patients have a negative attitude towards the relevance of doing clinical research, they will also be disappointed about this (beta $=-29 ; p=.001$ ). Results are presented in table 4 .

Satisfaction with extra checkups on health condition. One of the advantages in joining a trial may be that a patient feels comforted and secure by the extra check-ups on his or her health condition. This affective evaluation was positively associated with patient"s satisfaction on medical treatment $(r=33 ; p<.0001)$, a perceived improvement in health $(r=22 ; p<.01)$ and having experienced a personal benefit by participating $(r=32 ; p<.001)$. The hope some patients expressed as registered in the first interview was compared with their later evaluation of these check-ups. The difference in means turned out to deviate significantly from zero (means $1.43 \mathrm{vs}$. 1.85 ; paired $t$-test $t$-value $=5.55 ; p<.001$ ). So, patient satisfaction with this was relatively low. Specifically, $78.8 \%$ of the patients were less satisfied with this aspect of the trial, while only $21.2 \%$ of the patients were satisfied with it. Patient"s satisfaction or dissatisfaction with extra check-ups was significantly related with the patient's evaluation of "relevance of doing clinical research", "trust in physicians in general' and 'perceived severity of illness'. If patients have a low evaluation towards the relevance of doing clinical research, they will be dissatisfied with the health check-ups $($ beta $=.17 ; p=.066)$. Patients with a relatively low trust in physicians in general will feel dissatisfied with the extra checkups on their health (beta $=20 ; p=.007$ ). Finally, if patients perceive the severity of their illness as low they will feel more dissatisfied about the extra checkups (beta $=22 ; p=.008$ ). Results are also presented in table 4.

Satisfaction with the way information was disclosed. Patient satisfaction with information disclosure is also very high $(93.3 \%)$ : only $6.7 \%$ thought that the triall-clinician should have given some more explanation. Information about their health condition was evaluated by $80.8 \%$ as "very good"; $86.7 \%$ of them mentioned that the trial-clinician had explained repeatedly what to expect during trial participation; $95.2 \%$ mentioned that the trial-clinician had answered their questions adequately. Of all 135 patients $47(34.8 \%)$ recalled that the trial-clinician had informed them about the randomization procedure for treatment in the trial and $\| I$ of these 47 patients had also been informed about the treatment which eventually had been given (placebo or noc). All but one of them had strongly suspected they had been treated with the new or non-placebo treatment. Patient satisfaction with the way of information disclosure was given correlated positively with the perceived personal benefit $(r=26 ; p<.01)$, satisfaction with medical treatment $(r=.46 ; p<.001)$, satisfaction of getting insight into one's health $(r=.47 ; p<.00 \|)$ and satisfaction with extra health check-ups during the clinical trial $(r=32 ; p<.00 \|)$. Explained variance of patient satisfaction with the way information has been disclosed amounted to 19.5 percent. The more trust a patient has in medical experiments in general, the more satisfied he or she is with the way information has been provided $(r=.29 ; p<.00)$; 
beta $=24 ; p<.01)$. If patients worry a lot about their health, they are much more satisfied about the way information has been provided $(r=.26 ; p<.001 ;$ beta $=21 ; p<.05)$. Satisfaction with information disclosure is also higher, if patients perceive their health condition as low $(r=.16 ; p<.05 ;$ beta $=.17 ; p<05)$. The higher the perceived vulnerability, the more satisfied patients are with the way information has been disclosed $(r=09 ; p>05 ; r=.18 ; p<.05)$. And finally, the more patients are generally interested in medical affairs, the more satisfied they are with the way information has been disclosed $(r=.23 ; p<.01 ;$ beta $=.16 ; p<.05)$.

Satisfaction with the trial-clinician as a person. About $94 \%$ of the respondents had a positive attitude towards the trial-clinician. Trust in the trial-clinician was very high and most favorably evaluated was his or ther friendliness (97.8\%). All patients saw the trialclinician as very competent and conscientious; $98.2 \%$ thought the trial-clinician had a high degree of control over all treatment risks during the triai. About $96 \%$ said they appreciated the trial-clinician personally. Only $5.2 \%$ of the patients said that at times they felt they were treated as a number.About $77 \%$ reported having been treated carefully and prudently in the trial; $96.3 \%$ thought that the trial-clinician had been spending sufficient time on their behalf; $96.2 \%$ thought that the trial-clinician made good efforts to make the control visits go smoothly and $93.7 \%$ mentioned that the trial-clinician was very responsive to the requests they had in these matters.

Sixteen percent of the variance of the patient's satisfaction with the trial-clinician can be explained in regression analysis. If a patient expects to be treated as a special kind of patient in the trial, satisfaction with the trial-clinician will be more positive $(r=-35 ; p<.00)$ : beta $=-.39 ; p<.001)$. And if a patient has more trust in physicians in general, satisfaction with the trial-clinician is also high $(r=-.03 ; p>0.05 ;$ beta $=-.17 ; p<.05)$. In addition, we observed a high, positive correlation between the patient's satisfaction with the trial-clinician and his sacilsfaction with the procedure of information disclosure $(r=59 ; p<.001)$.

\section{Satisfaction with the way discomforts were experienced and efforts had to be} made during the trial. Of all patients $12.6 \%$ suffered from nausea and dizziness during or after the trial treatment. Of the $\$ 7.8 \%$ of the patients who had to perform physical efforts or exercises in the course of the trial, $14(58 \%)$ found this unpleasant.About $18.8 \%$ of the patients sometimes had to maintain unpleasant bodily positions during control visits. About $23.7 \%$ of the patients said that the trial treatment was painful: 13 patients described this as "very painful", whereas 19 found it 'bearable:. With regard to drug compliance $38.5 \%$ indicated they did not have to use any drug to be cested in the clinical trial. Of those who had to. $15.6 \%$ maintained that the medicine taking was unpleasant. About $46 \%$ did not mind taking their medicine regularly. Nearly $93 \%$ of all patients had no special diet in the clinical trial; of the 9 respondents who had such a diet; 3 found this bothersome. In $82.2 \%$ of the patients blood samples were taken during the clinical trial. Only 9 of them experienced this as unpleasant; $17.8 \%$ of the patients had no experience with traving blood-samples taken during the trial. With regard to waiting time during control visits, $49.6 \%$ of all participants never had to wait, while $37 \%$ had to wait sometimes and $13.4 \%$ had to wait regularly or always. Of all patients, $50.4 \%$ had to wait at lleast once a while during participation. The length of waiting time was usually indicated to be no more than 10 minutes. Of these patients, 19 had ance to wait longer than 30 minutes; 28 of the patients who had to wait once experienced this as annoying. 
Respondents indicated that sometimes new measurements had to be redone, because things went wrong. This was reported by $16.4 \%$ of the patients; 15 of them experienced this ance, 6 twice and 1 three times. Half of them experienced these incidents as unpl easant About $24 \%$ of the patients said they had experiences during the trial which turned out worse than they expected; the same time $40.7 \%$ of them mentioned that most aspects of the clinical trial turned out better than they had expected.

Patients were quite satisfied with the hospital examining rooms where the control visits of the trial took place. About $93 \%$ found them easy to locate; $9.8 \%$ found them noisy, while only $5.2 \%$ reported that the visits sometimes were disturbed by other personnel. Only $5.9 \%$ found the room too small" $19.4 \%$ were dissatisfied with the room's temperature and about 10\% made derogatory remarks on the lack of coziness and disliked the interior of the examining room.

The time and efforts which have to be spent in the clinical triall may be one of the reasons patients may decline to participate. With regard to satisfaction with the time-involvement of the trial, patients said they spent much more time on the trial than they previously expected (3.94 vs. 3.26 mean; paired t-test t-value $=5.98 ; p=.0001)$. Comparing prior expectations with later evaluations of trouble and efforts spent, the difference in means turned out to be not significant ( 3.94 vs. 3.99 mean; paired $t$-test $t$-value $=-.67 ; p=.502$ ). So satisfaction with this aspect of trial participation was neither high nor low. Patients evaluated the trouble and efforts in the clinical trial as they expected them to be. Thus, $44.8 \%$ of the patients were not dissatisfied, while $54.2 \%$ showed some dissatisfaction about this, because they experienced more efforts in the trial than they had previously expected. The satisfaction with this aspect of trial participation was significantly related to the patient's "interest in medical affairs in general', "the perceived severity of illness" and patient's 'trust in medical experiments". If patients have a relatively high interest in medical affairs in general, they indicate they are not dissatisfied about the trouble and efforts the trial demands (beta $=-. \| 7 ; p=.045$ ). If patients perceive their severity of illness as high, they reveall less problem with time, trouble and efforts (beta $=-.16 ; p=.066$ ). Also, patients having a high trust in medical experiments turn out to have less problem with the trouble and efforts in the trial (beta $=\ldots, 19 ; p=.033$ ). These and other results are also presented in table 4 . 
Table 4: Explaining patient"s (dis)satisfaction (ANCOVA) (A low value stands for dissatisfaction, a high score for satisfaction)

\begin{tabular}{|c|c|c|c|c|c|c|c|}
\hline & $\mathbf{B}$ & Beta & SE & t-value & Sight & $\begin{array}{l}\text { lower } \\
95 \%\end{array}$ & $\begin{array}{l}\text { upper } \\
95 \%\end{array}$ \\
\hline \multicolumn{8}{|l|}{$\begin{array}{l}\text { Satisfaction with obtaining } \\
\text { insight into one's heallth }\end{array}$} \\
\hline Interest in medical affairs $(\mathrm{h}-\mathrm{l})$ & -.08 & -.16 & .041 & -1.96 & .053 &. .160 & .0011 \\
\hline Trust in medical experiments $(h-1)$ & -.12 & -.19 & .0 .49 & -2.39 & .018 &. .214 &. .020 \\
\hline $\begin{array}{l}\text { Bellieving in relevancy of } \\
\text { doing clinical research }(h-1)\end{array}$ & -.25 & -.29 & .072 & -3.49 & $.00 !$ & -.329 & -.108 \\
\hline \multicolumn{8}{|l|}{$\begin{array}{l}\text { Satisfaction with } \\
\text { extra checkups on health }\end{array}$} \\
\hline Relewancy of doing clunical research $(h-1)$ & .16 & .17 & .085 & 1.85 & .066 & -.011 & .327 \\
\hline Trust in physicians in general $(\mathrm{h}-\mathrm{H})$ & .20 & .20 & .074 & 2.73 & .007 & .055 & .347 \\
\hline Severity of iliness (h-1) & .10 & .22 & .037 & 2.70 & .008 & .027 & .174 \\
\hline \multicolumn{8}{|l|}{$\begin{array}{l}\text { Satisfaction with efforts which } \\
\text { had to be made during the triall }\end{array}$} \\
\hline Interest in medical affairs $(h-1)$ & -.10 & -.17 & .049 & -2.02 & .045 & -.197 & -.002 \\
\hline Severity of illness (h-l) & .08 & -.16 & .043 & -1.85 & .066 & -.166 & .005 \\
\hline Trust in medical experiments $(h-l)$ & -.13 & -.19 & .060 & -2.16 & .033 & -.250 & -.011 \\
\hline
\end{tabular}

Satisfaction and compliance. Almost $12 \%$ of the patients intimated they had thought at one or more moments of the trial of declining further participation; 4 of these 16 felt 'obliged' to continue participation, although they would have preferred to quit the trial. Of all patients, $91.9 \%$ indicated you should always finish a clinical trial treatment, once you have agreed to participate in it. $6.7 \%$ did not agree with this, while $1.4 \%$ did answer. During the trial only $3.7 \%$ of all patients once asked the trial-clinician for another medical treatment, $93.3 \%$ never did so, while $3 \%$ did not remember whether they had asked.Asked if they would participate again in a similar type of study, the majority of respondents indicated they would volunteer again: $88.9 \%$ said definitely yes, $8.9 \%$ said definitely no, while $2.2 \%$ wrere undecided.

Expecting megative consequences of withdrawal. In total, $30.4 \%$ of the parients believed that declining participation would have negative consequences for their health condition, 54.1\% thought this was not the case and $15.5 \%$ did not answer. There is a significant negative correlation with the consideration to decline participation $(r=-17 ; p<.05)$.

Nineteen percent of the variance of expecting negative consequences of withdrawal for one's health condition can be explained. If a patient expects that a trial-clinician will show disapprovall if participation were declined, the more he or she expects drawbacks of withdrawal on their health condition $(r=.32 ; p<.001 ;$ beta $=25 ; p<.01)$. The more a patient expects to be treated as a speciall patient during the trial, the less likely a patient expects negative consequences for his or her health condition as a result of withdrawal $(r=-.21 ; p<.05 ;$ beta $=-16 ; p=.06)$. And the higher a patient scores on the extent to which a physician exerts control over his/her health (locus of controll), the less a patient expects 
negative consequences from withdrawal $(r=-34 ; p<.001 ;$ beta $=-21 ; p<.05)$. Correlation with the feeling that withdrawal could also have a negative impact on a further medical treatment is positive $(r=22 ; p<.01)$. About $5 \%$ of the patients expected that to decline participation would have negative consequences for their further medical treatment, $86.7 \%$ thought this was not the case and $8.1 \%$ did not answer.

Analysis of expecting negative consequences of withdrawal on further medical treatment yielded explained variance of 10 percent. If atient already expects negative consequences of withdrawal on medical treatment during informed consent this will also be found during the trial $(r=.27 ; p<.001$; beta $=.20 ; p<.05)$. And if a patient expects that a trial-clinician probably will not like a withdrawal, this leads to the idea that withdrawing will have negative consequences for the further medical treatment $(r=.26 ; p<.01$; beta $=.18$; $p<05)$.

\subsection{Changes in health and illness perceptions as confounding variables}

Comparing patient's health and illness perceptions during the first and second measurement revealed that patients felt significantly less ill in the course of the trial ( 3.84 vs. 4.16 mean; paired t-test; $t$-value $=-2.36 ; p<.05)$. Patients also perceiwed a lower severity of illiness during the same period ( 2.66 vs. 2.21 mean; paired t-test; $t$-value $=3.97 ; p<.01$ ). With regard to other health perceptions no significant differences were found. These findings are summarized in table 5.

Table 5: Changes in health and illness perceptions after repeated measurement (paired T-test)

\begin{tabular}{|c|c|c|c|c|c|c|}
\hline & $\begin{array}{l}\text { Ist } \\
\% \text { yes }\end{array}$ & $\begin{array}{l}\text { 2nd } \\
\% \text { yes }\end{array}$ & \multicolumn{2}{|c|}{ Means } & \multirow{2}{*}{$\begin{array}{l}\text { T-test } \\
\text { t-value } \\
-236\end{array}$} & \multirow{2}{*}{$\begin{array}{c}P \\
.020^{2}{ }^{2}\end{array}$} \\
\hline Feeling ill (yes-no) & $19.4 \%(26)$ & $\| 1.9 \%(16)$ & 3.84 & 4.16 & & \\
\hline Severity of illness (high -low) & $507 \%(68)$ & $36.4 \%(48)$ & 266 & 2.21 & 3.97 & $.001 *$ \\
\hline Perceived health condition (good-bad) & $45.5 \%(61)$ & $51.1 \%(69)$ & 2.70 & 2.56 & 1.48 & .14 \\
\hline Sacisfaction with health (high-low) & $56.3 \%(76)$ & $55.6 \%(75)$ & 2.46 & 2.48 & -26 & .79 \\
\hline Warrying on thealth (yes-no) & $17 \% \quad(23)$ & $15.6 \%(21)$ & 2.31 & 2.19 & 1.32 & .19 \\
\hline
\end{tabular}

0. Absolute numbers in parentheses

* Sigrifficantit differences at the 05 level

Changes in health and illness perceptions turned out to be allmost linearly independent from patient satisfaction with satisfaction with all previous mentioned aspects of trial participation. No statistically significant correlations have been found. In a doubly repeaced measurement MANOVA, the paired differences between patient's expectations and subsequent evaluations remain the same, even when controlling for the generally, subjective improvement in health and illness conditions. In other words, although patients felt less ill during the clinical trial than before it, this has no impact on the patient's satisfaction with trial participation. 


\subsection{Correlative analysis for further research}

The following results can be interpreted as a tentative, exploratory analysis meant for further research on satisfaction with trial participation. They do not belong to the data analysis guided by the model of explanation. Table 6 presents some relations between 'objective' study or trial characteristics, patient health and illness perceptions and patient evaluations of aspects of the trial. 'Objective' trial characteristics are taxonometric variables like the distincrion between "diagnostic' vs. "therapeutic' trials, trials involving 'invasive' vs. 'non-invasive' procedures, "drug-intervention' vs. "therapeutic intervention' trials and randomized vs. non-randomized studies. Next, correlates between these trial characteristics and aspects of patient satisfaction will be described. Numerical summaries of including these trial-characteristics in ANCOVA and regression analysis are given in table 7.

Table 6: Characteristics of trials, associated with heailth and ilnesis perceptions and patient evaluation of trial participation (T-test, Chi-square $\mathrm{N}=169$ ).

Health and illness perceptions

Percelved severicy of illnesis

Perceived health condition

Satisfaction with thealth

Worrying about health

Evaluation of trial participation

Learning about state of heatth

Fel secure by extra heaith checkups

Satisfied with medical treatment

Perceived improwement in health

Percerved personal benefit

Decining participation

Considered to withdraw at any time

Expect consequences of withdrawal

Considering to participace again

* significanit difference at .05 level

\begin{tabular}{|c|c|c|c|}
\hline $\begin{array}{l}\text { Diagnostic }(66) \text { is } \\
\text { theropeutic }(102)\end{array}$ & $\begin{array}{l}\text { Inwasive }(74) \text { is } \\
\text { montinwasive }(94)\end{array}$ & $\begin{array}{l}\text { Drug related }(82) \text { ws } \\
\text { intervention }(20)\end{array}$ & $\begin{array}{l}\text { RCT (109) ws } \\
\text { norm-rondomised } \\
(49)\end{array}$ \\
\hline
\end{tabular}

T-tests: t-valie and $p$ walue

$\begin{array}{rrrrrrrr}-2.29 & .024 * & 2.14 & 034 * & 3.03 & .01 * & -2.07 .040^{*} \\ 2.06 & .042^{*} & -.98 & .33 & -2.25 & .05^{*} & 2.55 .012^{*} \\ 2.43 & .017^{*} & .44 & .66 & -2.97 & .01^{*} & 2.42 .017^{*} \\ -3.24 & .001^{*} & .14 & .89 & 2.64 .01^{*} & -1.98 .050^{*}\end{array}$

$\begin{array}{rlrrrrrr}.91 & .37 & 1.25 & .09 & .19 & .84 & 2.11 .040^{*} \\ 2.15 & .03^{*} & 1.82 & .07 & 1.93 & .07 & 1.90 .060 \\ -3.74 & .001 * & .06 & .95 & 1.24 & .23 & -3.07 .003^{*} \\ .66 & .51 & -1.78 & .08 & -5.69 & .001^{*} & 2.86 .005^{*}\end{array}$

Chil-square statistics

$7.78 .01^{*} \quad 1.59$

$6.31101 *$

$8.64 .003^{*}$

$\begin{array}{cccccccc}13.2 & .001^{*} & 2.24 & .14 & .24 & .63 & 5.77 & .060 \\ 8.88 & .002^{*} & 4.66 & .03^{*} & .30 & .58 & 4.15 & .24 \\ 3.64 & .056 & .002 .96 & .08 & .78 & 1.14 .28\end{array}$

Satisfaction in diagnostic vs. therapeutic trials. In comparison with patients involved in therapeutic trials $(n=102)$, patients in diagnostic trials $(n=66)$ perceive a higher severity of illness. They perceive their health condition as worse, are somewhat less satisfied with their state of health and worry more about their health. Withdrawal at any moment during the trial was considered to a lesser degree by these patients, they expect less consequences of withdrawal on their state of health and have less problem with participating again. 
Patients in diagnostic trials appeared to be more satisfied with obtaining insight into their health condition, in comparison with patients in therapeutic trials (ANCOVA b-value $=-.33$; $\mathrm{p} \ll .01$ ). Furthermore, patients in diagnostic trials are also more comforted with the extra check-ups on their health condition (ANCOVA b-value=.39; $<.01$ ). They are more satisfied with their medical trial treatment in comparison with patients in therapeutic trials $(r=32 ; p<.001 ;$ beta $=.26 ; p<.001)$ and are also more satisfied with the personal benefit they thirik they have than patients in therapeutic trials $(r=.24 ; p<.01:$ beta $=.20 ; p<.02)$.

Satisfaction in invasive vs. non-invasive trial procedures. Patients in a trial with invasive diagnostic procedures $(n=74)$ perceive their illness as more severe in comparison with those in a non-invasive trial $(n=94)$. They also fear more consequences of withdrawal on their health. Patients in invasive trials were more satisfied with obtaining insight into their health condition, compared with patients in non-invasive types of trials (ANCOVA b-value $=-, 27 ; p<05$ ). No other significant differences were found.

Satisfaction in drug related vs, therapeutic intervention trials. Patients in a medication intervention trial $(n=82)$ perceive a lower severity of illness in comparison with patients involved in a therapeutic intervention trial $(n=20)$. They also perceive their state of health as better, perceive more improvement in their health condition, are more satisfied with their state of health and worry less about their health. Furthermore, they perceive more personal benefit than those involved in a therapeutic intervention trial. Although patients in medical intervention trials are more satisfied with obtaining insight into their health, this trial characteristic did not become a significant factor in the anallysis of covariance using patient's satisfaction with obtaining more insight into one's health condition as a dependent variable. No relation was found by including this trial characteristic as a factor in regression analysis to explain satisfaction with medical treatment or perceived personal benefit. In comparison with patients in therapeutic intervention trials, patients in medication intervention trials perceived more improvement into their health condition $(r=.40 ; p<.001 ;$ beta $=.39 ; p<.001)$.

Satisfaction in randomized vs. non-randomized studies. In comparison with patients involved in non-randomized studies $(n=49)$. patients in randomized studies $(n=109)$ perceive a lower severity of illness. They perceive their state of health as better and are more satisfied with their state of health. They also worry less about their state of health and perceive more improvement in their state of health. The same patients give relatively more consideration to withdrawing during the trial. These results are also valid for patients involved in placebo-controlled trials $(n=93)$.

Patients in randomized trialls were more frequently found to have obtained insight into their heaith (ANCOVA $b-v a l u e=-37 ; p<0$ ) . They also felc more secure by extra health checkups (ANCOVA b-value $=.49 ; p<.001$ ). Patients in RCTs also say they are more satisfred with their medical trial treatment $(r=.25 ; p<.01$; beta $=.17 ; p<.05)$ and they perceived more personal benefit from joining the study $(r=.26 ; p<.01 ;$ beta $=.22 ; p<.01)$. 
Table 7: Significant correlates in analysis of variance and regression analysis between trialcharacteristics and aspects of patients satisfaction $(\mathrm{N}=135)$

B-value by trial characteristics

\begin{tabular}{|c|c|c|c|c|}
\hline & $\begin{array}{l}\text { Diagnostic (54) w. } \\
\text { therapeutic }(8) \text { ) }\end{array}$ & 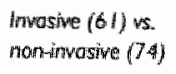 & $\begin{array}{l}\text { Medichtion }(62) \\
\text { ws theropt }(19)\end{array}$ & $\begin{array}{l}\text { RG }(7 B) \text { ws } \\
\text { now rontom }(47)\end{array}$ \\
\hline Obtainung insight into one's health & $-.33 p<.01$ & $-.27 p<05$ & NS & $-37 p<.001$ \\
\hline Feeling secured by extra health checkups & $.39 p<01$ & NS & NS & $49 p<001$ \\
\hline Satisfied with medical treatment & $.26 p<.001$ & NSS & NS & $.19 p<05$ \\
\hline Percelved personal benefit & $.20 p<.02$ & NS & NS & $.22 p<01$ \\
\hline Percewed improwement in health & NS & $\mathbb{N S}$ & $.39 p<.001$ & NS \\
\hline
\end{tabular}

Note: With regard to significant response differences no differential effects occurred with other cowariates in analysis of variance (see table 4).

Satisfaction in 'therapeutic" vs. "non-therapeutic experiments'. In comparison with patients in so-called non-therapeutic experiments $(n=80)$, patients in therapeutic experiments $(n=88)$ mentioned they had learned more about their state of health (3.39vs 3.81 mean; $t$-value $=-3.39 ; p<.001)$. They also perceive their health condition as somewhat better $(2.43$ vs 2.73 mean $t$-value $=-1.94 ; p<.05)$ and are somewhat more satisfied with their state of health $(2.22$ vs. 2.65 mean $t$-value $=2.73 ; p<.01)$.

The trial-clinicians themselves gave an evaluation of the achievable benefit of their clinical trial. They responded to the question whether their experimental treatment would work out better for their patients, compared to the regular treatment. Correlation with the medico-legal distinction of therapeutic ws. non-therapeutic experiments was very high $(r=.81 ; p<.001)$. So, not surprisingly, trial-clinicians maintain that the effect of medical treatment is higher in therapeutic experiments. In RCTs, chances of providing a better medical treatment are perceived as higher by patients (chi-square $=9.69 ; \mathrm{d} f=2 ; \mathrm{p}<.01$ ). Patients appear to be more satisfied with medical treatment in trials where a "better" medical treatment was provided (chi-square $=8.91 ; \mathrm{df}=4 \mathrm{p}=.06$ ). They also found more improvement in their health condition in these trials (chi-square $=12.60 ; d f=6 ; p<.05$ ) and they are more satisfied with their state of health (chi-square $=20.88 ; \mathrm{df}=8 ; \mathrm{p}<.01$ ).

No association was found between the trial-clinician"s assessment of expecting to provide a 'better' medical treatment and patient evaluations of perceiving better personal benefit $(r=-.027 ; p>05)$. So patient views on the expected benefits do not comply with the physician's point of view of providing a better medical treatment (chi-square $=13 ; \mathrm{df}=2 ; \mathrm{p}>\mathbf{0 5}$ ).

\section{CONCLUSIONSAND DISCUSSION}

We have studied patient satisfaction with several aspects of clinical trial participation and searched for factors related to it. We have used two distinct methods to assess patient satisfaction with clinical trial participation. First, satisfaction can be seen as a subjective evaluation with aspects of trial participation. This is the usual definition for satisfaction in literature. Secondly, we have assessed pacient satisfaction with aspects of trial participation 
by means of the methodology of repeated measurements. Thus we have compared prior expectations with subsequent evaluations. Satisfaction is defined as the difference between an evaluation during the trial and a previously given expectation before the trial. We maintain that dissatisfaction will become more clearly visible, when expectations before entering the trial and subsequent evaluations during the trial are compared with each other. Measuring patient satisfaction by means of repeated measurements is an important tool within the longitudinal assessment of a quality assurance program [12].

Besides this methodological distinction to assess patient satisfaction, we have classified it in a more substantial way according to aspects patients encounter in a trial. Patient: satisfaction and quality of care are both defined as multifaceted and multidimensional concepts [12]. We have made a distinction into satisfaction with medical-technical, interpersonal and organizational aspects of trial participation.

Satisfaction with medical-technical aspects of the trial-treatment was high among patients. Most of them perceived a personal benefit or felt an improvement in their state of health as a result of trial participation. Satisfaction appeared to be rather low with obtaining insight into their health state and with the comforting idea patients may have by getting extra health checkups. In our wiew, satisfaction with these aspects may be improved by informing patients during control visits more explicitly about the results of health checkups and about the possible impact of the trial treatment on their state of health. Patients were also satisfied with the way they were treated as a patient, the so-called interpersonal aspects. This includes the way information was disclosed and the extent to which they felt comforted as a patient during the trial.All patients showed a highly positive attitude towards the trial-clinician.

We have found that adverse patient experiences did not occur very often with regard to the organizational aspects of the trial. These concern matters like nausea, dizziness, making unpleasant physical efforts or maintaining unpleasant physical positions for longer spells during control visits. Patients generally did not evaluate it as a problem, when blood samples were taken or when waiting times at control visits were long. Patients hardly expect negative consequences of withdrawal from the trial for their health condition or for follow-up medical treatment. Comparing expectancies and evaluations with time and efforts spent in participating in the trial revealed that satisfaction was neither high nor low.

Satisfaction with trial participation can be explained and predicted from patient characteristics before the trial has evein started. General attitudes on care and medical research, like trust in medical experiments in general, the patient's belief in the relevance of doing clinical research and patient's interest in medical affairs in general are relevant in this respect. Secondly, health and illness perceptions before entering the trial are also important. Suffering from pain, the perceived health condition, the perceived severity of illness and worrying about health can be used to predict patient satisfaction during the trial. Thirdly, the patient's expectations of the trial also have a substantial impact on satisfaction, such as the feeling of being treated as a special kind of patient within the trial and the expectation to feel better under trial treatment than under regular care. These characteristics together explain between 10\% to $20 \%$ of the variance of satisfaction with trial participation. In other studies, variance explained in satisfaction has also been found not to exceed the 10\% [7]. Some other studies fail to find a relationship between 
expectations and patient satisfaction [14]. Although expectations are believed to be one of the primary determinants of patient satisfaction, we also find little evidence to suggest that: satisfaction can be seen as a result of fulfillment of expectancies alone.

In analysis by repeated measurements we found that patient perceptions of health and illness have significantly changed. Patients did feel better during the trial compared to the state they had said they were in just before participating. Patients felt considerably less ill and their perceived severity of illness was significantly lower. This change in health and illiness perceptions may, however, also be caused by other interventions or incidents apart from the patient's participation in a clinical trial. Sometimes patients obtain different treatments at the same time for the same affliction, or have more than one health problem for which they are being treated.

No relation could be found between changes in health and illness perceptions and the patient satisfaction with aspects of trial participation. Although patients evaluated several aspects of trial participation as rather low, given their prior expectacions, they generally perceived an improvement in their health condition. In a survey of elderly psoriasis patients, self-perceived changes in health status turned out to be a weak, but significant causal determinant of satisfaction with medical treatment [15]. Studying this relation in our hospital-wide sample with a variety of clinical trials, we have found a non-significant relation between changes in perceived health status and patient satisfaction with aspects of trial participation. Clearly, measures for satisfaction are not the same and the observed relation in the psoriasis study was rather weak. This may explain the differences in results.

Separating individuals into compliant and noncompliant ones is usually based on arbitrary criteria [16]. When clinicians use the term 'suspected non-compliance', they refer to their subjective, prior estimation of refusals and drop-outs of patients who enrol in a clinical trial. The reasons for patients to withdraw from trial participation in the course of a clinical trial will be related to their dissatisfaction with aspects of trial participation. "Suspected non-compliance" will therefore naturally be related to factors having an impact on patient satisfaction, as assessed in our survey. Determinants of patient satisfaction we have found could be useful in obtaining a more objectively measured insight into the notion of 'suspected non-compliance'. Of course, this idea still requires further study in follow-up research. Pre-entry patient categorization to pinpoint possible problems with compliance can be used to estimate the chances of early drop-out from a clinical trial. Prospectively designed studies on compliance behavior with baseline measurement and periodic determination of motivations, expectancies and levels of satisfaction are needed for future research [1].

Finally, correlative analysis of our data suggests that trial characteristics may be relevant for the analysis of patient satisfaction with trial participation. In particular the distinction between diagnostic vs, therapeutic trials and randomized vs. non-randomized trials should be of interest. We found that patients in diagnostic trials and RCTs appear to be more satisfied with many aspects of trial participation. When researchers analyze and explain patient satisfaction with trial participation this differentiation could be taken into consideration in follow-up studies. 


\section{Peferences}

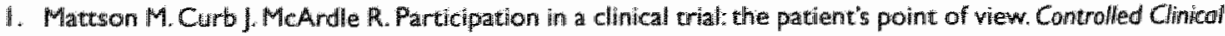
Tricts: $6(1985) 157-167$.

2. Gotay C.Accrual to cancer dinical trials: directions from the research literature Social Science ond Mediche $33(199 !) 569-577$

3. Llawellyn-Thomas H. Patients. whilligness to enter clinical trials: measiuring the association with perceiwed benefit and preference for decision participation. Social Science and Medicine 32 (199/1) 35-42.

4. Kaufmar, C. Informed consent and patient research. Sociol Science and Medicine 21 (1983).

5. Dudiey H. Informed consent - issues for the 1990s. British Journat of Urology 68 (1991) 561.564.

6. World Medical Assembly. Dechoration of Helsinki. Recommendations guiding physicians in biomedical research irvolwing human subjects. 1964, last amendment in Hong Kong (1989).

7. Linder-Pelz, S. Towards a theory of patient satisfaction. Socid Science and Medicine 16 (1982) $577-582$

8. Donabedian A The quality of care. How can it be assessed? Jounol of the Americon Medical Associotion 12 (1988) $1743-1748$.

9. Verheggen F. Nieman F Jonkers R. Determinants of patient participation in clinical trials in the context of informed consent: why patients enter a clinical trial or not. university hospital Mastricht. Submitted $(1995)$.

10. Verheggen F. Jonkers R. Kok G. Patient's perception on informed consent and the quality of informaticin disclosure in clinical trialls. university hospital Maastricht. Forthcoming (1996).

11. Mejfer W. Nienan F. Carpay J. Satisf ction of Clinical Patients at the uniwersity hospital Maastricht (1994).

12. Cleary, P. Mel, B. Patient satifaction as an indicator of quality care. In: The challenge of qualifo. L. Wyszewianstki (ed.). (special issue) Inquiry $25,33-48$ ( 1988$)$.

13. Zastowny T. Stratman W.Adams E. Fox M. Patient satisfaction and experience with health services and quality of care. Quolity Management in Health Care 3, 50-61 (1995).

14. Williams B. Patient satisfaction: a walld concept? Socid Science and Medicine 38 (1994) 509-516.

15. Hall J. Milburn M. Epstein A.A causal model of health status and satisfaction with medical care. Medical Care 31 (1993) 84-94.

16. Haynes R. Dantes R. Patient compliance and the conduct and interpretation of therapeutic trials. Controlled Clinvical Trials 8 (1987) $12-19$. 


\title{
I Concluding remarks.
}

\author{
Accepted for EFQM-publication ' 12 FreshViews on TQM' in adapted version
}

In these concluding remarks we will focus upon the understanding we have acquired by the sample survey into what is admittedly a subjective and qualitative interaction between patients and trial-clinicians. The aim of this study has been to obtain insight into how informed consent in clinical trials actually works in daily practice and to focus upon practical problems in providing adequate information and obtaining consent when patients are asked to participate in a clinical trial. Understanding the distinction between what might be called myth and reality of informed consent is relevant for assessing how it could be improved in daily practice. Yet, some questions still remain to be answered. The study was designed to answer the following research questions:

1.On which grounds do patients choose to participate in clinical trials and what are the reasons for some of them not to participate in a clinical trial?

2. How do patients experience and evaluate the information disclosure on the clinical trial as provided by the trial-climician and which factors influence the patients" evaluation of information disclosure?

3. How do patients experience and evaluate their participation in a clinical trial and which factors influence patient satisfaction with clinical trial participation?

We analyzed informed consent in clinical trials from a patient's point of view, by focusing upon patient motivation towards trial participation, patient's evaluation of information disclosure and patient satisfaction with trial participation. We hope to have provided useful insight into the way informed consent in clinical trials should be fulfilled, when analyzed from a patient's point of view.

We assumed that patients were able to give the reasons behind the choice and were guided by relatively stable attitudes and perceptions during their decision-making process. The patients' ability to answer our questionnaires was perceived as an indicator of this presumption of the patients' competence.

\section{Combined use of research perspectives}

Different research perspectives from Health Sciences have been used to answer research questions. Determinants of trial participation were analyzed by using behavioral modeis from social psychology (chapter 4). The quality of information disclosure next was evaluated from a patient's point of view, using patient education as a research perspective (chapter 5). Furthermore we applied quality assurance to assess patient satisfaction with clinical trial participation (chapter 6). Medico-legal aspects of informed consent were taken into consideration when answering research questions in the sample survey. The different research perspectives generated different assumptions and hypotheses towards the research questions in the study. This multidisciplinary approach was useful in the sample 
surwey to obtain insight into myth and reality of informed consent in clinical trials, by analyzing medico-legal aspects of informed consent, determinants of patient's motivation to participate or not, patients" perceptions of information disclosure, and satisfaction with trial participation.

\section{Informed consent: myth or reality?}

We have discussed what we have called the myth and reality of a rational decision-making and deliberate consent, implying an informed consideration, assessiment and patient choice. As we should realize that the "basics" of rational decision-making are not always met in daily practice of medical treatment and research, informed consent might be considered to be an ideal in the nature of a myth. By "Myth" we mean that some underlying principles of informed consent are considered more or less as indisputable ideology but seem to lack foundation. From a medico-legal perspective there are a number of myths in the principle of informed consent in clinical trials:

- the implicit assumption of competence is a prerequisite for a patient to partake actively in medical decision-making;

- the prerequisite thereby enables an individual person to make a voluntary and deliberate decision about trial participation;

- this decision to participate or not in a clinical trial and to undergo medical treatment is assumed to be primarily based upon information disclosure which is understood by the individual patient:

- and when several conditions are met when disclosing information and obtaining consent, the individual person's autonomy would be emphasized in the process of informed consent.

Modern medicine has made room for the informed consent doctrine and has recognized the right of patients to consent to and refuse certain kinds of treatment. Trial-clinicians and other professional workers in health care are increasingly under an obligation to provide adequate information disclosure and to obtain informed consent from patients prior to involwing them in clinical trials. In recent years, informed consent has also been specified in more detail in the health care legislation. In the Dutch law informed consent has been exempliffed in (draft) legal rules to emphasize patient rights in the medical treatment (Medical Contract Act) and protect human test subjects participating in clinical trials (Medical Research with Human Beings Bill). The implicit assumption which is expected to be fulfilled by following these regulations is the active involvement of patients in medical decision-making. However, our findings in the sample survey show that it is not realistic to assume this to be enough to fulfill the ideals of informed consent in daily practice. The legal doctrine of informed consent in clinical trials to date must be seen as insufficient to fashion a model of informed consent which is effective in daily practice. Also, the distinction between informed consent and its requirements in regular treatment and in clinical trials is not as clear as has been assumed in the law. Appeals to the patient's right of self-determination from the common law and legal vision of informed consent alone do not adequately enable patient involvement in medical decision-making. An adequate informed consent procedure requires additional interpretation of its legal requirements. Anallying the myths of informed consent reveals the existence of the following realities: 
- information disclosure is only one of the many factors which appear to be relevant in the patient's decision-making process of entering the trial - it appears not to be a determinant explaining trial participation;

- patient's evaluations of medico-legal requirements of informed consent are not considered as reasons to participate or not in a clinical trial;

- trial-characteristics, like the patient's perception about the expected drawback caused by the randomization procedure, have no direct influence on the participation rate.

- in addition to their perception of benefits, risks and discomforts, patient's perceptions towards health and illness are also relevant regarding the decision to partake in a clinical trial or not:

- some general attitudes towards medical care, research and institutions appear to have indirect effects upon trial participation, just as does the way patients are coping with their health and illness condition.

- patients' prior experiences regarding their health condition and more general attitudes towards medical care, research and institutions may also contribute importantly to their perceptions of information disclosure; prior experiences and general attitudes also have a substantial effect on patient satisfaction with trial participation;

- in actual trial situations as in our sample-survey, many fewer patients tend to refuse trialparticipation than in hypothetical situations;

- a sligned consent is not a valid indication that patients actually have understood the disclosed information;

- patients" perceived improvement in health condition shows no association with patient satisfaction with trial participation.

Despite the legal imperative of informed consent, some clinicians may be discomforted by or remain lukewarm about the process of informed consent. The need to obtain informed consent has sometimes been considered as a barrier for patients to obtain the necessary medical treatment or an entry into clinical trials [1]. Ask a physician what informed consent is and often the response will be 'a fiction", "a legal or bureaucratic obstacle for appropriate patient care", or "a signature on a consent form". Reasons for this are that they question whether the patient really will be informed, whether patients consent freely or under a certain duress caused by their situation of illness. Some of these criticisms come from those who are designated to provide patients with information in daily practice. Informed consent is unlikely to be successful if those who employing it have strong doubts about it. The tendency to treat informed consent as a mere legal obligation constitutes an obstacle to effective informed consent and can create barriers to the reception of transferred information [2]. Some other barriers towards adequate informed consent may be the following.

1. Although informed consent is ubiquitous in medicall practice, patient autonomy in medical decision-making is not always supported [3]. In some cases, patients indeed tend to be more passive participants to therapeutic decision making or may not communicate reservations about undergoing treatment within the confines of a clinical trial. Informed consent thus may be perceived as a fiction, masking a much simpler reality, that of the patient who decides whether or not to place trust in the physician's judgment. Instead. the idea of informed consent suggests that mutual agreement must be earned through 
conwersation, assuring that both physicians and patients 'profess'. If not conducted adequately, the process of obtaining informed consent could seem an elaborate ritual, a device that, when the subject is uneducated and uncomprehending, confers no more than the semblance of propriety on human experimentation [4].

2.The patient-doctor relationship is much more complex and contains more than simple information exchange. Patients do not go to a physician simply to be informed about their disease and the treatment options available. Patients come to physicians to resolve their problems and to be reassured. Their prime concern is not to be involwed in complex decision-making processes but to get necessary treatment and care [5]. Patients often do not understand or appreciate information regarding risks; they misassess probabilities; they are influenced by the precise way in which the physician presents information; and their anxieties, created by illness, get in the way of comprehension [6]. Empirical stuidies also suggest that as a result of illness, patients tend to feel they have to do what the doctor suggests, to become less aggressive in seeking alternatives, and to become inert out of a sense of powerlessness in the face of massive technical information [7]. Patients are likely to be quite sick and at least under stress. Sometimes their vision is blurred. Patients can be frightened or may feel extremely dependent on their physicians. Coerced initial or continued participation in a trial can always threaten the patient's autonomy. We went into more details of these kinds of impediments in chapter 2. These might limit the presumption of patients' comprehension and competence when obtaining informed consent in clinical trials.

3.Also, information overload diminishes rather than enhances comprehension [8]. Presumably no one would require that a patient must know as much as his or her physician about their condition and options. The effectiveness of communication is diminished by the provision of too much information. Too much information can simply overwhelm the patient, but too little information can leave the patient with an unrealistic or impoverished sense of the choices he or she is supposed to be evaluating. Studies hawe shown that relevant information disclosure may not be remembered by a sick, anxious and sometimes frightened patient. Illness has physical, cognitive and emotional sequelae and decision-making abilities can be undermined by emotional distress and diminished capacities [2]. Physical and emotional efforts of sickness may alter patient's perception, interpretation, understanding and retention of the information offered in the informed consent procedure, but this does not disqualify patients from an entitlement to proper informed consent. The aim should be to inform, not to bewilder or terrify.

\section{A basic assumption underlying informed consent is that most patients are sufficiently} capable of understanding, ewaluating and making decisions about their medical situation and prospects. The law presumes that the adult patient is competent to participate in decision-making and give informed consent. Even if the patient's actual cognitive and decision-making capacities are marginal, this presumption tends to sustain. An individual is competent to consent or refuse treatment so long as the individual understands the information needed to give informed consent [9]. An indicator for the patient's capacity to exercise autonomy might be the ability to consider different options and understanding a decision at hand $[10]$. The legall perspective also presumes that most 
patients are sufficiently capable of performing such an evaluative task, if only they are given adequate information. Reality shows that these assumptions towards informed consent do not always come to the fore in daily practice. It is, for example, not the information disclosure alone that is relevant in the decision-making process of a patient to participate or not in a clinical trial. In the present sample survey we have shown this, specifically for the decision-making process with regard to patient participation in clinical trials.

There is no evidence found in the literature that an "excessive pursuit" of informed consent will result in any significant increase in patient"s understanding of information disclosure [8]. Several studies of informed consent have demonstrated that how information is presented to and perceived by patients infuences the decision made or preference expressed. More needs to be known regarding the mast effective strategies for presenting information to elicit preferences and decisions in keeping with the individual's value system. The role of patient's preferences in the decision-making process is poorly understood. Also, relatively little is known about the factors that influence patient's treatment decisions or the role that information plays in decision-making.

5. When decision-making is regarded as a rational process, communicative interactions between individuals are thought to involve primarily the exchange of information. An obvious examplle of this point is the stress placed on information disclosure in the legal doctrine of informed consent, that tends to make informed consent an event racher than a process. Informed consent involves more than the mere transfer of information from physician to patient. Informed consent as a process can be seen as furthering numerous goals, including the development of patient-physician relationship, the protection and enthancement of patient autonomy and the encouragement of cooperation and compliance on the patient's part. Informed consent also involves the exchange between physician and patient, of the meanings attached to illness and to particular medical interventions. Without such an exchange of meanings, many of the barriers to informed consent will remain hidden, and therefore troublesome [2].

\section{Obtaining insight into informed consent to improve its functioning}

The results of the survey have been presented in separate sections, one questioning patient motivation and reasons behind the choice (chapter 4), one focusing on patient's evaluation of information disclosure (chapter 5) and one assessing patient satisfaction with trial participation (chapter 6). The sample survey provides valuable insight into what aspects are most relevant for those who consent, what are the concerns of those who decline trial participation, the patient's satisfaction with information disclosure and the extent to which they are satisfied with trial-participation. What can be derived from these findings in order to improve informed consent in clinical trials and its functioning in daily practice?

When the aim is to improve the quality of informed consent in clinical trials, socialpsychological determinants as identified in this sample survey should be emphasized as well as legal requirements of informed consent. Regarding the many considerations patients might have towards trial treatment and participation, we have found a few sociallpsychological determinants to be relevant for patients to decide to participate in a 
clinical trial or not. These briefly can be summarized as follows. In accordance with the Health Belief Model, both motivational belliefs on the relevance in reducing the threat to the patient's health condition (values") as well as the evaluations of the clinical triall the patient is approached for ("expectancies") are relevant in explaining patient behavior towards trial participation. Besides the perception of risks, benefits and discomforts, the patient's pierception towards health and illiness is also relevant regarding the decision to partake in a clinical trial or not. For 'old cases' these determinants are: the subjectively defined risks by undergoing new, untested diagnostic procedures or treatment in the trial; the patient's evaluation of the expected time-involvement in the crial; the patient's ewaluation of better personal comfort in participating in the trial, compared to that of the pre-trial treatment or the expected regular treatment and the perceived urgency to be treated immediately or as quickly as possible. For "new cases" determinants are the patient's evaluation of the expected time-involvement and expecting a better treatment in the trial, compared to the pre-trial or regular non-trial treatment. Some general patient's beliefs turn out to have an indirect effect upon trial participation, like the opinion the patient has of medical experiments in general, the patient's attitude to his or her pretrial treatment and the locus of control. Several health and illness perceptions also seem to have indirect effects upon trial-participation, like patients' suffering from pain, interest in medical affairs and worrying about health.

With regard to the evaluation of information disclosure, patients' prior experiences and more general attitudes towards medical care, research and institutions may also contribute importantly to their perceptions of risks, barriers and benefits. Much about what a patient hears is based upon his or her past experience and general beliefs about the disease, such as: their trust in medical experiments, their belief in the integrity of physicians doing clinical research, their value of benefit that other patients may gain, their attitude towards their earlier treatment and their interest in medical subjects and locus of controll.

Prior expectations and general attitudes towards medical care and research and health and illness perceptions before entering the trial as mentioned above also have a substantial effect on patient satisfaction with trial participation. While some of these factors inhibit, others may improve patients' satisfaction. Satisfaction was rather low with regard to obtaining insight into one's health state and with the patients" comforting idea they may have with getting extra health checkups. Patient satisfaction might be improved with those aspects by informing patients during control visits more explicitly about the results of health checkups and the possible impact of the trial treatment on their state of health.

It looks as though a signed consent is no valid indication that patients actually have understood the disclosed information. A completed consent form implies only that a trialcliniclan has made some efforts to communicate with the patient. When informed consent documents are used, this should be seen as the eventual outcome, no more no less. Also, the practical use of explanatory leaflets in combination with oral information disclosure should be reconsidered, as not all patients read written statements carefully. Written information can be used as an adjunct to verbal information, but is of secondary importance as a remembered source of information [40]. 
Several "tools" have been suggested, to obtain additional insight during the informed consent process, like a Patient Motivation Classification (PMC) which might be used by trial-clinicians and an Informed Decision Making Checklist (IDC) which could be useful as a general outline for patient education. Suggestions about the practical use of the PMC and IDC have been given in chapter 5. These efforts to contribute support to practice might be helpful in the daily practice of informed consent in clinical trials. Trial-clinicians are recommended to use the PMC, concerning patient's motivation towards trial participation. Also, the IDC, which also covers relevant socio-psychological aspects of enrollment, could be applied when obtaining informed consent. Besides the dewelopment and use of checklists to be used for evaluating research protocols (e.g. Good Clinical Practice and EORTC guidelines), Institutional Review Boards (IRBs) could play an important role when introducing practice guidelines towards informed consent applicable to human research subjects. IRBs could stimulate the use of the PMC and IDC and provide these instruments to trial-clinicians. Health educators could be involved in developing such practice guidelines and checklists and evaluate their use in daily practice. The PMC and IDC for which we provided preliminary outlines should be developed for further uise in daily practice and be analyzed in follow-up research.

Effective informed consent requires efforts to identify common barriers and the development of strategies for overcoming these barriers found in patient, physician. disease or institutional factors [2]. These barriers to informed consent may impede or impoverish the informed consent process or undermine one of the basic patient capacities needed, for example understanding, evaluation, deliberation and choice. Strategles aimed at dismantling the barriers that seem most amenable to effective interventions, like impediments of competence and autonomy, must be developed and tested empirically.A crucial option that also has to be pursued is that of devising effective procedures for improving the process of informed consent. These procedures should take into consideration the barriers that hamper the process as well as the array of potential strategies that may work for different patients. Specific interventions should enable trialclinicians to employ strategies, like those we have suggested to improve informed consent. Finally, the dismantling of these barriers is critical to improving further improving such procedures for which our model of intormed consent may be useful as a general outline. When evaluating the effectiveness of specific interventions in the process of informed consent; tike the PMC and IDC, we should assess whether these suggescions also lead to improvements, validate the relative importance of barriers of effective informed consent, establish the relative effectiveness of specific strategies and interventions and develop specified models to enable effective informed consent that may, with appropriate changes. be translated in other medical contexts and patient-physician situations [2]. Suggestions for further research concerning these issues will follow next. 


\section{Suggestions for further research}

Important lines of inquiry that should be addressed in follow-up research are the following:

\section{Patient motivation and trial participation}

- To analyze the use of the patient motivation classification (PMC) by trial-clinicians

- To explore the association between trial characteristics and patient participation (including prestratified design in old and new cases).

\section{Information disclosure and informed consent}

- To analyze the use of the informed decision-making checklist (IDC) as a general outline for patient education, aiming to involve patients in medical decision-making.

\section{Satisfaction with trial participation}

- To analyze the impact of trial characteristics on satisfaction with trial participation, in particular with regard to the typology of diagnostic vs. therapeutic trials and randomized ws. non-randomized trials.

- To analyze whether "suspected non-compliance" can be explained by those factors which have an impact on patient satisfaction with trial participation.

\section{Competence and autonomy to consent}

- To develop a 'test of competence' for practical use by trial-clinicians when obtaining informed consent.

- To assess impediments and encumbrances towards competence and autonomy during the process of informed consent.

\section{Patient involvement in medical decision-making}

- To assess how patient involvement in medical decision-making cam be beneficially increased when obtaining informed consent and how to support this adequately and to what extent.

The topics under the first three headings focus upon follow-up studies regarding the research questions in our sample survey. In the conduct of such follow-up research, measurements instruments which have been developed in our sample survey could be used in a shortened, adapted version, to analyze determinants of trial participation, to evaluate the quality of information disclosure and to assess patient satisfaction with trial participation in other settings. Determinants of trial participation in trials with healthy volunteers could, for example, be analyzed to assiess how information disclosure could be supported in these circumstances. An interesting point would also be to analyze differences between determinants of treatment choice in regular treatment settings and those we have found in this study towards clinical trial treatment.

The topics under the two latter headings refer to issues for empirical research, which were not addressed in our sample survey. Based upon our findings, however, it seems relevant to emphasize them in the future research field of informed consent. 
These suggestions for follow-up reseanch are addressed to health services researchers (4.1 to 4.5), clinical \& social scientists, such as epidemiologists (4.1 \& 4.3), ethicists (4.4), clinical psychologists (4.4) and health educators (4.2\& 4.5$)$, in collaboration with trialclinicians and Institutional Review Boards.

\section{I Patient motivation and trial participation}

Is the PMC applicable for trial-clinicians, when abtaining informed consent in clinical trials?

Regarding patient motivation and trial participation, an intervention study could be set up to analyze how the patient motivation classification could be used to be most relevant for trial-clinicians. Our main interest in the first part of the sample survey was to analyze patient motivation towards trial participation, focusing on informed consent from the patient's point of view (chapter 4). It is reasonable to assume that patient beliefs can explain patient behavior. The way patients perceive the clinical trial they are asked to participate in, then, will merely be influenced by their motivation. Our model of explanation was based upon social-psychological determinants. In follow-up research it: would be interesting, to explore the association between trial, organizational, environmental, physician and hospital factors which might affect trial participation and patient"s decision-making process. Such contextvariables could be added to the extended $H M B$, to the extent that one might hypothesize these to have a substantial impact on trial participation. In our study it appeared that some trial characteristics, such as patients" perception about the expected drawback caused by the randomization procedure, in the end proved to have no direct influence on the participation rate.

Which association can be found between trial characteristics and patient participation?

The relatively small number of non-participants in the complete sample survey did not enable us to analyze determinants per clinical trial or per types of trials. No differential causal analysis could be provided. A study on the possible impact of trial characteristics on the patient's trial participation would require another type of prestratified design, for instance an intervention study (prospective cohort study). Such a research study could only focus on a selected group of patients or a specific type of trial, which would make the eventual results only generalizable for a small population. The behavioral distinction between 'sick-role' and 'illiness-behavior' according to the HBM does not fit with a stratification of clinical trials based upon trial characteristics. Both behaviors may occur in patients in one and the same clinical trial. This could be analyzed further in additionall research. We then would also suggest incorporating stratification of respondents in old and new cases within the survey design to find replications of our results. 


\subsection{Information disclosure and informed consent}

Is the IDC useful as a general outline for patient education and can it be developed to be used as a decision aid for potients during the informed cansent process?

To improve the quality of informed consent we have set up an Informed Decision-making Checklist (IDC) which could be used as a general outline for patient education, to assist in handing the informed consent procedure in clinical trials in a clear and succinct way. We expect that this IDC then would enable patients to make an informed choice, when asked for a particular clinical trial. We have made suggestions in chapter 5 to add this checklist to a leaflet called "When you are asked for a clinical trial", which is awailable at our hospital as a supplement to the usual information disclosure when patients are asked for a clinical trial. This patient brochure has been developed in the course of the study, following analysis of the quality of written explanatory leaflets.

The practical use of the Informed-Decision-making Checklist (IDC) should be analyzed further, aiming to involve patients more in medical decision-making. The IDC should also be tested in its application as a decision aid during the informed consent process in a particular trial situation. As a general outline for patient education it would be widely applicable to patients with different clinical characteristics. The IDC can easily be individualized to meet specific patient needs towards information disclosure. As a decision aid in a given clinical trial situation, it may be helpful to provide specific information in ways that are tailored to the particular patient's characteristics and are focused on particular treatment cholces. Health educators could be involved in the selection of essentiall information and the preferred mode of presentation when developing the IDC as a decision aid for patients. In analyzing how the IDC may contribute to the patient's decision-making process, relevant issues are the evaluative study design being used, which outcome measures are used to evaluate effectiveness (cognitive, affective, behavioral) and what covariates are considered to be measured at a baseline before the intervention is introduced, like age, level of education and patient's preference of participating in treatment decisions [1 II].

\subsection{Satisfaction with trial participation}

Do differences in satisfaction occur between types of trials and how can these differences be explained odequately?

In reference to satisfaction with trial participation, correlational analysis suggests that some trial characteristics may be relevant for the analysis of patient satisfaction with trial participation, in particular with regard to the typology of diagnostic ws. therapeutic trials and randomized vs. non-randomized trials. We found that patients in purely diagnostic trials and in RCTs are more satisfied with most aspects of trial participation. When patient satisfaction with trial-participation is analyzed and explained in follow-up studies, this difference could be taken into consideration. 
Is it possible to explain non-compliance by using determinants of potients satisfoction, derived from patient choracteristies before the trial has even storted?

During our analysis of patient satisfaction we have made suggestions to obtain additional insight into so-called "suspected non-compliance". When clinicians use this term, they refer to the estimation of refusals and dropouts who enrol in a clinical trial. Participant compliance or adherence is an important aspect in the conduct of a clinical trial $[12,13]$. Behavioral processes impact on a trial at each of its phases beginining with planning and going through recruitment, informed consent, selection for participation, adherence to protocol, and outcome assessments [14]. When physicians are concerned that the relationship with their patients could be compromised by enrollment procedures, they may selectively approach only those patients who they anticipate will not have difficulty with the ensuing relationship [15]. Separating individuals into compliant and noncompliant ones is usually based on arbitrary criteria [16]. The reasons for patients to withdraw from trial participation in the course of a clinical trial might be related to the lack of satisfaction with aspects of trial participation. "Suspected non-compliance" therefore will naturally be rellated to factors having an impact on patient satisfaction, as assessed in our survey. Determinants of patient satisfaction we have found could be useful to obtain a more objectively measured insight into the notion of 'suspected non-compliance'. This issue still requires further studying in follow-up research. Pre-entry case categorization to analyze the possible problems with compliance can be used to estimate the likelihood of early withdrawal from a clinical trial. Prospectively designed studies on compliance behavior with baseline and periodic determination of motivations, expectancies and levels of satisfaction as the trial progresses could examine predictive relationships with compliance behavior [17]. Others have also used patient background problems to determine early termination in a clinical trial, such as patient's doubt about his or her diagnosis, questioning the need for medication, perceiving one's own schedule as too complex for follow-up visits, lack of a social suppiort system to help to identify study-related problems and being overly concerned about the randomization or double-masked process [18].

Research on the effectiveness of educational and behavior strategies to improve compliance suggests the need to combine the analysis of measurement, the extent and determinants of non-compliance [19]. To date, compliance research has been dominated by the perspective of the health professional. To better understand compliance behavior, the patient's decision-making process and the reasons for these decisions should also be examined [20].

Compliance research also lacks conceptual rigor, producing studies without regard of a conceptual framework [20]. Methodological flaws have included design features and study execution. The Health Belief Model is conceptually consistent with decision analysis and behavioral decision theory and could be followed in studying compliance [21]. The variables central to this model include perceived susceptibility and severity of a disease or condition, barriers and benefits to action, a cue to action and general health motivation. When analyzing compliance behavior according to the HBM, perceived barriers appear to be the most powerful predictor of thealth behavior, followed by vulnerability, benefits and severity, in descending order of power [22]. 


\subsection{Competence and autonomy to consent}

Is it possible to develop o "test of competence" for proctical use by trial-clinicians when they are obtoining informed consent?

How can one adequately assess impediments and encumbrances towards competence and autonomy during the process of informed consent?

Assessing patient's competence and judgement about the content of a clinical trial is one of the problems of informed consent. Adequate investigation of patient autonomy and competence when asked to enter a clinical trial seems difficult to realize. The competence to consent depends on a patient's ability to understand the relevant information necessary to reach a decision, to deliberate about the disclosed information and to formulate and express the final decision at hand [23]. Competence may be perceived as a prerequisite for the principle of respect for the patient's autonomy [24], denoting the capacity of a person to exercise the right to selfdetermination. This principle maintains that persons have the right to chart their own course and make their own decisions. Respect for autonomy engenders a positive or affirmative obligation in research, medicine and health care to disclose information and foster autonomous decision-making [25]. Several factors of autonomy are relevant, such as the ability to identify one's own desires and to assess what constitutes one's own best interest. Interesting empirical issues in this respect have been stated already, such as whether autonomy is diminished by effects of disclosure and the state of illness. We should strive not only to stimulate physicians to check for this, but also to remove the impediments to autonomous choice such as incompetence, cognitive and emotional encumbrances. We should then analyze ways to obtain insight into competence and autonomy, and also how these insights might be applied in the clinical trial process by trial-clinicians. When patient's competence and autonomy is assessed, questions of the following kind could be considered: is the patient aware of his or her condition and circumstances? does the patient understand the issues to be decided (testing cognitive function)? can the patient process the relevant information, consider the available options and choose rationally [10,26]? Assessment of competence and autonomy and its impediments and encumbrances should be incorporated in the suggested model of informed consent, which has been presented in chapter 2 .

\subsection{Patient involvement in medical decision-making}

How can potient involwement in medical decision-making be beneficially increased when obtaining informed consent? How to support this adequately and to whot extent?

Informed consenc has been proposed to encourage patient participation in medical decision-making, requiring the necessary information on which to base judgements. The intended effect of informed consent requirements may be denoted as a shift of the locus of medical decision-making and authority from clinician to patient [27]. The objective is not to steer the patient to the 'right' treatment option; rather, it is to enable the patient to make an informed decision in conjunction with his or her physician. In a shared medical decision-making process both physician knowledge and patient preference are taken into 
account [28]. A rational choice of treatment then also depends upon what the patient wants. The traditional emphasis in medical decision analysis on the question 'what is best', is then supplanted by "who decides' [29]. Supporting collaborative decision-making would be laudable goal in this respect.

The literature about shored decision-making is evolving and expanding. There is an accumulating body of evidence that patients tend to report strong preferences for having information. While previous research has supported the desire of patients to be informed, studies also suggested that patients are less willing to participate in medical decisionmaking. The research literature indicates that preferences about participating in treatment decision-making and trial entry vary widely, depending on the clinical situation and characteristics of the patient [11]. For the majority of patients, their desire to make decisions declines as they face more severe illness [30]. Patient's decision-making and information seeking are not necessarily linked, although the two are correlated. Patients want to be adequately informed and knowledgeable about their medical care without necessarily becoming responsible for medical care decisions [31]. Patients may express their autonomy by opting not to take the ultimate decisions, although they want information about their illiness as to why one treatment is recommended as opposed to another. However, it may be important to help patients learn a more active role and to encourage them to participate in decision-making [32]. Patients who wish to be involved in decision-making should clearly be enabled to do so. Decisional support could help patients to ask questions and involve them in the decision-making process. A number of recent findings indicate that patients involwed in the decision-making process tend to be more satisfied with their decision. In the dinical context, some efforts have already been made to emphasize the importance of patient involvement in medical decision-making [33]. Innovative communication tools like interactive shared decision-making programs (SDPs) are being developed through which patients can learn about their medical conditions and the treatment options available to them [28]. SDPs have been developed with regard to surgery in early stage breast cancer and need of adjuvant therapy, benign prostatic hyperplasia, mild hypertension and low back pain [32,34]. A considerable amount of work is underway to evaluate the use of such programs to help patients with treatment decision-making.

Patient decision supports, or decision aids describe choices and outcomes, using probabilities tailored to the patient's particular clinical profile. They aim to assist in clarifying values, augmenting decision implementation skills, identify patient's information needs and provide information relevant to choices so that patients can participate in treatment selection. Decision aids may also reduce emotional distress by enhancing patients" personal control over difficult situations, leading to improved patient outcomes. The use of decision aids may lead to effective decision-making in which patients make informed choices. An important issue is the selection of information to be presented in a decision aid. There are differing points of view about the relative importance of items of information about treatment protocols, side effects and anticipated treatment outcomes [11]. For each of these, there are other associated issues. What types of benefits should be described? Should probabilities be described in numerical, verbal or graphic form? And also: what is the preferred mode of presentation? There are many formats used in this kind of work. These include decision boards, interactive wideadiscs, personal computer 
programs and audiotape-booklets [35]. Each of those decision aids has associated tradeoffs regarding costs, time, portability, the ease of updating, with new information and the ease of constructing an individualized value-clarification component for a particular patient's clinical profile [11]. Value clarification can help patients who are unclear about the relative degrees of importance of the attributes in a decision and the implicit tradeoffs they will be making in selecting an alternative.

Supplementary decision aids fall roughly into two groups. One group includes those decision aids in which the patient rather passively receives a "bolus" of information in a standardized sequence [35]. This would include tape-recorded material, brochures and consent forms, for example the leaflet "When you are asked for a clinical trial' and the Informed Decision-making Checklist (IDC), developed in the study. In the second group of decision aids, the patient actively acquires the information in a individualized sequence. These include interactive video discs [34] and personal computer programs [35]. The incorporation of a value-clarification component seems easier in such a second type of individualized interactive format, than in a more standardized linear format of a decision aid [36].Vivid information presented on a computer screen may attract the respondents' attention to a greater extent than the same information presented in an oral or written form [37]. Regarding the process whereby the respondents gain the information, they also can control the pace, sequencing, and periodic review of the detalled 'bits' as they are fitted into the overall outline of the problem [35]. Interactive video discs have been primarily developed for treatment decisions rather than clinical trial entry [38]. Comparative effects of an interactive personal computer program and audio tape recorded material in providing clinical trial information has only been assessed to date in one efficacy study, concerning a hypothetical trial-situation [35]. Its result suggests that teaching with interactive approaches might not adversely affect trial accrual, but further work involving an actual trial entry decision is warranted.

One of the few published instruments related to decision-making is the development of a Decisional Conflict Scale (DCS). This scale elicits the patient's uncertainty in making a healthrelated decision, factors contributing to the uncertainty and perceived effective decisionmaking. The DCS has been evaluated among individuals deciding about influenza immunization and breast cancer screening and has met acceptable standards of reliability and validity [36]. The DCS is available to analyze if patients are certain about their decision ("it is clear what choice is best for me"), if they believe their choices were informed and consistent with their personal values (I am aware of the choice; I feel I know the benefits, risks and side-effects; or I need more advice and information about the choices") and anticipate sticking to their decision (I feel I have made an informed choice and I am satisfied with it'). It appeared that patients' high decision uncertainty is correlated with feeling less informed about options, risks and benefits and being unsure of values in making the decision. The DCS requires further testing for responsiveness to change during the informed consent process. A related measure is the Satisfaction With Decision scale (SWD), which correlates moderately with the DCS. Both constructs may be considered distinct, but related [39]. These are important measures of patient perceptions of the data and choices made. They are crucial to decision supports and could be used to test whether such aids improve patient's involvement in medical decision-making. More research is needed to explain the dynamics of patient decision-making as well as to 
develop outcome measures for decision aids [39]. Further work in this area might profitably pursue the relationship of desire to participate in decision-making and satisfaction with the decision. Comparison between our IDC, proposed for use in informed consent procedures in clinical trials, and the DCS for use in regular treatment choices show interesting resemblances, which require further analysis in follow-up studies.

The ideal of increasing patient participation in medical decision-making can be difficult to achieve in practice [19]. The question is how actively a physician should pursue patient participation and encourage reflection and choice. This depends on factors such as the significance and poignancy of the choice, the patient's degree of interest or aversion to participate in it and the degree to which the choice at hand can be meaningfully and adequately rendered to the particular patient. The extent to which patients wish to participate in decision-making thereby can be considered as a continuum: to relinquish, share or retain control over treatment decisions [40]. At one end, patients may prefer to leave all decisions regarding treatment to their physician (a passive role). In the middle, patients prefer to share responsibility with their doctor for deciding which treatment is best (a collaborative role). At the other end patients prefer to make the final selection about treatment they will receive (an active role). These three levels of desired involvement may have unique -although not necessarily mutually exclusive- information needs. If patients express a preference for active or collaborative involvement in decisionmaking, they probably want a greater amount of detailed information about illness and treatment than patients who which to relinquish decision-making to their physicians [41]]. Patients who are assertive, express more concerns and ask more questions conceivably acquire more information than less verbally active patients do. Such features of the patient's communicative style may elicit information disclosure. Physicians' perceptions of patient's information needs and requirements thereby may influence their informativeness. More systematic enquiry is needed to evaluate the process of giving patients unbiased choice and whether patients" preferences are influenced by the illness, its stage or the nature of risks involved in different treatment options [40]. The relationship between the degree of involvement in treatment decisiom-making, its impact on disease progression and psychological well-being is not well understood. Treatment decision-making role preferences may differ depending on factors such as illness severity and disease progression. The psychological impact of offering choice should be evaluated, in particular to identify conditions in which it may be associated with increased distress. Also, the long. term consequences of involving patients in decision-making needs to be understood. Several other factors are also likely to affect patient's decision-making. Patlient's preferences may for example be influenced by their attitudes and beliefs based on previous experience. The degree to which patients may participate in dinical decision-making may also vary depending on how complex the treatment choices are [2]. The potential for patients to exercise control seems greater in situations with clearly defined treatment options. Patients may gain a sense of controll over their iliness by playing a more active role in treatment decision-making. Patients" feelings of control over their health may also increase if they perceive that their needs for information have been satisfied [4|]. The inwolvement in decision-making also depends on how a patient is informed and feels about the probabilities of outcomes and about certain consequences of alternative therapeutic approaches [42]. The nature of the risk and benefit involved in different treatment options 
may also influence decision-making. The extent of information disclosure and explanation on the trial usually is proportional to the invasiveness of the trial procedure, with reasonable restraint for the simplest and safest diagnostic and therapeutic procedures. Different levels of disclosure may be required for different levels of risks. Sometimes important decisions must be made in the face of considerable uncertainty. It seems easier to explain procedures in which the choice is either to go ahead or to do nothing than trial procedures for which there are multiple alternatives, with subtle differences among them. The foregoing questions need to be addressed in research pragroms, aiming to unravel the intricacies of these relationships in communicative processes. They may direct behaviors of health care professionals who finally have to determine the kind, detail and amount of information to share with patients. As patients differ in the amount and type of information they want, and in the degree to which they wish to participate in decision-making, physicians need to be responsive to the wishes of individual patients [40]. The standard of adequacy in informed consent therefore may differ according to the context or the purpose for which consent is obtained.Additional empirical research could help in developing and testing methods for improving collaborative medical decision-making. It is important to evaluate the benefits of such participation, to identify the barriers to this participation and to develop and assess approaches to overcome these barriers. The effectiveness of decisional support also needs to be determined through clinical investigations. This seems a promising field of quality-of-care research, which also could be adopted when involving patients in the decision-making process and offering choice with regard to clinical triall participation.

When obtaining informed consent, some underling principles in the assessment of the patient-physician relationship should also be taken into consideration. Emanuel and others have distinguished four models of the patient-physician relationship: a poternalistic, informative, interpretive, and deliberative model [43]. Different models may be appropriate under different circumstances."The debate about patient involvement has sought to pinpoint the location of the right to make decisions on the continuum between selfdetermination and paternalism.

Paternalism, one of self-determination's contrary siblings, implies surrender of decisionmaking to the will of others. Physicians generally agree that the traditional paternalistic model is untenable as an ideal and only has applications in situations where the time to inform the patient delays the onset of urgently needed care. It is widely recognized that the paternalistic model is only justified during emergencies when time taken to obtain informed consent might irreversibly harm the patient [44]. Interventions based on this limited beneficence or paternalism can be justified, when signs of nonautonomy occurs, such as incompetence to perform certain tasks, lack of understanding and lack of voluntariness, and people are at risk of harm or lloss of benefits to themselves [25].

The informative model depicts the role of the physician as providing a patient with all relevant facts about the patient's case and executing the interventions that the patient selects. In this model "patient's autonomy is maximized and its conception is patient choice and control over medical decision-making. 
The third, interpretive, model is where physicians provide patients with relevant information to elucidate the patient"s values and what he or she actually wants. Physicians then act as advisors and coumselors for patients; the concept of autonomy becomes mixed with that of patient self-actualization.

In the fourth model, the deliberative model, physicians once again provide the relevant information and they use suasion to influence the patient's decision about what they should aspire to do. The conception of autonomy is moral selfdevelopment; the patient is empowered not simply to follow unexamined preferences or examined values, but to consider, through dialogue, alternative health-related values, their worthiness and their implications for treatment.

When obtaining informed consent in clinical trials the choice between one of these models depends upon the decision at hand. The ideal decision-making process is generally agreed to contain several elements, including the recognition that a decision is needed, the awareness of alternatives and their consequences, the ability to assess these consequences in terms of utilities and the freedom and the ability to implement a choice [45]. In reference to this ideal, previous models can be compared by evaluating their particular conception of patient autonomy, conceived as the patient's capacities to reflect about contemplated choices and their control over medical decisions. Choice that enhances autonomy thereby may be perceived as choice that is meaningful for individuals and allows them to express and develop their own individuality [46]. In the medio-centric view of the paternalistic model, a seemingly imbalanced physician-patient relationship occurs when patients are sick and seek security or when medical decision-making requires the interpretation of complex, technical information [33]. The physician then decides what is in the patient's best interest and patient autonomy is subordinated to the physician"s perception of the patient's wellbeing. Some, however, raise questions about whether the health professional could be expected to know what will promote the best interest of the patient [47] or can be trusted to act only in the patient's best interest. Instead of a "physician-based" standard for informed consent, the informative model is grounded in bioethics, urging the empowerment of patients to control their own care, and has become dominant in legal standards of informed consent. In terms of a shared decisionmaking, the informative model, in which authority and medical decision-making power is wested within the patient, is found by many "arid" [42]. The informative model presupposes that persons possess known and fixed vallues. However, people are often uncertain about what they want. The interpretive model rectifies this deficiency by recognizing that persons have the capacity to reflect on their wishes and to revise their own desires and preferences. Finally, the deliberative model recognizes that freedom and control over medical decisions allone do not constitute patient autonomy. Autonomy requires that individuals critically assess their own values and preferences, determine whether they are desirable and then be free to initiate action to realize the values. This model also implies the highest standard of competence. Patient involvement in decision-making is consistent with this deliberative model, which assumes that a choice should be based upon critical evaluation of existing medical evidence and on patient values for outcomes [39]. The physician with a caring attitude is the ideal embodied in the deliberative model [43]. The model of informed consent presented in chapter 3 , coming forward to prerequisites of a delliberative model, 
provides the necessary foundation for improving the process of patient-physician communication. Its features present a more elaborate view on decision-making. The role of communication is stressed, acknowledging that informed consent requires more than the exchange of information. Decision aids thereby could also support processes of communication and decision-making.

In new legal requirements in the Dutch context towards the quality of care (The Quality of Care Institutions Bill), health care institutions are obliged to provide responsible care, which is at least effective and efficient, but also patient-oriented and in accordance with realistic needs. These latter requirements also generate interest in understanding how patients make decisions. The importance of patient's participation in the decision-making process is acknowledged and has been the focus of increasing incerest. Patient involvement in medical decision-making might be perceiwed as one of the needs in an era of assessment and accountability, also referred to as the third revolution in health care [48]. In this latest paradigm, we can no longer afford to provide health care without knowing more about its successes and failures. Variations in medical practice have led to new research programs to define better the effectiveness of therapeutic interventions [42]. Some evidence already exists that an active patient role in medical decision-making contributes to improved medical outcomes by better matching treatment with patient values and needs [49]. Educational interventions to involve patients more actively in personal decisions about their care might have impact on therapeutic choices [50]. The decision-making process is also influenced by the extent of knowledge about the advantages and disadvantages of different treatment options available [40]. For some clinical situations, there is an extensive knowledge base, although the interpretation of data may vary widely between physicians. However, in other clinical situations the relative value of different treatment options is less well documented or known. How can patients make choices without information-yet can doctors make any better decisions on their behalf? When assessing medical effectiveness and improving medical practices, potential benefits might be derived from better information for physicians and also for patients in making decisions. If information about: the probable outcome of tests and treatments is known by patients as well as by providers, the risk of decision-making in the face of uncertainty can be shared in a more truly "informed" consent [28]. Such shared decision-making would seem basic to fostering the trust and mutual understanding requisite for the development of subject-clinician relationship [2]. In this way, informed consent can contribute to the quality of the subjectclinician relationship. 


\section{Refierences}

1. Peckham M. Informed consent ethical, legal and medical implications for doctors and patients who participate in randomized clinical crials. British Medical Joumal 286 (1983) $1117-1121$.

2. Coles W. Peters A. Wear S. Teaching informed consent. In: Hart I, Harden R. Further developments in assessing clinical competence. Montreal: Can-Heal Publications Inc. (1987) 241-270

3. White W. lnformed consent ambiguity in theory and practice. Journal of Heath Policy and the Law 8 (1983) 99-119.

4. Ingelfinger F. lnformed (but uneducated) consent. New Englond Journal of Medicine 287 (1972) 465-466.

5. Silverman W. The myth of informed consent: in daily practice and in clinical trials. Journol of Medical Ethics 15 (1989) 6 11.

6. Shatz D. Randiomized trials and the problem of suboptimal care: an overview of the controversy. Cancer Investigation 8 (1990) 191-205.

7. Meisel A. Roth L. Towards and informed discussion of informed consent: a review and critique of the empirical studies. Arizona Low Review 25 (1983) 265-346.

8. Wear S. Informed consent patient autonomy and physicion beneficence within clinical medicine. Dondnecht: Kluwer (1993).

9. Howe E. (Editorial) Approaches (and possible contraindications) for enhancing patient's autonomy, The Journal of Clinical Ethics 5 (1994) 179-188.

10. Annas J. The Right of Potients. The basic ACLU guide to potient rights. Humana Press Totowa, New Jersey (1992).

II I. Llewelly-Thomas H. Patients' health-care decision-making: a framework for descriptive and experimental inwestigations. Medical Decision Making 15 (1995) $101-106$.

12. Vander Stichele R. Measurement of patient compliance and the interpretation of randomized clinical trials. Eur J Clin Phormacol 41 (1991) 27-35.

13. Rimer B. Participant enrollment, participation and compliance in chemopreventive trials: $111-1117$. In: The Biology and Prevention of Aerodigestive Tract Cancer, edited by G. Newell \& W. Hong, Plenum Press, Nlew Yark (1992).

14. Leventhal H. Nerenz D. Leventhal E. Love R. Bendena L. The behavioral dynamics of clinical trials. Preventive Medicine 20 (1991) 132-146.

15. Morrow G. Hickok J. Burish T. Behavioral aspects of clinical trials. An integrated framework from behavior theory. Cancer (supplement) 9 (1994) 2676-2682.

16. Haynes R. Dantes R. Patient compliance and the conduct and interpretation of therapeutic trials. Controlled ClinicalTrials 8 (1987) 12-19.

17. Mattson M. Participation in a clinical trial. The patient's point of view. Controlled Clinical Trials 6 (1985) I56167.

18. Cramer J. Collins J. Mattson R. Can categorization of patient background problems be used to determine early termination in a clinical trial? Controlled Clinicol Trials 9 (1988) 47-63.

19. Forrow L.Wartman S. Brock D. Science, ethics and the making of clinical decisions. Implications for risk factor intervention. JAMA 259 (1988) 3161-3167.

20. Morris L. Schultz R. Patient Compliance: an overview. Jaurnal of Clinical Pharmocology Therapy 17 (1992) 283. 295

21. Enaker S. Politser P. How decisions are reached: physician and patient. Annals of Internol Medicine 97 (1982) 262-268.

22. Leventhal H. Cameron L. Behavioral theories and the problem of compliance. Patient Educotiovi and Counseling 10 (1987) 117-138.

23. Tepper A. Elwork A. Competence to consent to treatment as a psychollegal construct. Law and Humar Behavior B (1984) 205-223.

24. Mackillop W. Johnson A. Ethical problems in clinical research: the need for empirical studies of the clinical trial process. Journal of Chronic Disease 3 (1986) 177-188.

25. Childress F.The place of autonomy in bioethics. Hastings Center Report I (1990) 12-16.

26. Finucane P. Myser C. Ticehurst S. 'Is she fit to sign, docor?" - practical ethical issues in assessing the competence of elderly patients. The Medical Journal of Austrolia 159 (1993) 400-403.

27. Shatz D.Auronomy, beneficence and informed consent rethinking the connections. Cancer Investigation 4 (1986) $257-269,353-361$. 
28. Kasper I. Mulley A. Wennberg I. Developing shared decision-making programs to improve the quallity of health care. Quality Review Bufletin 18 (1992) 183-190.

29. Garder H. Sneiderman C. Ensuring value by supporting consumer decision-making.joumal of Occupotianal Medicine $12(11990) 1123-1126$.

30. Ende J. Kazis L. Ash A. Moskowitz M. Measuring patient's desire for autonomy: decision-making and imformation seeking preferences among medical patients. Journol of Generol Internal Medicine 4 (1989) 23 30.

31. Strull W. Lo B. Charles G. Do patients want to participate in medical decision-making? JAMA 252 (1984) 2990-2994.

32. Barry M. Fowler F. Mulley A. Henderson J. Wennberg J. Patient reactions to a program designed to facilitate patient participation in treatment decisions for benign prostatic hyperplasia. Medicol Care 33 (1995) 771 . 782

33. Laffel G. How professionals view their patients (Editorial). Quality Manogement in Health Care 2 (1993) y-vii.

34. RandallT. Producers of wideodisc programs strive to expand patient's role in medical decision-making process. JAMA 270 (1993) 160-162.

35. Llewellyn-Thomas H.Thiel E. Sem, F. Harrison Woermke D. Presenting clinical trial information: at comparison of two methods. Patient Eduction and Counseling 25 (1995) 97-107.

36. O'Connor A.Validation of a decisional conflict scale. Medical Decision Making 15 (1995) 25-30.

37. Lachman R. Lachman J. Butterfield E. Cognitive psychology ond information processing an introduction. New Jersey. Lawrence Erlbaum Associates (1979). In: Llewellyn-Thomas H. Thiel E. Sem, F.Harrison Woermke D. Presenting clinical trial information: a comparison of two methods. Patient Educotion and Counseling 25 (1995) 97-107.

38. Bronner A. DeHoog R. The intertwining of information search and decision aiding. ACTA Psychologico 56 (1984) $113-123$.

39. Holmes-Rovner H. Kroll J. Smitt N. et al. Patient satisfaction with health care decisions: the Satisfaction with Decision-scale. Medical Decision Moking I (| 996) 58-64. In: Holmes-Rowner M. Evaluating standards for Patient Decision Supports. Medical Decision Making || (1995) 2-3.

40. Richards M. Ramirez A. Degner L. Fallowfield L. Maher E. Neuberger J. Offering choice of treatment to patients with cancer.A review based upon a symposium held at the I0th annual conference of the British Psychosocial Oncology group. European Journal of Concer $3 \| \mathrm{A}$ (1995) ||12-116.

41. Hack T. Degner L. Dyck D. Relationship between preferences for decisional control and illness information among women with breast cancer: a quantitative and qualitative analysis. Social Science and Medicine 39 (1994) 279-289.

42. Mulley A. Supporting the patient's role in decision-making.Journal of Occupotional Medicime 12 (1990) 11271128 .

43. Emanuel E. Ernanuel L. Four models of the physician-patient relationship. AMMA 16 (1992) 2221-2226.

44. President's commission for the study of ethical problems in medicine and biomedical research. Making Heolth Core Decisions. Washington DC: US Gowernment printing office (1982).

45. Hogarth R. Judgernent and choice. New York: Random House (1987). In: Coulton C. Decision making in support: patiertit perceptions and preferences. J Clin Epidemiol Suppl. 43 (1990) $5 / 15-545$.

46. Agich, G. Reassessing autonomy in long-term care. Hastings Center Report 4 (1990) 12-17.

47. Veatch R.A.bandoning informed consent. Hastings Center Report 2(1995) 5-12.

48. Reiman A.Assessment and accountability. The third revolution in medical care. The New Englond Journal of Medicine 319 (1988) 1220-1222.

49. Greenfield S. Kaplan S.Ware J. Expanding patient involwement in care: effects on patient outcomes. Annals of internal Medicine 102 (1985) 520-528.

50. Wagner E. Barret P. Barry M. BarlowW. Fowler F.The effect of a shared decision-making program on rates of surgery for benign prostatic hyperplasia. Medical Core 33 (11995) 765-770. 


\section{B Summary.}

This thesis focuses upon informed consent and the patient's choice to participate in clinical trials. Informed consent can be defined as a process of decision-making, resulting in a deliberate and voluntary giving or refusing consent towards a medical treatment or participation in a clinical trial, based upon adequate information disclosure which is sufficiently well understood by a competent patient. Based on the legal and empirical literature about what is known about myth and reality of informed consent, we have conducted a hospital-wide sample survey at the university hospital Maastricht.

We interviewed patients who were asked to participate in clinical trials, in which we also acknowledged patients who chose to refuse trial participation. The aim of this study has been to obtain more insight into how informed consent in clinical trials actually works in daily practice and to focus upon practical problems in providing adequate information and obtaining consent when patients are asked to participate in a clinical trial. Insight into what might be called myth and reality of informed consent is relevant for understanding how it could be improved in daily practice. The study was designed to answer the following research questions:

1.On which grounds do patients choose to participate in clinical trials and what are the reasons for some of them not to participate in a clinical trial?

2.How do patients experience and evaluate the information disclosure on the clinical trial as provided by the trial-clinician and which factors influence the patients' evaluation of information disclosure?

3. How do patients experience and evaluate their participation in a clinical trial and which factors influence patient satisfaction with clinical trial participation?

In chapter 2 we stated that informed consent as a rational decilsion-making process, implying an informed consideration, assessment and patient choice, may be perceived as an ideal in the nature of a myth. We thereby questioned the legal premise of an implicit assumption of the patient's ability of a rational decision-making and also the premise of rational reasons upon which a patient's decision would be based.After analyzing the legal doctrine of informed consent in clinical trials, we have set out an outline of a model of informed consent, the features of which would provide the necessary foundation for any further process of patient education and counseling. It consists of three stages: a comprehensive disclosure stage, emphasizing the integrated, detailed provision of information; a core disclosure stage, presenting the essentials of the choice at hand in an approachable and palatable fashion; and the stage of assessment, clarification and making a choice. The model implies a psycho-legal construct of competence to consent, which depends upon a patient's ability to understand the relevant information necessary to reach a decision, to deliberate about the disclosed information and to formulate and express the final decision at hand. A more gradual distinction is suggested between informed consent requirements in regular treatment ws. clinical trials, based upon concepts like achievable benefit and risks disclosure. 
Chapter 3 reviews empirical studies of informed consent in clinical trials, showing that the ideals of informed consent are not yet fully achieved when patients are asked to participate in clinical trials. Empirical research on informed consent may be defined as: "the study of actual informed consent decisions by patients (or their proxies) with regard to consent, and the impact of consent on patients or the clinical trial outcome. We made a distinction between studies of information disclosure and comprehension ("informed') and studies of decision-making procedures and patient motivation to participate in a clinical trial (consent'). The latter ones may be distinguished into studies of patients who actually were or had been enrolled in a clinical trial and those of patients who are asked in a study to give hypothetical answers but were not, nor ever had been enrolled in a clinical trial. Studies show that patients being asked in clinical trials use information prowided during the informed consent process. There is no evidence found in the empirical literature that an "excessive pursuit" of informed consent will result in any significant increase in patient's understanding of information disclosure. Moreover, the level of comprehension necessary to participate in medical decision-making is unclear. Empirical findings currently offer no conclusive evidence that informed consent is or is not feasible.

Empirical research into patients" motivation to participate when being recruited for clinical trials and of what has been told during the informed consent process is scarce. We concluded that this field of research would be enriched by more investigations. Also, the limitations of previous empirical research on informed consent should be addressed, such as: the use of non-patient subjects or hypothetical situations; the failure to consider what physicians actually told patients; focusing only on patient recall as the key to understanding; a lack of generalizability of results, allowing investigator bias where the investigator is also the subject"s physician. Another major aspect of social science research dealling with informed consent is the lack of a direct and explicit link between the empirical research in physücian-patient communication and the implications of these research findings for the formation of policies dealing with informed consent. This scientific approach to understanding the informed consent process can allow us to realize more fully the intendied goals of informed consent and to find out whether and which solutions actually work in practice.

Our main interest in the sample survey was to analyze patient motivation towards and satisfaction with trial participation, focusing on informed consent from the patient's point of view. The surwey comprises a sample of patients approached for the average clinical trial at the university hospital Maastricht. This sample includes participants as well as nonparticipants, selected from 26 clinical trials. In total $\| 72$ participants and 26 nonparticipants were recruited from all the patients involved in 26 clinical trials, after they were asked to participate. In a one-hour personal interview these 198 patients were interviewed, during which general attitudes towards clinical trials, benefits and disadvantages and health perceptions were taken into consideration. Of those who participated, 135 patients were interviewed again by telephone after a two-month period of time about their satisfaction with trial participation, alongside a control group of 34 patients. Furthermore, context-variables of each elinical trial have been analyzed. The 32 trial-clinicians involved were also interviewed, to obtain additional information about the informed consent procedure. Data-analysis involved factor analysis, path analysis, logistic regression analysis and analysis of variance. To obtain insight into reasons behind 
the choice, determinants of trial participation were analyzed by using behavioral models. from social psychology (chapter 4). The quality of information disclosure was subsequently evaluated from a patient's point of view (chapter 5). We then analyzed patient satisfaction with clinical trial participation (chapter 6).

In chopter 4 we focused upon determinants of trial participation, to obtain more insight. into the reasons behind the patient's choice and found an adequate explanation why patients enter a clinical trial or not. We wanted to know on which grounds patients choose to participate in the clinical trial they are asked for and what are the reasons some of them refuse to participate. It is reasonable to assume that patient beliefs can explain patient behavior. Therefore our model of explanation was based upon social-psychological determinants, to account for trial participation. In the analysis of determinants to explain participation, the extended Health Belief Model (HBM) was used as a frame of reference. Assessment of the perceived risks and barriers, compared with the perceived benefits appears to describe the general process underlying the decision to participate in a clinical trial. The main results show that patients asked for a clinical trial will make this decision by drawing up a personal balance account. This comprises the physical and emotional added value they hope to gain from the trial treatment compared to the non-trial treatment. They also consider the risks they expect they may run in it and also weigh up the extra time that the trial will demand. The extent they feel physically threatened by their illness will also influence the decision. Furthermore, this personal motivation is very much determined according to several subjectively defined 'frames of reference'. The direct effects are examined in the context of a causal model "which shows that other socialpsychological variables affect participation indirectly. The patient's personal balance account determining the decision to participate was found to be dependent on patient's opinions about medical care, research and institutions in general and on the way they were coping with their illness. It also appeared to be relevant to make a distinction between old cases (performing "sick-role-behavior") and new cases (performing "illness behavior"). Relatively long-term patients $(n=130)$ show a slightly different motivation whether or not to enter a clinical trial than short-term patients $(n=68)$, who have been sick less than three months. Based upon our findings, we presented the outline of a Patient Motivation Classification ( $P M C$ ), to enable trial-clinicians to obtain additional insight into patient motivation about entering a clinical trial.

In chopter 5 we examined patient's evaluation of information disclosure in clinical trials. We wanted to know how patients experience and evalluate the information disclosure on the clinical trial as provided by the trial-clinician and which factors influence the patient's evaluation of information disclosure. We did not examine patient's recall and decisionmaking capacities. Instead, we analyzed patient perceptions on information disclosure and factors having an impact on it. Patient satisfaction with information disclosure is thereby assumed as a measurement of the quality of the informed consent process. Most of the patients are proved to be quite satisfied with the oral and written information disclosure, whether they participated or not.Also, the evaluation of the role of the trial-clinician in this information disclosure was very positive. We found that very few patients had any doubt about the medical competence and risk-avoiding capacities of the crial-clinicians they encountered. In other studies, many patients fail to recall major proportions of 
information on consent, suggesting that such communications are complex and for many patients difficult to grasp, despite the fact that most patients report being satisfied with the intormation disclosed. There is also no general agreement as to what information must be effectively imparted to the patient if he or she is to reach a rational decision. To improve the quality of informed consent and facilitate patient's involvement in medical decisionmaking, an Informed Decision-making Checklist (IDC) is suggested which could be used as a general outline for patient education. This IDC focuses on those aspects of information about a clinical trial which proved from our findings to be relevant determinants of trialparticipation as perceived by patients.

In chapter 6 we analyzed the patient's satisfaction with trial participation, which is perceived as an indicator for the quality of trial participation from the patient's point of view. We wanted to know how patients experience and evaluate their participation in a clinical trial and which factors influence the eventual patient satisfaction with clinical trial participation. Patient satisfaction with trial participation was analyzed in two distinct ways. The first entalled the patient's evaluation of aspects of trial participation which could not be anticipated beforehand. Patient satisfaction was analyzed at one moment of time, when only experiences could be used as a potential source of evaluation. The second involved comparing patient's expectancies at the moment of taking a decision to enter the trial with evaluations in the course of the clinical trial, analyzed by means of a follow-up repeated measurement. Patient satisfaction is multifaceted and multidimensional. We therefore have focused upon patient's satisfaction with trial participation, differentiated into medicaltechnical, interpersonal and organizational aspects. Patient satisfaction with most of these aspects of trial participation is rather high. Dissatisfaction, however, occurs in particular when both prior expectations and subsequent evaluations can be compared with each other.

Satisfaction with aspects of trial participation can partly be explained and predicted from patient characteristics before the trial starts. Prior expectations and general attitudes towards medical care and research before entering the trial have a substantial impact on satisfaction with aspects of trial participation. Changes in patient's health and illiness perceptions, such as feeling ill, severity of illmes $s_{i}$ perceived health condition and satisfaction and improvement on health, were analyzed as confounding factors and had no association with patients satisfaction. Patients felt better compared to the state they said they were in just before participating. Patients felt considerably less ill and their perceived severity of illness was significantly lower. In our study, the self perceived health improvement of patients was not related to their satisfaction in the clinical trial.

In the concluding remarks in chopter 7 we focused upon the understanding we have acquired as a result of the sample survey into what is admittedly a subjective and qualitative interaction between patients and trial-clinicians. As we should realize that the foundations for rational decision-making are not always met in the daily practice of medical treatment and research, informed consent might be considered to be an ideal in the nature of a myth. From a medico-legal perspective there are a number of myths in the principle of informed consent in clinical trials:

- the implicit assumption of competence is a prerequisite for a patient to partake actively in medical decision-making; 
- this prerequisite enables an individual person to make a voluntary and deliberate decision about trial participation;

- the decision to participate or not in a clinical trial and to undergo medical treatment is assumed to be primarily based upon information disclosure which is understood by the individual patient;

- and when several conditions are met when disclasing information and obtaining consent, the individual person's autonomy would be emphasized in the process of informed consent.

When analyzing these myths of informed consent, we may deduce the existence of the following realities:

- information disclosure is only one of the many factors which appear to be relevant in the patient's decision-making process of entering the trial - it appears not to be a determinant explaining trial participation;

- pacient's evaluations of medico-legal requirements of informed consent are not considered as reasons to participate or not in a clinical trial;

- trial-characteristics, like the patient's perception about the expected drawback caused by the randomization procedure, have no direct influence on the participation rate;

- in adidition to their perception of benefits, risks and discomforts, patient's perceptions towards health and illness are also relevant regarding the decision to partake in a clinical trial or not;

- some general attitudes towards medical care, research and institutions appear to have indirect effects upon trial participation, just as does the way patients are coping with their health and illness condition.

- patients' prior experiences regarding their health condition and more general attitudes towards medical care, research and institutions may also contribute importantly to their perceptions of information disclosure; prior experiences and general attitudes also have a substantial effect on patient satisfaction with trial participation;

- in actual trial situations as in our sample-survey, many fewer patients cend to refuse trialparticipation than in hypothetical situations;

- a signed consent is not a valid indication that patients actually have understood the disclosed information;

- patients' perceived improvement in health condition shows no association with patient satisfaction with trial participation.

In recent years, informed consent has been specified in more detail in the health care legislation. In the Dutch law informed consent has been exemplified in (draft) legal rulles to emphasize patient rights in the medical treatment (Medical Contract Act) and to protect human test subjects participating in clinical trials (Medical Research with Human Beings Bill). The legal doctrine of informed consent in clinical trials to date must be seen as insufficient to fashion a model of informed consent which is effective in daily practice. Also, the distinction between informed consent and its requirements in regular treatment and in clinical trials is not as clear as has been assumed in the law. The implicit assumption which is expected to be fulfilled by following these regulations is the active involvement of patients in medical-decision-making. The reality shows that it is not realistic to assume this 
to be enough to fulfill the ideals of informed consent in daily practice. An adequate informed consent procedure requires additional interpretation of its legal requirements. This also requires an exploration of interaction between patients and trial-clinicians in the daily practice of the informed consent process.

The sample survey provides valuable insight into what aspects are most relevant for those who consent, what are the concerns of those who decline trial participation, patients' satisfaction with information disclosure and the extent to which they are satisfied with trial-participation. What can be derived from these findings in order to improve informed consent in clinical trials and its functioning in daily practice? Regarding the many considerations patients might have towards trial treatment and participation, we have found only some social-psychological determinants to be mosit relevant for patients to decide to participate in a clinical trial. Besides benefits, risks and discomforts, patients' perceptions towards health and illness are also relevant regarding the decision to partake in a clinical trial or not. When the aim is to improve informed consent in clinical trials, these social-psychological determinants should be emphasized, alongside the legal requirements of informed consent.

Suggestions have been given based upon the findings in the sample-survey to obtain additional insight during the informed consent process, such as a Patient Mativation Classification (PMC) to be used by trial-clinicians and an Informed Decision-making Checklist (IDC) which could be used as a general outline for patient education. These efforts to contribute support to practice might be helpful in the daily practice of informed consent in clinical trials. Essential to the improvement of informed consent as a process is the identification of the most serious barriers inhibiting effective communication between physician and patient and shared decision-making. The model of informed consent thereby could provide the necessary foundation for improving the process of patient-physician communication. Its features present a more elaborate wiew on decision-making. The role of communication is stressed, acknowledging that informed consent requires more than the exchange of information. Decisional support could also help patients to involve them in the decision-making process and support processes of communication.

Informed consent has been proposed to encourage patient participation in medical decision-making. Some efforts have already been made to emphasize the importance of patient involvement in medical decision-making. Additional empirical research could help in developing and testing methods for improving collaborative medical decision-making. More research is needed to explain the dynamics of patient decision-making. Several factors are likely to affect patient's decision-making towards medical treatment. The intricacies of their relationships in communicative processes should be unraveled in research programs. This quality-of-care research, could also be adopted when involwing patients in the decision-making process and offering choice with regard to clinical trial participation. 


\title{
Mythe en werkelijkheid van informed consent en overwegingen van patiënten om al of niet deel te nemen aan medisch-wetenschappelijk onderzoek.
}

\begin{abstract}
Dit manuscript bevat een rapportage van een onderzoek naar informed consent - op deugdelijke informatie gebaseerde toestemming - voor medisch-wetenschappelijk onderzoek. Ingegaan wordt op overwegingen van patiènten om al of niet aan dergelijk onderzoek mee te werken, hun tevredenheid over de informatieverstrekking en ower deelname aan het onderzoek zelf.Allereerst is nagegaan wat tot nu toe in de (gezondheidsrechtelijke en empirische) literatuur bekend is over mythe en werkelijkheid van informed consent bij medisch-wetenschappelijk onderzoek. Op grond hiervan is een ziekenhuisbreed empirisch onderzoek opgezet in het academisch ziekenhuis Maastricht (azM). Het doel van het onderzoek was om meer inzicht te verwerwen in de wijze waarop irformed consent voor medisch-wetenschappelijk onderzoek in de praktijk gestalte krijgt. De studie werd opgezet om de volgende onderzoekswragen te beantwoorden:
\end{abstract}

I.Op grond van welke overwegingen beslissen patiënten om deel te nemen aan medischwetenschappelijk onderzoek en wat zijn de redenen voor een aantal van deze patiënten om niet deel te nemen?

2. Hoe ervaren en beoordelen patiënten de informatie die de arts-onderzaeker verstrekt over het medisch-wetenschappelijk onderzoek en welke factoren zijn bepalend voor deze beoordeling?

3.Hoe ervaren en beoordelen patiènten de deelname aan een medisch-wetenschappelijik onderzoek en welke factoren bepalen de tevredenheid van patiënten over deelname?

Bij de beantwoording van de onderzoekswragen is gebruik gemaakt van gedragsmodellen uit de sociaal-psychologie om determinanten van deelname te analyseren.

Gezondheidswoorlichting en -opvoeding (GVO) diende om de kwaliteit van de informatieverstrekking te analyseren zoals patiënten deze beoordelen. Vanuit de kwaliteitszorg werd de tevredenheid wan patienten bepaald over hun deelname aan medisch-wetenschappelijk onderzoek. Voor het empirisch deel wan het onderzoek heeft de gezondheidsrechtelijke theorie betreffende informed consent als referentiekader gediend. Deze combinatie van vakgebieden leidde tot verschillende veronderstellingen en hypotheses ten aanzien van de onderzoeksvragen. Het onderzoek heeft inzicht verschaft in de overwegingen van diegenen die besluiten om deel te nemen aan onderzoek, de redenen zijn om af te zien van deelname, de rol van de informatieverstrekking en in hoeverre tevredenheid over deelname aan medisch-wetenschappelijk onderzoek verklaard kam worden. 
In hoofdstuk 2 wordt ingegaan op de gezondheidsrechtelijke doctrine van informed consent. Het onderzoek gat over mythe en werkelijkheid van informed consent. Informed consent is in zeker opzicht een mythe. Ogenschijnlijk gaat het om een rationeel besluitvormingsproces, dat resulteert in een weloverwogen toestemming van patienten op grond van de verstrekte informatie. Het onderscheid tussen informed consent en de daaraan gesteld vereisten bij medisch-wetenschappelijk onderzoek en bij de reguliere patiêntenzorg is daarbij minder duidelijk dan wordt verondersteld. Na analyse van medisch-ethische en juridische voorwaarden ten aanzien van informed worden de contouren van een model van informed consent aangegeven, dat bedoeld is om informed consent te concretiseren in de dagelijkse praktijk. Het model gaat uit van drie fasen: die van uitgebreide informatieverstrekking; die van kerninformatieverstrekking, waarbij de nadruk wordt gelegd op de essenties van de keuze en tenslotte die van beoordeling, verheldering en het maken van een keuze ten aanzien van de deelname. Deze benadering kan de grondslag vormen bij de verdere uitwerking van informed consent.

In hoofdstuk 3 is de literatuur beschreven op het terrein van empirisch onderzoek naar informed consent bij medisch-wetenschappelijk onderzoek. Hieruit blijkt dat de idealen wan informed consent nog niet zijn gerealiseerd. Empirisch onderzaek naar informed consent wordt in de literatuur omschreven als 'de studie van feitelijke besluitvorming van patienten (en hun naasten) ten aanzien van toestemming op grond van informatie en de effecten van deze toestemming op patiènten of de uitkomsten van medischwetenschappelijk onderzoek'. Onderscheid is gemaakt tussen studies naar informatieverstrekking en het begrijpen ervan ('informed') en studies naar besluitvormingsprocessen en motivatie van patiënten om deel te nemen aan medischwetenschappelijk onderzoek ("consent") De laatste kunnen worden onderverdeeld in onderzoek bij patiènten die feiteliik zijn betrokken bij of hebben deelgenomen aan medisch-wetenschappelijk onderzoek en diegenen wie opvattingen zijn gevraagd zonder dat zij ooit aam onderzoek deelnamen.

Empirisch onderzoek naar de motivatie van patiënten wanneer zij worden benaderd voor medisch wetenschappelijk onderzoek en naar de informatieverstrekking bij de informed consent-procedure is schaars. Er zouden meer van dergelijke studies moeten plaatsvinden. Daarbij moet rekening worden gehouden met een aantal beperkingen van eerdere studies naar informed consent, zoals het gebruik van nilet-patiënten of hypothetische situaties, niet nagaan wat artsen feitelijk vertellen aan patiënten, alleen de nadruk leggen op herinnering als indicator voor begrip van de informatieverstrekking, gebrek aan generaliseerbaarheid van resultaten en het risico van onderzoeksbias doordat de onderzoeker van informed consent tevens de arts is waardoor patiënten behandeld worden. Een ander aandachtspunt bij onderzoek naar informed consent is de directe en expliciete samenhang tussen empirische studies naar de arts-patiènt communicatie en de implicaties van de bevindingen voor informed consent. Een wetenschappelijke benadering om het proces van informed consent te begrijpen zou de mogelijkheid moeten bieden om de beoogde doelstellingen van informed consent beter te kunnen realiseren. Het geeft ook de mogelijkheid om te bepalen welke oplossingen feitelijk werken in de praktijk. 
Het belangrijkste doel wan het empirische deel var het onderzoek was het analyseren wan de motivatie van patiënten woor deelrame aan medisch-wetenschappelik onderzoek en hun tevredenheid over de deeiname. De nadruk lag daarbij op informed consent, bezien vanuit de belevingswereld van patiënten. Het onderzoek strekte zich wit over een steekproef van patienten bij 26 studies die in de periode van februari tot oktober 1993 besloten om al of niet deel te nemen aan een medisch-wetenschappelijke onderzoek: 172 patiënten werden geinterviewd die desgevraagd besloten hadden om deel te nemen, evenals 26 patiënten die besloten hadden niet deel te nemen. In tweede instantie zijn 135 patiënten tijdens dan wel na deelname nog eens tel efonisch geinterviewd over hun ervaringen. Dit gebeurde ook bij 34 patiënten die niet eerder waren geinterviewd en tevens dienden als controle groep. Tenslotte zijn 32 betrokken arts-onderzoekers geinterviewd over de informed-consentprocedure in de concrete 26 studies. 0 m meer inzicht te krijgen in de overwegingen die ten grondslag liggen aan de keuze van patiénten on al of miet deel te nemen, zijn determinanten voor deelname onderzocht aan de hand van modellen voor verklaring van gedrag uit de sociale psychologie (hoofdstuk 4). De kwaliteit van de informatieverstrekking werd geanalyseerd, zoals deze ervaren is door patiënten (hoofdstuk 5). Verder is inzicht verschaft in de tevredienheid van patienten met hun daadwerkelijke deelname aan het onderzoek (hoofdstuk 6).

Om meer inzicht te kriggen in de overwegingen woor de keuze van patiènten wordt in hoofdstuk 4 ingegaan op de determinanten voor deelname aan medisch-wetenschappelijk onderzoek. Nagegaan is op grond wan welke redenen patiènten kiezen voor deelname en wat de redenen zijn om niet deel te nemen. Bij de analyse van determinanten om deelname te verklaren werd het Health Belief Model (HBM) als referentiekader gebruikt. $\mathrm{Er}$ is een afdoende verklaring gevonden waarom patiënten al of niet deelnemen aan medisch-wetenschappeliik onderzoek. Patienten nemen een beslissing op grond van een persoonlijke afweging van de verwachte fysieke en emotionele voordelen die zij] verwachten ten aanzien van de behandeling in het onderzoek, vergeleken met de reguliere behandeling. Zij nemen ook de rïsico's in overweging die zij verwachten te lopen en beoordelen de extra tijdsinvesting die het onderzoek met zich meebrengt. Daarnaast is de mate waarin zij zich urgent voelen of zich zorgen maken over de ziekte van invloed. De persoonlijke motivatie is verder afhankelijk van een aantat subjectief gedefinieerde referentiekaders. De persoonlijke afweging is op haar beurt afhankelijk van de algemene mening over medische zorg, onderzoek en zorginstellingen en tevens van de manier warop men met de ziekte die men heeft omgaat. Het bleek relevant ce zijn om een onderscheid te maken tussen diegenen die langer en minder lang ziek zijin dan drie maanden. Patienten die all langer ziek zijn vertonen "sick-role" gedrag ("old" cases n=130) en patiènten die minder lang ziek zijn 'illness-role" gedrag ("new' cases $n=68$ ). Beide type patiënten hebben op een aantal aspecten een andere motivering ten aanzien van de deelname. Op grond wan deze bevindingen werd een Patient Motivatie Classificatie (PMC) ontwikkeld, die arts-onderzoekers in staat stelt om meer inzicht te krijgen in de motiwatie van patiënten die door hen benaderd worden om deel te nemen aan medischwerenschappelijk onderzoek. 
In hoofdstuk 5 wordt ingegaan om de beoordeling van de informatieverstrekking door patienten en factoren die hiervoor bepalend zijn. Hierbij zijn niet de cognitieve vaardigheden van patiënten en hun bekwaamheid tot het nemen van beslissingen onderzocht, In plaats daarvan werd de tevredenheid van patienten over de informatieverstrekking beschouwd als een indicator voor de kwaliteit van het informed consent proces. Gebleken is dat de meeste patiënten heel tevreden zïn ower de mondelinge en schriftelijke informatie, of zij nu beslissen om deelnemen of niet. De rol die de arts-onderzoeker speelt bij die informatieverstrekking wordt ook heel positief beoordeeld. Weinig patiënten twifelen aan de medische competentie en risico-mijidende capaciteiten van de arts-onderzoekers.

In andere studies kan een groot aantal patiënten zich belangrijke aspecten van de informatie op grond waarvan ze toestemming hebben gegeven niet herinneren. Dit suggereert dat dergeijike communicatie complex en voor veel patienten moeilijk te begrijpen is, hetgeen niet wegneernt dat de meesten blijk geven van tewredenheỉd over de verstrekte informatie. Uit de literatuur valt niet af te leiden dat een grotere nadruk op informatieverstrekking leidt tot een beter begrip van die informatie door patiënten. Ook is onduidelike welke mate van begrijpen vereist is voor actieve betrokkenheid van patienten bij de medische besluitvorming. Ter verbetering van de kwaliteit van de informed consent en om patiënten meer te betrekken bij de medische besluitvorming is een Informed Decision-making Checklist (IDC) voorgesteld. Deze zou kunnen worden gebruikt als een algemene leidraad bij de patiénteninformatie over medisch-wetenschappelijk onderzoek. De IDC richt zich op die inhoudelijke aspecten van informatieverstrekking, die met name relevant blijken te zijn voor de deelname aan medisch-wetenschappelijk onderzoek.

In hoofdstuk 6 wordt ingegaan op de analyse van de tevredenheid van patiënten over hun deelname aan medisch-wetenschappelijk onderzoek. Patiëntentevredenheid is gehanteerd als een indicator voor de kwaliteit van deelname. Nagegaan is hoe patiënten de deelname aan een medisch-wetenschappelijk onderzoek hebben ervaren en welke factoren bepalend zijn voor hun de tevredenheid over die deelname. De tevredentheid is op twee verschillende manieren vastgesteld. Een eerste analyse had betrekking op de beoordeling van die aspecten van deelname waarover men patienten niet op woorhand een oordeel kumnen geven. Tevredenheid werd geanalyseerd op een moment wanneer alleen ervaringen dienden als een potentiele basis voor het patiëntenoordeel. Een tweede onderzoeksmethode was om de werwachtingen van patiënten op het moment van de beslissing om deel te nemen, te vergelijken met hun ervaringen. Bij de verdere analyse wan patiëntentevredenheid is een onderscheid gemaakt tussen medisch-technische, interpersoonlijke en organisatorische aspecten. De tevredenheid van patiënten over deelname is over het algemeen vrij hoog. Ontevredenheid over deelname blijkt met name naar woren te komen bij de tweede methode, als zowel verwachtingen als ervaringen met elkaar worden vergeleken.

Tevredenheid over aspecten van de deelname kan deels worden verklaard en voorspell uit. patiëntenkenmerken die gevormd zijn voordat het onderzoek wordt gestart. Eerdere verwachtingen en algemene attitudes ten aanzien van medische zorg en onderzoek hebben een inwloed op de tevredenheid over deelname. Veranderingen in percepties van de patiënten ten aanzien van gezondheid en ziekte zoals: zich ziek woelen, de ernst van de ziekte, gezondheidstoestand, tewredenheid met en verbetering van de gezondheid bleken 
geen verband te hebben met de tevredenheid van patiënten over deelname. Patiènten voelden zich tijdens en na deelname minder ziek en vonden dat ze er minder ernstig aan toe waren dan toen ze bes/oten om aan het onderzoek deel te nemen.

Deze waargenomen verbetering in de gezondheidstoestand bleek echter niet samen te hangen met hun tevredentheid over deelname aan medisch-wetenschappelijk onderzoek.

In hoofdstuk 7 volgen de conclusies en aanbevelingen. Informed consent is een subjectieve en kwalitatieve interactie tussen patiènten en arts-onderzoekers en in zeker opzicht een mythe. Ogenschijnlijk gaat het om een rationeel besluitvormingsproces, dat resulteert in een weloverwogen toestemming. Wat betreft de 'mythe' van informed consent wordt vanuit de gezondheidsrechtelijke inwalshoek bij medisch-wetenschappelijk onderzoek uitgegaan van het wolgende:

- De impliciete veronderstelling wan de bekwaamheid van de patiènt geldt als een noodzakelijke voorwaarde orm actief deel te kunnen nemen aan de medische besluitvorming.

- Verondersteld wordt dat de individuele patiënt in staat wordt gestell om een vrijwillige en weloverwogen beslissing te nemen over deelname aan medisch-wetenschappelijk onderzoek.

- Verondersteld wordt dat het besluitvormingsproces en de uiteindelijke keuze of al of niet deel te nemen met name gebaseerd is op informatieverstrekking die wordt: begrepen door de patiènt;

- Wanneer bij de informatieverstrekking en het verkrijgen van de toestemming wordt. voldaan aan bepaalde kwalificaties wordt ervan uitgegaan dat de autonomie van de individuele patiënt is gewaarborgd in het proces van informed consent.

Analyse van de mythe van informed consent levert de volgende realiteit op:

- Informatieverstrekking blijkt een van de vele relevante factoren te zijn in her. besluitvormingsproces ten aanzien van deelname aan medisch-wetenschappelijk onderzoek. Het blijkt echter geen determinant te zijn voor de deelname.

- De evaluatie van patiënten van juridische vereisten van informed consent zijn geen redenen om al of niet deel te nemen aan medisch-wetenschappelijk onderzoek.

- Objectieve kenmerken van medisch-wetenschappelijk onderzoek "zoals de door de patiënt waargenomen nadelen van randomisatie, hebben geen directe invloed te hebben op de deelliname.

- Naast de afweging van voordelen, risico's en nadelen is de door de patiènt ervaren gezondheidstoestand relevant voor de beslissing om al of niet deel te nemen aan medisch-wetenschappelijk onderzoek.

- Algemene opvattingen over medische zorg, onderzoek en zorginstellingen en de manier waar men met de ziekte omgaat, zijn indirect van invloed op de motivatie ten aanzien van de deelname. Deze opvattingen, eerdere ervaringen en de omgang het ziekte zijin ook bepalende factoren woor de beoordeling van de informatie over en de tevredenheid over de deelname aan medisch-wetenschappelijk onderzoek.

- Bij het feitelijk doen wan medisch-wetenschappelijk onderzoek is er sprake van een veel geringer aantal weigeraars dan in hypothetische siltuaties.

- Schriftelijke toestemming is geen goede indicatie dat de patient informatie heeft begrepen. 
- De door patienten wargenomen verbetering in de gezondheidstoestand blikt geen verband te vertonen met hun tevredenheid over de deelname aan medischwetenschappelijk onderzoek.

De moderne geneeskunde heeft ruimte gemaakt voor de informed consent doctrine en de rechten wan patienten worden daarbij erkend ten aanzien van het geven van toestemming of het weigeren wan bepaalde behandelingen.A.rts-onderzoekers en andere professionals in de gezondheidszorg hebben steeds meer de verplichiting om adequate informatie te verstrekken en op basis daarvan toestemming te krijgen wan patiënten alvorens hen te betrekken in medisch-wetenschappelijk onderzoek. In de Nederlandse gezondheidszorg is de jongste decennia informed consent nader uitgewerkt, zowel woor de medische behandeling (de WGBO) als voor de deelname aan medisch-wetenschappelijk onderzoek (de Wet Medisch-wetenschappelijk onderzoek met Mensen). Door het naleven van deze juridische vereisten wordt verondersteld dat een actieve betrokkenheid van patiënten aan de medische besluitworming valt te verwachten. De werkelijkheid leert echter dat dit onvoldoende is om de idealen van informed consent in de dagelijkse praktijk te kunnen realiseren. Een adequate informed consent-procedure vereist ook verdere interpretatie en concretisering van deze wettelijke vereisten. Ook is een nadere analyse nodig wan de interactie tussen patiënten en arts-onderzoekers in de dagelijkse praktijk van informed consent, zoals in dit onderzoek. Hieruit blifkt dat informed consent meer omvat dan informatieverstrekking alleen, maar ook een goede onderlinge communicatie vereist.

Ten aanzien van de vele overwegingen die patiënten kunnen hebben ten aanzien van de behandieling in en deelname aan medisch-wetenschappelijk onderzoek, bleek een aantall sociaal-psychologische determinanten het meest relevant te zijn bij de besluitvorming om al of niet deel te nemen aan medisch-wetenschappelijk onderzoek. Naast de afweging van voordelen, risico's en nadelen blijkt bovendien de door de patiënt waargenomen gezondheidstoestand ook relevant in de beslissing om al of niet deel te nemen. Om de informed consent-procedure bij medisch-wetenschappelijk onderzoek te verbeteren zouden deze sociaal-psychologische determinanten moeten worden benadrukt, naast juridische vereisten van informed consent. Hiertoe zouden de Patiènt Motivatie Classificatile (PMC) en de Informed Decision-making Checklist (IDC) nader kunnen worden uitgewerkt. Verder is het voor de verbetering van informed consent van belang de meest relevante barrières te identificeren die effectieve communicatie tussen arts en patiènt en een gezamenli|ke besluitvorming in de weg staan. Het model van informed consent kan daarbij als uitgangspunt dienen bij het verbeteren van het. communicatieproces tussen arts en patiënt. Het maakt de contouren zichtbaar van een meer nauwgezet beeld van besluitworming, waarin de rol van onderlinge communicatie wordt benadrukt. Door gebruik te maken wan beslissingsondersteunende hulpmiddelen in het proces van communicatie zouden patiènten meer betrokken kunnen worden bij de medische beslutiturming. 
Informed consent is voorgesteld om de betrokkenheid van patiënten bij de medische besluitvorming te vergroten, waarbij het gaat om het inzicht om weloverwogen te kunnen beslissen. Er zijn al verschillende pogingen ondernomen die het belang benadrukken om patiënten meer te betrekken bij de medische besluitvorming. Meer onderzoek is vereist om de dynamiek te werklaren in de besluitworming van patiënten, warop verschillende factoren van invloed kunnen zijn. Deze vorm wan kwaliteit-van-zorg onderzoek zou ook kunnen wordien toegespitst op het betrekken van patiënten bij de medische besluitvorming en het maken van een keuze ten aanzien van deelname aan medischwetenschappelijk onderzoek.

De volgende suggesties worden gedaan woor vervolgonderzoek. Deze zijn gerelateerd aan de beantwoording van de onderzoekswragen en bevindingen wit het onderzoek.

\section{Patiënt motivatie en deelname}

- Verdere ontwikkeling van de Patient Motivatie Classificatie (PMC) en anallyse van de bruikbaarheid ervan voor arts-onderzoekers.

- Onderzoek naar het verband tussen trialkenmerken en deelname aan medischwetenschappelijk onderzoek (met stratificatie vooraf tussen zogenoemde 'old' en new cases').

\section{Informatieverstrekking en informed consent}

- Verdere ontwikkeling van de Informed Decision-making Checklist (IDC) en toetsing van de bruikbaarheid ervan als een algemene leidraad bij de patiënteninformatie.

\section{Patiëntentevredenheid en compliance}

- Analyse of de factoren die voorafgaand aan de deelname bepalend blijken te zijin voor de patiëntentevredenheid ook een verklaring kunnen geven voor de "suspected noncompliance", de verwachtte uitval wan patiënten tijdens het onderzoek.

\section{Competentie en autonomie}

- Onderzoek naar de haalbaarheid en mogelijkheid van een 'bekwaamheidstest' die door arts-onderzoekers kan worden gebruikt tijdens de informed consent-procedure.

- Analyse van de belletsels bij en beperkingen ten aanzien van de bekwaamheid en autonomie die zich kunnen voordoen in het proces van informed consent bij medischwetenschappeliik onderzoek.

\section{Het betrekken van patiënten bij de medische besluitvorming}

- Nagaan hoe bij informed consent de betrokkenheid van patiènten bilj de medische besluitvorming op een zinvalle manier kan worden versterkt en hoe en tot welke mate dit op een adequate manier kan worden ondersteund. 


\section{Dankwoord}

Allereerst wil ik stil staan bil een gesprek dat $i k$ had met mijn moeder, toen zij onder behandeling was voor een Non-Hodgkin Lymfoom. Zij werd destijds gevraggd om mee te werken aan een medisch-wetenschappelijk onderzoek Het ging om een gerandomiseerd geneesmiddelenonderzoek waarbil ze zelf mogelijk baat bij zou kunnen hebben. Ze vroeg toen ook om minn advies. Ik gaf aan om de overwegingen samen met haar op een rijtje te willen zetten, maar ook dat ze zelf moest aangeven wat haar het beste leek om uiteindelijk zelf een beslissing te nemen. Ze besloot gezien haar gezondheidstoestand er niet aan mee te doen. Later besefte ik haar zelfbeschikking te hebben benadrukt, waar het bij informed consent toch uiteindelijk om draait. Ik draag dit proefschrift ter nagedachtenis aan haar op. Het onderzoek werd op de proef gesteld en gerelativeerd door de gebeurtenissen die zich in diezelfde periode hebben voorgedaan. Ik heb daarbij gelukkig de steun gekregen, waardoor ik ook weer verder kon gaan. Mijn eigen familie heeft daarin een belangrijke rol gespeeld. Huub, Ludy, Karl en Mireille, het is goed om dat te merken. In mijn naaste omgeving heeft Mireille van dichtbil meegemaakt wat er gebeurt als je besloten hebt om te gaan promoveren. Ik heb mede dank zij jou met veel plezier aan het proefschrift gewerkt. Het vergt heel wat, maar andere zaken hoeven daar toch niet onder te lijden.

Prof mr FCB van Wijmen, Frans, jou betrolkkenheid bij het onderzoek heeft in belangrijke mate bigedragem aan het uiteindelijke resultaat. Het bleek interessant om de visie op informed consent vanuit het Gezondheidsrecht te spiegelen aan de dagelijkse praktijk. Mer plezier denk ik terug aan onze etentjes waarbij tevens de voortgang van het onderzoek aan de orde kwam en zeker ook aan de Curaçaoce week, inclusief het snorkelen. Je enthousiasme over het onderzoek heb ik erg gewaardeerd, llk verheug me er op onze gezamenlijke ideeèn na deze "proeve van bekwaamheid" verder te realiseren.

Prof dr G Kok, Gerjo, jou opmerkingen over de artikelen waren 'to the point' en daarbij altijd weer verhelderd. Datzelfde kan ook gezegd worden over jou verdere bijdrage aan het onderzoek, waarvoor mijn dank.

Prof dr E Reerink, Evert, jou suggesties bleken relevant bij beslissingen over publicaties in tildschriften en bijdragen aan conferenties. Dit kwam het uitdragen van het onderzoek zeker ten goede. Ook jou inzicht was van belang in de loop van de studie.

De tevredenheidsmeting was mede jou idee. Ik zet de verdere samenwerking graag met je voort.

Dr FHM Nieman, Fred, de methodologie van kwantitatief empirisch onderzoek is jou sterke kant. Je hebt me op weg geholpen bij de ontwikkeling van de vragenlijsten en verder wegwijs gemaakt in de wetenschappelijke analyse van de beschikbare data. Zonder jou kritische inbreng was dat beslist heel anders gegaan. Ik heb me daarnaast ook regelmatig mex jou ingelaten over ander onderzoek, dan die aampak waar jij woor staat. We blijken het hierover niet altijd met elkaar eens te zịn, maar dat prikkkelt in ieder geval de geest.

Dr R Jonkers, Ruud, vanaf het eerste uur werd je via Gerjo Kok vanwege je know-how in de parientenvoorlichting bij het onderzoek betrokken. Jij bent er altijd dichtbiij geblleven, ondanks je drukke werkzaamheden bij ResCon Research \& Consultancy. Ook jou betrokkenheid heb ik als plezierig en zinvol ervaren. 
Door dr JJ Carpay werd als eerste informed consent als onderwerp woor sociaalwetenschappelik onderzoek gesuggereerd en ben ik in de aflopen jaren in de gelegenheid gesteld om een dag per week aan het onderzoek te kunnen besteden en dit proefschrift te realiseren. Mijn dank hierwoor.

Dr AG Mulley Jr, Albert, you were immediately prepared upon my request to become formally involved in my PhD-study and to review my manuscript. I hope that we can set up further collaboration in next future, as I perceive the development of Shared Decisionmaking Programs to involwe patients in medical decision-making as a promising field of quality-of-care research.

Mw drs Linda Wittebrood, mw Karin Frambach en mw Coby Smits hebben geholpen bij het veldwerk. Linda, ik was blij met jou betrokkenheid bij de enquêtering van de patiënten en organisatie van het veldwerk. Jij hebt daarbij ook de patiëntenfolder opgesteld, 'Gevraagd voor medisch-wetenschappelijk onderzoek'. Deze blijkt te voorzien in een behoefte, wat ook blijkt uit het feit dat diverse ziekenhuizen de tekst ervan hebben overgenomen. Karin, ook jou bijdrage aan de patiëntenenquêtering mag niet onvermeld blijwen. En Coby, door jou roll tijdens de dataverwerking is mil veel werk bespaard gebleven. Ik had het overigens ook nooit zo systematisch en consequent als jou kunnen valbrengen.

Ik wil ook mw prof mr Inez de Beaufort, prof dr Bart van den Borne, dr Albert Mulley en prof dr Hans Philipsen bedanken voor hun bereidwilligheid om onder voorzitterschap van prof dr Sjef van der Linden deel uit te maken van de beoordelingscommissie.

Het slagen van het veldwerk was afhankelijk van de samenwerking met anderen. De artsonderzoekers en andere betrokken wil ik hartelijk danken voor hun medewerking aan het onderzoek, te weten: dr F Bär, dr J van der Beek, H Boender, mw E Chan, D Dartee, $R$ van Doorn, mw L Dijkman, P Eerdmans, P van Es, mw $M$ van Gasselt, F Geisler, J Heesakkers, mw M Hochstenbach, dr L. Hofstra, dr P Hupperets, F Huygen, W IJzerman, prof dr R Janknegt, prof dr P Kitslaar, D Koster, dr W van Kuilk, H Kupfer, F Kwinten, dr K Leunissen, prof dr P de Leeuw, prof dr H Neumann. H Pennings, mw H Quint, KP de Roos, dr H Schouten, H van Suijlekom, H de Swart, M Verhaegh, dr FVermeer, J Veraart, dr G Walenkamp, prof dr EWouters en prof dr J Wilmink. Ik wil Bob Wilkinson danken voor de consciêntieuze manier waarop hij de engelstalige teksten in de hoofidstukken $\mid$ en 4 tot en met 8 heeft gecorrigeerd.

De lay-out van het proefschrift is verzorgd door José Linders. Bedankt voor deze finishing touch.

Ik wil ook nog een woord van dank richten aan mijn collega's in het azM, miln familie, vrienden en bekenden voor de steun, aandacht en tijd die ik kreeg.

Verder dank ik alle patiënten die hun medewerking aan het onderzoek hebben verleend. Door hun perspectief te benadrukken in dit proefschrift hoop ik dat beter begrepen zal worden hoe informed consent in de dagelijkse praktijk werkt.

Frank 


\section{Curriculum Vitae}

Frank Verheggen was born on the 8 th of March 1965 in Beek, the Netherlands.

After finishing highschool in 1983 (Gymnasium $B_{4}$ Henric van Veldekecollege, Maastricht), he studied Health Sciences at the University of Maastricht. His thesis in the direction of Management and Organization, focused on the development and use of practice guidelines in the university hospital Maastricht. After graduating in 1988 he was a research fellow during his civil serwices, analyzing the use of legislation, organizational procedures and practice guidelines for patient care. This again took place at the university hospital Maastricht. Here, he was appointed in March 1990 as Quality Assurance Coordinator for setting up a hospital-wide quality assurance program and became secretary of the Quality Council. In the spring of 1990 he participated in the HOPE-exchange program of the hospital committee of the European Community. He started his $\mathrm{PhD}$ study on informed consent in clinical trials in September 1991. From 1992, he became one of the editors of the Dutch scientific journal 'Quality and Care', which was founded 1992. In the spring of 1993 he was the chairman of the Organizing committee for the IOth conference of the International Society for Quality Assurance (ISQua) held in May-June in Maastricht. From January 1994 he became secretary of the Medical Audit Committee of the hospital. Since 1994, he is one of the course leaders for the annual QA summer course of the University of Maastricht. In April 1995 became chairman of the Quality Key Group and has been appointed as Quality Manager of the hospital. In this respect he is responsible for the hospital-wide program for TQM and CQI, for publishing the annual Quality Report, for education \& training in quality assurance of hospital staff and for the quality of care research-program. He has published articles on the field of QA and held lectures on results of the hospital quality assurance and research program. 